\title{
Modeling studies to evaluate performance of the horizontal wells completed in shale
}

\author{
Abbas Belyadi \\ West Virginia University
}

Follow this and additional works at: https://researchrepository.wvu.edu/etd

\section{Recommended Citation}

Belyadi, Abbas, "Modeling studies to evaluate performance of the horizontal wells completed in shale" (2011). Graduate Theses, Dissertations, and Problem Reports. 3108.

https://researchrepository.wvu.edu/etd/3108

This Dissertation is protected by copyright and/or related rights. It has been brought to you by the The Research Repository @ WVU with permission from the rights-holder(s). You are free to use this Dissertation in any way that is permitted by the copyright and related rights legislation that applies to your use. For other uses you must obtain permission from the rights-holder(s) directly, unless additional rights are indicated by a Creative Commons license in the record and/ or on the work itself. This Dissertation has been accepted for inclusion in WVU Graduate Theses, Dissertations, and Problem Reports collection by an authorized administrator of The Research Repository @ WVU.

For more information, please contact researchrepository@mail.wvu.edu. 


\title{
MODELING STUDIES TO EVALUATE PERFORMANCE OF THE HORIZONTAL WELLS COMPLETED IN SHALE
}

\author{
Abbas Belyadi \\ Dissertation submitted to the \\ College of Engineering and Mineral Resources \\ at West Virginia University \\ in partial fulfillment of the requirements \\ for the degree of \\ Doctor of Philosophy \\ in \\ Petroleum and Natural Gas Engineering
}
Khashayar Aminian, Ph.D., Chair
Sam Ameri, M.S.
H. Ilkin Bilgesu, Ph.D.
Pramod Thakur, Ph.D.
Daniel E. Della-Giustina, Ph.D.

\begin{abstract}
Morgantown, West Virginia
\end{abstract}
2011

Keywords: Horizontal Well; Hydraulic Fracture; Natural Fracture

Copyright 2011 Abbas Belyadi 


\title{
ABSTRACT
}

\section{Modeling studies to evaluate performance of the horizontal wells completed in shale}

\begin{abstract}
Abbas Belyadi
The results of the modeling studies to determine the production performance of multiple fractured horizontal wells completed in shale formation has been summarized in this dissertation. A commercial reservoir simulator was utilized to model both single and dual porosity reservoir (with and without adsorption) with multiple layers. The impact of reservoir characteristics including natural fractures and hydraulic fractures properties on the production performance were investigated. In addition, the results were utilized to investigate the flow regimes for horizontal wells with one or multiple hydraulic fractures.

Flow regime identification in low permeability reservoirs is extremely critical to evaluate performance of the horizontal wells. In this research, a number of possible flow regimes were identified using both log-log plot of inverse of the flow rate and its derivative versus time. They included linear, tri-linear (second linear), and pseudo-steady state. In addition, Decline Curve Analysis (DCA) and Production Type Curves (PTC) were also considered in this study to confirm the observed flow regimes and their production behavior. The results of this study will provide an understanding of flow behaviors in low permeability reservoirs. Understanding of the flow behavior can then be used to predict production from low permeability reservoirs such as Marcellus shale.
\end{abstract}




\section{ACKNOWLEDGEMENTS}

This dissertation is the result of my momentous journey in obtaining a doctorate of philosophy degree in Petroleum and Natural Gas Engineering (PNGE) at West Virginia University (WVU). I would like to express my gratitude towards certain outstanding individuals for helping make this dissertation a success.

My sincere gratitude is to my academic advisor, Dr. Kashy Aminian, for his support during my studies at WVU. I really appreciate his help, patience, and guidance during my stay at WVU. His assistance was invaluable to me and undoubtedly a memorable experience. Looking to the future, one of my goals is becoming as good an advisor to my mentees as Dr. Kashy has been to me.

In addition, I would also like to extend my appreciation to Professor Sam Ameri, Chairman of the PNGE Department, for his endless support during the course of my stay at WVU. Being more than just a professor to me, his advice always motivated me to thoroughly complete my research work. He greatly educated me regarding various beneficial scholastic endeavors as both an undergraduate and graduate student at WVU. I remain extremely indebted to Professor Sam Ameri for his continuous support and relentless assistance.

Special thanks to Dr. Ilkin Bilgesu, for his consideration and patience during my education at WVU. He has been continuously helpful during my education at WVU. Likewise, I am also grateful to Dr. Bilgesu for his dedicated participation in the examining committee.

I also want to thank Dr. Pramod Thakur for his participation in the examining committee. His class during my graduate study at WVU was extremely beneficial to my continued education. 
In closing, I want to thank Dr. Daniel E. Della-Giustina for taking the time to be involved in the examining committee. His valued contribution to this review is highly appreciated.

\section{DEDICATION}

I am grateful to God for making my dream a reality by obtaining a Doctor of Philosophy degree in Petroleum \& Natural Gas Engineering at West Virginia University.

This dissertation is dedicated to my lovely parents, Zareen and Mohammad. Mom and dad, I love you both very much. Most importantly, I would like to dedicate my doctoral work to my gorgeous wife Roshanak. 


\section{TABLE OF CONTENTS}

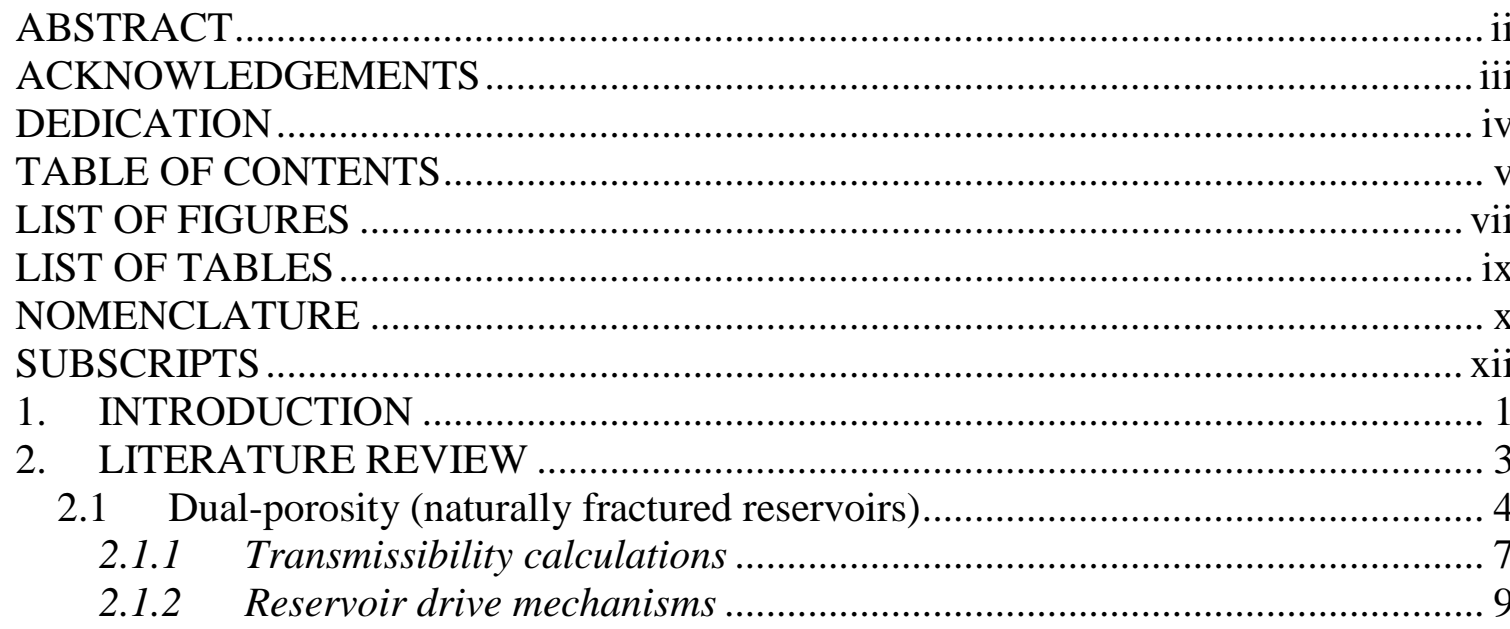

2.2 Flow behavior in horizontal wells without hydraulic fractures in single porosity systems

2.2.1 Dimensionless fracture conductivity ....................................................... 11

2.3 Flow behavior in horizontal wells with hydraulic fractures in single porosity

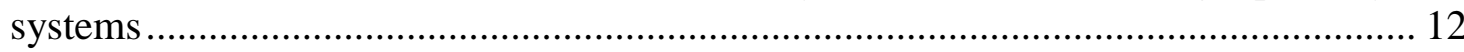

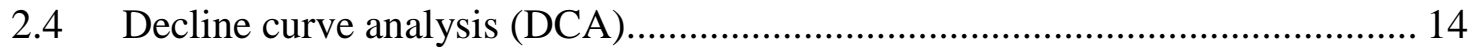

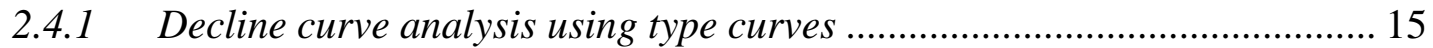

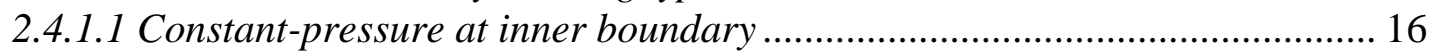

2.5 Type curves for horizontal wells (single porosity).......................................... 19

2.5.1 Type curves for hydraulically fractured horizontal wells (single porosity) 21

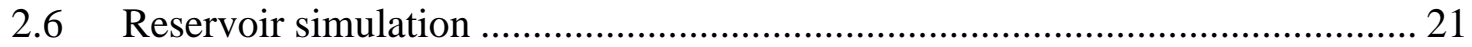

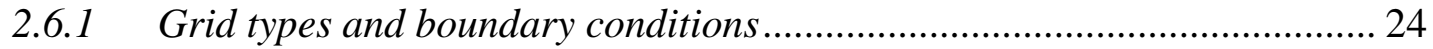

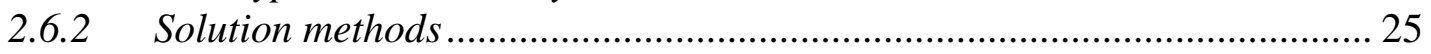

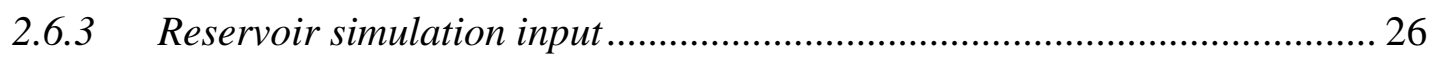

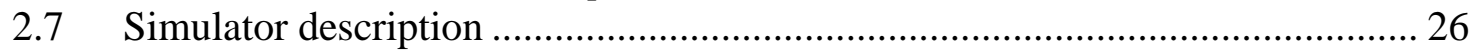

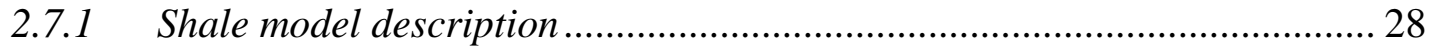

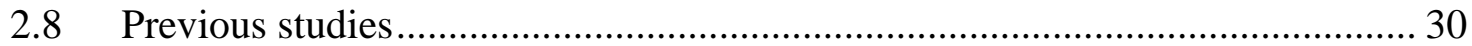

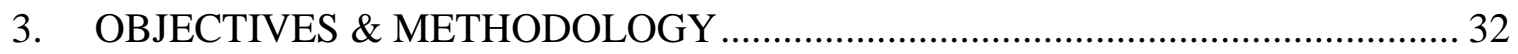

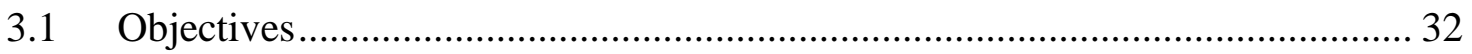

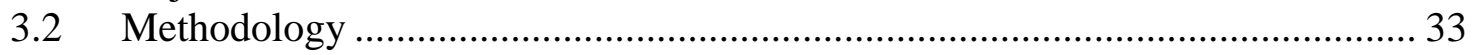

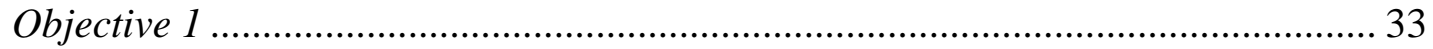

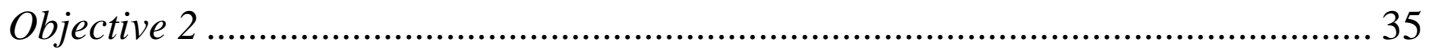

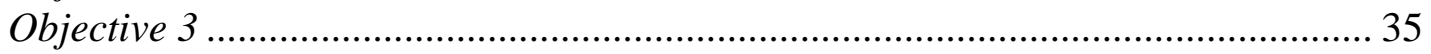

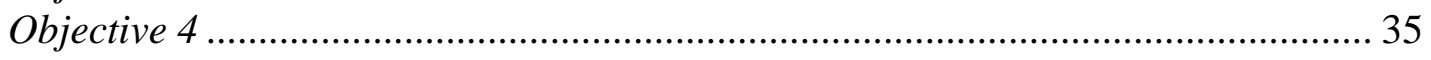

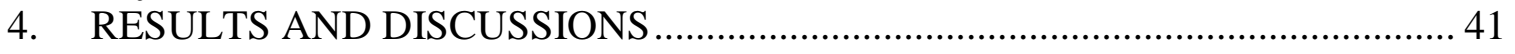

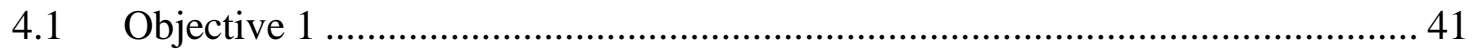

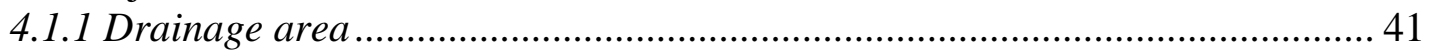

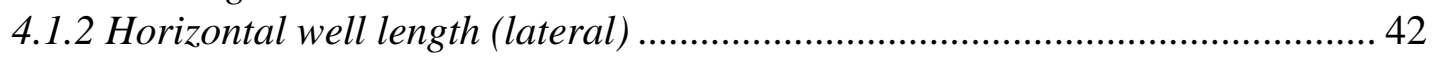

4.1.3 Location of horizontal lateral at a target formation ....................................... 43 


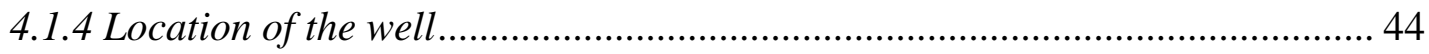

4.1.5 Reservoir thickness ................................................................................. 45

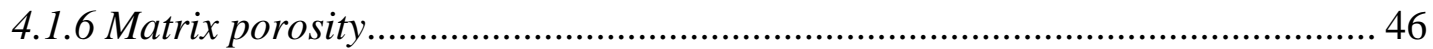

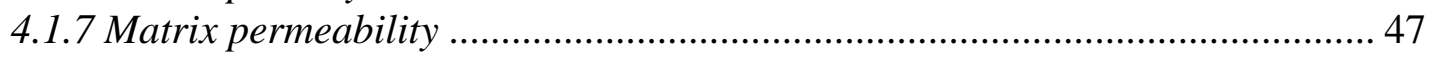

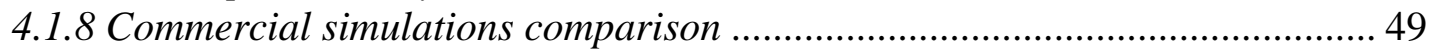

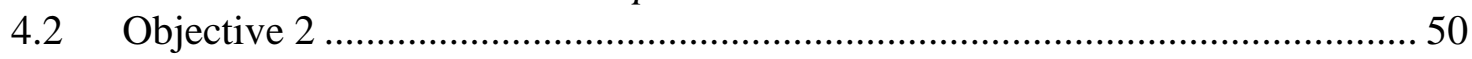

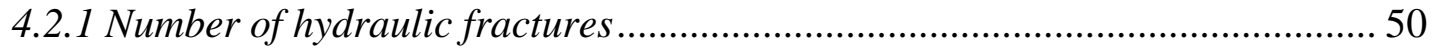

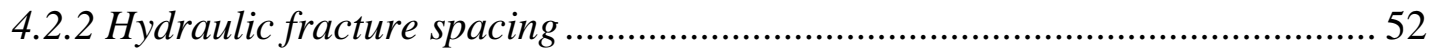

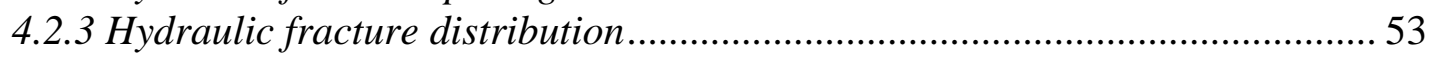

4.2.4 Contributions of the horizontal well and hydraulic fracture .......................... 54

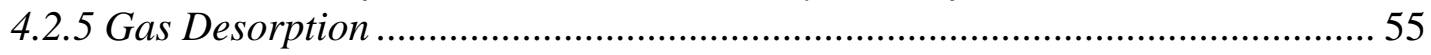

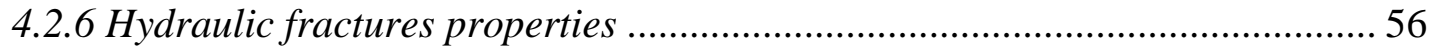

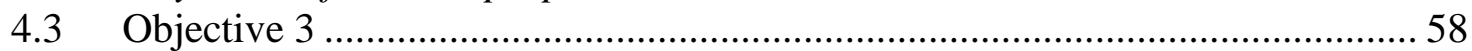

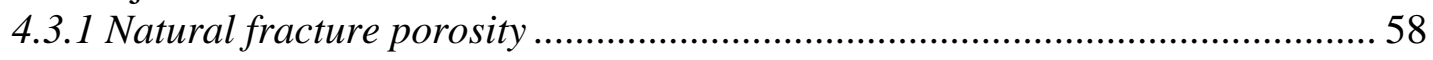

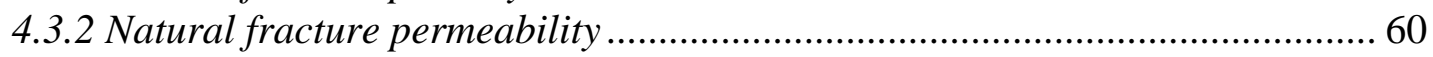

4.3.3 Natural fracture permeability and number of hydraulic fractures ...................6. 62

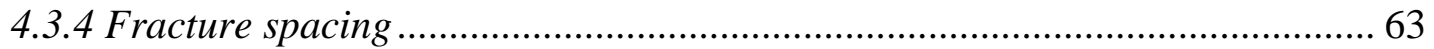

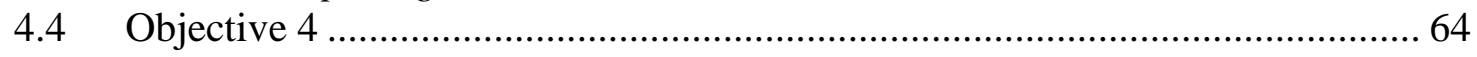

4.4.1 Flow regimes in horizontal wells with hydraulic fractures in dual porosity

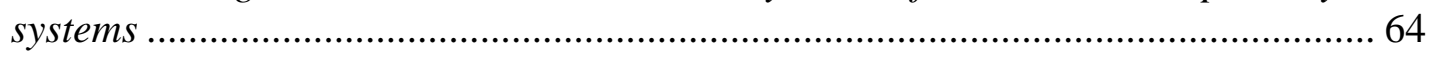

4.4.2 Flow regimes verification using decline curves analysis (DCA).................... 67

4.4.3 Flow regimes verification using production type curve (PTC) ...................... 70

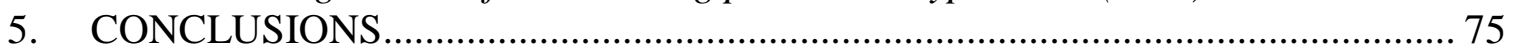

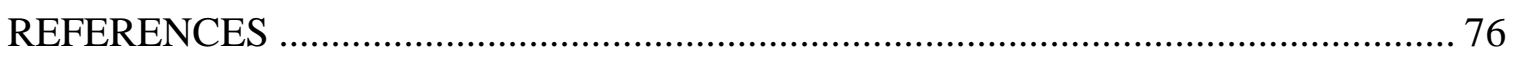

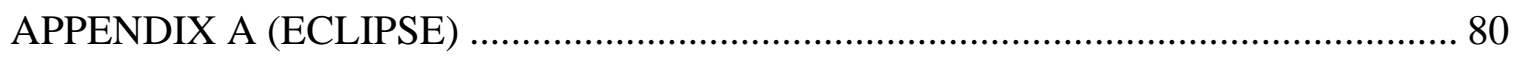

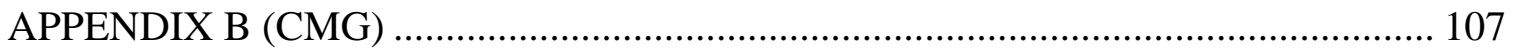

APPENDIX C (ECLIPSE MODELS LAYOUTS) ................................................. 122 


\section{LIST OF FIGURES}

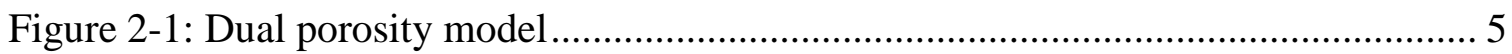

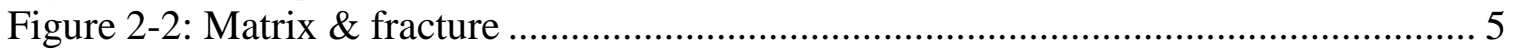

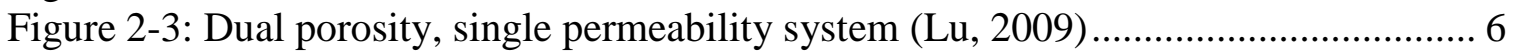

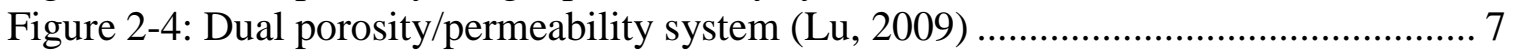

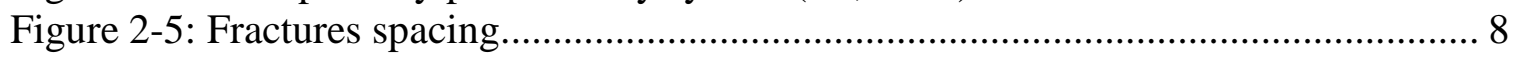

Figure 2-6: Matrix and fracture cells (block to block connection) ..................................... 8

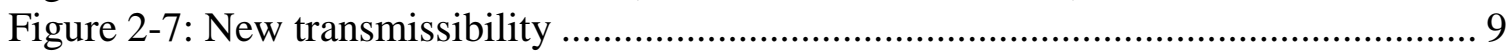

Figure 2-8: Flow regimes in horizontal well............................................................. 10

Figure 2-9: Dimensionless fracture conductivity........................................................ 11

Figure 2-10: Early radial flow (fracture storage) regime ................................................ 12

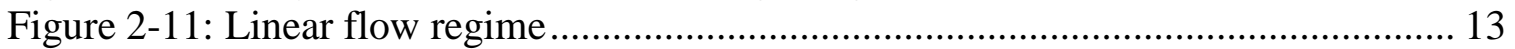

Figure 2-12: Tri-linear flow regime (Ozkan, 2009) ...................................................... 13

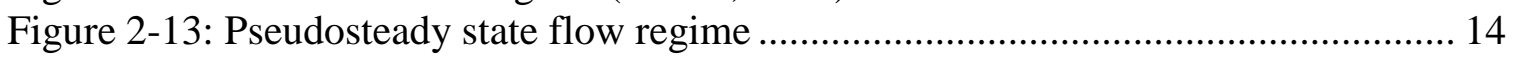

Figure 2-14: Decline curve analysis .......................................................................... 15

Figure 2-15: Type curves for Arps empirical rate-time decline equations ....................... 16

Figure 2-16: Dimensionless flow rate for plane radial system ........................................ 17

Figure 2-17: Production decline type curves for gas wells producing against a constant

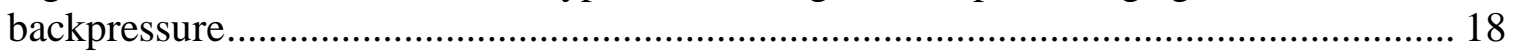

Figure 2-18: Cumulative production decline type curves for gas wells producing against a

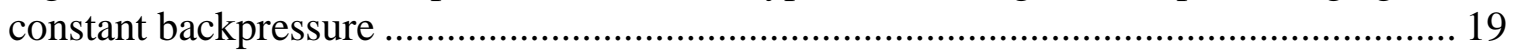

Figure 2-19: Type curve for horizontal wells in infinite reservoirs ................................ 20

Figure 2-20: Type curve for horizontal wells in finite square drainage area.................... 20

Figure 2-21: Body center grids .................................................................................. 24

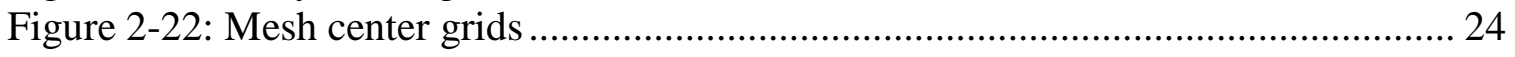

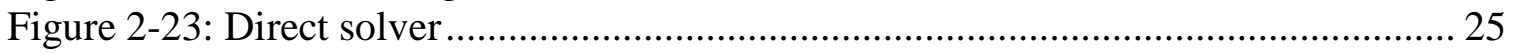

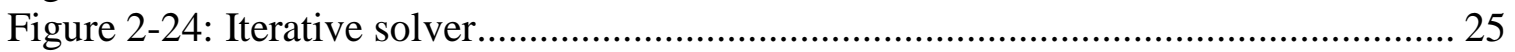

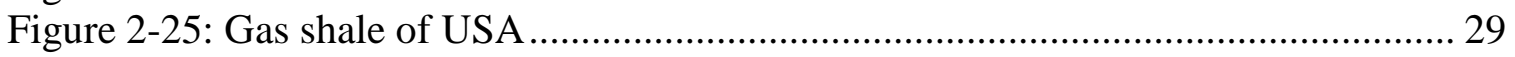

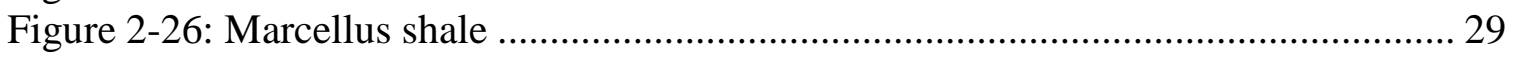

Figure 4-1: The impact of the size of the drainage area on production profile of $3000-\mathrm{ft}$

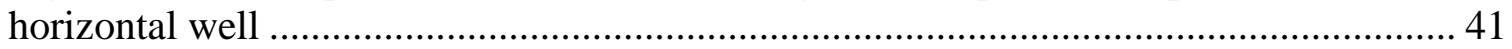

Figure 4-2: The impact of the horizontal lateral on cumulative production ...................... 42

Figure 4-3: The impact of the location of horizontal lateral at a target formation ........... 43

Figure 4-4: Horizontal well placement at the center of a target formation........................ 43

Figure 4-5: The impact of the location of the well .................................................... 44

Figure 4-6: Two different locations of the wells. ........................................................... 44

Figure 4-7: The impact of reservoir thickness on cumulative production ......................... 45

Figure 4-8: The impact of matrix porosity on cumulative production.............................. 46

Figure 4-9: The impact of matrix permeability (typical natural fracture) on cumulative

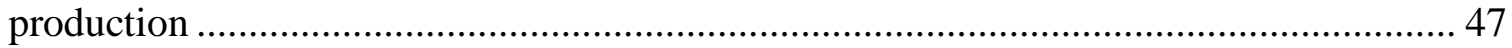

Figure 4-10: The impact of matrix permeability (high natural fracture) on cumulative

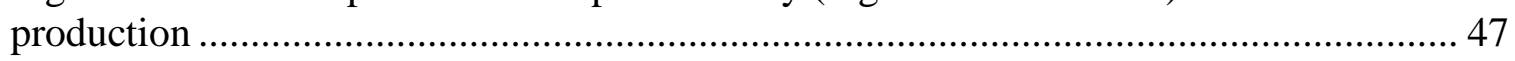

Figure 4-11: ECLIPSE vs. CMG .......................................................................... 49

Figure 4-12: The impact of the number of hydraulic fractures on cumulative production50 
Figure 4-13: The impact of the number of hydraulic fractures on initial production rate 51 Figure 4-14: The impact of the number of hydraulic fractures on cumulative production51 Figure 4-15: The impact of hydraulic fracture spacing 52 Figure 4-16: Comparison production from one and two horizontal wells in a $4000 \times 2000$ $\mathrm{ft}^{2}$ area 53

Figure 4-17: The contribution to the production from horizontal well with hydraulic

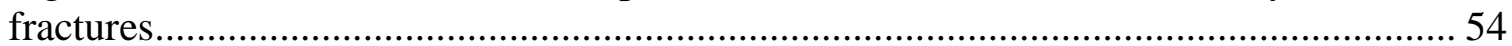
Figure 4-18: The contribution of horizontal well with 4 hydraulic fractures to production

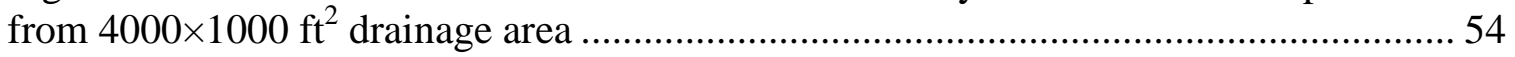

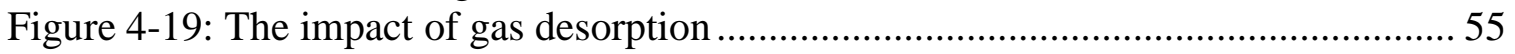

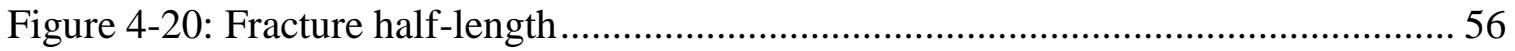

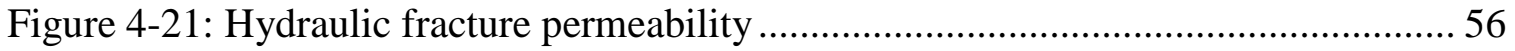

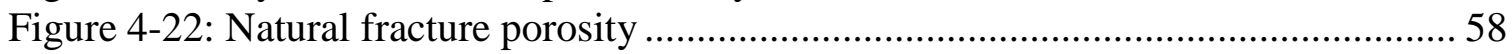

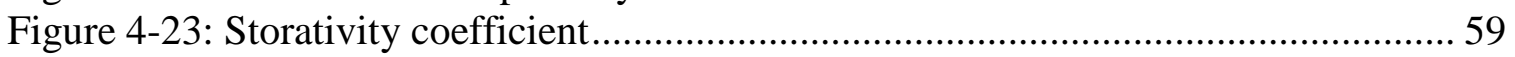

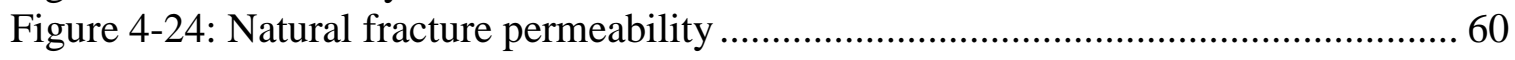

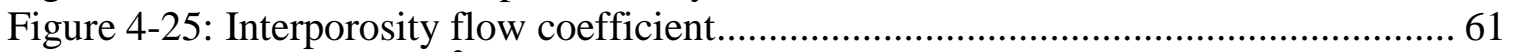

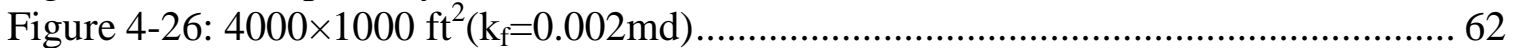

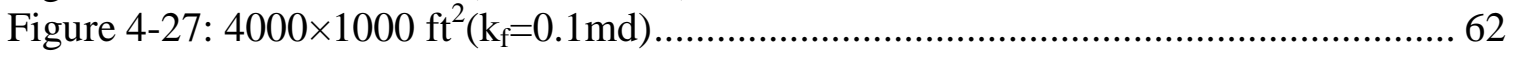

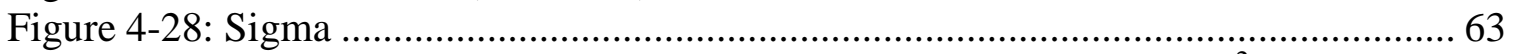

Figure 4-29: Diagnostic plot showing various flow periods $\left(4000 \times 1000 \mathrm{ft}^{2}-1 \mathrm{Frac}\right) \ldots \ldots .65$

Figure 4-30: Diagnostic plot showing various flow periods $\left(4000 \times 1000 \mathrm{ft}^{2}-4\right.$ Fracs $) \ldots . .65$

Figure 4-31: Diagnostic plot showing various flow periods $\left(4000 \times 1000 \mathrm{ft}^{2}-7\right.$ Fracs $) \ldots . .66$

Figure 4-32: Diagnostic plot showing various flow periods $\left(4000 \times 1000 \mathrm{ft}^{2}-13\right.$ Fracs $) \ldots 66$

Figure 4-33: Diagnostic plot showing various flow periods $\left(4000 \times 2000 \mathrm{ft}^{2}-4\right.$ Fracs $) \ldots . .67$

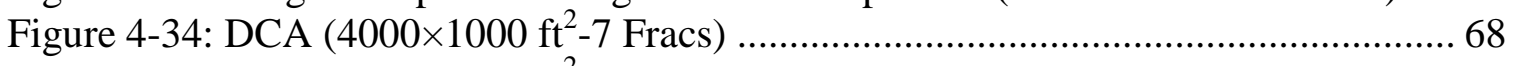

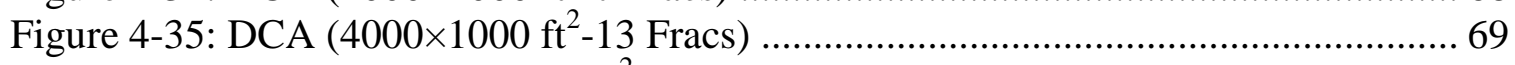

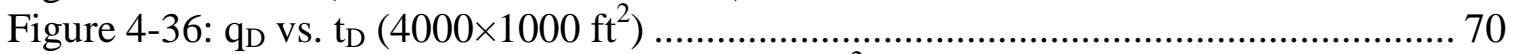

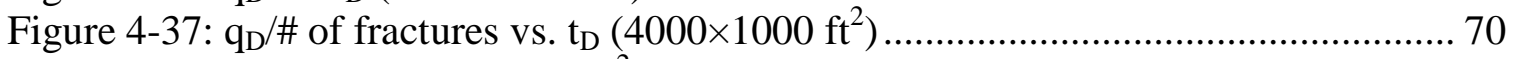

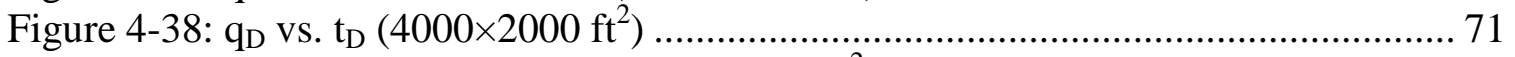

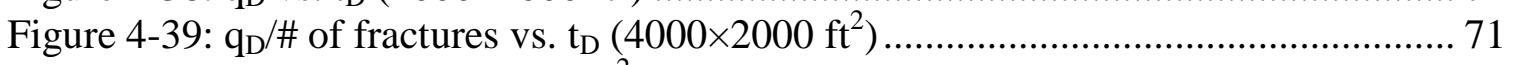

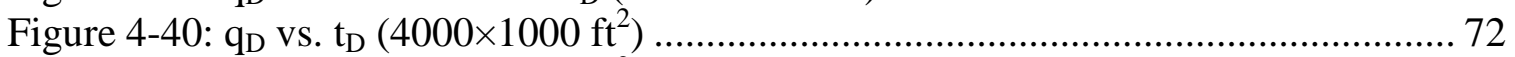

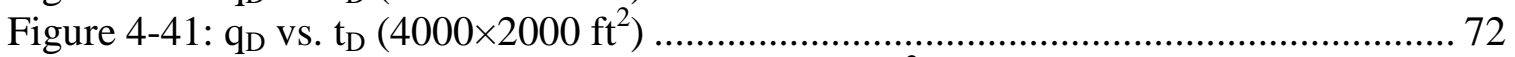

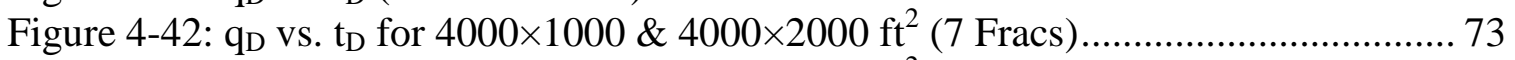

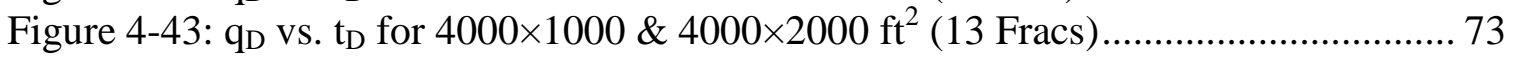




\section{LIST OF TABLES}

Table 1: Successive over-relaxation method (SOR) ...................................

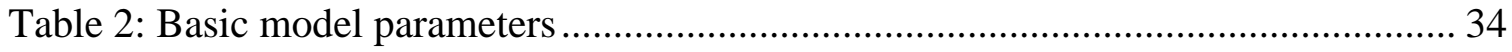

Table 3: Various drainage areas and horizontal well length configuration ...................... 37

Table 4: The impact of the properties of hydraulic fracture on production performance. 38

Table 5: The impact of the natural fracture characteristics on production performance .. 39

Table 6: Flow regimes in hydraulically fractured horizontal wells ................................ 40

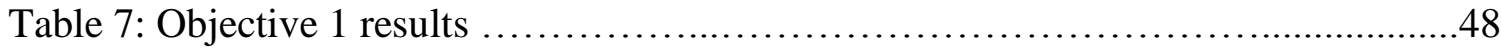

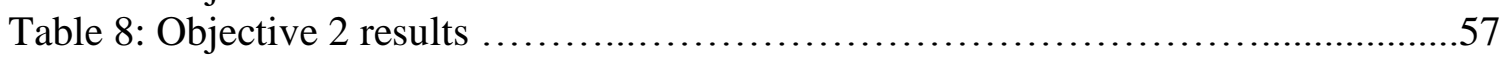

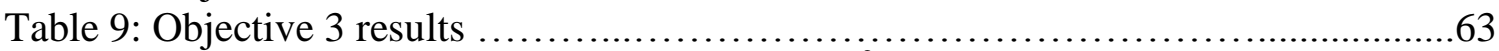

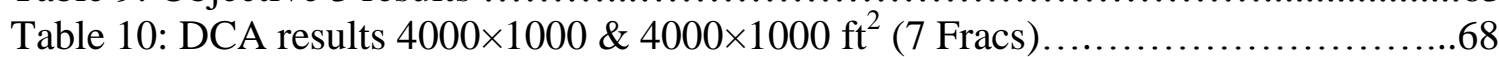

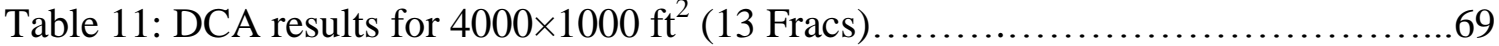

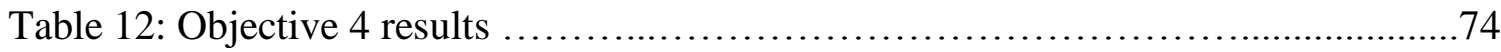




\section{NOMENCLATURE}

$K=\mathrm{X}$-direction permeability of the matrix blocks

$V=$ matrix cell bulk volume

$\sigma=$ factor of dimensionality, $\mathrm{LENGTH}^{-2}$ to account for the matrix/fracture interface area per unit volume, that is the size of the blocks in the matrix volume.

$P V=$ pore volume

$S_{o}, S_{w}, S_{g}=$ oil, water, and gas saturations

$B=$ formation volume factor, $\mathrm{RB} / \mathrm{STB}$

$V=$ ratio of total volume of one porous system to bulk volume

$C=$ wellbore storage coefficient

$\alpha=$ block shape parameter

$\lambda=$ interporosity flow coefficient

$\omega=$ storativity coefficient

$n=$ number of fracture planes

$L_{m}=$ fracture spacing

$h=$ thickness, $\mathrm{ft}$

$\varphi=$ porosity, fraction of bulk volume

$\mu=$ viscosity, $\mathrm{cp}$

$k=$ permeability, $\mathrm{md}$

$r_{w}=$ wellbore radius, $\mathrm{ft}$

$r_{e}=$ external boundary radius, $\mathrm{ft}$

$w_{f}=$ fracture width, in

$x_{f}=$ fracture half length, $\mathrm{ft}$

$b=$ hyperbolic exponent

$p_{i}=$ initial pressure, $\mathrm{ft}$

$p_{w f}=$ bottomhole flowing prerssure, psia (kpa) 
$G_{i}=$ initial gas in place, surface measure

$G_{p}=$ cumulative gas production, surface measure

$q=$ producing rate at time $\mathrm{t}, \mathrm{vol} / \mathrm{unit}$ time

$q_{D}=$ dimensionless rate

$q_{D d}=$ decline curve dimensionless rate

$q_{i}=$ initial surface rate of flow at $\mathrm{t}=0$

$t=$ time, years

$t_{D}=$ dimensionless time

$c_{t}=$ total compressibility, $\mathrm{psi}^{-1}\left(\mathrm{pa}^{-1}\right)$

$D=$ nominal exponent decline rate, $1 /$ time

$D_{i}=$ initial nominal decline rate $(\mathrm{t}=0), 1 /$ time

$e=$ base of natural logarithms, $(2.718 \ldots)$

$Q_{D}=$ dimensionless cumulative production

$s=$ skin factor, dimensionless

$\gamma_{g}=$ gas specific gravity, dimensionless

$G_{p}=$ cumulative production (Mscf)

$G_{p D}=$ dimensionless cumulative production

$k_{v}=$ vertical permeability (md)

$k_{h}=$ horizontal permeability (md)

$p_{p}=$ pseudopressure $\left(\mathrm{psi}^{2} / \mathrm{cp}\right)$

$r_{w D}=$ dimensionless wellbore radius

$T=$ temperature $\left({ }^{\circ} \mathrm{R}\right)$ 


\section{SUBSCRIPTS}

$$
\begin{aligned}
& f=\text { fracture } \\
& m=\text { matrix } \\
& f+m=\text { total system }
\end{aligned}
$$




\section{INTRODUCTION}

Unconventional reservoirs play enormous roles in hydrocarbon production in the United States. Devonian black shale, called the Marcellus that is found in the Appalachians, has shown notable promise in the past few years. Marcellus shale formation is expected to be a key contributor to the natural gas supply of the United States. Unconventional reservoirs such as Marcellus shale present several challenges compared to conventional reservoirs. The first challenge is that shale formations are considered to be dual porosity or naturally fractured formations. A naturally fractured reservoir contains two storage volumes for hydrocarbons including the rock matrix and natural fractures. The second challenge is the adsorbed gas which is contained within organic material in the shale. These two major key differences between conventional gas reservoirs and shale gas reservoirs can have a dramatic impact on production performance.

The interest in exploration of ultra-low permeability formations has increased in the recent years due to declining reserves from the conventional reservoirs. Emergence of the ultra-low permeability formations, such as Marcellus Shale, as a target of exploration and development, has created new challenges for resource development. Shale contains two gas storage mechanisms including sorbed gas (contained within organic material), and free gas (contained within gas-filled porosity). These different storage mechanisms affect the speed and efficiency of gas production. Almost all shale formations require multistage stimulation treatments to achieve economic production. Although both vertical and horizontal completions can be used in the low permeability formations, horizontal wells with multi-stage hydraulically fractured completions are considered to be the most cost effective in achieving commercial production. The limited field experience with multiple hydraulic fractures in horizontal wells indicates that significant increase in initial production can be achieved as the number of hydraulic fractures is increased. However, the production performance particularly over longer time periods is not well established.

The recoverable gas and deliverability play enormous roles in evaluating the economic potential of shale gas reservoirs. Shale gas reservoirs are organic-rich formations which 
are both the source rock as well as the reservoir rock. Shale is typically composed of variable amounts of clay minerals and often other minerals such as quartz and calcite dominate. Substantial quantities of organic matter (Kerogen) are present in shales and are reported as the total organic content (TOC). Matrix permeability is extremely low in gas shale reservoirs (10-1,000 nD). Therefore an enormous conductive surface area between the well and the reservoir must be achieved through completion to produce gas at commercial rates. Multi-stage hydraulic fracturing treatments are used to create the necessary surface area to connect the complex natural fracture network to the well. It is also believed that hydraulic fracturing enhances the connectivity of the natural fracture system.

There is no tool or methodology readily available for analysis and prediction of the production from horizontal wells with multiple hydraulic fractures in ultra-low permeability shale formations such as Marcellus shale.

The overall goal of this research is to study the impact of reservoir characteristics, hydraulic fractures, and natural fractures on production performance of shale formation such as Marcellus shale. To achieve this goal, a number of case scenarios were modeled to evaluate the production performance of the horizontal wells completed in the shale formation. Flow regimes for horizontal wells with multi-stages of hydraulic fractures were investigated using both log-log plot of the inverse of the flow rate (1/q) and its derivative versus time. 


\section{LITERATURE REVIEW}

Both hydraulic fractures and natural fractures play significant roles in well performance in low permeability reservoirs. Rosa and Carvalho (1988) were the first to extend the horizontal well solutions to dual porosity systems. The general solution for pressure transient in dual porosity systems are often provided by log-log type curves. However, all flow regimes predicted by the model are rarely observed from filed data and the analysis is often incomplete. Lu et al (2009) utilized the direct synthesis method for horizontal wells. They concluded that there are a number of flow regimes present and one or more could be masked or missing depending on reservoir parameters. The flow regimes include the early radial flow (in vertical direction) and it has short duration in thin or high vertical permeability reservoirs. The next flow regime is known as intermediate linear flow regime and is developed because the length of the horizontal well is often much greater than the formation thickness. Subsequently, the transition period becomes dominant, and finally late radial flow period is observed. Ozkan et al (2009) and Brown et al (2009) introduced the concept of tri-linear flow for hydraulically fracture horizontal wells. They indicated that the contribution of micro-Darcy formation beyond the stimulated volume is negligible and flow is mainly linear perpendicular to the hydraulic fracture. The tri-linear flow couples three linear flow regions including the hydraulic fracture, the inner area between the fractures, and the area beyond the tip of the fracture.

In hydraulic fracturing, fluid (pad) is injected into an underground formation at a high pressure to part of the formation. Fracture fluid and proppants (slurry) are then pumped into the created fracture to keep the fracture open. The fracture filled with proppants creates a very conductive flow path with large permeability (Rosa, 1988) toward the wellbore. The well is flushed to displace slurry from the wellbore to the fracture. The appropriate amount and type of proppant are extremely significant to the success of fracturing treatments. There are several types of proppants including sand, resin coated sand, and manmade ceramic or bauxite. The sand types consist of Brady sand and Ottawa sand. Additionally, resin coated sand consists of curable resin coated sand and procured resin coated sand. 


\subsection{Dual-porosity (naturally fractured reservoirs)}

Shale formations are more accurately characterized by dual porosity model than single porosity model. In dual porosity systems, there is a convoluted interaction between the naturally occurring fractures in the reservoir and rock matrix. Therefore, these reservoirs can act as two reservoirs including the fracture and the matrix. Although the dual porosity concept was introduced by Barenblatt et al, their contribution is limited to the derivation of the pressure factor in blocks segments (using a zero compressibility restriction) in the most permeable medium. The dual porosity model is a case of heterogeneous behavior between fracture and matrix where only one of the two porous mediums (fracture) has a substantial amount of permeability to produce to the well. The second porous medium (matrix) does not directly produce to the well due to extremely low permeability but it will instead supply or feed the fracture porous medium. Warren and Root were the first to complete line-source solution in terms of pressure in the most permeable medium for pseudosteady interporosity flow. In addition to permeability and skin, Warren and Root showed that two parameters namely the storativity coefficient, $\omega$ and the interporosity flow coefficient, $\lambda$, controlled dual/double porosity behavior. The first variable is the storativity coefficient, $\omega$, which compares how large is the fracture storativity compared to total storativity of the reservoir. The storativity coefficient, $\omega$, is shown with the following equation (Warren \& Root, 1962).

$$
\omega=\frac{(\phi V C)_{f}}{(\phi V C)_{f+m}}
$$

The second variable is the interporosity flow coefficient, $\lambda$, which describes the well connectivity of natural fracture to matrix rock (Warren \& Root, 1962). The interporosity flow coefficient, $\lambda$, is shown with the following equation (both $\lambda$ and $\omega$ are dimensionless).

$$
\lambda=\frac{\alpha k_{m} r_{w}^{2}}{k_{f}}
$$

Where:

$$
\alpha=\frac{4 n(n+2)}{L_{m}^{2}}
$$


Where $n=1$ for multilayered reservoir and $L$ is characteristics dimension of such a block. Mavor and Cinco added wellbore storage and skin to the pseudosteady-state interporosity flow solution of Warren and Root. Then this solution was extended by Bourdet and Gringarten to account for transient interporosity flow for the analysis of dual porosity system. Cinco and Samaniego later published a similar solution.

As mentioned earlier, dual porosity systems (Figure 2-1) consist of two porous media regions including primary (matrix) porosity and secondary (fracture) porosity. The primary porosity region, which has very low permeability, contains most of the fluid in the system. However, the secondary porosity system has greater permeability. Fluid flow to the wells only occurs through the secondary porosity system.

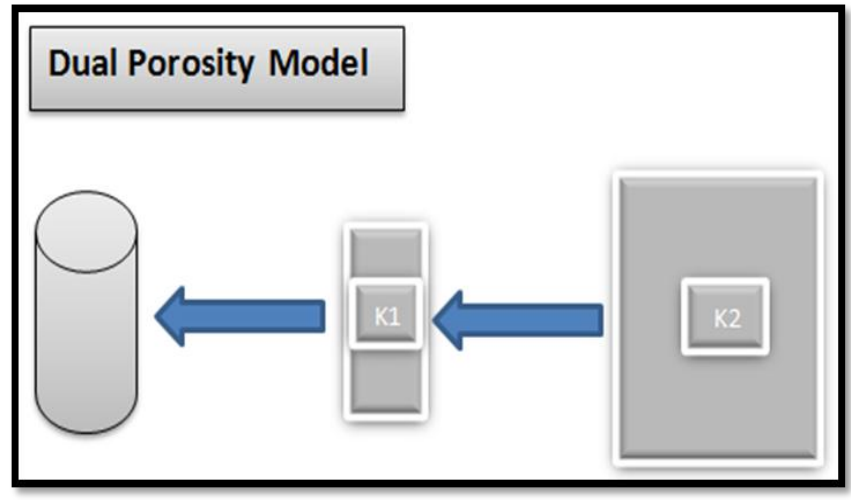

Figure 2-1: Dual porosity model

Fluid exists in two interconnected systems including matrix and fracture in dual porosity reservoirs as shown in Figure 2-2.

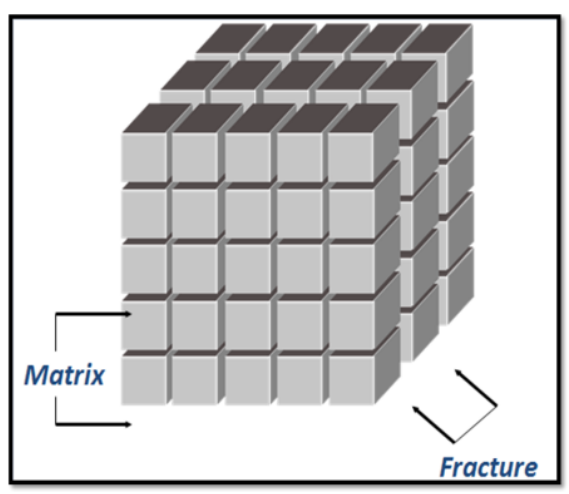

Figure 2-2: Matrix \& fracture 
Matrix usually provides the bulk of the reservoir volume and fracture usually provides the permeability. The reservoir is termed dual porosity/permeability if the matrix is linked through both the fracture and matrix blocks. Flow takes place between neighboring cells. However, the reservoir is dual porosity and single permeability if the matrix is linked only through the fracture system. In reservoir simulation for single porosity systems, fracture cell properties are not used. However, in dual porosity systems, flow takes place between fracture cells and between each matrix cell and its corresponding fracture cell. Flow does not take place in neighboring matrix cells.

In dual porosity and single permeability system, flow takes place from matrix to fracture cell and continues to flow between fracture cells as shown in Figure 2-3. The matrix blocks have no mutual transmissibility in dual porosity and single permeability system (Lu, 2009).

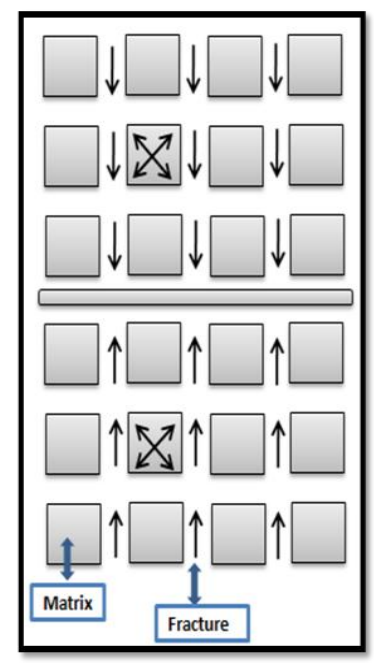

Figure 2-3: Dual porosity, single permeability system (Lu, 2009)

However, in dual porosity/permeability system, flow takes place from matrix to fracture cells and continues to flow between fracture cells and from matrix cells to another neighboring matrix cell as shown in Figure 2-4. The matrix blocks have their normal transmissibility in dual porosity/permeability system (Lu, 2009). 


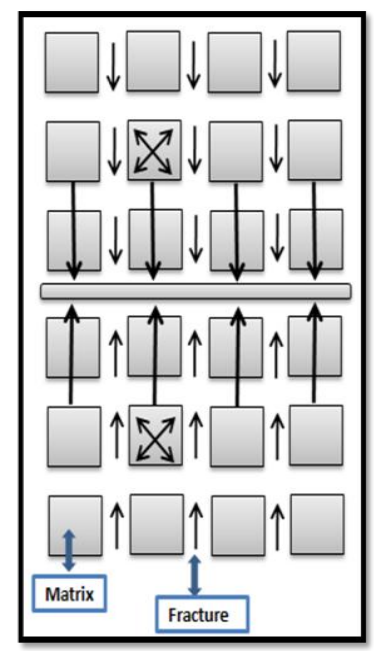

Figure 2-4: Dual porosity/permeability system (Lu, 2009)

The separation of matrix blocks by natural fractures was first introduced by Warren and Root (1962). Shale matrix permeability is very low and it can reach as low as $10^{-9} \mathrm{md}$ (Ming, 1993). However, the matrix can store more gas than natural fracture due to its larger volume. Therefore the porosity is higher in the matrix when compared to natural fracture. It is important to note that there is different permeability including matrix permeability, natural fracture permeability, and hydraulic fracture permeability in dual porosity with hydraulic fractures.

\subsubsection{Transmissibility calculations}

The matrix-fracture coupling transmissibility terms, exist between the matrix grid and fracture grid cell, are proportional to the bulk volume and it is shown by the following equation.

$$
T R=C D A R C Y . K . V . \sigma
$$

$\mathrm{K}$ is $\mathrm{X}$-direction permeability of the matrix block, $\mathrm{V}$ is the matrix cell bulk volume, and $\sigma$ is the shape factor (fracture spacing). The following form of the matrix block shape factor, $\sigma$, has proposed by Kazemi et al (1976).

$$
\sigma=4\left(\frac{1}{l_{x}^{2}}+\frac{1}{l_{y}^{2}}+\frac{1}{l_{z}^{2}}\right)
$$

Where $1_{x}, 1_{y}$, and $1_{z}$ are $X, Y$, and $Z$ dimensions of the blocks of material making up the matrix volume. Sigma, $\sigma$, can be treated as a history matching parameter since it acts as a 
multiplier on the matrix-fracture coupling. Fracture spacing is used to calculate the matrix to fracture transfer coefficient and fracture spacing is measured from center of fracture to center line of fracture in the appropriate direction as shown in line arrow $A$ in Figure 2-5.

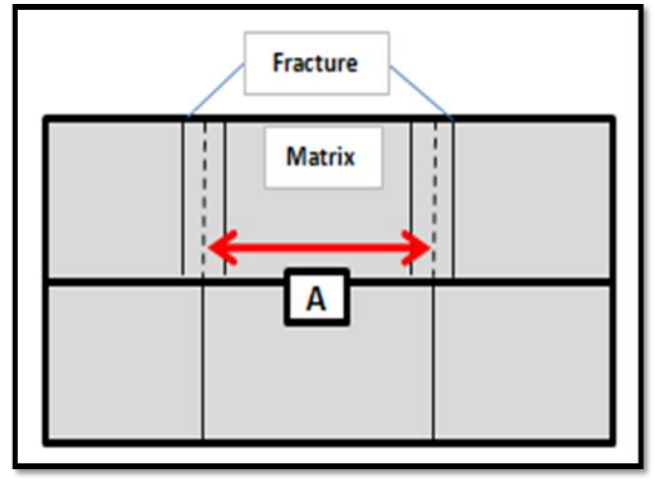

Figure 2-5: Fractures spacing

Figure 2-6 shows a transmissibility of the two physical cells including matrix and fracture blocks and contact between upper fracture and lower matrix. In addition the matrixfracture flow and fracture-fracture flow in porous media is indicated by different arrows in Figure 2-6. Flow occurs from matrix blocks which contains extremely low permeability to more permeable fracture blocks.

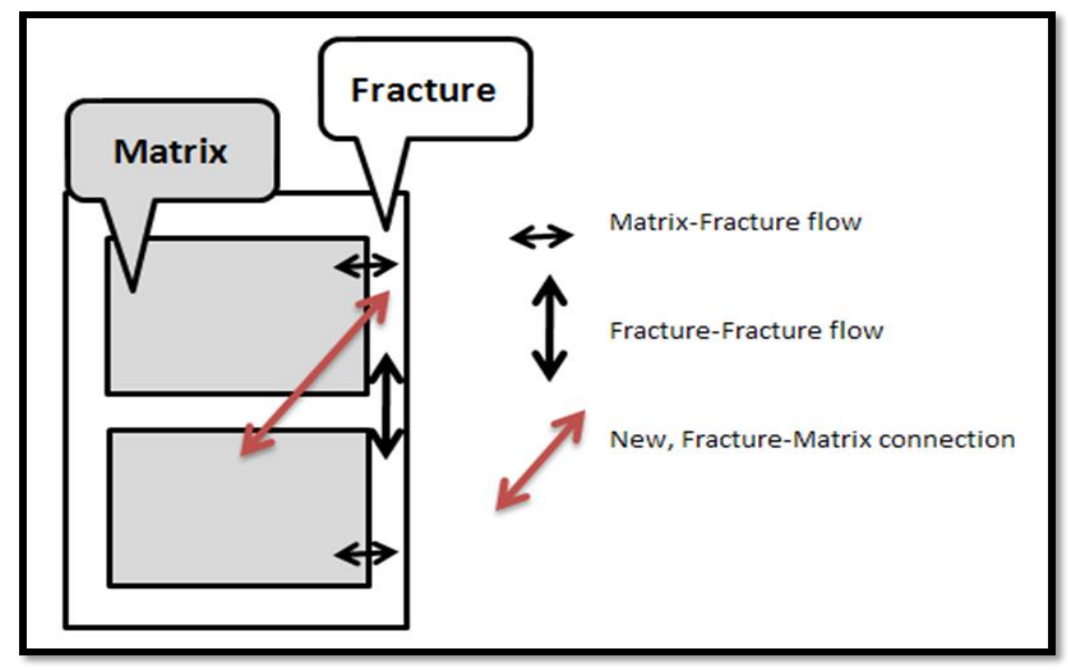

Figure 2-6: Matrix and fracture cells (block to block connection) 
A new multiplier is applied to transmissibility between the new upper fracture and lower matrix. New transmissibility between these cells is different from the contact between the two vertically neighboring fractures cells and two vertical neighboring matrix cells as shown in Figure 2-7.

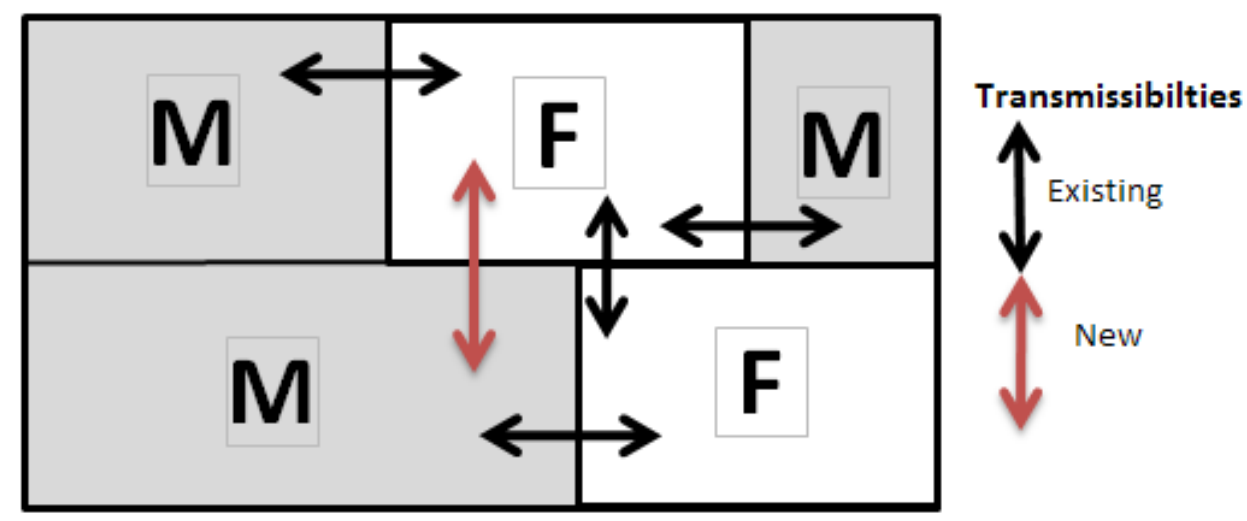

Figure 2-7: New transmissibility

\subsubsection{Reservoir drive mechanisms}

Reservoir drive is the energy that moves oil and natural gas from subsurface rock to the production well. There is two set of reservoir drive that exists for oil and gas production from a reservoir. Reservoir drive includes natural drive mechanisms (primary drive) and artificial drive mechanisms (enhanced recovery). The majority of oil and gas is stored in the matrix system; however productions of these are through fracture which contains higher permeability. The oil production is usually due to a combination of different drive mechanisms. These physical mechanisms includes liquid and rock expansion, solution gas drive, gas cap, water drive, and gravity drainage that can be associated for production from matrix blocks. However, drive mechanisms of natural gas production is due to gas expansion and water drive.

Total gas in place within a grid block is shown by the following equation.

$$
\text { Total gas in place }=P V \cdot S_{g} \cdot \frac{1}{B_{g}}
$$

Where: $S_{g}=1-S_{w}-S_{o}$ 
Solution gas drive is the most widespread reservoir drive which is the principle drive mechanisms in $1 / 3$ of the world's reservoirs. Reservoir pressure decreases and dissolves gas bubbles out of reservoir when oil is produced from the reservoir. Reservoir pressure falls below the bubble point (no gas cap) as the reservoir depletes. This gas expansion will occur in the pore spaces and pushes the reservoir oil through the pores to the production well. Roughly $1 / 3$ of the world's reservoir has water drive. These reservoirs have access to aquifers that can maintain the reservoir pressure wholly or partially. It will provide water to replace some or all of the volume of fluids produced resulting in higher recovery factor. Gas cap drive reservoirs effectiveness is dependent upon its size relative to the size of the oil zone. Pressure will not drop as rapidly as oil produces because the gas cap expands and prevent the pressure from dropping. Gravity drainage is the least common primary recovery mechanism. The force of gravity will push the hydrocarbons out of reservoir into wellbore and produce.

\subsection{Flow behavior in horizontal wells without hydraulic fractures in single porosity systems}

Several flow regimes can be established when analyzing transient-pressure responses and production behavior in horizontal wells with no hydraulic fractures. Flow regimes including early radial flow, intermediate linear flow, and late pseudoradial can be seen during transient-pressure responses as shown in Figure 2-8.

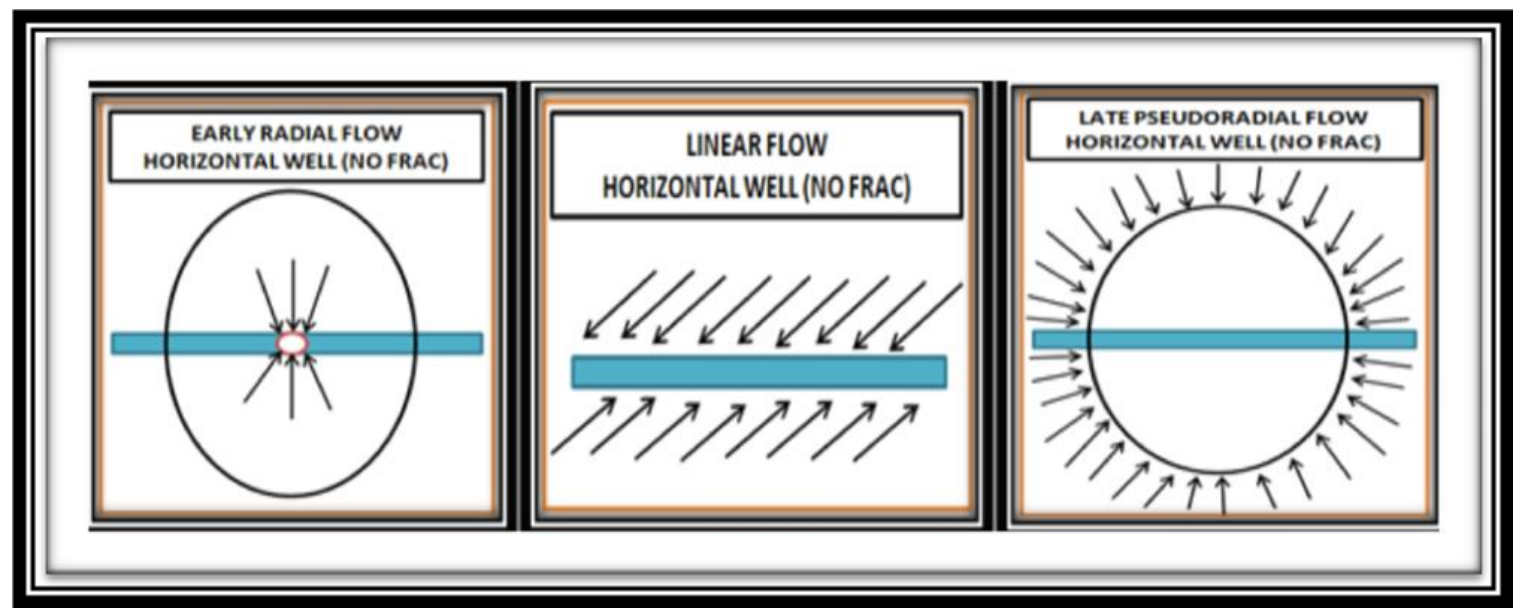

Figure 2-8: Flow regimes in horizontal well 
Early radial flow is the first flow behavior to be seen if wellbore storage effect is nonexistent. The presence of the upper and lower boundaries has not yet touched any boundaries during early radial flow. There might also be a linear flow regime between the early and last time radial flow periods. At pseudoradial flow, the presence of the upper and lower boundaries may cause a radial in the horizontal plane.

\subsubsection{Dimensionless fracture conductivity}

Dimensionless fracture conductivity is a key design parameter in well stimulation that controls the productivity index of a fracture well. Dimensionless fracture conductivity is calculated as the fracture conductivity divided by the product of reservoir permeability and fractures half-length as shown by the following equation (Lee \& Wattenbarger, 1996).

$$
F_{c D}=\frac{k_{f} w_{f}}{k x_{f}}
$$

The inflow performance of a fractured well is controlled by dimensionless fracture conductivity. Dimensionless fracture conductivity parameters are illustrated in Figure 2-

9.

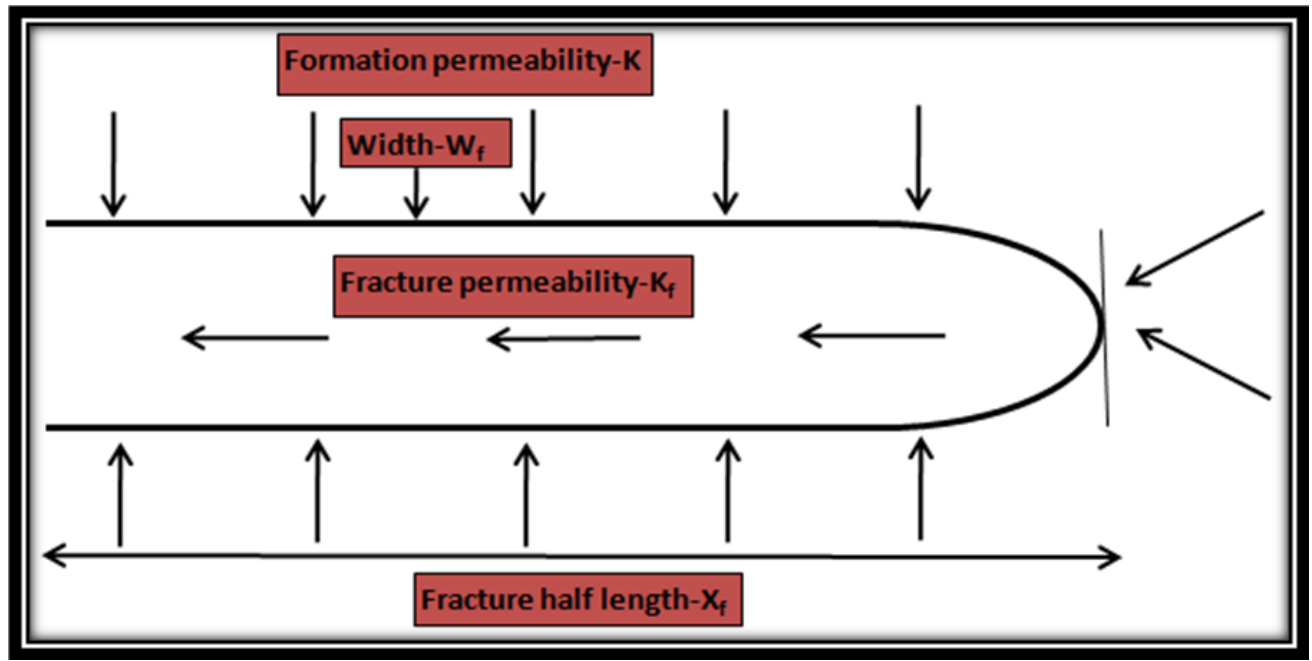

Figure 2-9: Dimensionless fracture conductivity

If dimensionless fracture conductivity value is more than 100 , the fracture behavior is considered high (infinite) conductivity. However, if dimensionless fracture conductivity 
value is less than 100, the fracture behavior is considered low (finite) conductivity. In this paper, dimensionless fracture conductivity value is more than 100 therefore bilinear flow behavior is not shown for high conductivity fracture reservoirs.

\subsection{Flow behavior in horizontal wells with hydraulic fractures in single porosity systems}

There are two different types of fracture behavior observed from the well testing point of view analysis. Fracture behavior consists of finite conductivity fractures (low conductivity) and infinite conductivity fractures (high conductivity). There is no appreciable pressure loss in the fracture for high conductivity fracture when compared to low conductivity fracture. Different flow regimes can occur when analyzing transient pressure responses and production behavior of multiple fractured horizontal wells in shale reservoirs. In addition, hydraulic fracturing changes the flow geometry in the reservoir by creating high conductivity channels. Hydraulic fractures are finiteconductivity porous medium. In this research, flow regimes including linear flow, Pseudo-steady state flow, and perhaps tri-linear flow are found during transient-pressure responses. At early time, radial flow most likely forms as shown in Figure 2-10. Early radial flow is most likely fracture storage acting like a fluid in the wellbore known as wellbore storage. Early radial flow regimes are short in duration and can be identified using unit slope line on log-log plot.

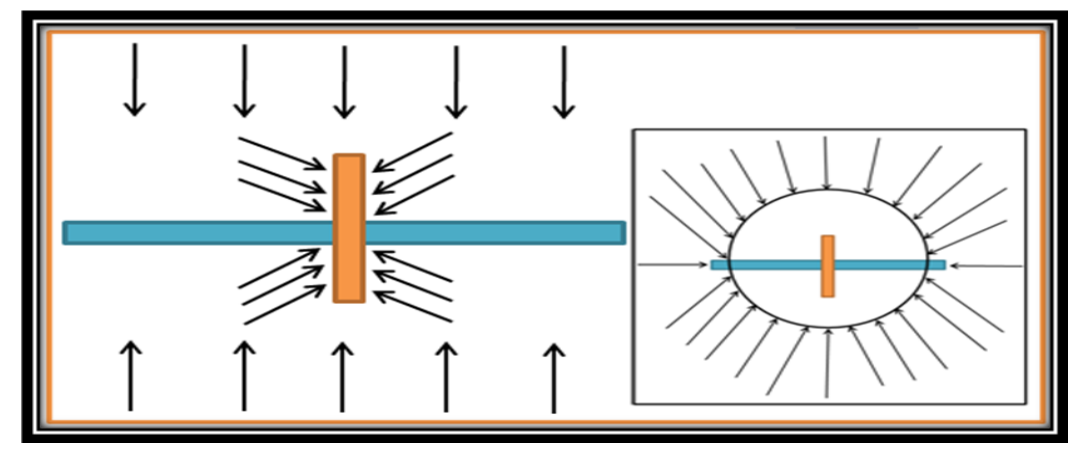

Figure 2-10: Early radial flow (fracture storage) regime

Tight/shale wells continue to be in linear flow for a number of years depending on the size of the reservoir. Linear flow is a pattern in which gas flows toward the hydraulic fracture for horizontal hydraulically fractured reservoirs as shown in Figure 2-11. We 
assume the two hydraulic fractures along the length of the horizontal well are identical as shown below. Linear flow regime can be identified using $1 / 2$ slope line on log-log plot.

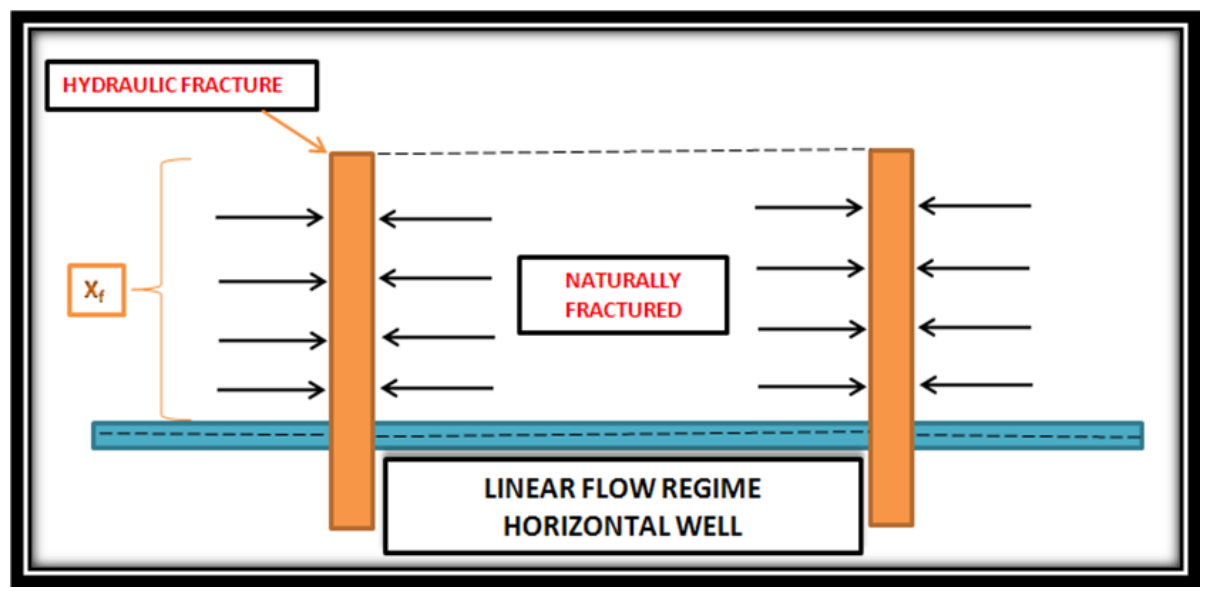

Figure 2-11: Linear flow regime

A late linear flow or tri-linear flow is another possibility that can occur during horizontal pressure transient flow. Tri-linear flow is basically linear flow in three adjacent flow regions including inside the hydraulic fractures, natural fractured, and formation as shown in Figure 2-12 (Ozkan, 2009). Tri-linear flow regime can be identified using 1/2 slope line on log-log plot.

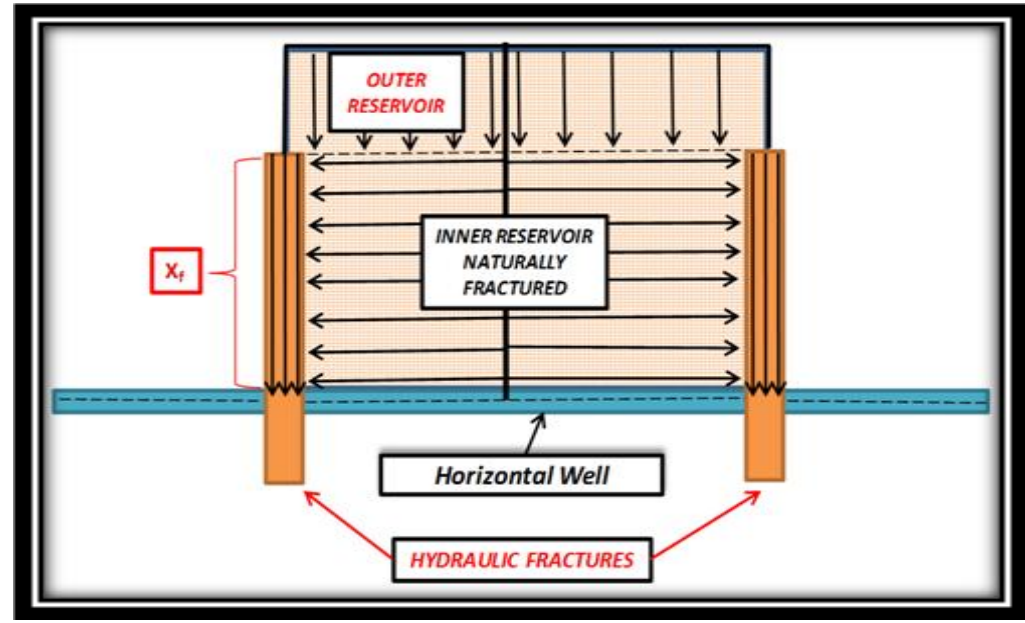

Figure 2-12: Tri-linear flow regime (Ozkan, 2009) 
Boundary-dominated flow or pseudosteady state takes place when the fluid in the reservoir hits the boundaries. In a stabilized pseudosteady state the production takes place from the entire reservoir. The pressure disturbance has reached all the reservoir boundaries as shown in Figure 2-13. Pseudosteady state flow regime can be identified using unit slope line on log-log plot.

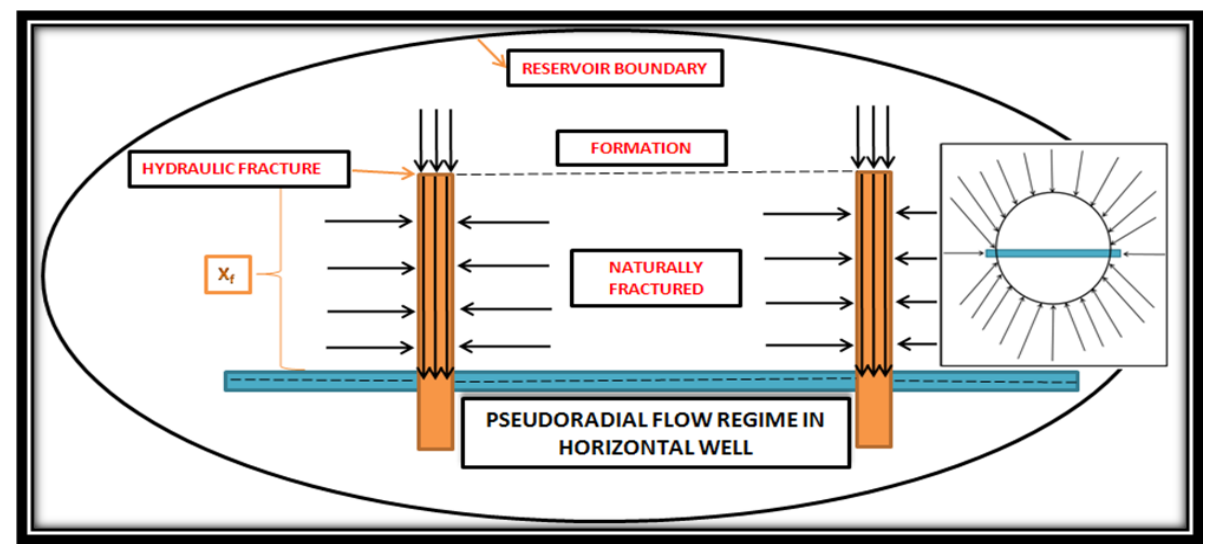

Figure 2-13: Pseudosteady state flow regime

\subsection{Decline curve analysis (DCA)}

Today, there is still a lot of numbers of studies are based on empirical Arps decline curve analysis. Although, Arps decline curve analysis was proposed approximately 60 years ago. Production decline curve analysis is still used for forecasting future production in both oil and gas wells. However, there is still a large number of uncertainties involved in forecasting future production of these wells. Forecasting future production is most likely the most imperative item in determining oil and natural gas economic evaluation. Decline curves are easy to obtain, plot, and most importantly simple to analyze. Decline curve analysis is basically a plot of production rate versus time on semi-log, or log-log, or any specially scaled paper. Decline curve consists of three different equations including exponential decline, hyperbolic decline, and harmonic decline.

Value of $b$ ranges from zero to 1 in hyperbolic decline and it is shown by the following empirical rate-time given by Arps equation. 


$$
q=\frac{q_{i}}{\left(1+b D_{i} t\right)^{(1 / b)}}
$$

However, value of $b$ is equal to zero in exponential decline and it is shown by the following equation.

$$
q=q_{i} e^{-D t}
$$

Lastly, value of $b$ is equal to one in harmonic decline and it is shown by the following equation.

$$
q=\frac{q_{i}}{\left(1+b D_{i} t\right)}
$$

As value of $b$ increases, the life of the well increases considerably. Figure 2-14 also shows layout for various decline curve shapes in oil and natural gas property evaluation.

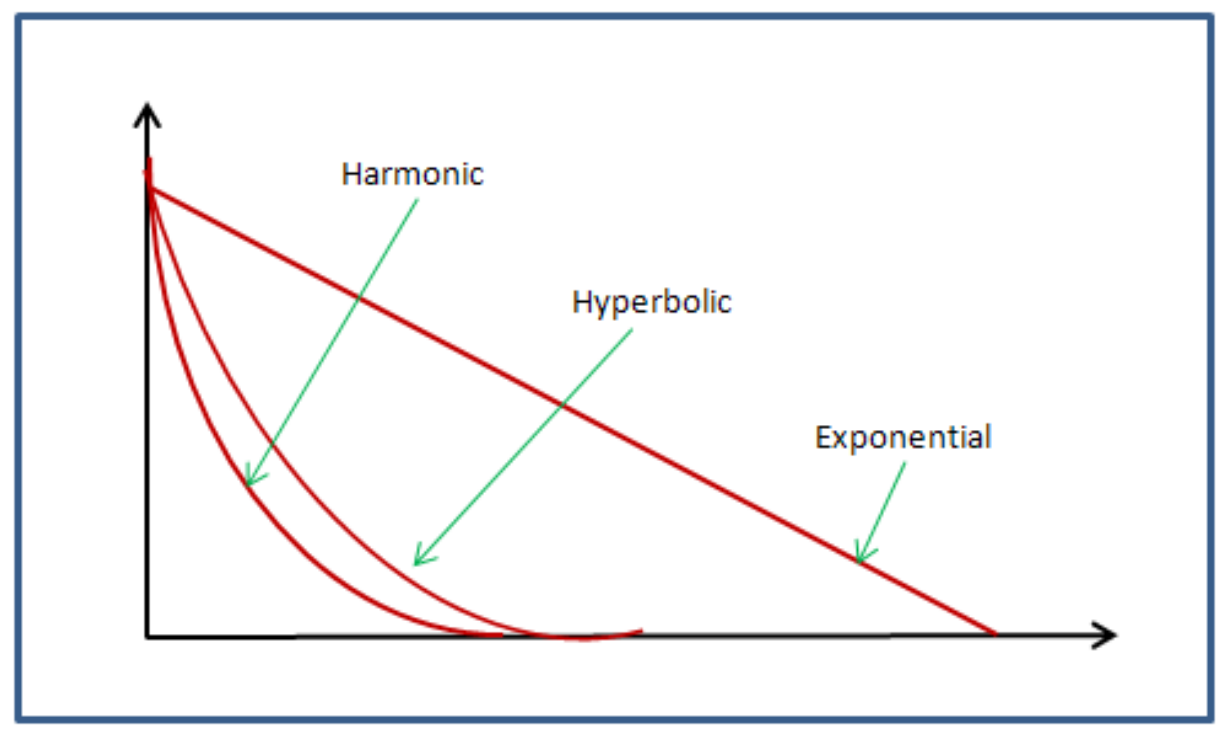

Figure 2-14: Decline curve analysis

\subsubsection{Decline curve analysis using type curves}

Rate-time decline curve extrapolation is one the oldest tools that is used in the petroleum engineering. Ramsay and Slider were the first to analyze rate-time decline curve from 1964 to 1968 . Slider method, analyzing rate-time decline curve, was rapid and easy to 
understand so it was used comprehensively by Ramsay in his evaluation in the number of wells to determine the distribution of the decline curve exponent $b$. Gentry's Figure 2-15 show the Arps exponential, hyperbolic, and harmonic solutions for decline curve analysis all in one curve (Fetkovich, 1980).

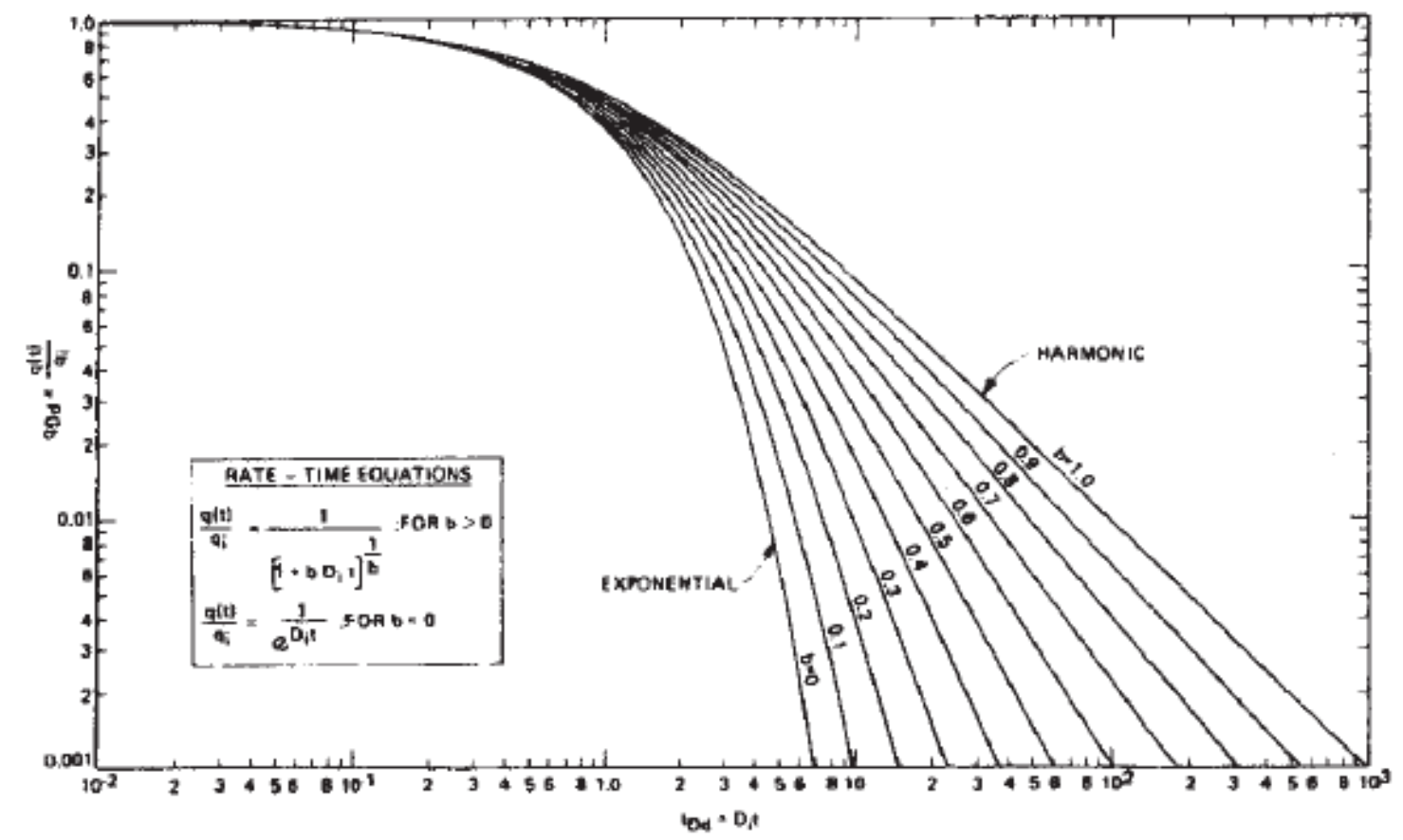

Figure 2-15: Type curves for Arps empirical rate-time decline equations

Empirical rate-time equation given by Arps is used in approximately all conventional decline curve analysis (Equation 7).

\subsubsection{Constant-pressure at inner boundary}

Constant-pressure solution for predicting decline production rate with time was first published by Moore, Schilthuis and Hurst. The results were presented in terms of dimensionless flow rate, $q_{D}$ and a dimensionless time, $t_{D}$ in graphical form. These results were presented for finite, infinite, slightly compressible and single-phase plane radial flow system. Dimensionless flow rate, $q_{D}$ is shown by the following equation (Fetkovich, 1980).

$$
q_{D}=\frac{143 T / q(t) \mu B}{k h\left(p_{i}-p_{w f}\right)}
$$


And dimensionless time, $t_{D}$ is shown by the following equation.

$$
t_{D}=\frac{0.00634 k t}{\phi \mu c_{t} r_{w}^{2}}
$$

Constant-pressure solution is used as a series of constant-pressure step function for water influx problems using dimensionless cumulative production, $Q_{D}$. The relationship between dimensionless cumulative production, $Q_{D}$ and Dimensionless flow rate, $q_{D}$ is shown by the following equation.

$$
t_{D}=\frac{d\left(Q_{D}\right)}{d t_{D}}
$$

Figure 2-16 shows a dimensionless flow rate for plane radial system, infinite and finite outer boundary, and constant pressure at the inner boundary.

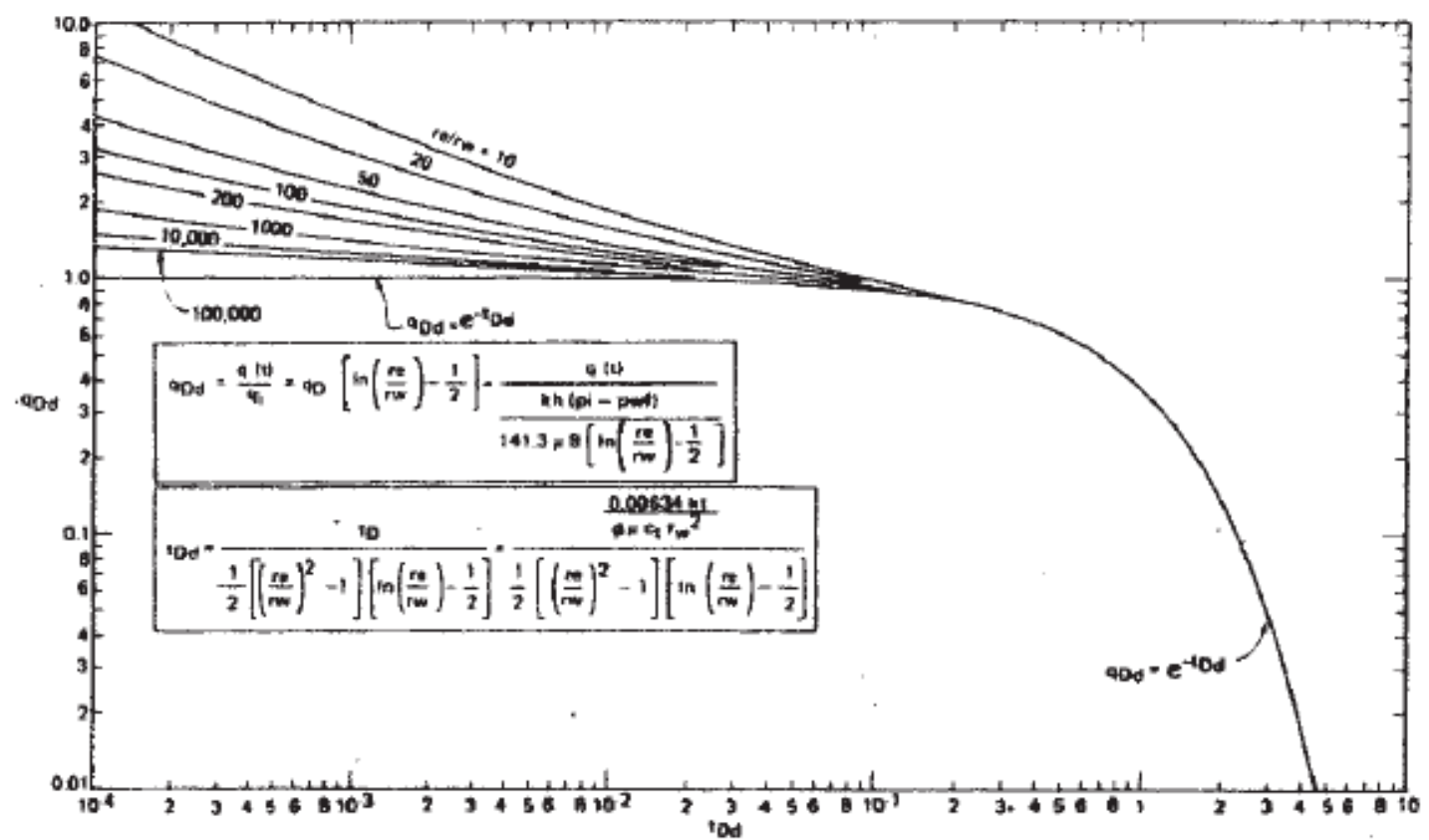

Figure 2-16: Dimensionless flow rate for plane radial system

Aminian et al developed more sets of type curves for gas well production type curve using two well-known equations including radial pseudo-steady state gas well deliverability and general material balance by the following equation. 


$$
m\left(P_{R}\right)-m\left(P_{w f}\right)=\frac{1422 T}{k h}\left[\ln \left(\frac{r_{e}}{r_{w}}\right)-0.75+s\right] q+B q^{2}
$$

Where:

$$
B=\frac{3.161 * 10^{-12} \beta T \gamma_{g}}{h^{2} \mu}\left(\frac{1}{w}-\frac{1}{r_{e}}\right)
$$

The dimensionless production rate and dimensionless time are defined by the following equations respectively.

$$
\begin{gathered}
q_{D}=q / q_{i} \\
t_{D}=q_{i} t / G_{i}
\end{gathered}
$$

These type curves are shown in Figure 2-17.

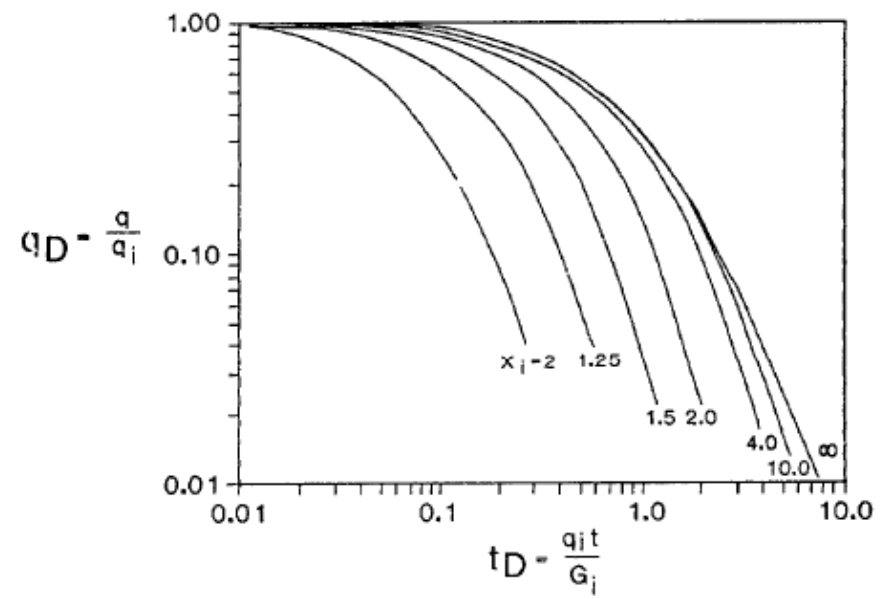

Figure 2-17: Production decline type curves for gas wells producing against a constant backpressure

In addition, Aminian et al enhanced the matching process by generating a set of cumulative production type curves. The dimensionless cumulative production is defined by the following equation.

$$
G_{D}=G_{P} / G_{i}
$$


The cumulative production type curves are shown in Figure 2-18.

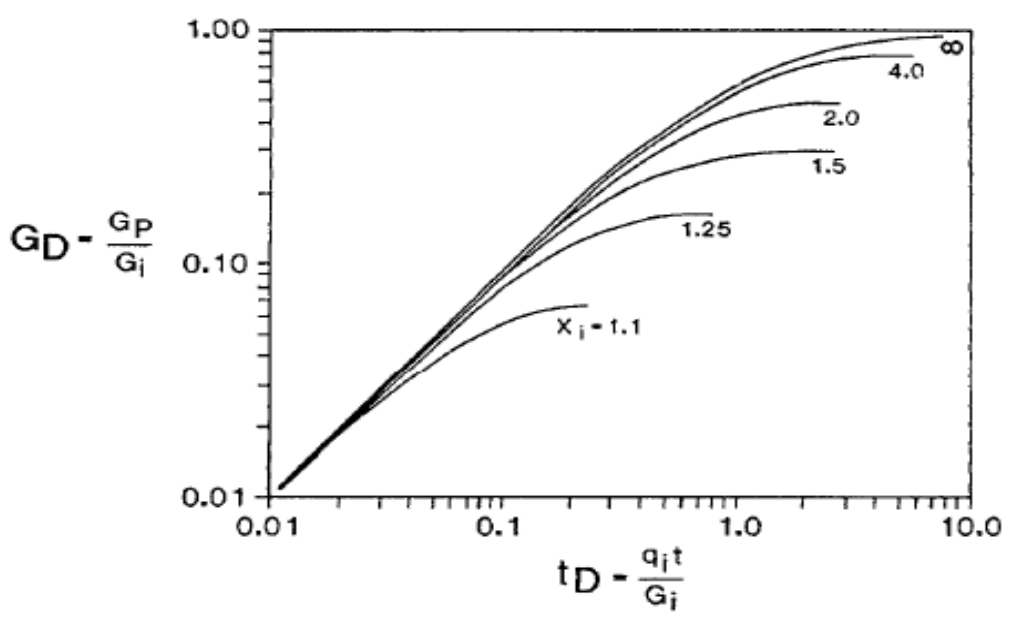

Figure 2-18: Cumulative production decline type curves for gas wells producing against a constant backpressure

\subsection{Type curves for horizontal wells (single porosity)}

To predict the production performance of horizontal wells completed in the low permeability gas reservoirs, the type curve can be employed during preface evaluation. Aminian et al (1989) has predicted horizontal well production performance by developing production type curves. The production type curves can be effectively grouped by two dimensionless wellbore radii $\left(r_{w D}\right)$ and the dimensionless well length $\left(L_{D}\right)$. The dimensionless wellbore radius $\left(r_{w D}\right)$ and the dimensionless well length $\left(L_{D}\right)$ are defined by the following equations.

$$
\begin{gathered}
r_{w D}=2 r_{w} / L \\
L_{D}=(L / 2 h) k_{V} / k_{H}
\end{gathered}
$$

Figure 2-19 shows the type curve for infinite reservoirs. The dimensionless cumulative production and dimensionless time are defined by the following equations.

$$
\begin{aligned}
G_{p D} & =\left(\frac{36 T}{h \phi \mu C_{t} L^{2} p_{p}}\right) G_{p} \\
t_{D} & =\left(\frac{0.001055 k}{\phi \mu c_{t} L^{2}}\right) t
\end{aligned}
$$




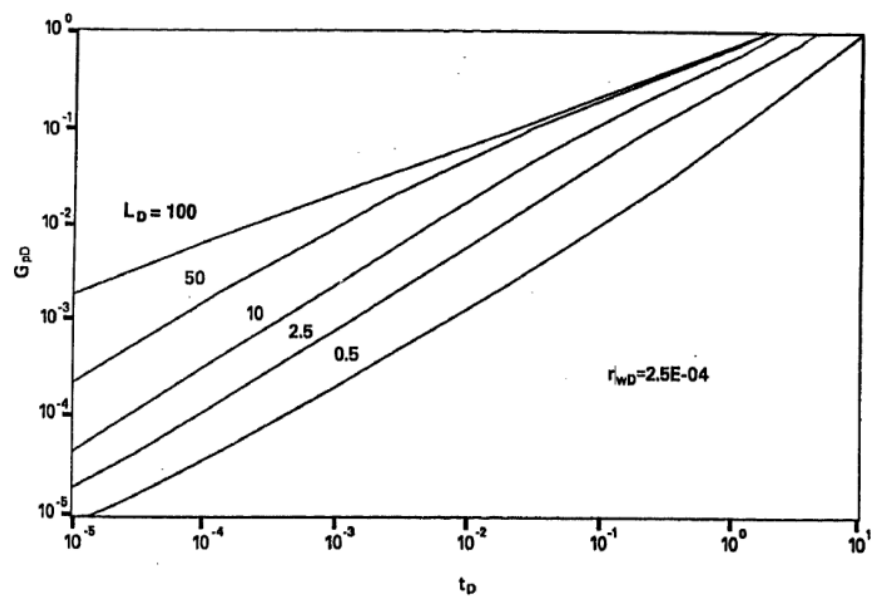

Figure 2-19: Type curve for horizontal wells in infinite reservoirs

Figure 2-20 shows the type curve for finite reservoir with a square drainage area. The dimensionless cumulative production and dimensionless time are redefined by the following equations.

$$
\begin{aligned}
G_{p D A} & =\left(\frac{36 T}{h \phi \mu C_{t} A p_{p}}\right) G_{p} \\
t_{D A} & =\left(\frac{0.001055 k_{h}}{\phi \mu c_{t} A}\right) t
\end{aligned}
$$

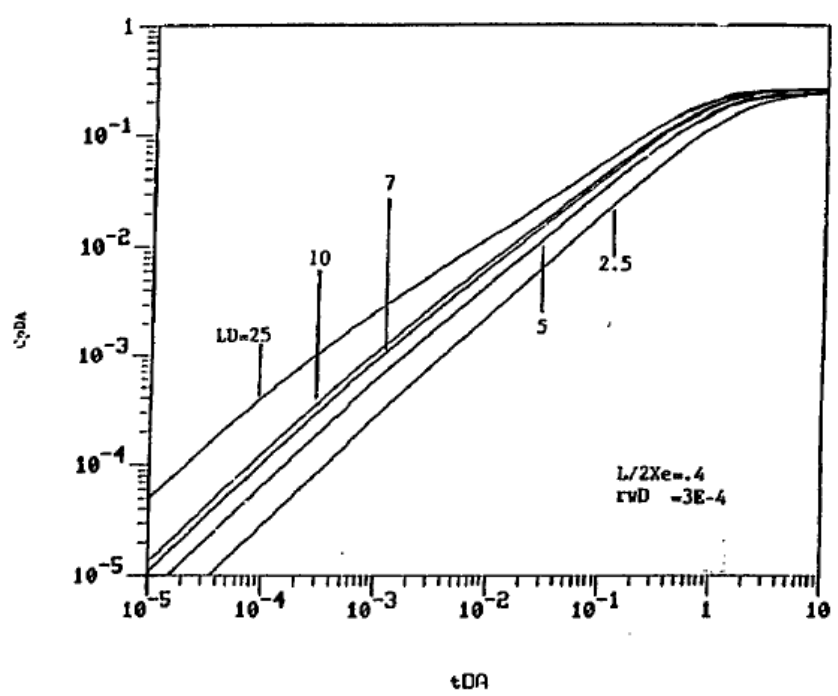

Figure 2-20: Type curve for horizontal wells in finite square drainage area 
Flow rate, permeability, thickness of reservoir, change of pseudo pressure are used to calculate dimensionless flow rate as shown by the following equation.

$$
q_{D}=\left(\frac{1424 T}{k h p_{p}}\right) q
$$

In addition, permeability, porosity, viscosity, total compressibility, hydraulic fractured spacing, and real time are used to calculate dimensionless time as shown by the following equation.

$$
t_{D}=\left(\frac{0.02532 k}{\phi \mu c_{t} L^{2}}\right) t
$$

\subsubsection{Type curves for hydraulically fractured horizontal wells (single porosity)}

Alenezi et al (2011) developed a set of production type curves for hydraulically fractured horizontal wells in unconventional reservoirs for single porosity systems. It was noted that two dimensionless groups (Equations $23 \& 24$ ), were necessary for developing these type curves. These two dimensionless variables have demonstrated the gas production type curves, the dimensionless well length, and a well penetration ratio. As a result, the number of hydraulic fractures does not affect production type curves and more hydraulic fractures will be needed to boost the production performance in low permeability reservoirs. In addition to these results, fracture half length, fracture permeability, and fracture width effects were insignificant on type curves in low permeability reservoirs.

\section{$2.6 \quad$ Reservoir simulation}

There are four different conventional methods of estimation reserves including volumetric, material balance, decline curve, and reservoir simulation. Reservoir simulation is the most complex technique for calculating reserves. Reservoir simulation is an extension of the material balance technique. Reservoir simulators represent the reservoir as a number of cells, all interconnected rather than representing reservoir as one single cell as done in material balance technique. The size of these cells can be controlled 
as small or as large as desired and can be geometrically arranged in one, two, or three dimensions (Thompson, 1985).

Reservoir simulation is one of the most practical tools used to evaluate performance of horizontal wells completed in shale formation. In this research, a numerical reservoir simulator was employed to model a horizontal well completed in a dual porosity reservoir. In dual porosity, flow occurs from extremely tight matrix blocks to more permeable fracture blocks and finally to the wellbore. The matrix porosity system often changes within shale gas reservoirs. This transient behavior is an important factor. Some of the natural gas is found within the pore structure while some is adsorbed on the surface of the shale. Still some natural gas is found within the system of natural fractures. The dual porosity model can be used together with the coal bed methane model to replicate reservoirs for adsorbed gas on the rock formation. In the dual porosity system, two simulation cells are associated with each block in the geometric grid. These cells represent the rock matrix and the rock fracture volume. In general the rock matrix has a high porosity and a low permeability while the rock fracture has a low porosity and a high permeability.

Reservoir simulation is a combination of physics, mathematics, reservoir engineering, and computer programming to develop a tool to handle different rock and fluid properties in the reservoir and also to evaluate the wells under various operating conditions (Ertekin, 2001). Reservoir simulation is a form of numerical modeling that is used to interpret physical phenomena and extend it to project future performance. The process involves representing the reservoir as a number of cells in three dimensions and modeling the development of reservoir and fluid properties through time and space in a series of discrete steps. The combination of the material balance equation and Darcy's law is used to solve for each cell and each time steps.

Darcy's law without gravity terms is shown by the following equation:

$$
q=-\frac{k}{\mu} \nabla P
$$


Material balance equation which is the mass flux equals to accumulation plus injection or production (Mass flux=Accumulation + Inj /Prod) is shown by the following equation:

$$
-\nabla M=\frac{\partial}{\partial t}(\varphi \cdot \rho)+Q
$$

Simulator flow equation with gravity term is shown by the following equation:

$$
\nabla[\lambda(\nabla P-\gamma \cdot \nabla z)]=\frac{\partial}{\partial t}\left(\frac{\varphi}{\beta}\right)+\frac{Q}{\rho}
$$

Where:

$$
\lambda=\frac{k}{\mu \beta}
$$

The well model flow rate phase is shown by the following equation:

$$
\begin{gathered}
q_{p, j}=T_{w j} M_{p, j}\left(P_{j}-P_{w}-H_{w j}\right) \\
\text { Where: } \\
T_{w j}=\frac{c \theta \cdot K h}{\ln \left(r_{o} / r_{w}\right)+S} \\
M_{o, j}=\frac{K_{o, j}}{\beta_{o, j} \cdot \mu_{o, j}}+R_{v} \frac{K_{g, j}}{\beta_{g, j} \cdot \mu_{g, j}} \\
M_{g, j}=\frac{K_{g, j}}{\beta_{g, j} \cdot \mu_{g, j}}+R_{v} \frac{K_{o, j}}{\beta_{o, j} \cdot \mu_{o, j}} \\
P_{w}=\text { Nodal Pressure connection- BHP- Head connection to datum }
\end{gathered}
$$

Mathematical equation of fluid flow in porous media is called partial differential equation (PDE) which is an equation involving functions and their partial derivatives. Partial differential equation is shown by the following equation:

$$
\frac{\partial^{2} p}{\partial x^{2}}+\frac{\partial^{2} p}{\partial y^{2}}+\frac{\partial^{2} p}{\partial z^{2}}=\eta \frac{\partial p}{\partial t}
$$

Where $\eta$ is a diffusivity coefficient and makes Equation 29 non-linear. Pressure depends on both time and location in partial differential equation.

Reservoir simulation is a set of numerical solutions in which computer models are used for prediction of dynamic behavior for all types of reservoir. An analytical solution 
(continuous) is an exact solution to an approximate problem however; numerical solution (discrete) is an approximate solution to an exact problem. Partial differential equations are approximated into three techniques, which include finite difference, finite elements, and boundary elements. In finite difference, governing equations discretized on a fixed grid however governing equations solved using basis functions in finite element/boundary element. Finite difference operator consist of six types, which include forward difference operator, backward difference operator, shift operator, central difference operator, average operator, and difference operator (Ertekin, 2001).

\subsubsection{Grid types and boundary conditions}

There are two types of grids, which consist of body center grids and mesh center grids. The pressure is calculated at grid block center in the body center grids as shown in Figure $2-21$.

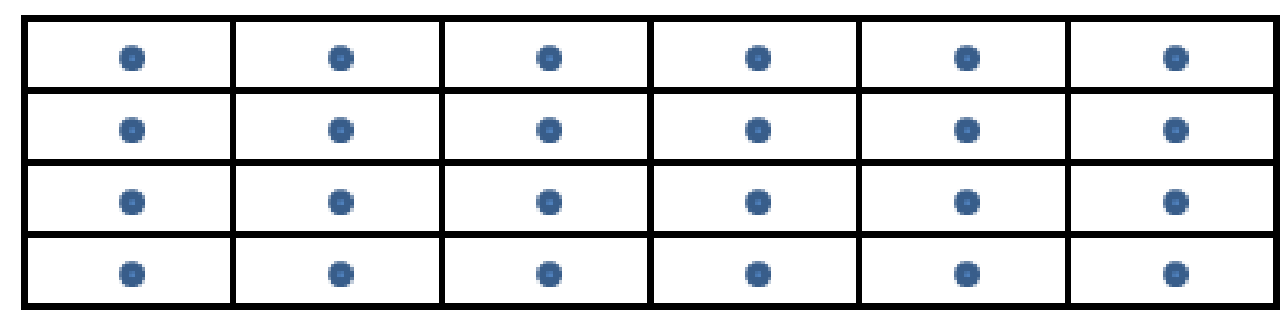

Figure 2-21: Body center grids

Body center grids are recommended to use when modeling no-flow boundary (flow inside the grid only). However the pressure is calculated at nodes in the mesh center grids as shown in Figure 2-22.

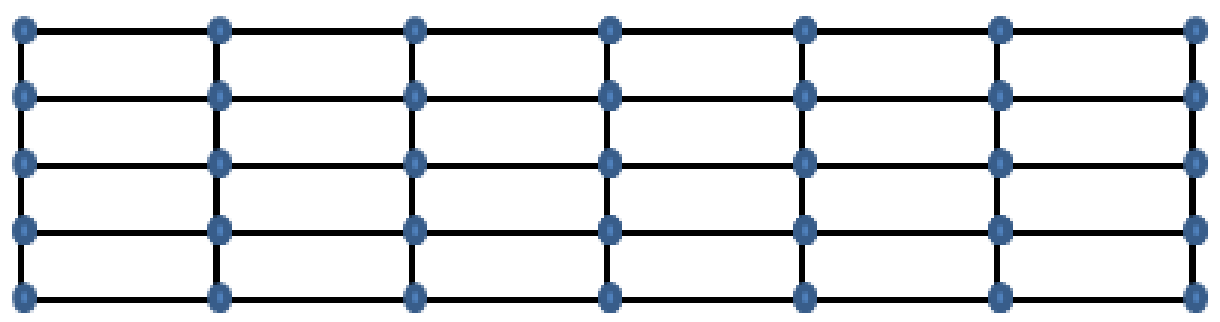

Figure 2-22: Mesh center grids

There are three types of boundary conditions commonly encountered in the solution of partial differential equations, which consist of Dirichlet boundary conditions, Neumann boundary conditions, and Robin boundary conditions. In the Dirichlet boundary, 
dependent variable (pressure) is specified at the boundary conditions however, in Neumann boundary conditions, gradient of dependent variable is specified at the boundary. In addition, Robin or (mixed) boundary conditions are a combination of both types of Dirichlet and Neumann boundary conditions.

\subsubsection{Solution methods}

There are two different ways of solving a system of linear algebraic equations, which consist of direct solver and iterative solver. Direct solvers consist of four types including Cramer's rule, Matrix inversion, Gaussian Elimination, and Matrix decomposition. Thomas algorithm is a direct solver for tri-diagonal systems of equations. A layout of direct solver is shown in Figure 2-23.

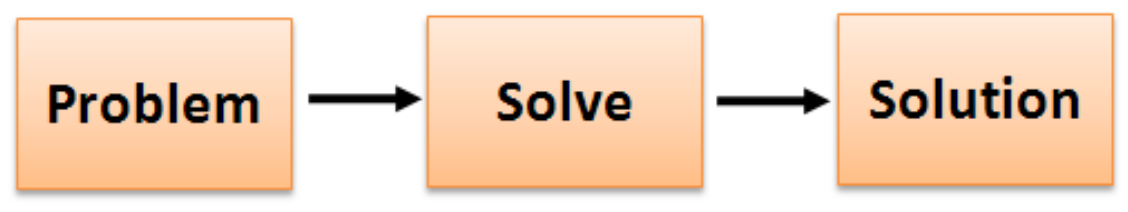

Figure 2-23: Direct solver

Iterative methods are used for linear problems involving a large number of variables (sometimes in order of millions) and nonlinear equations. Iterative solvers are consists of four types including Successive Over-relaxation Method (SOR), Iterative Direction Implicit Procedure (ADIP), Strongly Implicit Procedure (SIP), and Newton-Raphson Method. A layout of iterative solver is shown in Figure 2-24.

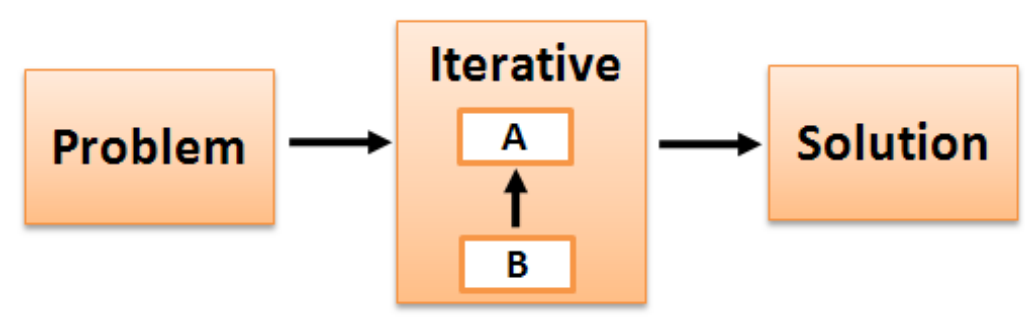

Figure 2-24: Iterative solver 
Successive Over-relaxation Method consists of Jacobi method, Gauss-Seidel Method, and Pointwise SOR (PSOR). Jacobi Method, Gauss-Seidel Method, and Pointwise SOR are iterative methods used to solve a linear system of equations that is used in most of the reservoir simulation. Table 1 shows the element-based formulas for Successive Overrelaxation method.

Table 1: Successive over-relaxation method (SOR)

\begin{tabular}{|c|c|c|}
\hline \multicolumn{3}{|c|}{ Successive Over-relaxation Method (SOR) } \\
\hline $\begin{array}{c}\text { Jacobi method } \\
x_{\xi}^{(k+1)}=\frac{1}{a_{i i}}\left[b_{i}-\sum_{j i}^{n} a_{i j} x_{j}^{(k)}\right]\end{array}$ & $\begin{array}{c}\text { Gauss-Seidel method } \\
x_{i}^{\langle k+1)}=\frac{1}{a_{i i}}\left[b_{i}-\sum_{j>i}^{n} a_{i, j} x_{j}^{(k)}-\sum_{j<i}^{n} a_{i, j} x_{j}^{(k+1)}\right]\end{array}$ & $\begin{array}{l}\text { Pointwise SOR } \\
x_{i}^{(k+1)}=x_{i}^{(k)}+\frac{w_{o p t}}{a_{i j}}\left[b_{i}-\sum_{j=1}^{n} a_{i, j} x_{j}^{(k)}-\sum_{j=1}^{n} a_{i j} x_{j}^{(k+1)}\right] \\
\text { where } w_{o p t}=\frac{2}{1+\sqrt{1-\rho_{G}}}\end{array}$ \\
\hline
\end{tabular}

\subsubsection{Reservoir simulation input}

A large quantity of input data requires for reservoir simulator and produces phenomenal amounts of output. Plenty of information must be supplied for every cell in the model (100's to 1000's) where data is provided to each cell. This data consists of porosity, permeability, thickness, elevation, initial saturation, and initial pressure. Either horizontal or vertical wells are located within the cell and the required well production rates are specified as a function of time. Relative permeability, capillary pressure, and pore volume compressibility is required for each rock type. In addition, formation volume factors, viscosity, gas solubility, and density are required for each fluid type. And reservoir description including faults, pinchouts, aquifers, and layering are also required. The equations are solved to provide pressure and saturations for each block and production of each phase from each well. Ultimately, any reservoir simulator is a tool that needs an excellent engineering judgment for obtaining practical results.

\subsection{Simulator description}

ECLIPSE originated in the late 1970's from ECL however the first commercial release of Schlumberger software ECLIPSE was announced in 1983 SPE. ECLIPSE reservoir simulators have been used for commercial reservoir simulation for more than 25 years in 
global oil and gas industries. Today almost all oil and gas companies and many government agencies use ECLIPSE for simulation purposes. ECLIPSE approximates the partial differential equation by finite difference technique which is fully implicit. The ECLIPSE simulation software is one of the most inclusive and robust set of numerical solutions for prediction of dynamic behavior for any type of reservoir structure and degrees complexity. ECLIPSE software covers multiplicity of reservoir simulation, specializing in blackoil, compositional, thermal, FrontSim, and FrontSim-Compositional. Simulator capabilities can be customized to meet oil and gas industry needs by selecting from a wide range of add-on options - such as coalbed methane, gas field operations, calorific value-based controls, reservoir coupling, and surface networks. ECLIPSE Compositional simulation is used for handling multi component fluid behavior. Compositional simulation is practical for the requirement of equation of state for compositional changes associated with depth or reservoir fluid phase behavior description. Compositional model is used for works including condensates or volatile crude oils, gas injection programs, and secondary recovery. ECLIPSE Compositional simulation is capable to model:

- Gas injection to increase or maintain reservoir pressure

- Miscible flooding, as the injection gas goes into solution with oil

- Carbon dioxide flooding, with the gas soluble in both oil and water

- Carbon dioxide storage under various conditions

- Thick reservoirs with a compositional gradient due to gravity

- Reservoirs with fluid compositions near the bubble point

- High-pressure, high-temperature reservoirs

- Natural-fracture reservoirs (Dual porosity reservoirs)

- Assessment of asphaltene precipitation impacts on reservoir performance

- Chemical reactions, combustion, biodegradation, decay of radioactive tracers, and nonequilibrium reactions

- Reactions involving waterborne components such as bacteria or dissolved solids 
Moreover Blackoil simulation is used for modeling extensive well controls and it assumes that the reservoir fluids consist of three phases-oil, water, and gas. ECLIPSE Blackoil simulation is capable to model:

- Directional relative permeability

- Vertical or nonvertical equilibrium

- Dual porosity and permeability

- Non-neighbor connections

- Three-component miscible flood modeling

- Multiple aquifers (analytical and numerical)

- Crossflow and commingling in wells

- Chemical reactions

- Well, group, and field economic controls

- Highly deviated and horizontal wells

- Different geometry grid options, including corner point, conventional blockcenter, radial, Cartesian, perpendicular bisection, local grid refining, and hybrid gridding

- Multiple rock types, pressure volume-temperature (PVT) regions, and rock compaction

- Hysteresis, tracers, and brine tracking

\subsubsection{Shale model description}

In this work, a commercial reservoir simulator was utilized to model dual porosity reservoir with multiple layers to evaluate production performance of the horizontal wells completed in unconventional reservoirs such as Marcellus shale. Figure 2-25 shows gas shale in the United States. 


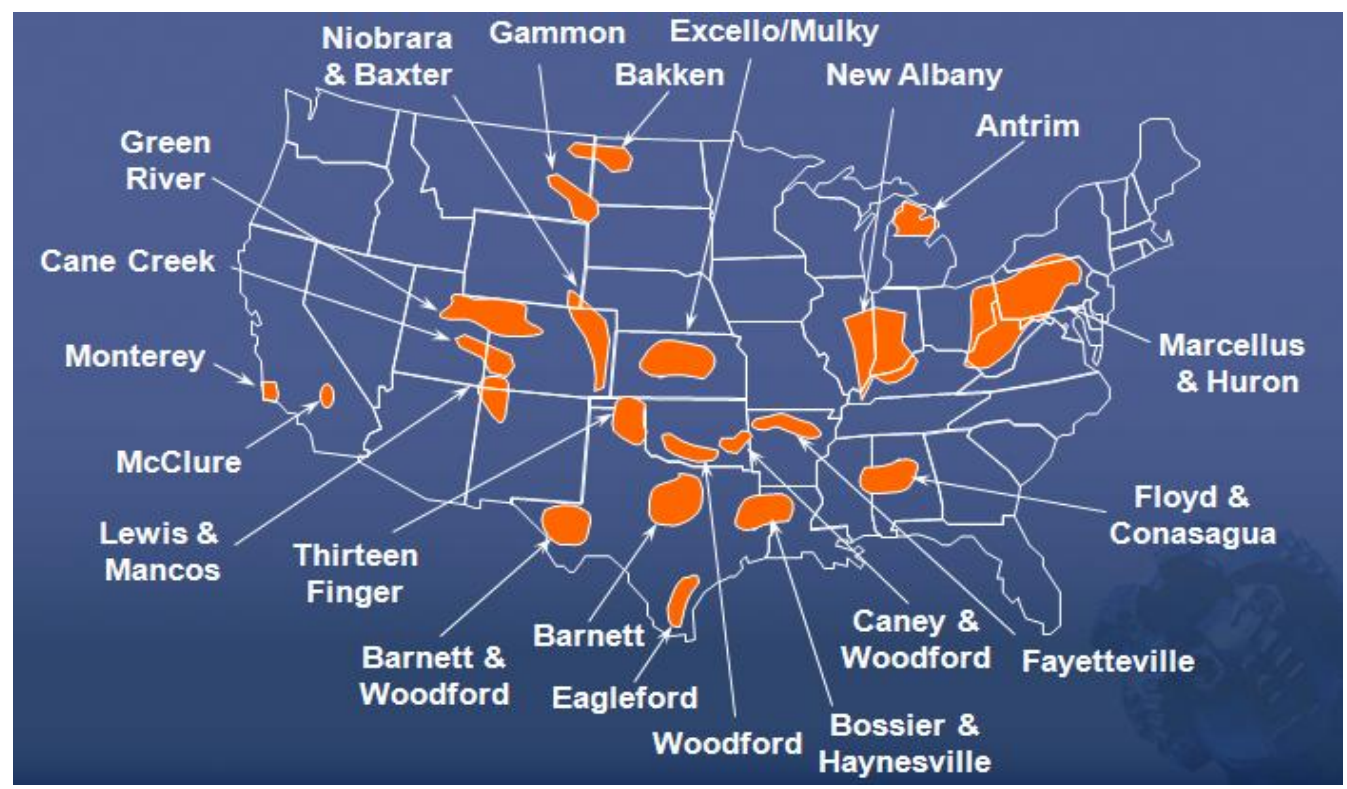

Figure 2-25: Gas shale of USA

In addition, Figure 2-26 shows a map of Marcellus shale formation in the eastern part of United States (primarily Appalachian Basin) for the area of interest in this research.

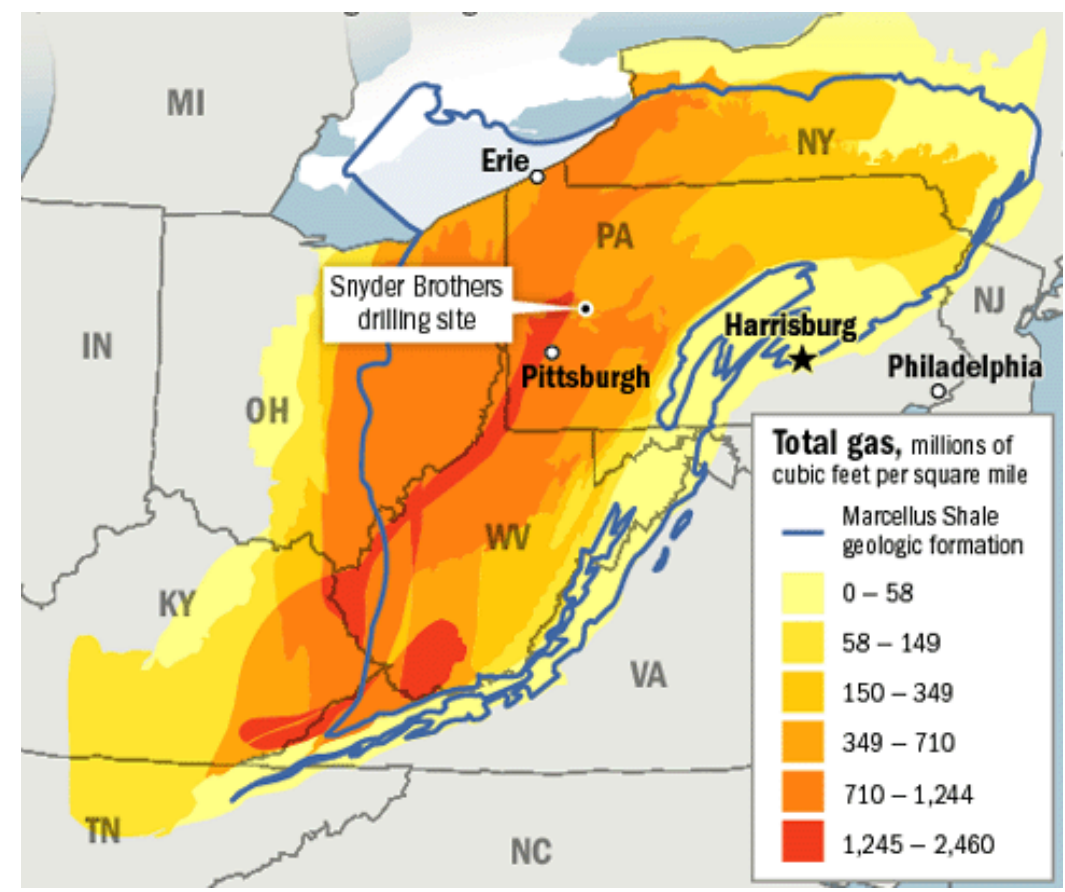

Figure 2-26: Marcellus shale 


\section{$2.8 \quad$ Previous studies}

Shale gas reservoirs enhancement has become an essential part of the United States gas supply. Numerical simulations for evaluating performance of horizontal wells completed in shale are in the developmental stage. In addition, there are quite a few studies regarding pressure transient responses and production behavior of horizontal wells with a number of hydraulic fractures in shale formation, and most of these studies are in developmental stages. This section contains a brief overview of several publications of previous work.

Cheng (2010) conducted a study for impacts of the number of perforation clusters and cluster spacing on production performance of horizontal shale gas wells. This work focused on the number of fractures and its impacts in the gas production for horizontal shale gas wells using numerical simulation. Increasing the number of perforation clusters will minimize the initial gas rate and the cumulative production. In addition, decreased cluster spacing can significantly reduce gas production.

Ozkan et al (2009) conducted a study for practical solutions for pressure transient responses of fractured horizontal wells in unconventional reservoirs. In this paper, an analytical tri-linear flow solution is presented to simulate the pressure transient and production behavior of fractured horizontal wells in unconventional reservoirs. Tri-linear flow is another possibility that can occur during pressure transient response of multiple fractured horizontal wells in some unconventional reservoirs.

Cipolla et al (2009) conducted a study for modeling well performance in shale-gas reservoirs. This work focused on modeling well performance in shale-gas reservoirs using numerical simulation. In addition, the reservoir simulation work focused on evaluating the effects of gas desorption and stress dependent network permeability in horizontal completions using typical properties of Barnett shale. Desorbed gas may constitute $5-15 \%$ of total gas production but the desorbed gas is mainly produced at the latter life of the well. More complex fracture networks (smaller network blocks) can improve the recovery of adsorbed gas. 
Schweitzer and Bilgesu (2009) conducted a study of the economic impact on well and fracture design completion of Marcellus shale wells. In this paper, numerical simulation has been conducted with several wellbore configurations for gas production from Marcellus shale. Horizontal wells found to be more economical than vertical wells in Marcellus shale. Vertical wells were found to be economical in scenarios involving higher gas prices.

Lewis (2008) conducted a study for production data analysis of shale reservoirs. The effects of adsorption were demonstrated for different systems including single porosity, dual porosity, hydraulically fractured, and dual porosity with a hydraulic fracture. A variety of analysis methods were examined for analyzing systems with adsorbed gas, this work is only for vertical wells completed in shale reservoirs. 


\section{OBJECTIVES \& METHODOLOGY}

\section{$3.1 \quad$ Objectives}

The goal of this study was to predict and analyze the production performance of horizontal wells with multiple hydraulic fractures in ultra-low permeability formations such as Marcellus shale. To achieve the goals, a commercial reservoir simulator was utilized to model a horizontal well with multiple hydraulic fractures completed in an ultra-low permeability formation such as Marcellus shale. The impact of a number of parameters including horizontal wellbore length, size of the drainage area, hydraulic fracture spacing, number of the hydraulic fractures, permeability of the hydraulic fracture, propped fracture half length, well placement, matrix porosity, natural fracture porosity, matrix permeability, and natural fracture permeability on production profile generated by the model will provide a better understanding of the production performance in unconventional reservoirs.

More specifically, the objectives of this study are:

1. To develop a base model for simulating the production performance of horizontal wells with multiple hydraulic fractures in ultra-low permeability formations such as Marcellus shale.

2. To investigate the impact of the number and the properties of hydraulic fractures on the production performance.

3. To investigate the impact of the formation and natural fracture characteristics on the production performance.

4. To identify the flow regimes associated with the hydraulically fractured horizontal wells. 


\subsection{Methodology}

In this study, a commercial reservoir simulator (ECLIPSE) was used to model horizontal wells completed in shale and to investigate the impact of hydraulic fracture properties as well as the formation and natural fracture characteristics on the production performance. A dual porosity model with multiple layers was used and the model also accounts for adsorbed gas. The following sections describe the methodology that was employed to achieve each objective:

\section{Objective 1}

In this section of the research, the objective was to develop a base model to predict the production of horizontal wells with multiple hydraulic fractures completed in shale. Table 2 summarizes the basic model parameters used in this study. The base model developed in simulation runs was a rectangular drainage that was 4000 feet in length and 1000 feet in width with 3000 feet of horizontal lateral. The simulation runs were done for a total of 30 years. The parameters that were considered included size of the drainage area, horizontal well length and configuration, reservoir thickness, matrix permeability, and matrix porosity. Table 3 shows a summary of these simulation runs. 
Table 2: Basic model parameters

\begin{tabular}{|c|c|}
\hline \multicolumn{2}{|c|}{ Basic Model Parameters } \\
\hline \multicolumn{2}{|l|}{ Reservoir Parameters } \\
\hline Depth, $\mathrm{ft}$ & 7000 \\
\hline Thickness, $\mathrm{ft}$ & 75 \\
\hline \multicolumn{2}{|l|}{ Rock Properties } \\
\hline Fracture spacing, $1 / f t^{2}$ & 0.0073 \\
\hline Compressibility, 1/psia & $1 \times 10^{-6}$ \\
\hline Density, $\mathrm{lb} / \mathrm{ft} \mathrm{t}^{3}$ & 150 \\
\hline \multicolumn{2}{|l|}{ Initial Conditions } \\
\hline Reservoir pressure, psia & 3000 \\
\hline Water saturation, fraction & 0.15 \\
\hline \multicolumn{2}{|l|}{\begin{tabular}{|l} 
Natural Fracture Properties \\
\end{tabular}} \\
\hline Porosity type & Dual \\
\hline Fracture Porosity, fraction & 0.005 \\
\hline Matrix porosity, fraction & 0.05 \\
\hline Fracture perm, $l, j, k$, md & $0.002,0.002,0.0002$ \\
\hline Matrix perm, $l, j, k, m d$ & $0.0004,0.0004,0.00004$ \\
\hline \multicolumn{2}{|l|}{ Hydraulic Fractures Properties } \\
\hline Half length, $\mathrm{ft}$ & 500 \\
\hline Width, in & 0.01 \\
\hline Top of Fracture, $\mathrm{ft}$ & 7000 \\
\hline Bottom of Fracture, $\mathrm{ft}$ & 7075 \\
\hline Permeability, md & 20,000 \\
\hline porosity, fraction & 0.2 \\
\hline \multicolumn{2}{|l|}{ Well Production Controls } \\
\hline$P_{\text {wf, psia }}$ & 500 \\
\hline \multicolumn{2}{|l|}{ Fluid Properties } \\
\hline Standard Pressure, psia & 14.7 \\
\hline Standard Temperature, ${ }^{\circ} \mathrm{F}$ & 60 \\
\hline Reference Temperature, ${ }^{\circ} \mathrm{F}$ & 120 \\
\hline \multicolumn{2}{|l|}{ Adsorption } \\
\hline "Gas Diffusion Coefficient, $\mathrm{ft}^{2} /$ day & 1 \\
\hline Sorption Time, day & 62 \\
\hline Langmuir Pressure, psia & 635 \\
\hline Langmuir Concentration, MSCF/ton & 0.08899 \\
\hline
\end{tabular}




\section{Objective 2}

The second objective was to study the impact of the number and the properties of hydraulic fractures on the production performance. The base model developed in the previous section was utilized here. Table 4 shows a summary of these simulation runs.

\section{Objective 3}

The third objective was to study the impact of the formation and natural fracture characteristics. Again, the base model developed in the previous section was utilized here. The impact of natural fracture permeability, natural fracture porosity, and fracture spacing were studied in this section. Table 5 shows a summary of these simulations runs.

\section{Objective 4}

The fourth objective was to identify the flow regimes associated with the hydraulically fractured horizontal wells. A general approach to analyze production data from reservoir simulation was used to identify flow regimes associated with the hydraulically fractured horizontal wells completed in shale formation. Diagnostic plots were prepared to investigate the various flow regimes for the hydraulically fractured horizontal wells completed in shale. The diagnostic plot is a log-log plot of the inverse of the flow rate $(1 / q)$ versus time. Literature review (Chapter 2.3) demonstrated flow regimes including linear flow, tri-linear, and pseudo-steady state flow that were observed during transientpressure responses in horizontal wells with hydraulic fractures in single porosity systems. Shale wells exhibit transient flow for years and eventually exhibit boundary dominated flow depending on the number of hydraulic fractures. Boundary dominated flow occurs after the pressure transient reaches all the reservoir boundaries.

Derivative method was also employed along with diagnostic plot for flow regimes identification of hydraulic fractured horizontal wells completed in shale formation. Fivepoint finite difference method was used to estimate the derivative values. This method is described below. 
Backward difference $(d t l)$ and forward difference $(d t r)$ were calculated first followed by the calculations of $m_{L}$ and $m_{R}$ then finally the derivative was calculated using five-point method as shown by the following equation:

$$
\begin{gathered}
\Delta p^{\prime}=\frac{\left(m_{L} \Delta t_{R}\right)+\left(m_{R} \Delta t_{L}\right)}{\Delta t_{R}+\Delta t_{L}} \\
\text { Where: } \\
m_{L}=\frac{\Delta p_{L}}{\Delta t_{L}}, m_{R}=\frac{\Delta p_{R}}{\Delta t_{R}}
\end{gathered}
$$

In addition, DCA is used to confirm the observed flow behaviors in hydraulically fractured horizontal wells completed in shale. Decline curves are the most common means of forecasting production. The plot of the flow rate $(q)$ versus time is matched to a decline curve to determine three variables including the initial production rate, $q_{i}$, the initial nominal decline rate, $D_{i}$, and the hyperbolic exponent, $b$. The hyperbolic exponent, $b$, can be used for flow regime identification.

Finally, attempts were made to develop PTC to validate the indicated flow regimes. Table 6 shows a summary of simulation runs made to achieve a better understanding of the flow regimes. 
Table 3: Various drainage areas and horizontal well length configuration to develop a base model Various drainage areas and horizontal well length configuration to develop a base model

\begin{tabular}{|c|c|c|c|}
\hline Fixed input $^{*}$ & Runs & Parameter Varied & Comments \\
\hline \multirow{3}{*}{3000 Lateral } & Run 1 & $4000 \times 2000$ (drainage area) & \multirow{3}{*}{$\begin{array}{l}\text { Horizontal wells with different drainage area were } \\
\text { modeled to compare production performance. }\end{array}$} \\
\hline & Run 2 & $4000 \times 1000$ (drainage area) & \\
\hline & Run 3 & $4000 \times 500$ (drainage area) & \\
\hline Fixed input* & Runs & Parameter Varied & Comments \\
\hline \multirow{4}{*}{$4000 \times 1000$ (3000 Lateral) } & Run 1 & Horz well placement (15') & \multirow{4}{*}{$\begin{array}{l}\text { The effect of the horizontal well placement (lateral) } \\
\text { was modeled to compare production performance. }\end{array}$} \\
\hline & Run 2 & Horz well placement (45') & \\
\hline & Run 3 & Horz well placement (60') & \\
\hline & Run 4 & Horz well placement (74.99') & \\
\hline Fixed input ${ }^{*}$ & Runs & Parameter Varied & Comments \\
\hline \multirow{2}{*}{$\begin{array}{c}4000 \times 1000 \text { ( } 3000 \text { Lateral) } \\
4 \text { stages }\end{array}$} & Run 1 & Well in the center & \multirow{2}{*}{$\begin{array}{l}\text { The impact of horizontal well location is studied to } \\
\text { compare production performance. }\end{array}$} \\
\hline & Run 2 & Well on the edge & \\
\hline Fixed input $^{*}$ & Runs & Parameter Varied & Comments \\
\hline \multirow{3}{*}{$4000 \times 1000$ (3000 Lateral) } & Run 1 & Thickness $=75^{\prime}$ & \multirow{3}{*}{$\begin{array}{l}\text { Horizontal wells with different thickness were } \\
\text { modeled to compare production performance. }\end{array}$} \\
\hline & Run 2 & Thickness $=60^{\prime}$ & \\
\hline & Run 3 & Thickness $=30^{\prime}$ & \\
\hline Fixed input* & Runs & Parameter Varied & Comments \\
\hline \multirow{2}{*}{$\begin{array}{l}4000 \times 1000 \\
4 \text { stages }\end{array}$} & Run 1 & Horizontal lateral $=3000^{\prime}$ & \multirow{2}{*}{$\begin{array}{l}\text { Different horizontal well length with } 4 \text { hydraulic } \\
\text { fractures were modeled to compare production } \\
\text { performance. }\end{array}$} \\
\hline & Run 2 & Horizontal well lateral=4000' & \\
\hline Fixed input* & Runs & Parameter Varied & Comments \\
\hline \multirow{4}{*}{$\begin{array}{c}4000 \times 1000 \text { ( } 3000 \text { lateral) } \\
4 \text { stages }\end{array}$} & Run 1 & Matrix por $=5 \%$ & \multirow{4}{*}{ Vary matrix porosity to study the production } \\
\hline & Run 2 & Matrix por $=7 \%$ & \\
\hline & Run 3 & Matrix por $=8 \%$ & \\
\hline & Run 4 & Matrix por $=10 \%$ & \\
\hline Fixed input ${ }^{*}$ & Runs & Parameter Varied & Comments \\
\hline \multirow{3}{*}{$\begin{array}{c}4000 \times 1000 \text { (3000 lateral) } \\
4 \text { stages } \\
k_{f}=0.005 \mathrm{md} \& 0.1 \mathrm{md}\end{array}$} & Run 1 & Matrix perm $=0.001 \mathrm{md}$ & \multirow{3}{*}{$\begin{array}{l}\text { Vary matrix perm to study the production } \\
\text { performance. }\end{array}$} \\
\hline & Run 2 & Matrix perm $=0.0004 \mathrm{md}$ & \\
\hline & Run 3 & Matrix perm $=0.0001 \mathrm{md}$ & \\
\hline
\end{tabular}


Table 4: The impact of the number and the properties of hydraulic fracture on production performance

\begin{tabular}{|c|c|c|c|}
\hline \multicolumn{4}{|c|}{ The impact of the number and the properties of hydraulic fractures on production performance } \\
\hline Base case* & Runs & Parameter Varied & Comments \\
\hline \multirow{4}{*}{3000 Lateral } & Run 1 & $4000 \times 1000$ (7 Fracs) & \multirow{4}{*}{$\begin{array}{l}\text { Different horizontal well length with hydraulic fracture \& different drainage area } \\
\text { were modeled to compare production performance. }\end{array}$} \\
\hline & Run 2 & $4000 \times 2000$ (7 Fracs) & \\
\hline & Run 3 & 4000X1000 (13 Fracs) & \\
\hline & Run 4 & $4000 \times 2000$ (13 Fracs) & \\
\hline Base case* & Runs & Parameter Varied & Comments \\
\hline \multirow{2}{*}{$\begin{array}{c}4000 \times 1000 \\
(3000 \text { Lateral) }\end{array}$} & Run 1 & Horz well with 4 fracs & \multirow{2}{*}{$\begin{array}{l}1 \text { horizontal well with } 4 \text { fractures versus } 4 \text { vertical wells with } 1 \text { fracture for each } \\
\text { well were modeled to compare production performance. }\end{array}$} \\
\hline & Run 2 & 4 vert wells & \\
\hline Base case* $^{*}$ & Runs & Parameter Varied & Comments \\
\hline \multirow{7}{*}{$\begin{array}{c}4000 \times 1000 \\
(3000 \text { Lateral) }\end{array}$} & Run 1 & No Frac & \multirow{7}{*}{$\begin{array}{l}\text { Horizontal wells with multiple hydraulic fractures were modeled to compare } \\
\text { production performance. }\end{array}$} \\
\hline & Run 2 & 1 Frac & \\
\hline & Run 3 & 2 Fracs & \\
\hline & Run 4 & 3 Fracs & \\
\hline & Run 5 & 4 Fracs & \\
\hline & Run 6 & 7 Fracs & \\
\hline & Run 7 & 13 Fracs & \\
\hline Base case* & Runs & Parameter Varied & Comments \\
\hline \multirow{2}{*}{$\begin{array}{c}4000 \times 1000 \\
(3000 \text { Lateral) }\end{array}$} & Run 1 & $1000 \mathrm{ft}$ spacing & \multirow{2}{*}{$\begin{array}{l}1 \text { horizontal well with } 4 \text { fractures with different spacing were modeled to } \\
\text { compare production performance. }\end{array}$} \\
\hline & Run 2 & $250 \mathrm{ft}$ spacing & \\
\hline Base case* & Runs & Parameter Varied & Comments \\
\hline $\begin{array}{c}4000 \times 1000 \\
(3000 \text { Lateral) }\end{array}$ & Run 1 & $\begin{array}{l}\text { Different number of fracs } \\
(1,3,4,7,13 \text { Fracs })\end{array}$ & Compares the initial production rates for different number of fractures. \\
\hline Base case* & Runs & Parameter Varied & Comments \\
\hline \multirow{3}{*}{$\begin{array}{c}4000 \times 1000 \\
(3000 \text { Lateral) }\end{array}$} & Run 1 & 1 year & \multirow{3}{*}{$\begin{array}{l}\text { Compares the cumulative production after } 1,5 \text { and } 10 \text { years for different number } \\
\text { of fractures. }\end{array}$} \\
\hline & Run 2 & 5 years & \\
\hline & Run 3 & 10 years & \\
\hline Base case* & Runs & Parameter Varied & Comments \\
\hline \multirow{2}{*}{$\begin{array}{c}4000 \times 2000 \\
(3000 \text { Lateral) } \\
\end{array}$} & Run 1 & 1 Horz with 13 Fracs & \multirow{2}{*}{$\begin{array}{l}1 \text { horizontal well with } 13 \text { fractures versus } 2 \text { horizontal wells with } 7 \text { fractures } \\
\text { were modeled to compare production performance. }\end{array}$} \\
\hline & Run 2 & 2 Horz with 7 Fracs & \\
\hline Base case* & Runs & Parameter Varied & Comments \\
\hline \multirow{4}{*}{$\begin{array}{c}4000 \times 1000 \\
(3000 \text { Lateral) }\end{array}$} & Run 1 & 4 stages (Des with Frac) & \multirow{4}{*}{ Impact of gas desorption was studied for horizontal wells. } \\
\hline & Run 2 & 4 stages ( No Des with Frac) & \\
\hline & Run 3 & Horz (No Des with No Frac) & \\
\hline & Run 4 & Horz (Des with No Frad) & \\
\hline Base case* & Runs & Parameter Varied & Comments \\
\hline \multirow{4}{*}{$\begin{array}{c}4000 \times 1000 \\
(3000 \text { Lateral) }\end{array}$} & Run 1 & $K_{f}=5,000 \mathrm{md}$ & \multirow{4}{*}{$\begin{array}{l}\text { Hydraulically fractured horizontal wells with different hydraulic fractured } \\
\text { permeability were modeled to compare production performance. }\end{array}$} \\
\hline & Run 2 & $K_{\mathrm{f}}=10,000 \mathrm{md}$ & \\
\hline & Run 3 & $K_{f}=10,000 \mathrm{md}$ & \\
\hline & Run 4 & $\mathrm{~K}_{\mathrm{f}}=200,000 \mathrm{md}$ & \\
\hline Base case* & Runs & Parameter Varied & Comments \\
\hline \multirow{3}{*}{$\begin{array}{c}4000 \times 1000 \\
(3000 \text { Lateral) }\end{array}$} & Run 1 & $X_{f}=250 \mathrm{ft}$ & \multirow{3}{*}{$\begin{array}{l}\text { Hydraulically fractured horizontal wells with different fractured half-length were } \\
\text { modeled to compare production performance. }\end{array}$} \\
\hline & Run 2 & $X_{\mathrm{f}}=300 \mathrm{ft}$ & \\
\hline & Run 3 & $X_{f}=500 \mathrm{ft}$ & \\
\hline
\end{tabular}


Table 5: The impact of the formation and natural fracture characteristics on production performance

\begin{tabular}{|c|c|c|c|}
\hline \multicolumn{4}{|c|}{ The impact of the formation and natural fracture characteristics on production performance } \\
\hline Base case* & Runs & Parameter Varied & Comments \\
\hline \multirow{3}{*}{$\begin{array}{c}4000 \times 1000 \text { (3000 lateral) } \\
4 \text { stages }\end{array}$} & Run 1 & Frac por $=1 \%$ & \multirow{3}{*}{$\begin{array}{l}\text { Vary natural fracture porosity to study the production } \\
\text { performance. }\end{array}$} \\
\hline & Run 2 & Frac por $=0.5 \%$ & \\
\hline & Run 3 & Frac por $=0.2 \%$ & \\
\hline Base case* & Runs & Parameter Varied & Comments \\
\hline \multirow{6}{*}{$\begin{array}{l}4000 \times 1000 \text { ( } 3000 \text { lateral) } \\
4 \text { stages }\end{array}$} & Run 1 & Frac perm $=0.1 \mathrm{md}$ & \multirow{6}{*}{$\begin{array}{l}\text { Vary natural fracture permeability to study the } \\
\text { production performance. }\end{array}$} \\
\hline & Run 2 & Frac perm $=0.05 \mathrm{md}$ & \\
\hline & Run 3 & Frac perm $=0.05 \mathrm{md}$ & \\
\hline & Run 4 & Frac perm $=0.01 \mathrm{md}$ & \\
\hline & Run 5 & Frac perm $=0.005 \mathrm{md}$ & \\
\hline & Run 6 & Frac perm $=0.002 \mathrm{md}$ & \\
\hline Base case* & Runs & Parameter Varied & Comments \\
\hline \multirow{3}{*}{$\begin{array}{l}4000 \times 1000 \text { (3000 lateral) } \\
k_{\mathrm{f}}=0.002 \& 0.1 \mathrm{md}\end{array}$} & $\begin{array}{l}\text { Run } 1 \\
\end{array}$ & 4 Fracs & \multirow{3}{*}{$\begin{array}{l}\text { Relationship between natural fracture permeability \& } \\
\text { HF to study the production performance. }\end{array}$} \\
\hline & Run 2 & 7 Fracs & \\
\hline & Run 3 & 13 Fracs & \\
\hline Base case* & Runs & Parameter Varied & Comments \\
\hline \multirow{3}{*}{$\begin{array}{c}4000 \times 1000 \text { (3000 Lateral) } \\
4 \text { stages }\end{array}$} & Run 1 & $\sigma=0.001$ & \multirow{3}{*}{$\begin{array}{l}\text { The impact of fracture spacing is studied to compare } \\
\text { production performance. }\end{array}$} \\
\hline & Run 2 & $\sigma=0.01$ & \\
\hline & Run 3 & $\sigma=0.1$ & \\
\hline Base case* & Runs & Parameter Varied & Comments \\
\hline \multirow{3}{*}{$\begin{array}{c}4000 \times 1000 \text { (3000 Lateral) } \\
7 \text { stages }\end{array}$} & Run 1 & 0.00009125 & \multirow{3}{*}{$\begin{array}{l}\text { The impact interporosity flow coefficient, } \lambda \text { is studied } \\
\text { to compare production performance. }\end{array}$} \\
\hline & Run 2 & 0.0000365 & \\
\hline & Run 3 & 0.00000365 & \\
\hline Base case* & Runs & Parameter Varied & Comments \\
\hline \multirow{3}{*}{$\begin{array}{c}4000 \times 1000 \text { (3000 Lateral) } \\
7 \text { stages }\end{array}$} & Run 1 & 0.090909091 & \multirow{3}{*}{$\begin{array}{l}\text { The impact of storativity coefficient, } \omega \text { is studied to } \\
\text { compare production performance. }\end{array}$} \\
\hline & Run 2 & 0.038461538 & \\
\hline & Run 3 & 0.003984064 & \\
\hline
\end{tabular}


Table 6: Flow regimes in hydraulically fractured horizontal wells

\begin{tabular}{|c|c|c|c|}
\hline \multicolumn{4}{|c|}{ Flow regimes in hydraulically fractured horizontal wells } \\
\hline Base case* $^{*}$ & Runs & Parameter Varied & Comments!!! \\
\hline \multirow{5}{*}{$4000 \times 1000$ (3000 lateral) } & Run 1 & 1 Frac & \multirow{5}{*}{ Study of the flow regimes. } \\
\hline & Run 2 & 2 Fracs & \\
\hline & Run 3 & 4 Fracs & \\
\hline & Run 4 & 7 Fracs & \\
\hline & Run 5 & 13 Fracs & \\
\hline Base case $^{*}$ & Runs & Parameter Varied & Comments!!! \\
\hline \multirow{5}{*}{$4000 \times 2000$ (3000 lateral) } & Run 1 & 1 Frac & \multirow{5}{*}{ Study of the flow regimes } \\
\hline & Run 2 & 2 Fracs & \\
\hline & Run 3 & 4 Fracs & \\
\hline & Run 4 & 7 Fracs & \\
\hline & Run 5 & 13 Fracs & \\
\hline
\end{tabular}




\section{RESULTS AND DISCUSSIONS}

The following sections summarize the results of modeling and simulation studies as well as the interpretation of the results for each objective.

\section{$4.1 \quad$ Objective 1}

Various drainage areas and horizontal well length configuration were considered in developing a base model for this section. In this study, a dual porosity model was utilized and simulation runs with single-porosity model generated similar results. It is believed that the low permeability assigned to the natural fractures masks the impact of dual porosity system.

\subsubsection{Drainage area}

Figure 4-1 compares the production from a 3000 feet horizontal well in $4000 \times 2000$, $4000 \times 1000$ and $4000 \times 500 \mathrm{ft}^{2}$ drainage areas. As can be observed, the production profiles are very close for the first 3-5 years and the profiles for $4000 \times 2000,4000 \times 1000 \mathrm{ft}^{2}$ cases are very similar up to 10 years. This indicates that there is very little contribution to the production beyond 500 feet on either side of the well in first 5-10 years. Since the first 5 years of the production are considered to be the most significant period in economic terms, the practical size for the drainage area was assumed to be $4000 \times 1000 \mathrm{ft}^{2}$ for the study.

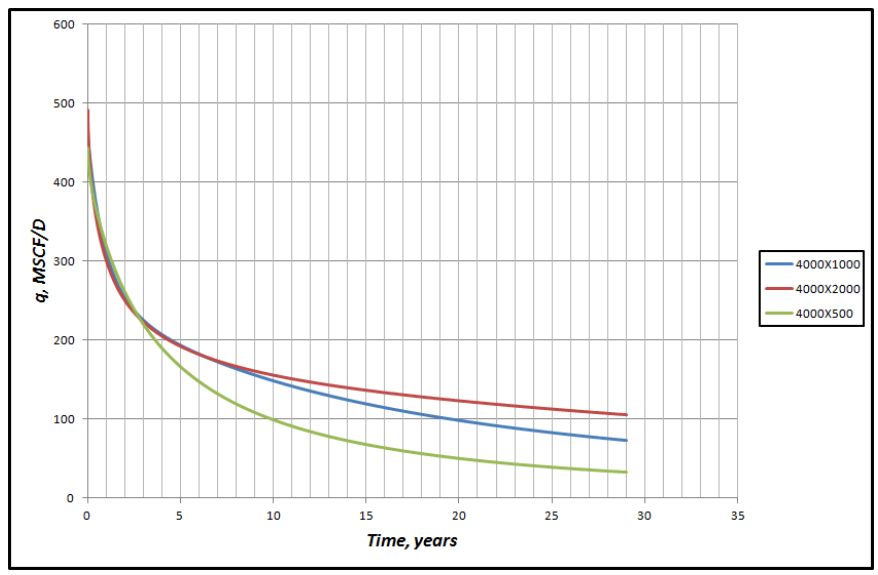

Figure 4-1: The impact of the size of the drainage area on production profile of 3000-ft horizontal well 


\subsubsection{Horizontal well length (lateral)}

Figure 4-2 compares the cumulative production for 3000 and 4000 feet of horizontal lateral with four uniformly spaced identical hydraulic fractures at the same locations. There appears to be little difference between the two cases. This tends to indicate that cumulative production is primarily controlled by hydraulic fractures and horizontal well length does not have any significant impact on the cumulative production.

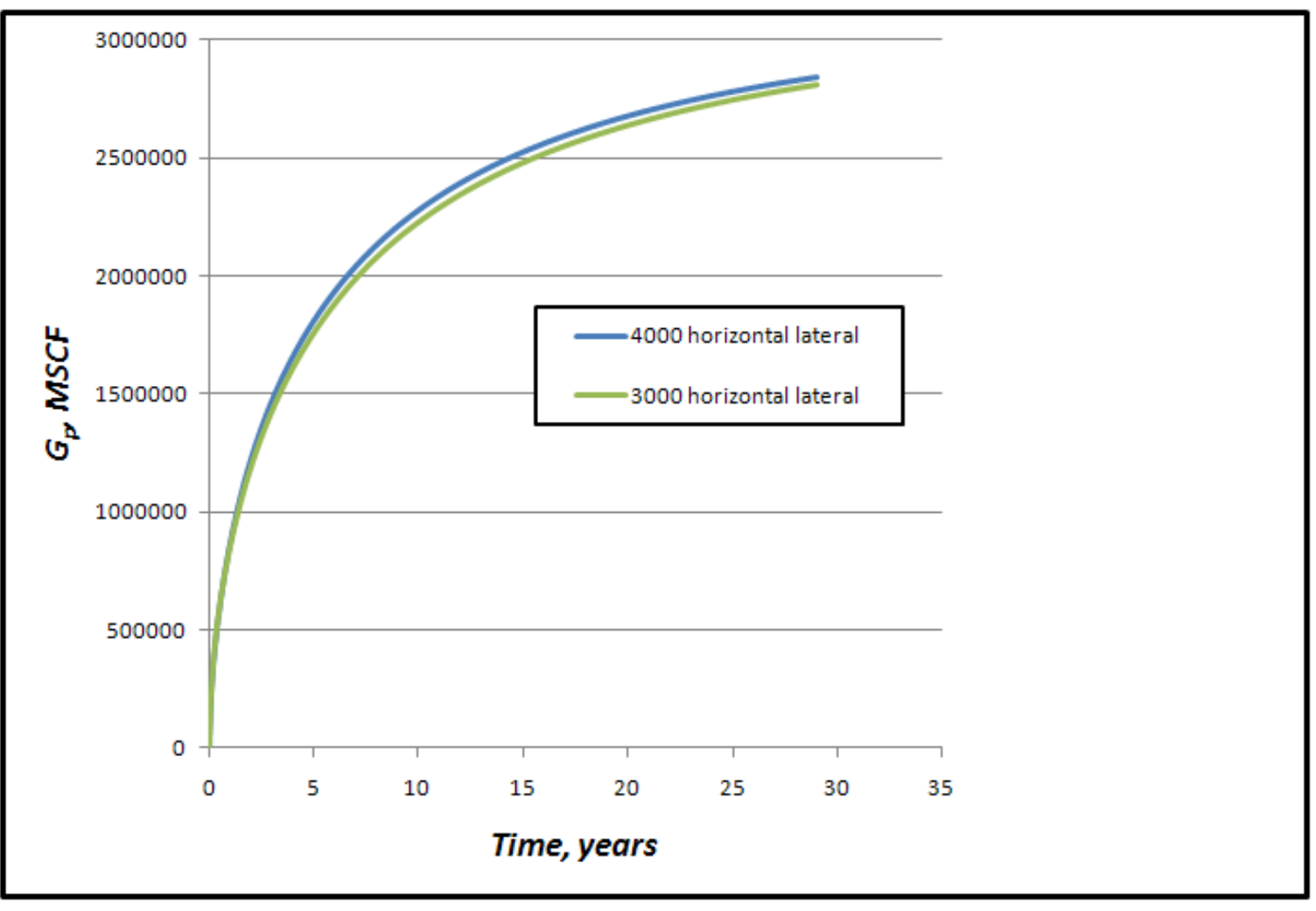

Figure 4-2: The impact of the horizontal lateral on cumulative production 


\subsubsection{Location of horizontal lateral at a target formation}

Figure 4-3 compares the cumulative production from a 3000 feet horizontal well in a $4000 \times 1000 \mathrm{ft}^{2}$ drainage area with horizontal lateral placed at a different vertical location within the formation. As it can be seen, placing a well at the center of a target formation provides better production performance. Figure 4-4 illustrates the horizontal well placement at the center of a target formation.

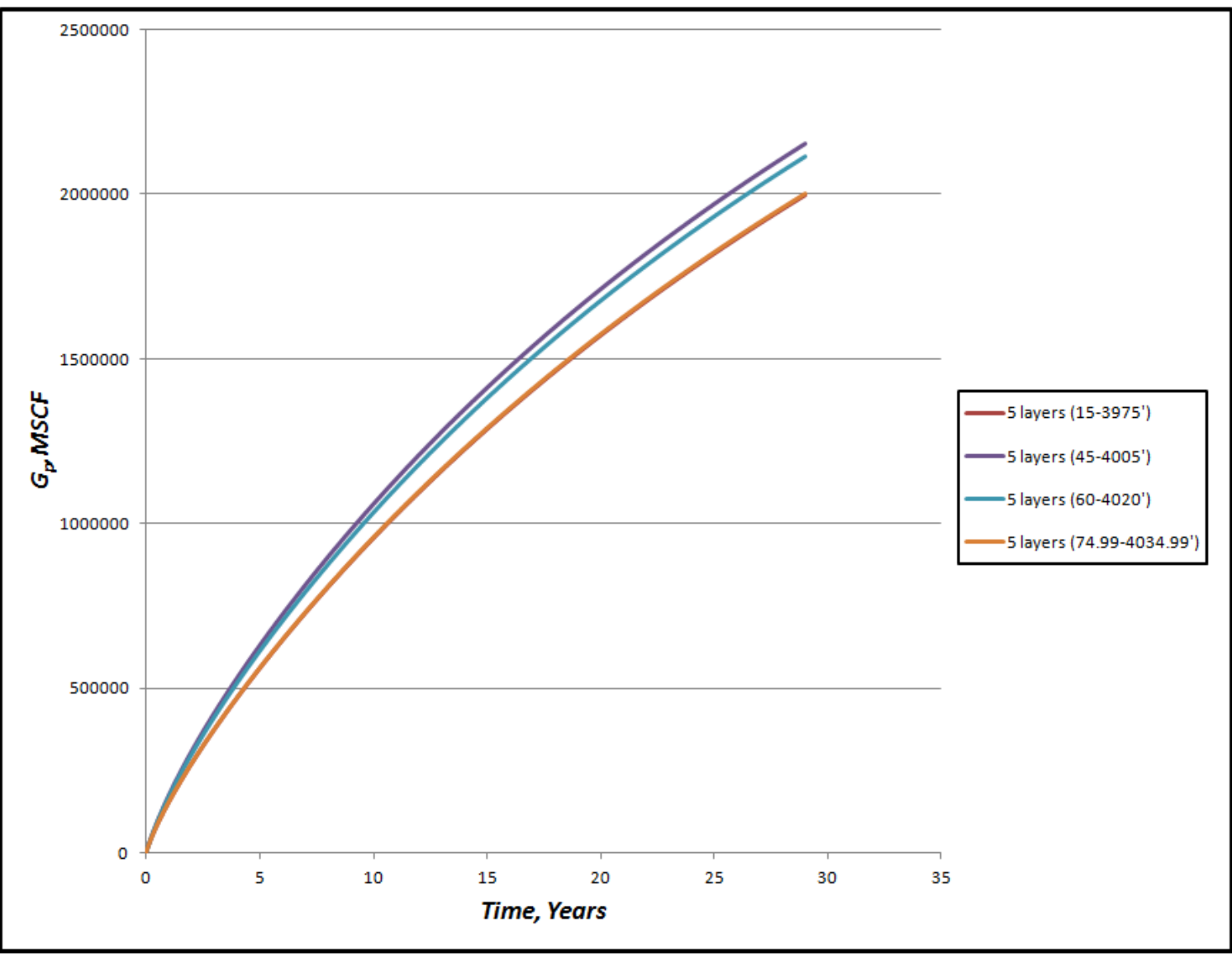

Figure 4-3: The impact of the location of horizontal lateral at a target formation

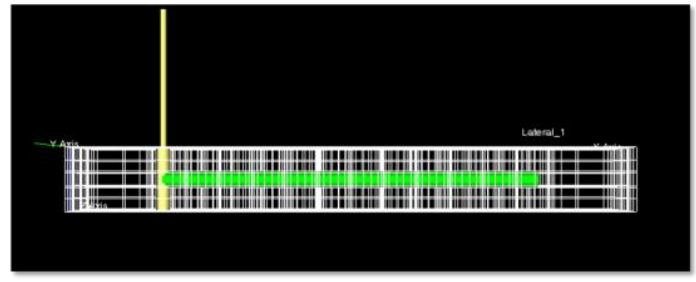

Figure 4-4: Horizontal well placement at the center of a target formation 


\subsubsection{Location of the well}

Figure 4-5 compares the production from 3000 feet horizontal well in a $4000 \times 1000 \mathrm{ft}^{2}$ drainage area with 4 stages in two different well locations. As can be noted, the cumulative production profile is not impacted by the location of the well. Figure 4-6 illustrates two different locations of the wells, edge and center of the reservoir respectively.

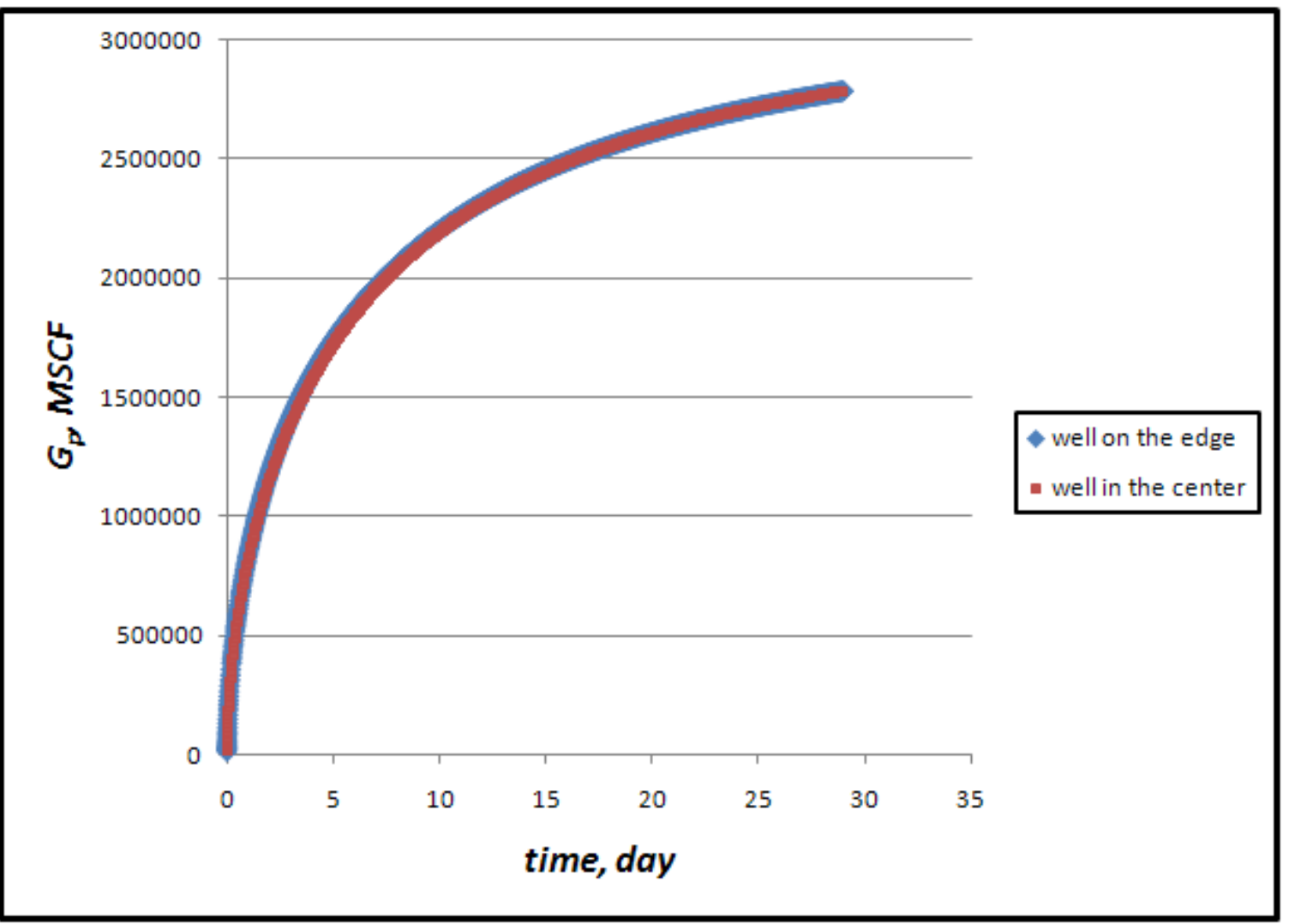

Figure 4-5: The impact of the location of the well
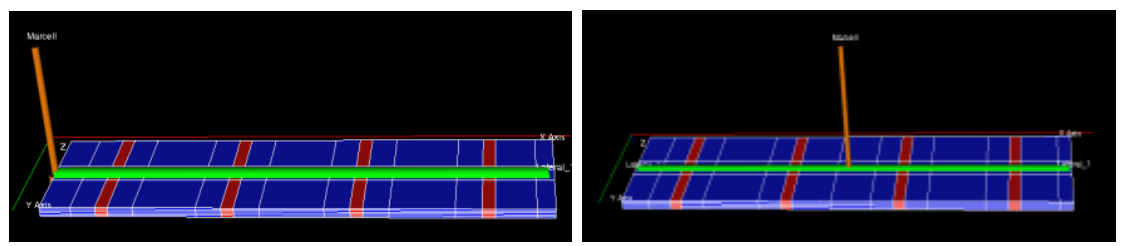

Figure 4-6: Two different locations of the wells. 


\subsubsection{Reservoir thickness}

Figure 4-7 compares the cumulative production from a 3000 feet horizontal well in a $4000 \times 1000 \mathrm{ft}^{2}$ drainage area with different reservoir thicknesses. As can be seen, the cumulative production is noticeably impacted by various reservoir thicknesses.

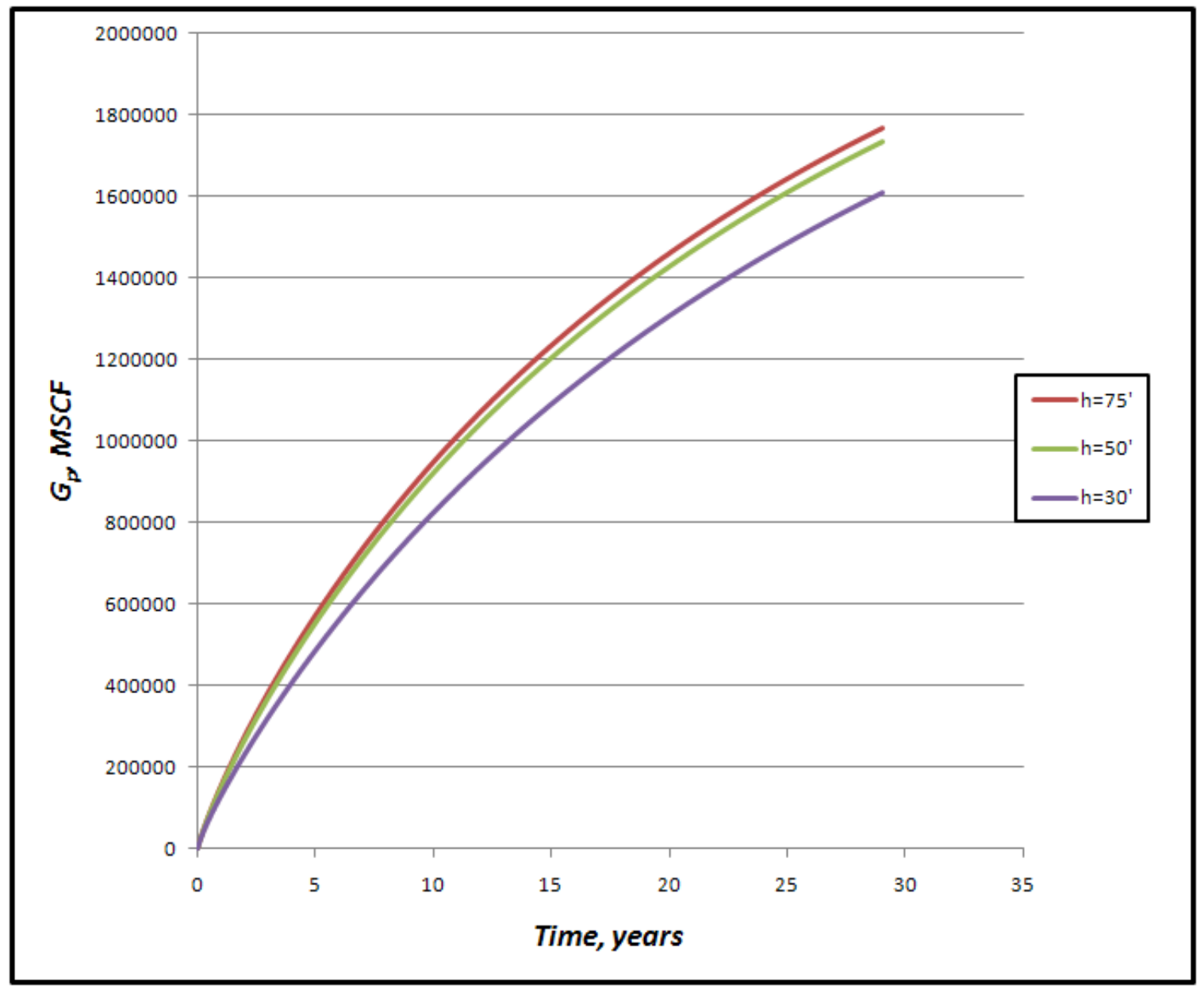

Figure 4-7: The impact of reservoir thickness on cumulative production 


\subsubsection{Matrix porosity}

Matrix porosity is varied from $5-10 \%$ in a 3000 feet horizontal well in a $4000 \times 1000 \mathrm{ft}^{2}$ drainage area with 4 fractures which is shown in Figure 4-8. Matrix porosity has a significant impact on the recovery mainly after the first 3-5 years.

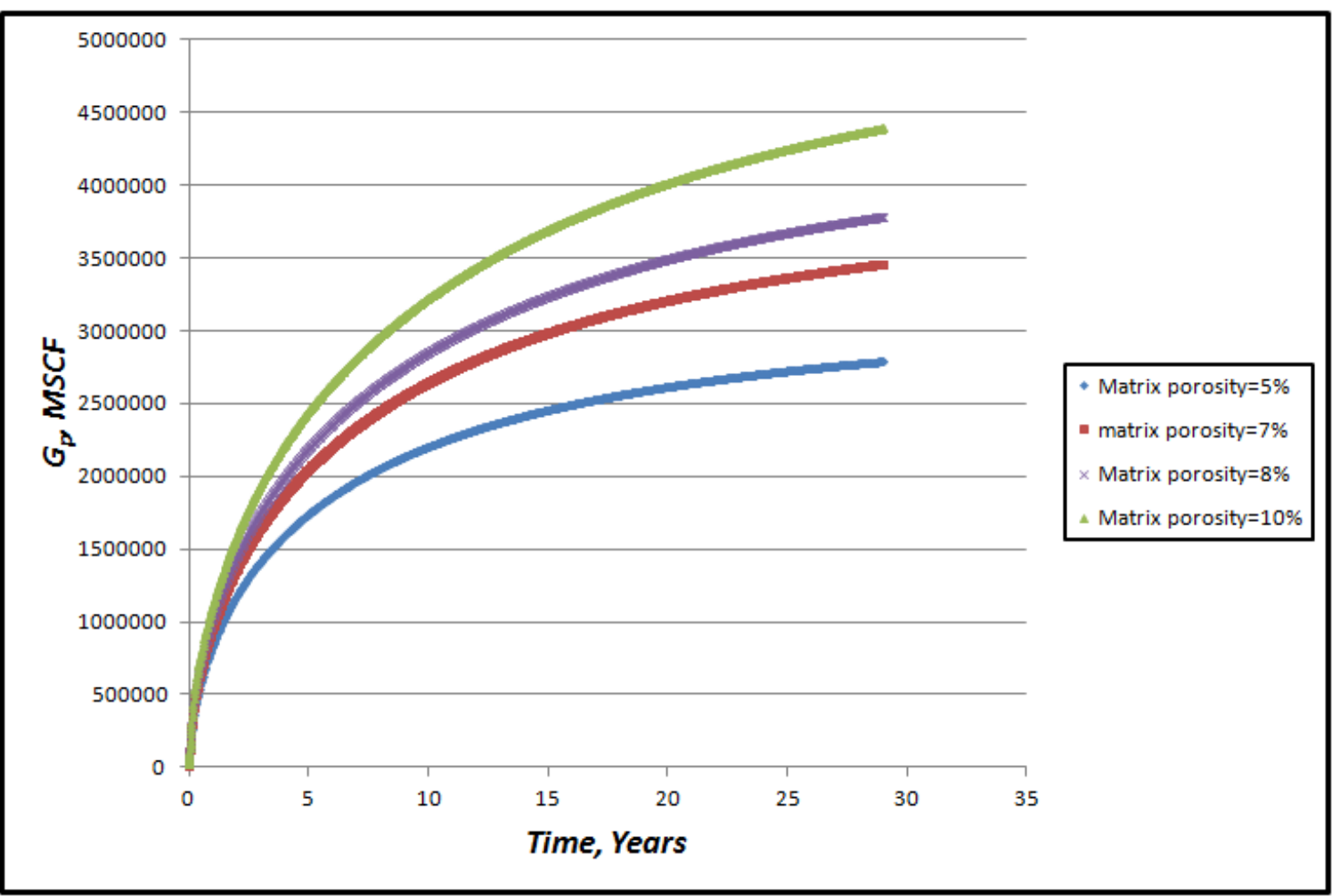

Figure 4-8: The impact of matrix porosity on cumulative production 


\subsubsection{Matrix permeability}

Matrix permeability is varied from 0.001 to $0.0001 \mathrm{md}$ in a 3000 feet horizontal well in a $4000 \times 1000 \mathrm{ft}^{2}$ drainage area with 4 fractures which is shown in Figure 4-9 and 4-10. Two set of runs for different natural fracture permeability ( $\left.k_{f}=0.005 \mathrm{md} \& k_{f}=0.1 \mathrm{md}\right)$ are shown below respectively. Matrix permeability has significantly less impact on the recovery when compared to natural fracture permeability.

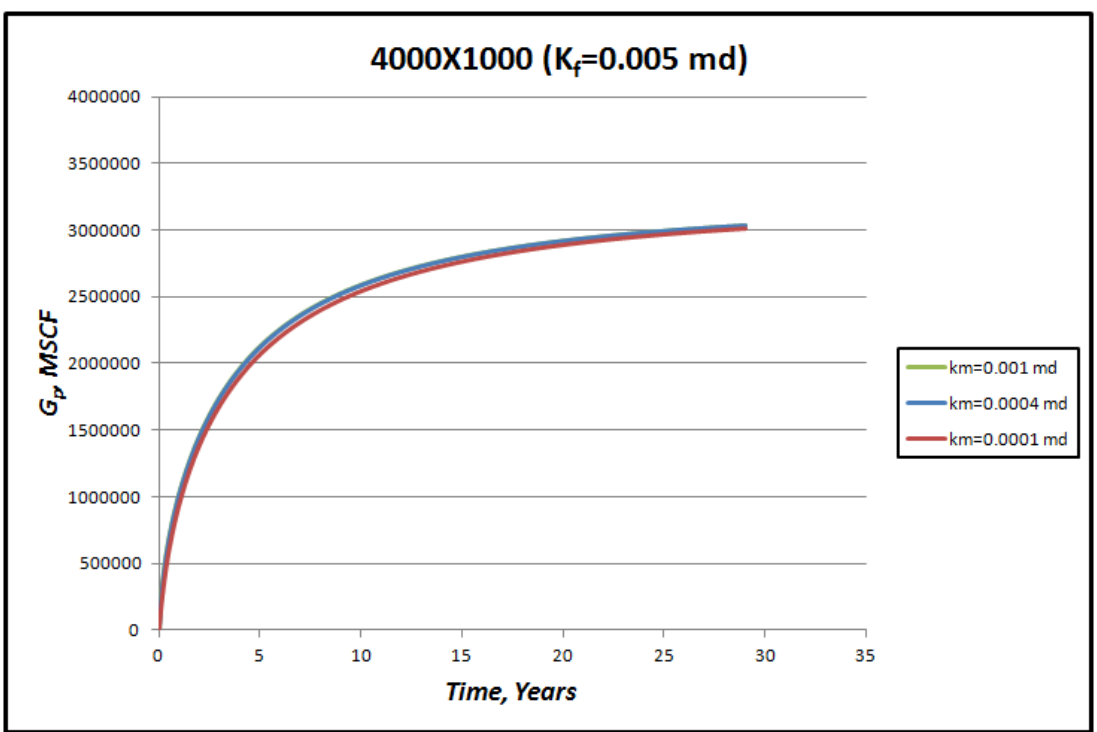

Figure 4-9: The impact of matrix permeability (typical natural fracture) on cumulative production

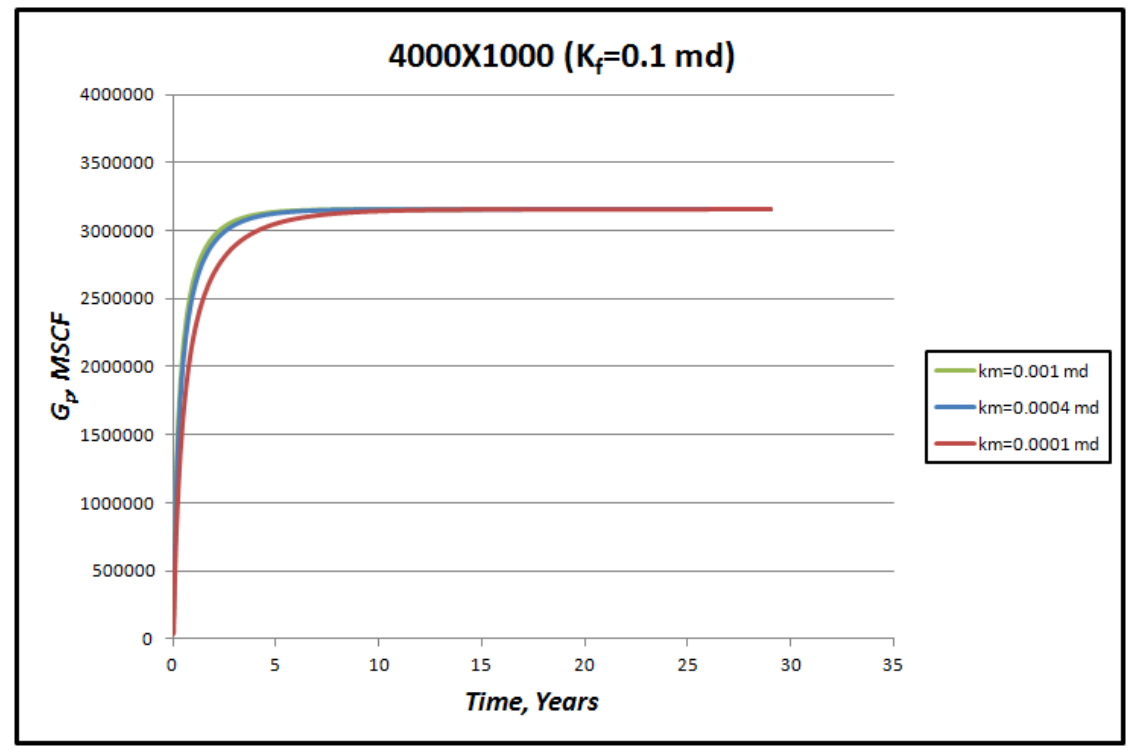

Figure 4-10: The impact of matrix permeability (high natural fracture) on cumulative production 
Table 7 shows the base case and results for parameters studied in this section.

Table 7: Objective 1 results

\begin{tabular}{|c|c|}
\hline Parameter studied & Results (base case*) \\
\hline Drainage area & $\begin{array}{l}\text { There is very little contribution to the production beyond } 500 \text { feet on either } \\
\text { side of the well in first } 5-10 \text { years. The practical size for the drainage area } \\
\text { was assumed to be } 4000 \times 1000 \mathrm{ft}^{2} \text { for the study. }\end{array}$ \\
\hline $\begin{array}{l}\text { Horizontal well length } \\
\text { (lateral) }\end{array}$ & $\begin{array}{l}\text { Cumulative production is primarily controlled by hydraulic fractures and } \\
\text { horizontal well length does not have any significant impact on the } \\
\text { production. Horizontal lateral was assumed to be } 3000 \text { feet for this study. }\end{array}$ \\
\hline $\begin{array}{c}\text { Location of horizontal } \\
\text { lateral at a target formation }\end{array}$ & $\begin{array}{l}\text { Placing a well at the center of a target formation provides better } \\
\text { production performance. }\end{array}$ \\
\hline Location of the well & $\begin{array}{l}\text { The cumulative production profile is not impacted by the location of the } \\
\text { well. }\end{array}$ \\
\hline Reservoir thickness & $\begin{array}{l}\text { The cumulative production is noticeably impacted by various reservoir } \\
\text { thicknesses. Reservoir thickness was assumed to be } 75 \text { feet for this study. }\end{array}$ \\
\hline Matrix porosity & $\begin{array}{l}\text { Matrix porosity has a significant impact on the recovery mainly after the } \\
\text { first 3-5 years. Matrix porosity was assumed to be } 5 \% \text { for this study. }\end{array}$ \\
\hline Matrix permeability & $\begin{array}{l}\text { Matrix permeability has significantly less impact on the recovery when } \\
\text { compared to natural fracture permeability. Matrix permeability was } \\
\text { assumed to be } 0.004 \text { md for this study. }\end{array}$ \\
\hline
\end{tabular}




\subsubsection{Commercial simulations comparison}

Schlumberger ECLIPSE software and Computer Modeling Group (CMG) were compared and plotted in the same graph to confirm the numerical simulations results. A case for $3000 \mathrm{ft}$ of horizontal lateral with multiple hydraulic fractures in $4000 \times 1000$ and $4000 \times 2000 \mathrm{ft}^{2}$ drainage areas are compared in this research. Figure 4-11 shows a horizontal well with no hydraulic fracture using both ECLIPSE and CMG simulations. Similarly, two simulations demonstrate almost identical results.

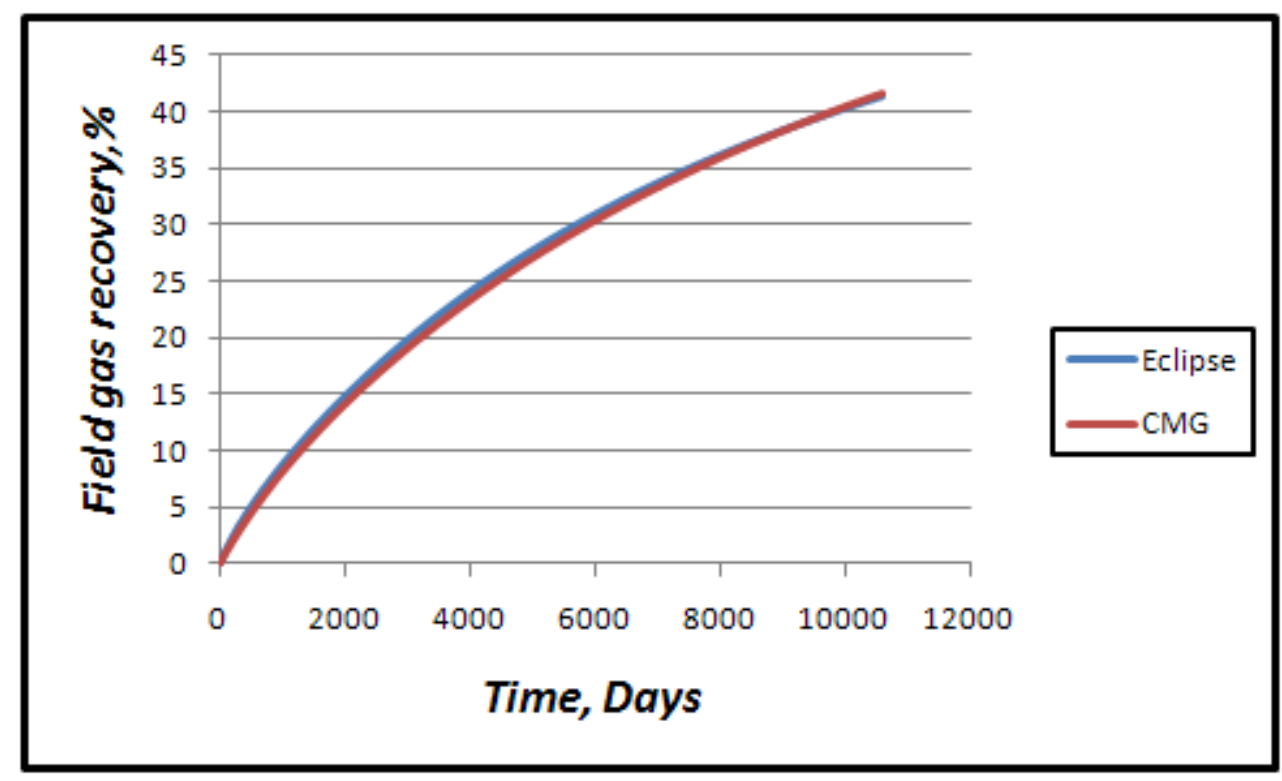

Figure 4-11: ECLIPSE vs. CMG 


\subsection{Objective 2}

Various cases were studied in this section and the base model utilized in the simulation runs was a rectangular drainage that is $4000 \times 1000 \mathrm{ft}^{2}$. The properties of hydraulic fractures were considered in this study. Generally, due to extreme contrast between the reservoir and fracture permeability values, the fractures behave as "infinite conductivity" fractures. This tends to support the conclusion that moderate variations in fracture properties do not alter their behavior.

\subsubsection{Number of hydraulic fractures}

Figure 4-12 illustrates the production for different numbers of hydraulic fractures from 1 to 13 . The fractures are uniformly spaced, have identical properties, are parallel with each other, and perpendicular to the well. As can be observed, the early production is significantly impacted by the number of fractures. However, the long term production indicates a diminishing improvement in production as the numbers of fractures are increased. Particularly, the increase in recovery after 30 years between 7 and 13 fractures is negligible and between 4 and 7 fractures is insignificant.

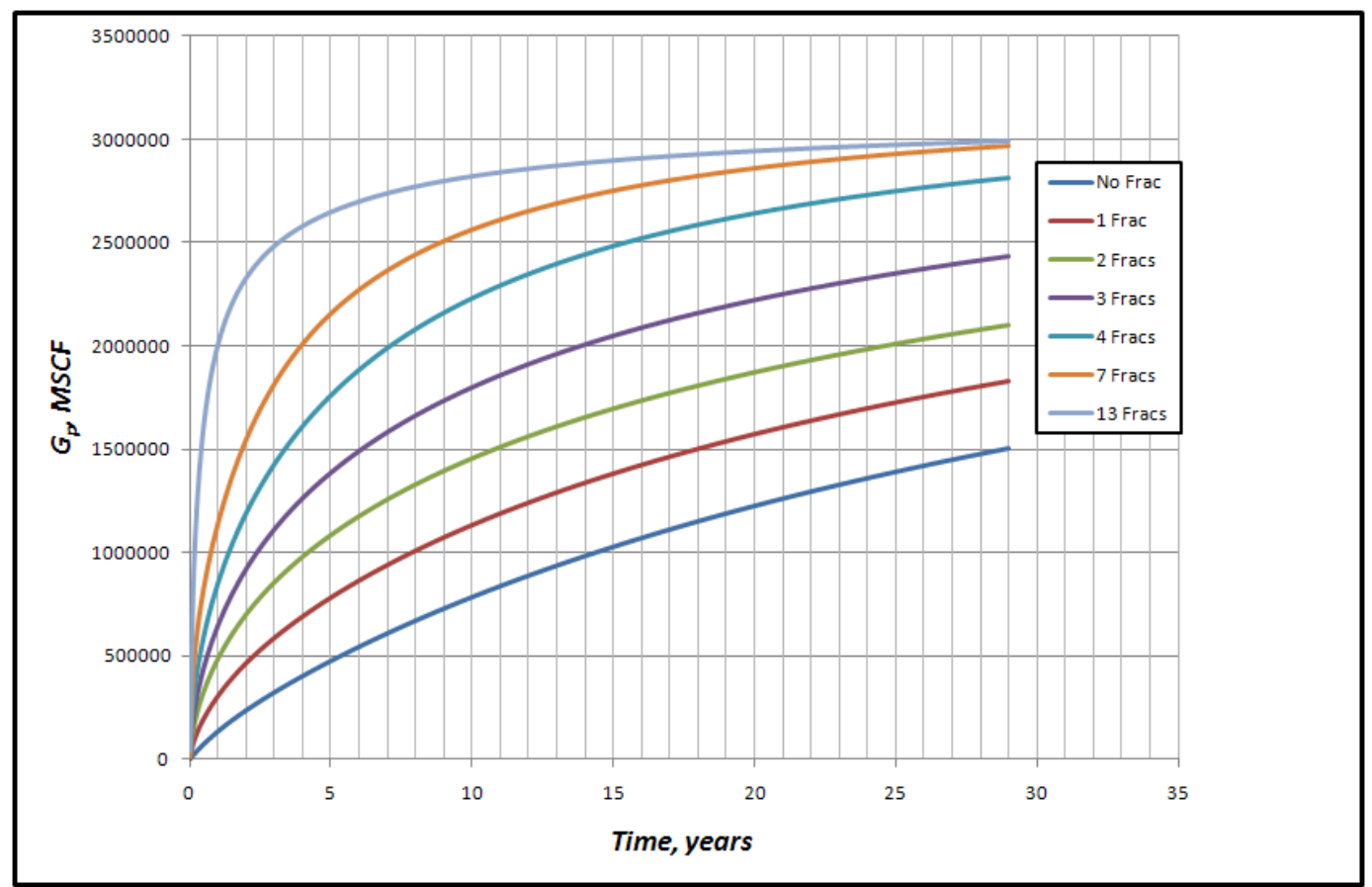

Figure 4-12: The impact of the number of hydraulic fractures on cumulative production 
Figure 4-13 compares the initial production rates for different numbers of fractures. As noted, the initial production rate increases almost linearly with the number of fractures. However, if one compares the cumulative production after 1, 5 and 10 years as illustrated in Figure 4-14, it is evident that increasing number of fractures does not increase the recovery significantly.

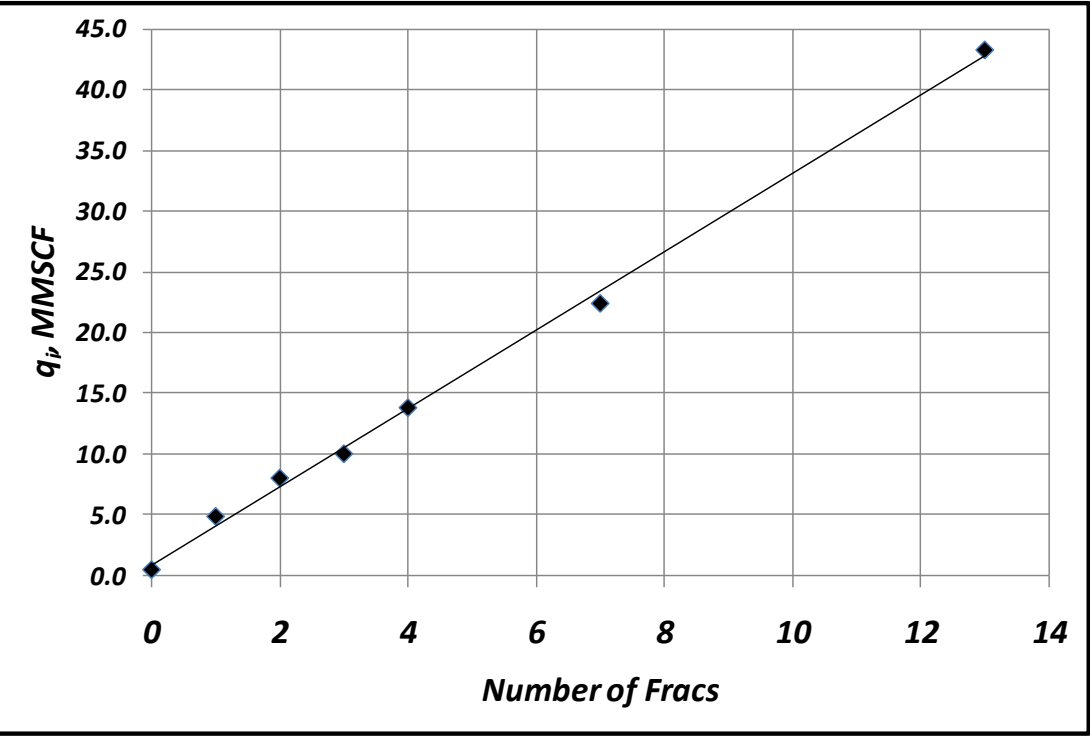

Figure 4-13: The impact of the number of hydraulic fractures on initial production rate

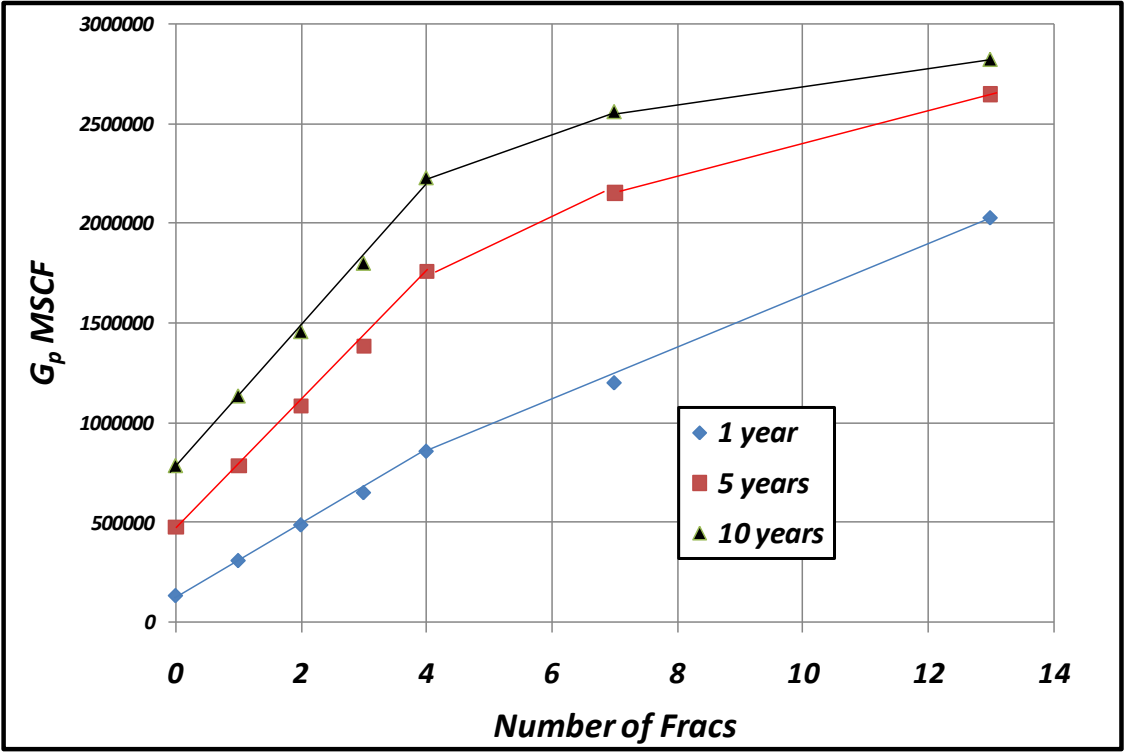

Figure 4-14: The impact of the number of hydraulic fractures on cumulative production 


\subsubsection{Hydraulic fracture spacing}

Hydraulic fracture spacing appears to have significant impact on production. Figure 4-15 compares two cases with 4 fractures with spacing of 1000 feet and 250 feet. It appears the wider more uniform spacing provides much greater production. Interestingly, the early production during the first year is not impacted by the spacing. This indicates the early production is primarily from areas adjacent to the fracture.

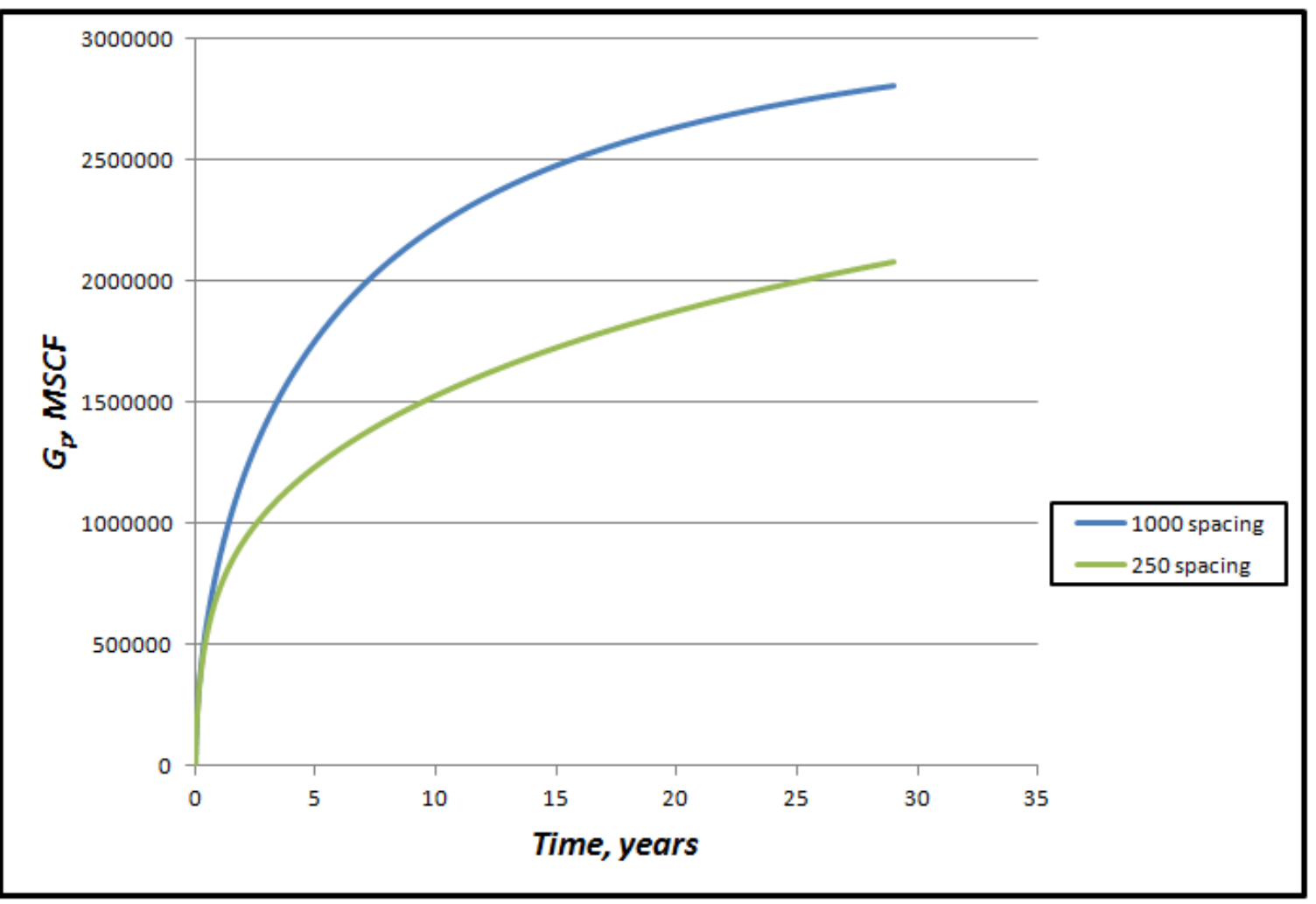

Figure 4-15: The impact of hydraulic fracture spacing 


\subsubsection{Hydraulic fracture distribution}

An interesting comparison is illustrated in Figure 4-16. One scenario is a 3000 feet horizontal well with 13 fractures in a $4000 \times 2000 \mathrm{ft}^{2}$ drainage area and the second scenario is two horizontal wells with 7 fractures both in the same drainage area. Figure 416 clearly indicates that it is not the number of fractures, but rather the distribution of the fractures that enhances the production.

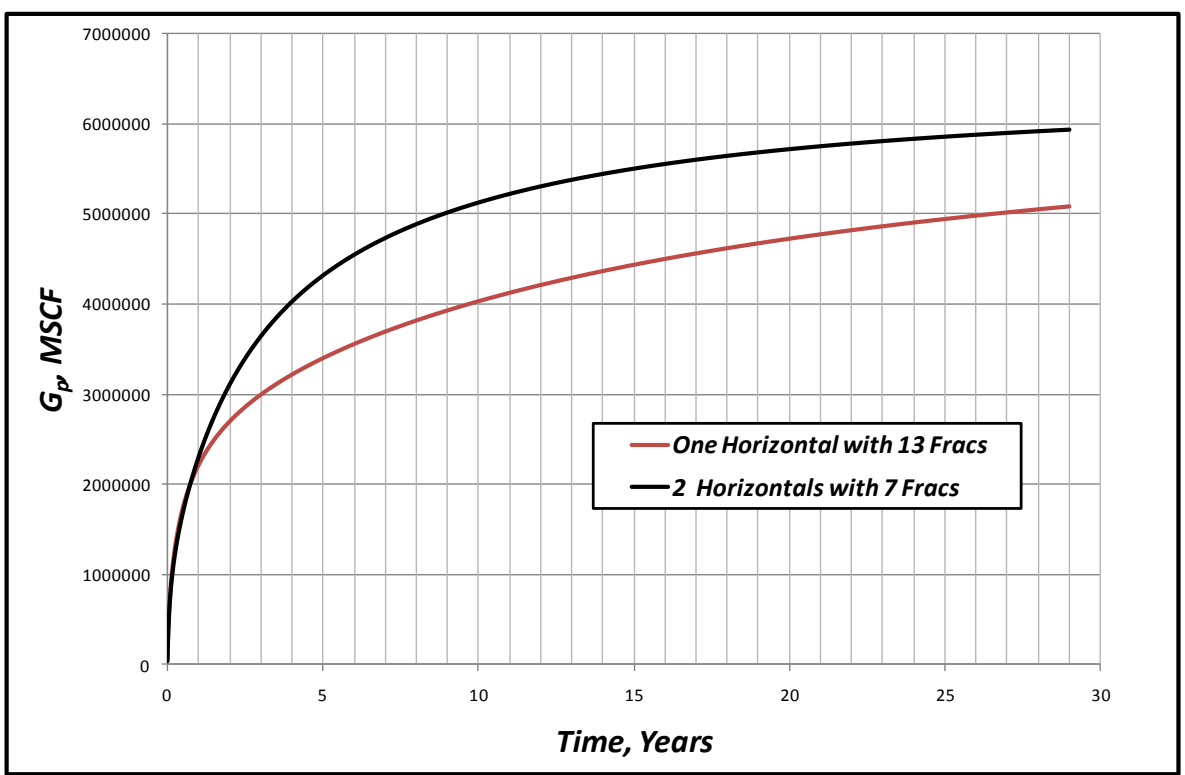

Figure 4-16: Comparison production from one and two horizontal wells in a $4000 \times 2000 \mathrm{ft}^{2}$ area 


\subsubsection{Contributions of the horizontal well and hydraulic fracture}

Figure 4-17 compares the production from a 3000 feet horizontal well with 7 and 13 hydraulic fractures in $4000 \times 1000$, and $4000 \times 2000 \mathrm{ft}^{2}$ drainage areas. As can be seen, during the first 3-5 years, little contribution to the production is achieved beyond 500 feet from each side of the well. In addition, there appears to be a large difference between the two cases beyond the first year of production.

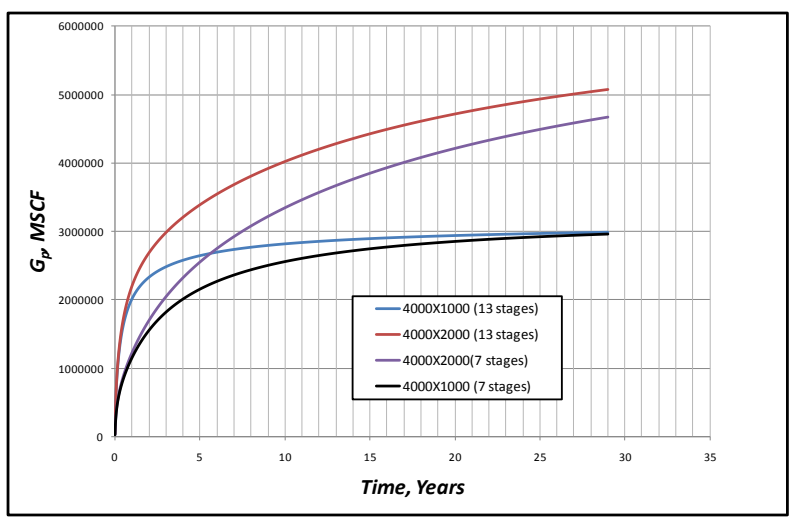

Figure 4-17: The contribution to the production from horizontal well with hydraulic fractures

A case with four vertical wells at the same location as the four hydraulic fractures was simulated and the results are compared in Figure 4-18. It clearly indicates that the contribution of the hydraulic fractures to production is significantly higher than the horizontal well.

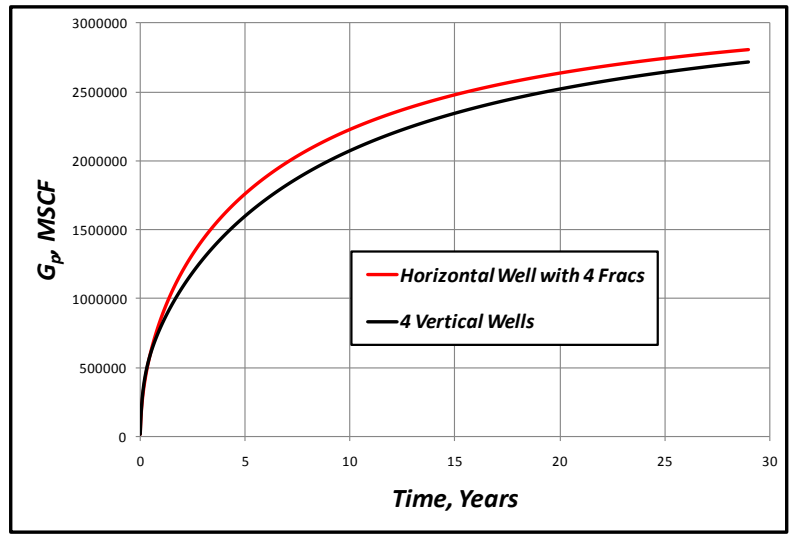

Figure 4-18: The contribution of horizontal well with 4 hydraulic fractures to production from $4000 \times 1000 \mathrm{ft}^{2}$ drainage area 


\subsubsection{Gas Desorption}

A case with one horizontal well without fracture and a case with one horizontal well with 4 fractures were simulated with and without adsorbed gas and results are compared in Figure 4-19. The impact of desorption was found to be negligible during early stages of production since the pressure depletion is limited, however the impact of desorption at the latter times is substantial.

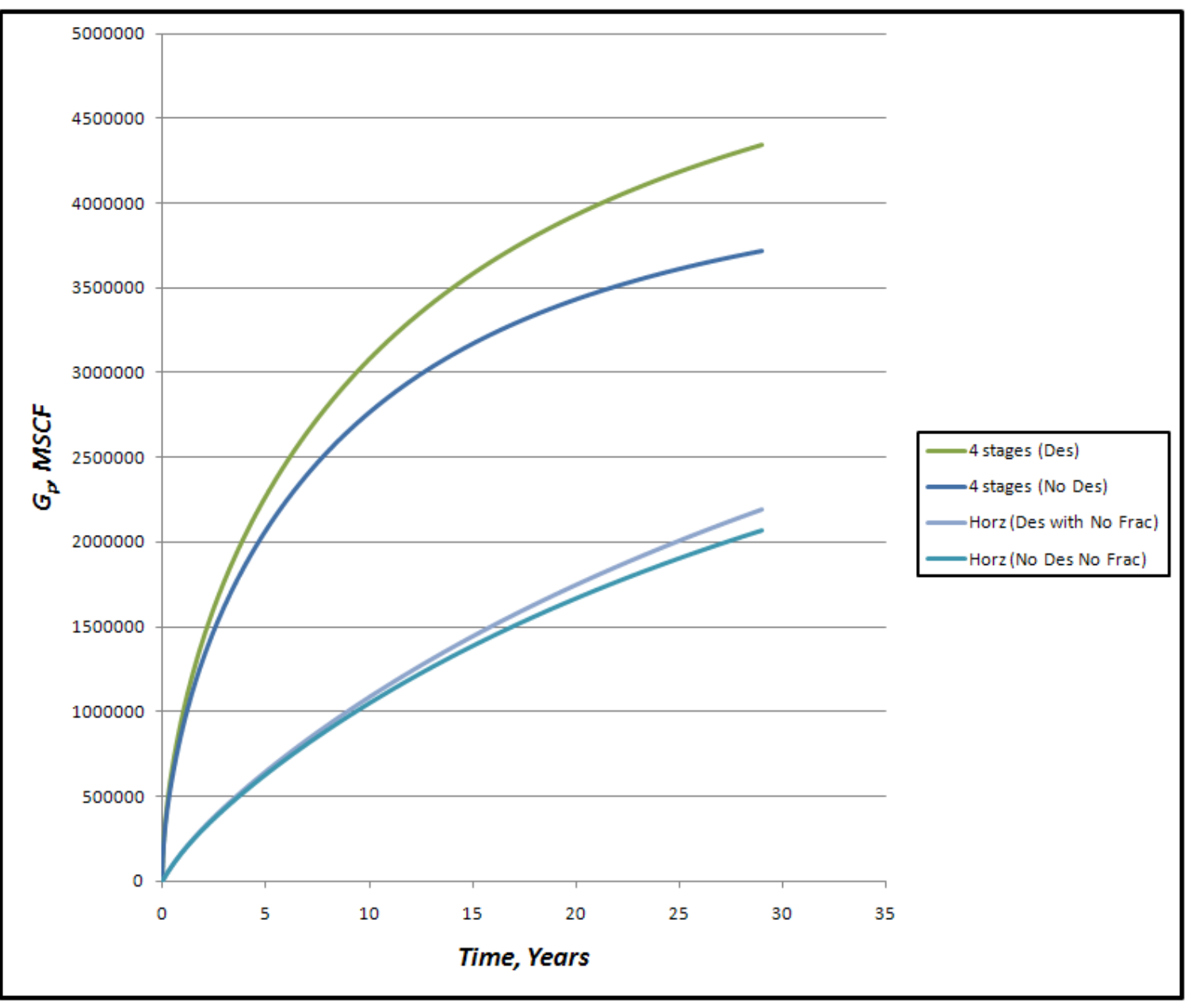

Figure 4-19: The impact of gas desorption 


\subsubsection{Hydraulic fractures properties}

Figure 4-20 compares the impact of fracture half-length from 250-500 feet in a 3000 feet horizontal well in $4000 \times 1000 \mathrm{ft}^{2}$ drainage area for 4 fractures. As can be seen, fracture half length has a significant impact on production performance in hydraulically fractured reservoirs.

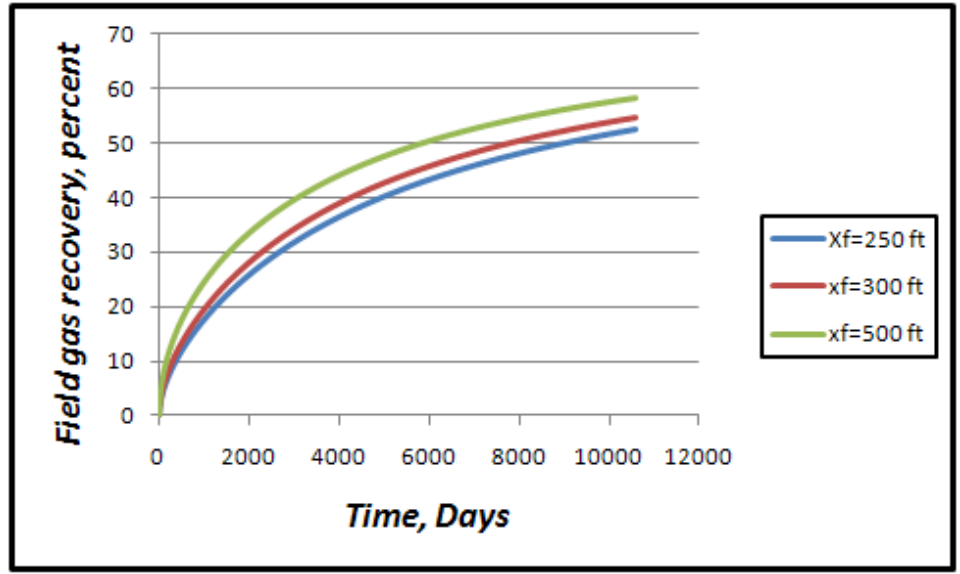

Figure 4-20: Fracture half-length

Figure 4-21 compares the impact of hydraulic fracture permeability from 5,000-200,000 md in a 3000 feet horizontal well in a $4000 \times 1000 \mathrm{ft}^{2}$ drainage area for 4 fractures. As can be seen, hydraulic fracture permeability has a minor impact on production performance for hydraulically fractured reservoirs.

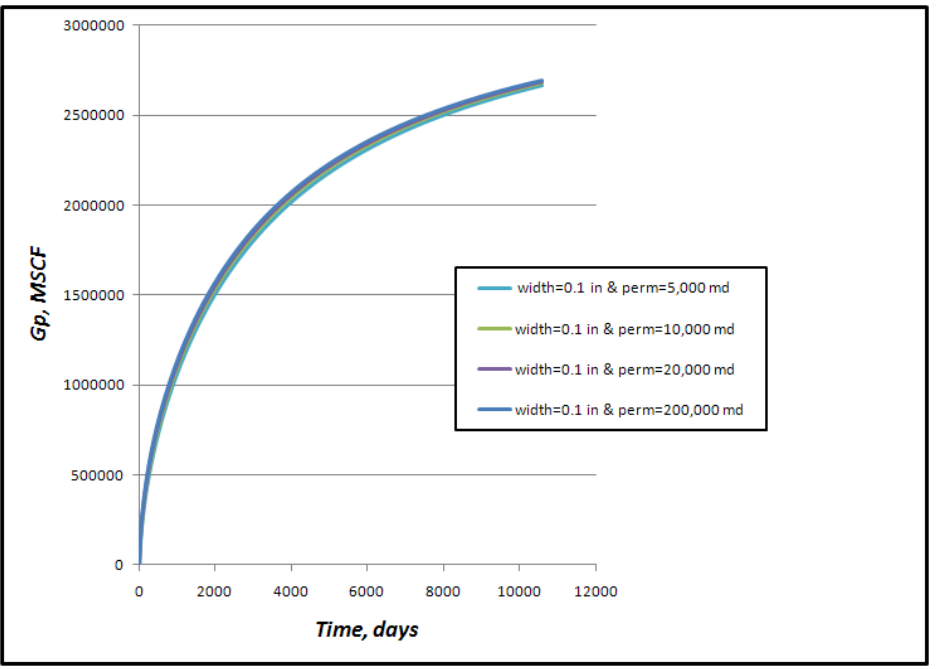

Figure 4-21: Hydraulic fracture permeability 
Table 8 shows the results for parameters studied in this section.

Table 8: Objective 2 results

\begin{tabular}{|c|c|}
\hline Parameter studied & Results \\
\hline $\begin{array}{l}\text { Number of hydraulic } \\
\text { fractures }\end{array}$ & $\begin{array}{l}\text { The early production is significantly impacted by the number of fractures. } \\
\text { However, the long term production indicates a diminishing improvement in } \\
\text { production as the numbers of fractures are increased. }\end{array}$ \\
\hline Hydraulic fracture spacing & The wider more uniform spacing provides much greater production. \\
\hline $\begin{array}{l}\text { Hydraulic fracture } \\
\text { distribution }\end{array}$ & $\begin{array}{l}\text { It is not the number of fractures, but rather the distribution of the fractures } \\
\text { that enhances the production. }\end{array}$ \\
\hline $\begin{array}{l}\text { Contributions of the } \\
\text { horizontal well and } \\
\text { hydraulic fracture }\end{array}$ & $\begin{array}{l}\text { The contribution of the hydraulic fractures to production is significantly } \\
\text { higher than the horizontal well. }\end{array}$ \\
\hline Gas Desorption & $\begin{array}{l}\text { The impact of desorption was found to be negligible during early stages of } \\
\text { production however the impact of desorption at the latter times is } \\
\text { substantial. }\end{array}$ \\
\hline $\begin{array}{l}\text { Hydraulic fractures } \\
\text { properties }\end{array}$ & $\begin{array}{l}\text { Fracture half-length has a significant impact on production performance. } \\
\text { Hydraulic fracture permeability has a minor impact on production } \\
\text { performance. }\end{array}$ \\
\hline
\end{tabular}




\subsection{Objective 3}

In this section, the impact of the formation and natural fracture characteristics on the production performance of the horizontal wells in low permeability formations were investigated. The parameters studied included natural fracture porosity, natural fracture permeability, interporosity flow coefficient, and storativity coefficient.

\subsubsection{Natural fracture porosity}

Natural fracture porosity variations range from $0.2-1 \%$. As can be seen, natural fracture porosity has a minor impact on the cumulative production in the first 10 years as shown in Figure 4-22.

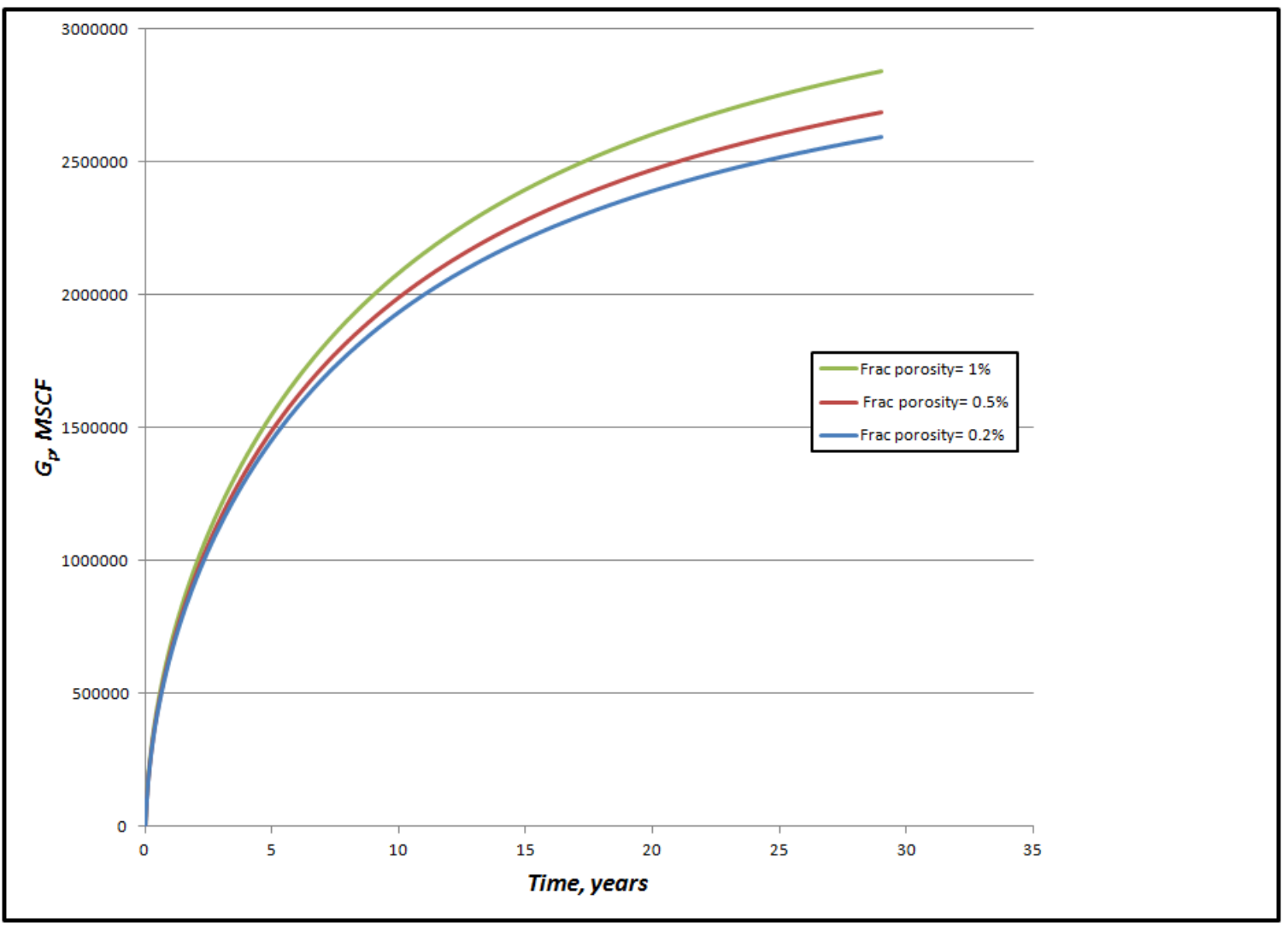

Figure 4-22: Natural fracture porosity 
In addition, the impact of storativity coefficient, $\omega$, in the cumulative production profile is shown in Figure 4-23. Omega, $\omega$, is mainly controlled by natural fracture porosity, $\varphi_{\mathrm{f}}$. Figure 4-23 indicates that the cumulative production profile from 3000 feet horizontal well in a $4000 \times 1000 \mathrm{ft}^{2}$ drainage area is not impacted by storativity coefficient, $\omega$.

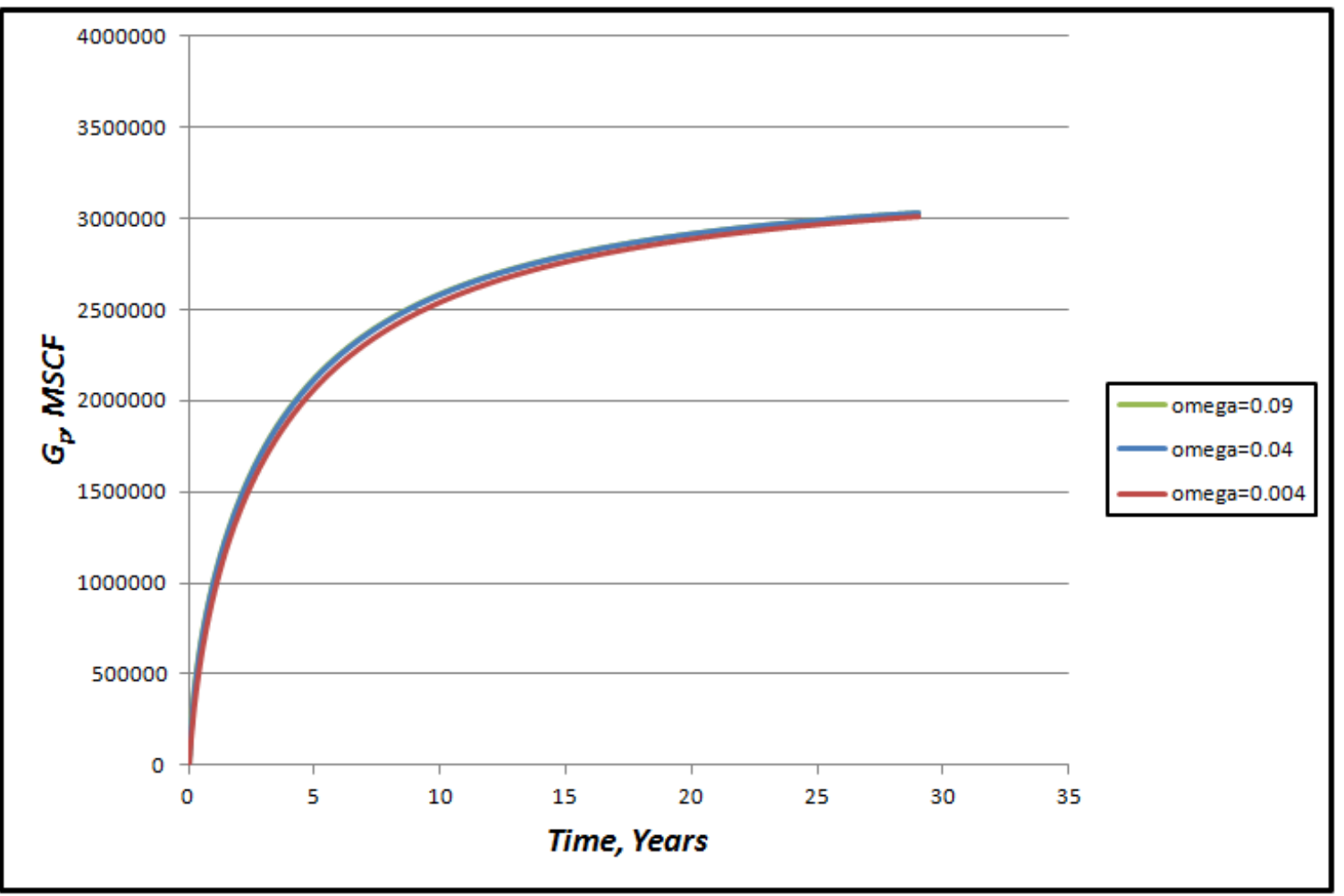

Figure 4-23: Storativity coefficient 


\subsubsection{Natural fracture permeability}

Natural fracture permeability is varied from $0.02-0.1 \mathrm{md}$ in a 3000 feet horizontal well in a $4000 \times 1000 \mathrm{ft}^{2}$ drainage area with 4 fractures. As can be seen, natural fracture permeability has a major impact on the cumulative production profile as shown in Figure 4-24.

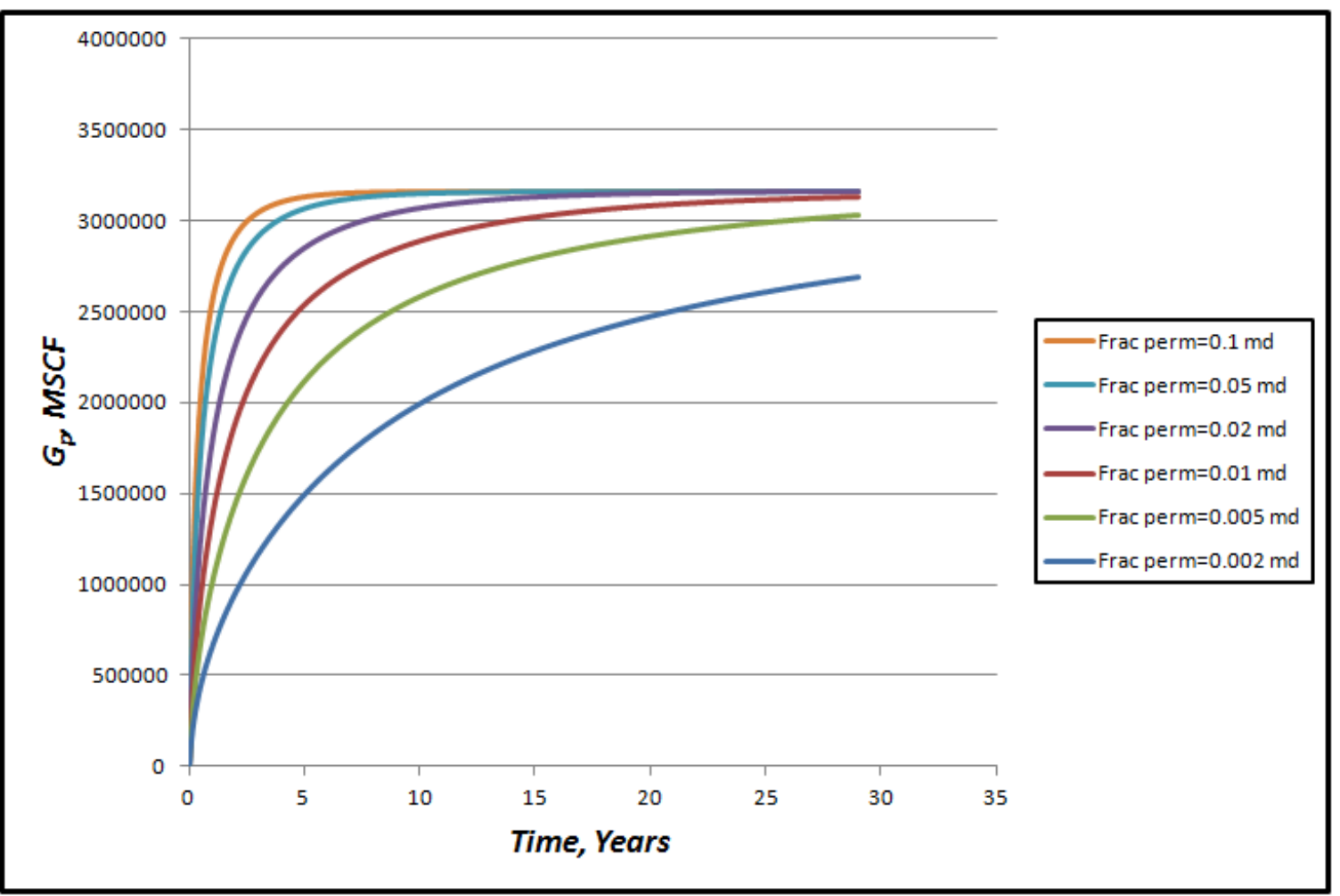

Figure 4-24: Natural fracture permeability 
In addition, the impact of interporosity flow coefficient, $\lambda$, on the cumulative production profile is shown in Figure 4-25. Interporosity flow coefficient, $\lambda$, is mainly controlled by natural fracture permeability, $k_{f}$ (see Equation 2). Figure 4-25 indicates that cumulative production profile is highly impacted by interporosity flow coefficient, $\lambda$.

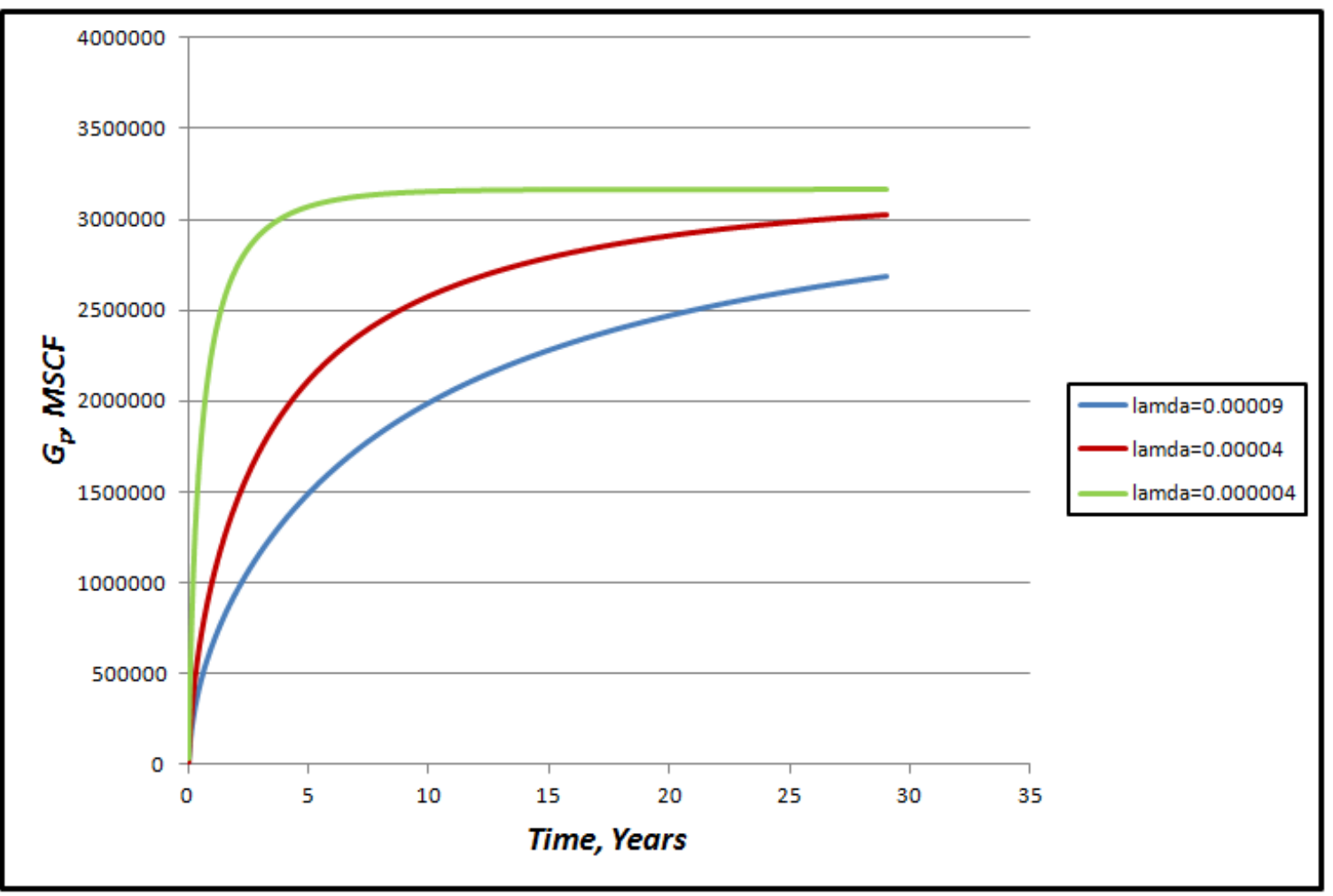

Figure 4-25: Interporosity flow coefficient 


\subsubsection{Natural fracture permeability and number of hydraulic fractures}

The relationship between natural fracture permeability and number of stages is studied. Figure 4-26 shows typical natural fracture permeability $\left(k_{f}=0.002 \mathrm{md}\right)$ such as shale with 3000 feet horizontal well in a $4000 \times 1000 \mathrm{ft}^{2}$ drainage area with 4 fractures, 7 fractures, and 13 fractures. However, Figure 4-27 shows high natural fracture permeability $\left(k_{f}=0.1\right.$ md) with a 3000 feet horizontal well in a $4000 \times 1000 \mathrm{ft}^{2}$ drainage area with 4 fractures, 7 fractures, and 13 fractures. As a result, the number of hydraulic fractures can be reduced when natural fracture permeability is high as indicated in Figures 4-26 and 4-27 respectively.

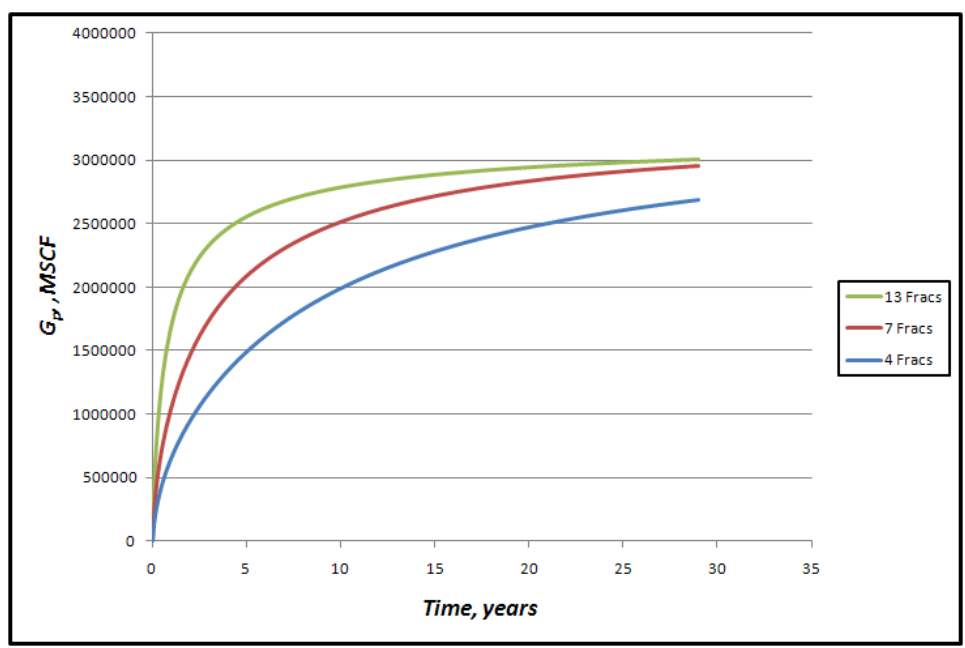

Figure 4-26: $4000 \times 1000 \mathrm{ft}^{2}\left(\mathrm{k}_{\mathrm{f}}=0.002 \mathrm{md}\right)$

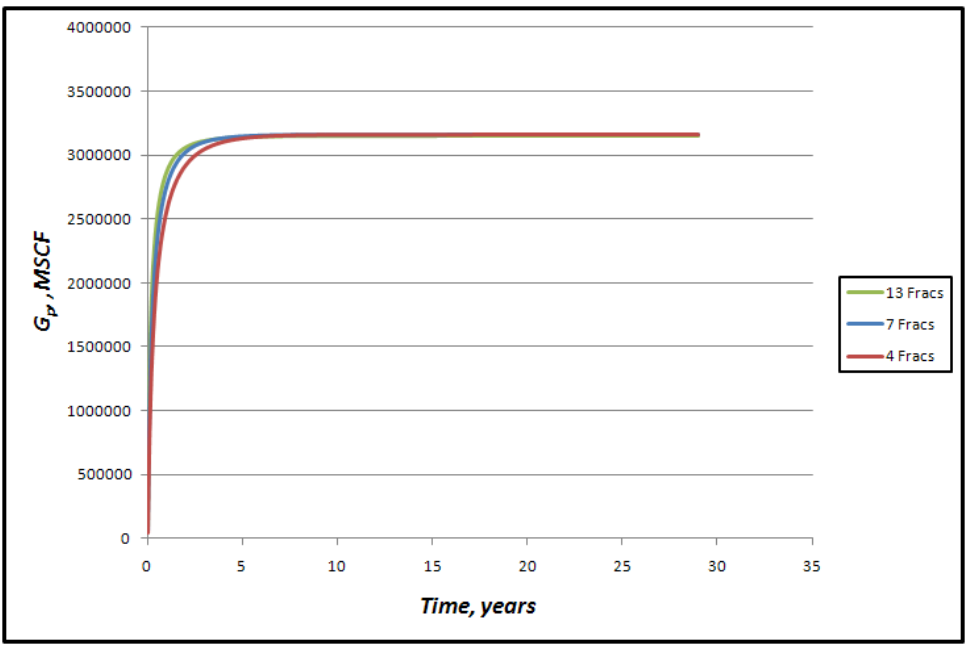

Figure 4-27: $4000 \times 1000 \mathrm{ft}^{2}\left(\mathrm{k}_{\mathrm{f}}=0.1 \mathrm{md}\right)$ 


\subsubsection{Fracture spacing}

Figure 4-28 compares the natural fracture spacing $(\sigma)$. As noted, the production profile is not impacted by $\sigma$.

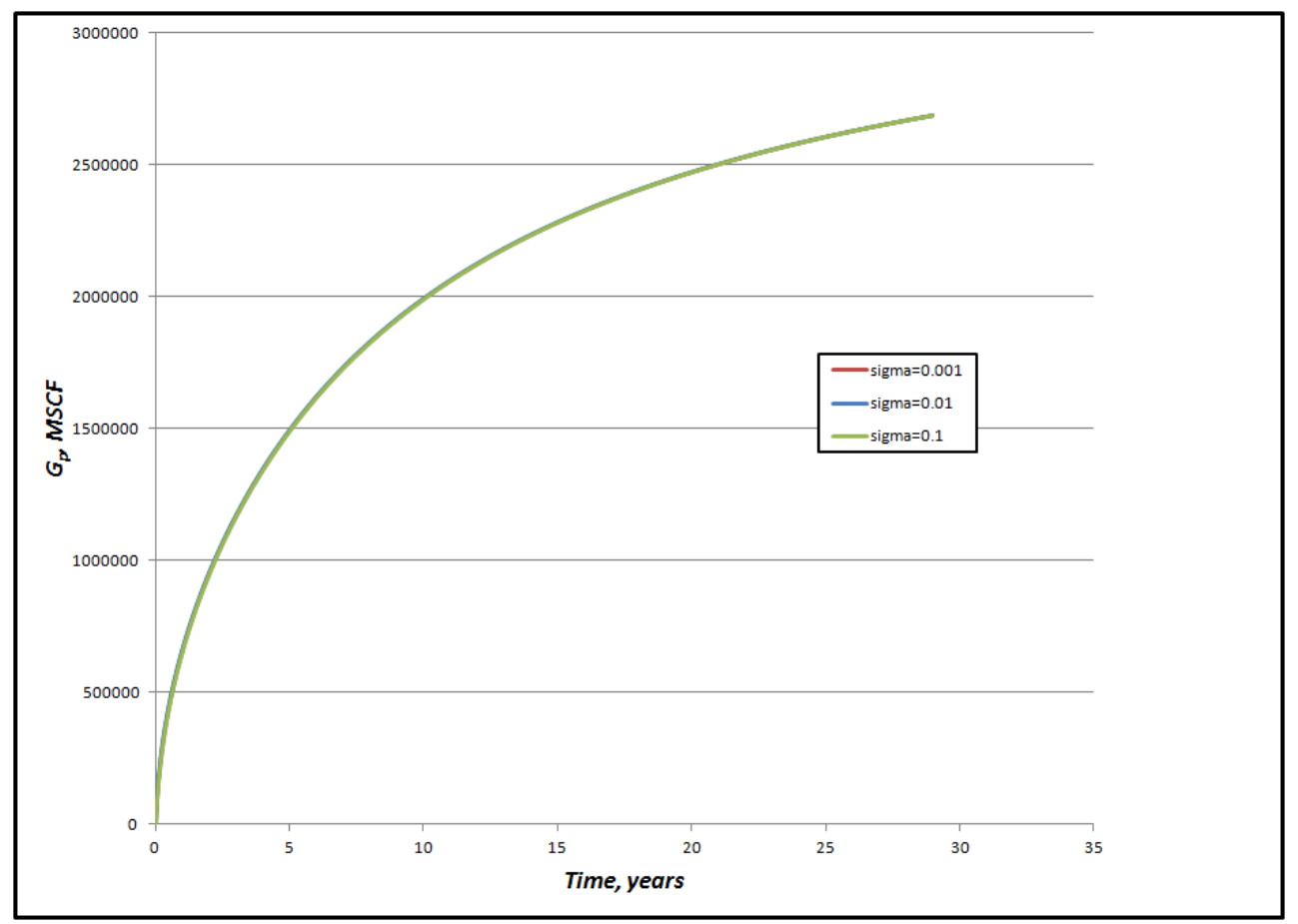

Figure 4-28: Sigma

Table 9 shows the results for parameters studied in this section.

Table 9: Objective 3 results

\begin{tabular}{|c|l|}
\hline Parameter studied & \multicolumn{1}{|c|}{ Results } \\
\hline Natural fracture porosity & $\begin{array}{l}\text { Natural fracture porosity has a minor impact on the cumulative production in } \\
\text { the first } 10 \text { years. }\end{array}$ \\
\hline \hline Natural fracture permeability & $\begin{array}{l}\text { Natural fracture permeability has a major impact on the cumulative } \\
\text { production. }\end{array}$ \\
\hline \hline $\begin{array}{c}\text { Natural fracture permeability and } \\
\text { number of hydraulic fractures }\end{array}$ & $\begin{array}{l}\text { The number of stages can be reduced when natural fracture permeability is } \\
\text { high. }\end{array}$ \\
\hline \hline Fracture spacing & The production profile is not impacted by natural fracture spacing. \\
\hline
\end{tabular}




\subsection{Objective 4}

In this section, to achieve a better understanding of the production behavior, diagnostic plots were prepared to investigate the various flow regimes. For diagnostic plots, we utilized inverse of flow rate $(1 / q)$ and its derivative versus time on log-log scale.

\subsubsection{Flow regimes in horizontal wells with hydraulic fractures in dual porosity systems}

Figure 4-29 to 4-33 show various examples to illustrate the results. Figure 4-29 to 4-32 are diagnostic plots for 3000 feet of horizontal lateral with 1, 4, 7, and 13 hydraulic fractures in a $4000 \times 1000 \mathrm{ft}^{2}$ drainage area. Figure 4-29 to 4-32 show similar flow regimes. They include the dual porosity effect, which is believed to be primarily within the fracture plane. Due to the high conductivity of the fracture, this flow has similar characteristics as the wellbore storage. This flow is followed by a linear flow and duration depends on the drainage geometry. As a result, the linear flow for cases with one fracture appears somewhat longer than the case for 4 or 7 fractures. The flow regime appears to be masked in the case of 13 fractures by the boundary effects (both vertical and lateral). Lastly, the production is impacted by the boundaries. As it can be seen for the case with 1 fracture in Figure 4-29, the boundary effects are barely visible while in Figure 4-32 they are very dominant and appear to indicate pseudo-steady state behavior. 


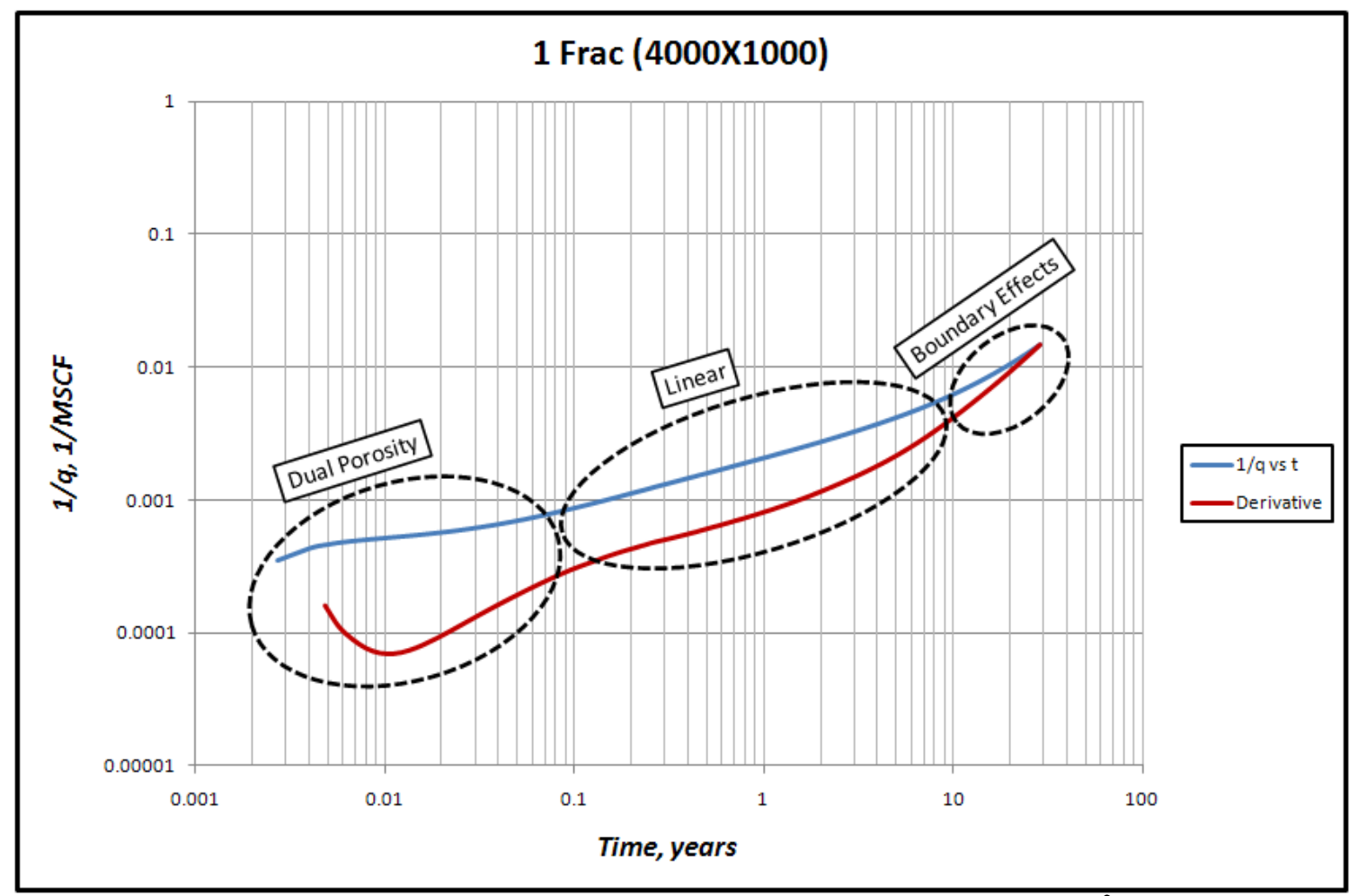

Figure 4-29: Diagnostic plot showing various flow periods $\left(4000 \times 1000 \mathrm{ft}^{2}-1\right.$ Frac $)$

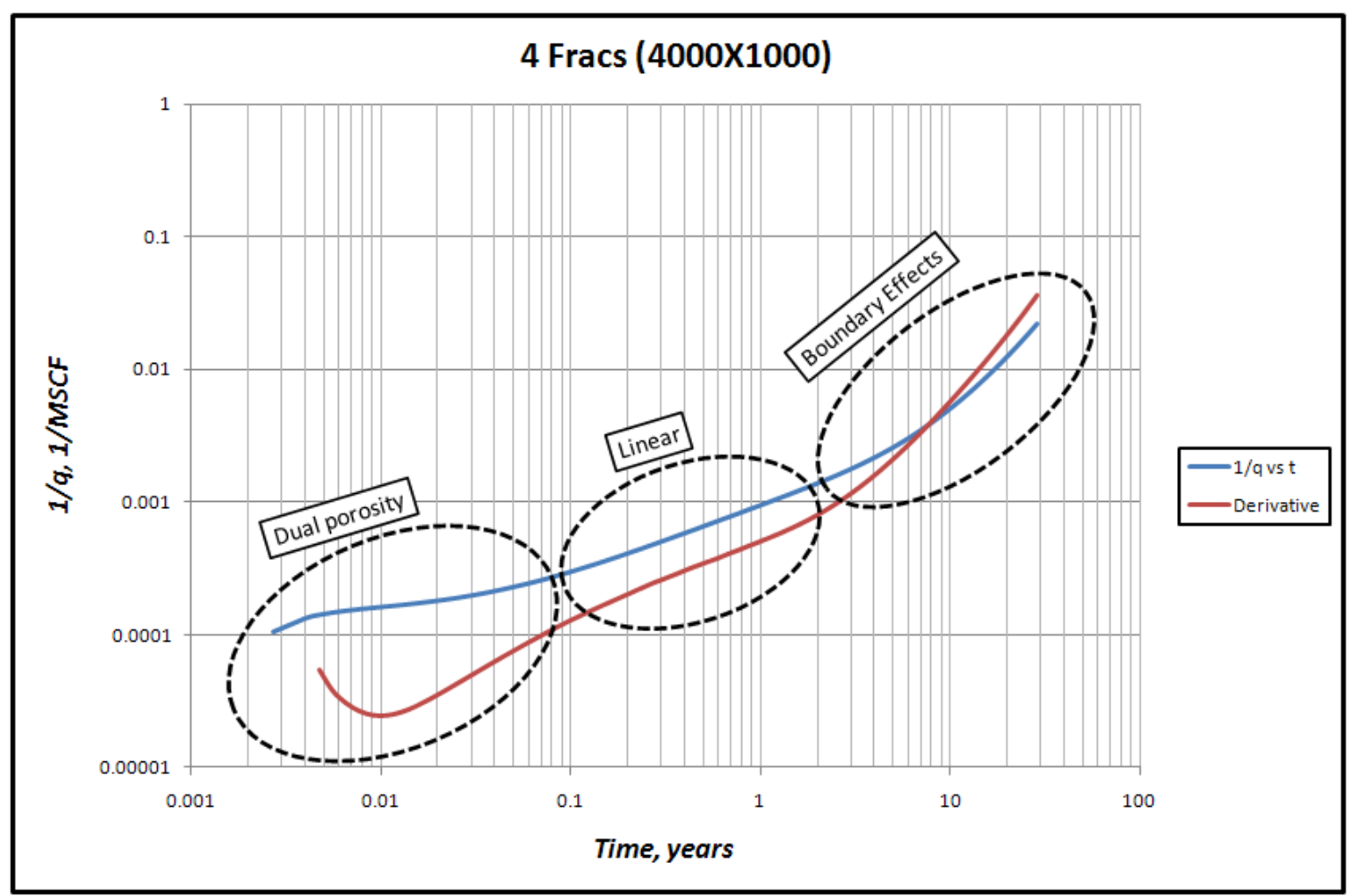

Figure 4-30: Diagnostic plot showing various flow periods $\left(4000 \times 1000 \mathrm{ft}^{2}-4 \mathrm{Fracs}\right)$ 


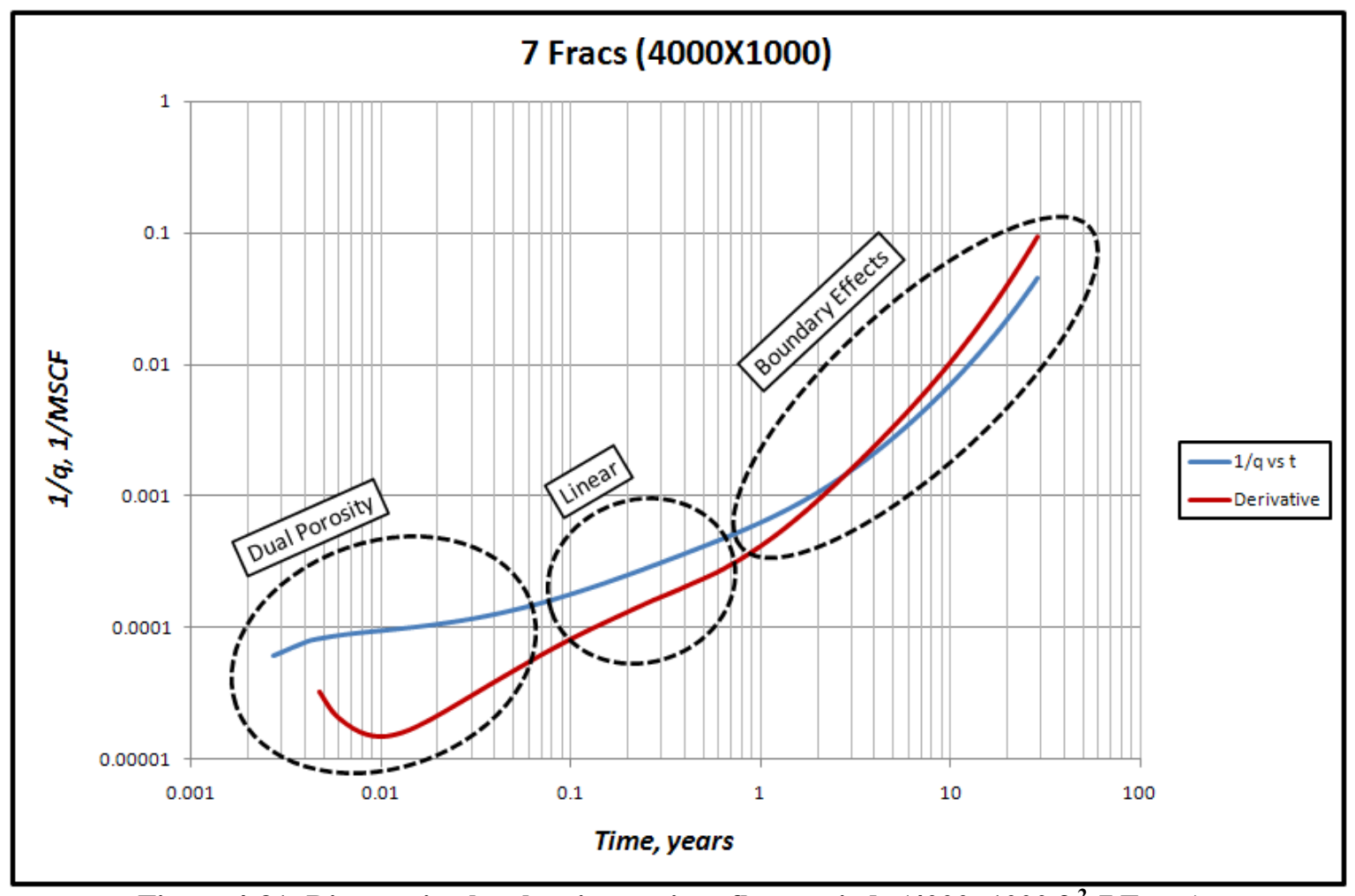

Figure 4-31: Diagnostic plot showing various flow periods $\left(4000 \times 1000 \mathrm{ft}^{2}-7\right.$ Fraps)

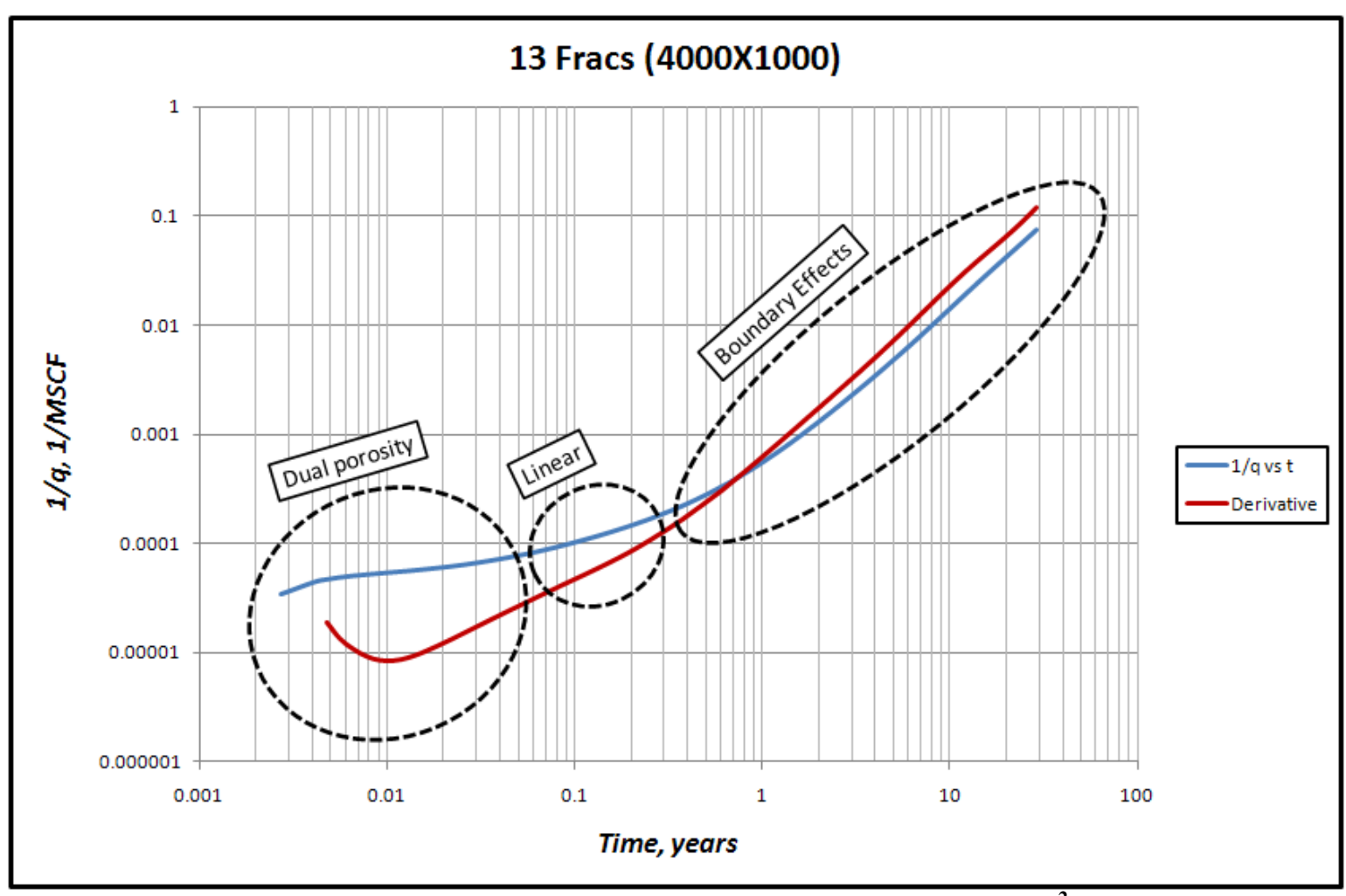

Figure 4-32: Diagnostic plot showing various flow periods $\left(4000 \times 1000 \mathrm{ft}^{2}-13\right.$ Fracs $)$

66 
Figure 4-33 illustrates the diagnostic plot for a 3000 feet horizontal lateral with 4 hydraulic fractures in a $4000 \times 2000 \mathrm{ft}^{2}$ drainage area. The plot tends to indicate two separate linear flow periods. The first linear flow is from a region between the fractures while the second one is most likely from beyond the tip of the fracture and could be considered as a tri-linear flow.

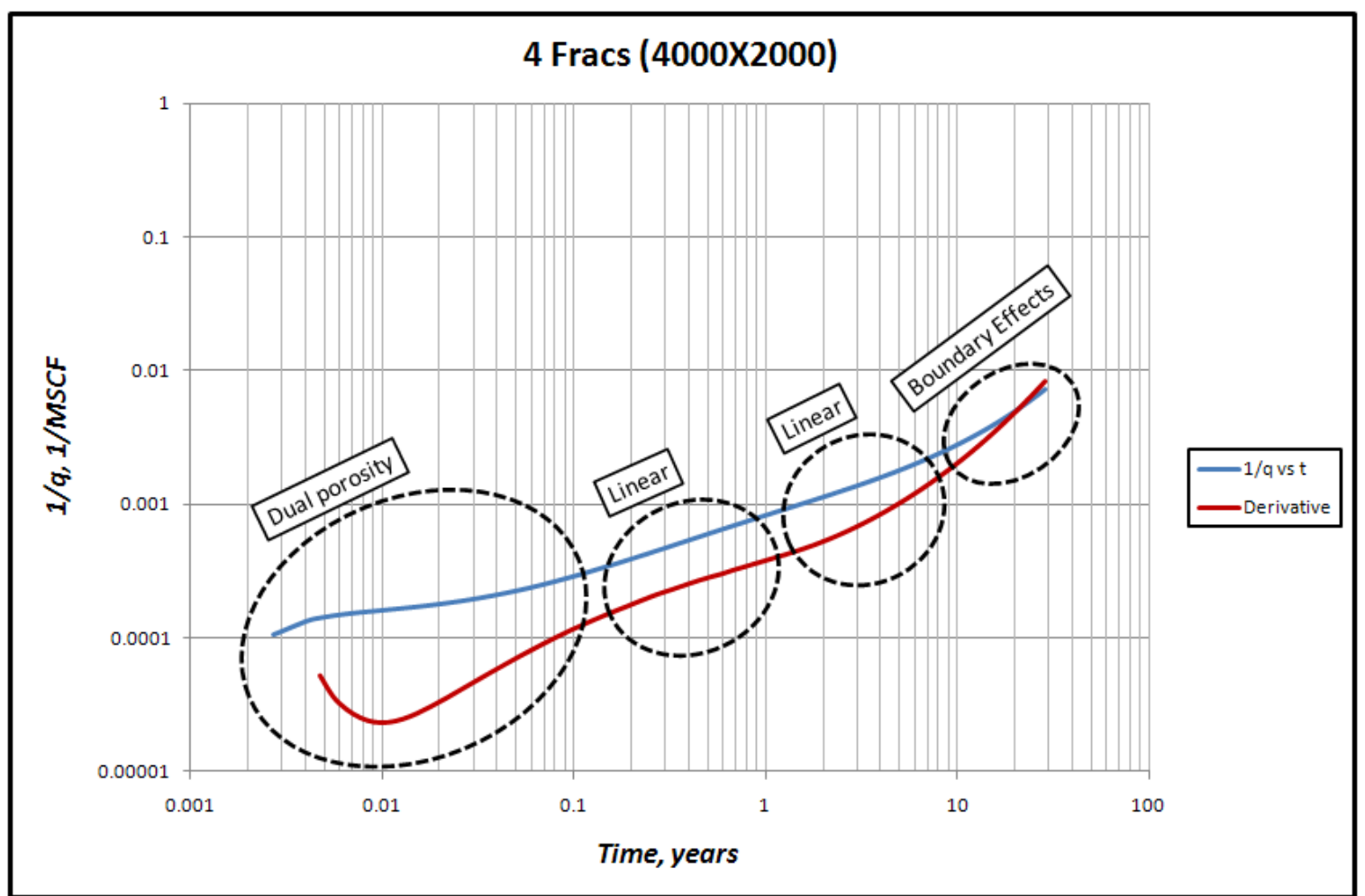

Figure 4-33: Diagnostic plot showing various flow periods $\left(4000 \times 2000 \mathrm{ft}^{2}-4\right.$ Fracs $)$

\subsubsection{Flow regimes verification using decline curves analysis (DCA)}

Decline curves analysis was performed to confirm the indicated flow regimes in the previous section. A case for 3000 feet of horizontal lateral with 7 fractures in a $4000 \times 1000 \mathrm{ft}^{2}$ drainage area is studied in this section. Linear flow period was indicated to be approximately 0.2 to 2 years in the inverse of flow rate $(1 / q)$ and its derivative (Figure 4-31). In addition, DCA clearly verifies the results by showing almost 2 years of linear flow regime for the same time period as shown in Figure 4-34. 


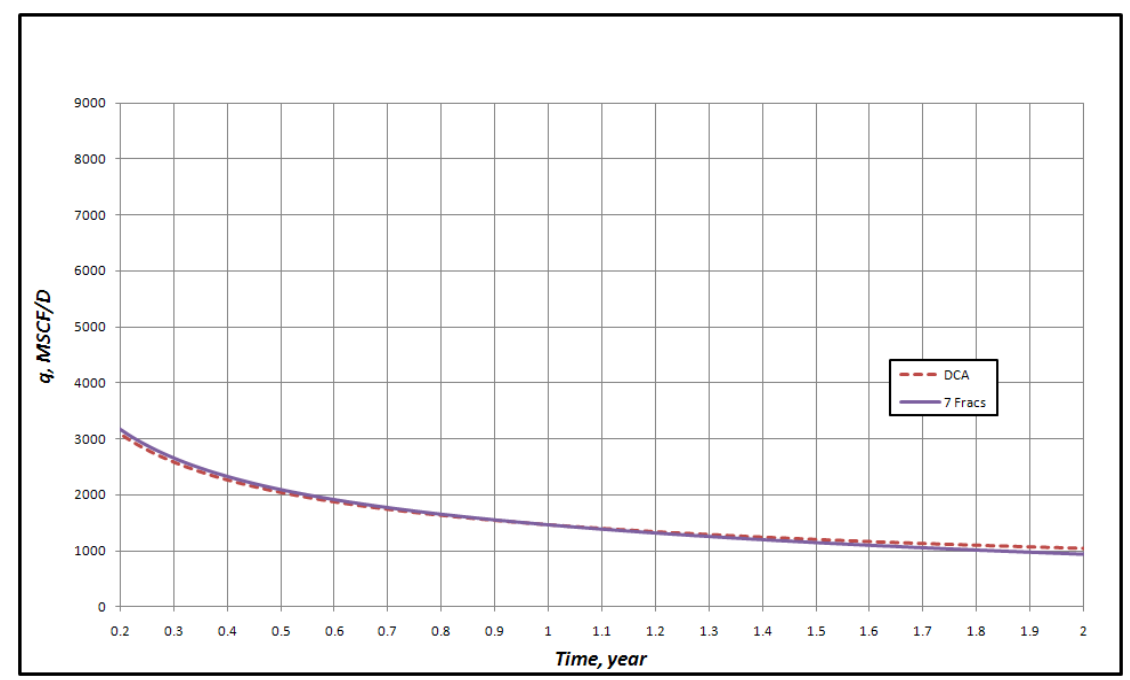

Figure 4-34: DCA $\left(4000 \times 1000 \mathrm{ft}^{2}-7\right.$ Fracs $)$

Table 10 shows DCA after matching the results $\left(b\right.$, and $\left.D_{i}\right)$ parameters of cases for 3000 feet of horizontal lateral with 7 fractures in $4000 \times 1000$ and $4000 \times 2000 \mathrm{ft}^{2}$ drainage areas. As indicated, $b=2$ for first two years of the production which is the indication of early linear flow followed by a harmonic decline $(b=1)$ during depletion period for different natural fracture permeability in a $4000 \times 1000$ and $4000 \times 2000 \mathrm{ft}^{2}$ drainage areas. In addition, the values of $D_{i}$ were varied from 11 to 14 for the first 2 years and then these values decrease during depletion period.

Table 10: DCA results $4000 \times 1000 \& 4000 \times 1000 \mathrm{ft}^{2}$ (7 Fracs)

\begin{tabular}{|c|c|c|c|c|}
\hline \multicolumn{2}{|c|}{$4000 \times 1000$ (7 Fracs) } & \multirow{2}{*}{\begin{tabular}{||c||}
$0-1.5$ years \\
$D_{i}, \mathbf{b}$ \\
\end{tabular}} & \multirow{2}{*}{\begin{tabular}{|c|}
$1.5-5$ years \\
$D_{i}, \mathbf{b}$ \\
\end{tabular}} & \multirow{2}{*}{\begin{tabular}{||c|}
$5-30$ years \\
$D_{i}, b$ \\
\end{tabular}} \\
\hline Kf (md) & $\mathrm{Km}(\mathrm{md})$ & & & \\
\hline 0.002 & 0.0004 & 14,2 & $3.7,1$ & $3.6,1$ \\
\hline 0.005 & 0.0004 & 12,2 & 5,1 & 9,1 \\
\hline 0.01 & 0.0004 & 12,2 & 6,1 & 15,1 \\
\hline \multicolumn{2}{|c|}{$4000 \times 2000$ (7 Fracs) } & $0-1.5$ years & $1.5-5$ years & $5-30$ years \\
\hline $\mathrm{Kf}(\mathrm{md})$ & $\mathrm{Km}(\mathrm{md})$ & $D_{i}, b$ & $D_{i}, b$ & $D_{i}, b$ \\
\hline 0.002 & 0.0004 & 11,2 & $2.7,1$ & 2,1 \\
\hline 0.005 & 0.0004 & 11,2 & 3,1 & 3,1 \\
\hline 0.01 & 0.0004 & 12,2 & 3,1 & 4,1 \\
\hline
\end{tabular}


A case for 3000 feet of horizontal lateral with 13 fractures in a $4000 \times 1000 \mathrm{ft}^{2}$ drainage area is also studied in this section. Linear flow period was indicated to be approximately 0.1 to 0.35 years in the inverse of flow rate (1/q) and its derivative (Figure 4-32). In addition, DCA clearly verifies the results by showing almost half a year of linear flow regime for the same time period as shown in Figure 4-35.

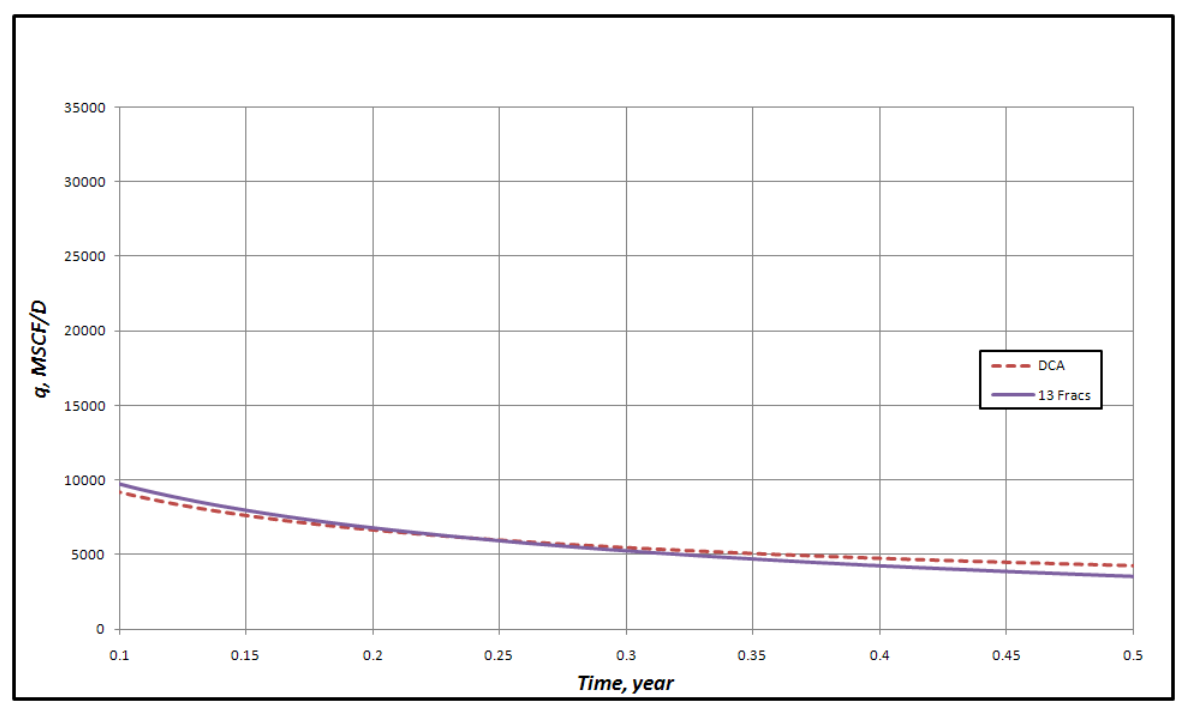

Figure 4-35: DCA $\left(4000 \times 1000 \mathrm{ft}^{2}-13\right.$ Fracs $)$

Table 11 shows DCA after matching the results ( $b$, and $D_{i}$ ) parameters of cases for 3000 feet of horizontal lateral with 13 fractures in $4000 \times 1000 \mathrm{ft}^{2}$ drainage area. As indicated, $b=2$ for the first half year of the production which is the indication of early linear flow followed by a harmonic decline $(b=1)$ during depletion period for different natural fracture permeability in a $4000 \times 1000 \mathrm{ft}^{2}$ drainage area. In addition, the values of $D_{i}$ were varied from 30 to 45 for the first 2 years and then these values decreases during depletion period. The linear flow period becomes significantly shorter for 13 fractures as mentioned in the previous section.

Table 11: DCA results for $4000 \times 1000 \mathrm{ft}^{2}(13$ Fracs $)$

\begin{tabular}{|c|c|c|c|c|}
\hline \multicolumn{2}{|c|}{$4000 \times 1000$ (13 Fracs) } & $0-0.5$ years & $0.5-5$ years & 5-30 years \\
\hline $\mathrm{Kf}(\mathrm{md})$ & $\mathrm{Km}(\mathrm{md})$ & $D_{i}, b$ & $D_{i}, b$ & $D_{i}, b$ \\
\hline 0.002 & 0.0004 & 45,2 & 20,1 & 20,1 \\
\hline 0.005 & 0.0004 & 30,2 & 22,1 & 15,1 \\
\hline 0.01 & 0.0004 & 30,2 & 25,1 & 30,1 \\
\hline
\end{tabular}




\subsubsection{Flow regimes verification using production type curve (PTC)}

Attempts were made to develop production type curves to confirm the indicated flow regimes in the previous section. The production type curves are shown in Figures 4-36 and 4-37 using Equations 23 and 24.

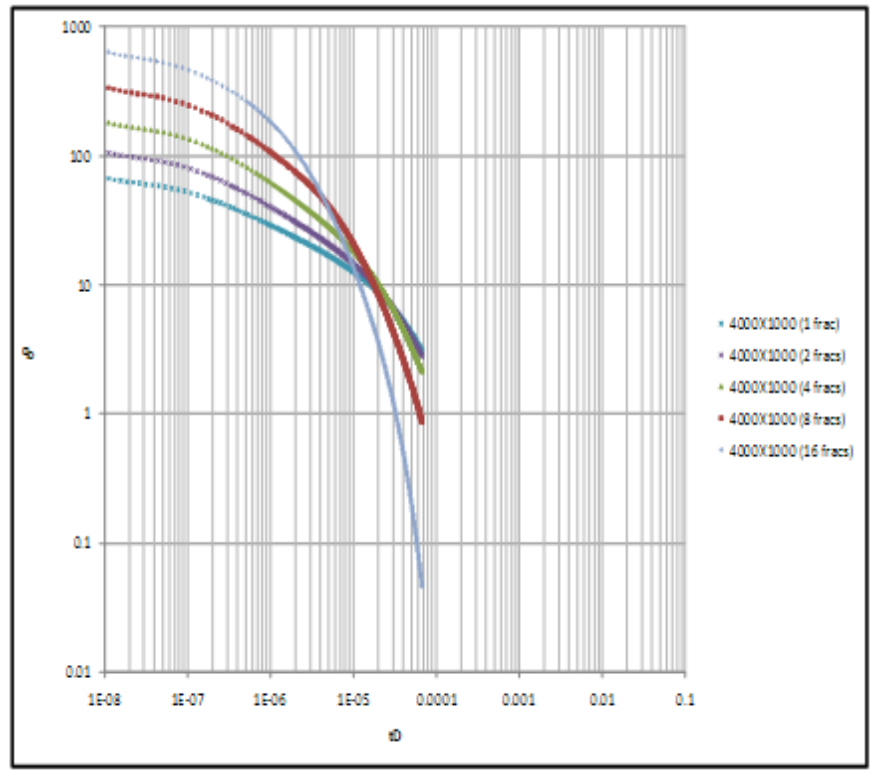

Figure 4-36: $q_{D}$ vs. $t_{D}\left(4000 \times 1000 \mathrm{ft}^{2}\right)$

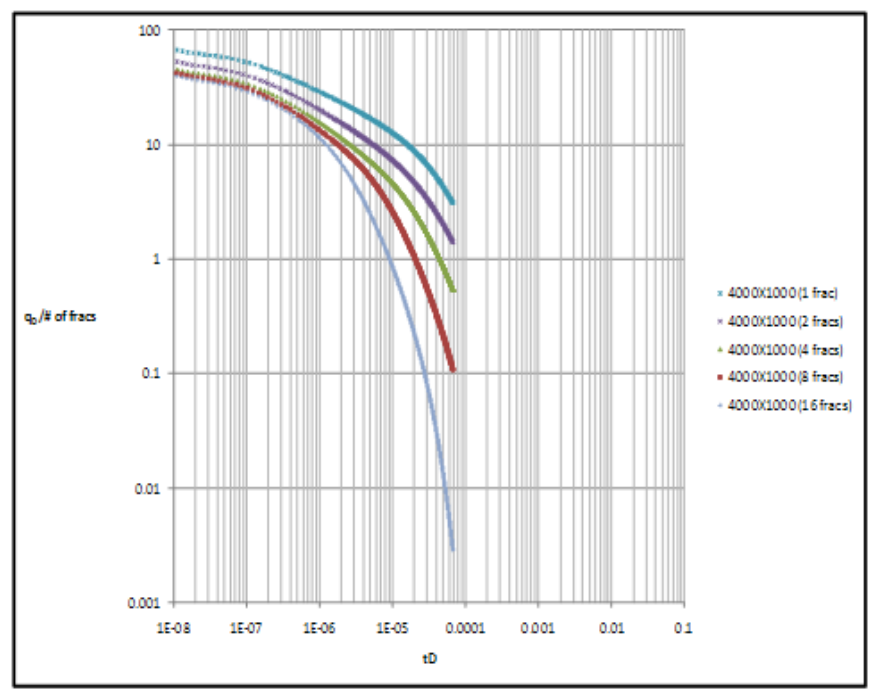

Figure 4-37: $q_{D} / \#$ of fractures vs. $t_{D}\left(4000 \times 1000 \mathrm{ft}^{2}\right)$ 
In addition, the production type curve with a case 3000 feet of horizontal lateral with different fractures in $4000 \times 2000 \mathrm{ft}^{2}$ drainage area are shown in Figures 4-38 and 4-39 using Equations 23 and 24.

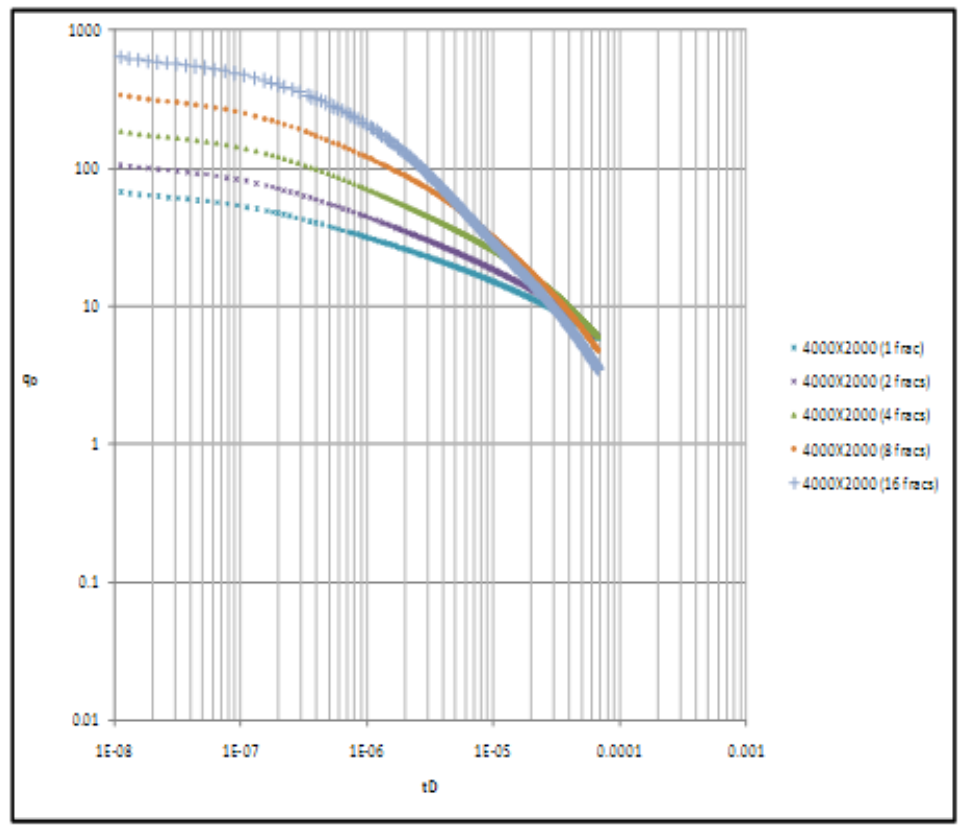

Figure 4-38: $q_{D} v s . t_{D}\left(4000 \times 2000 \mathrm{ft}^{2}\right)$

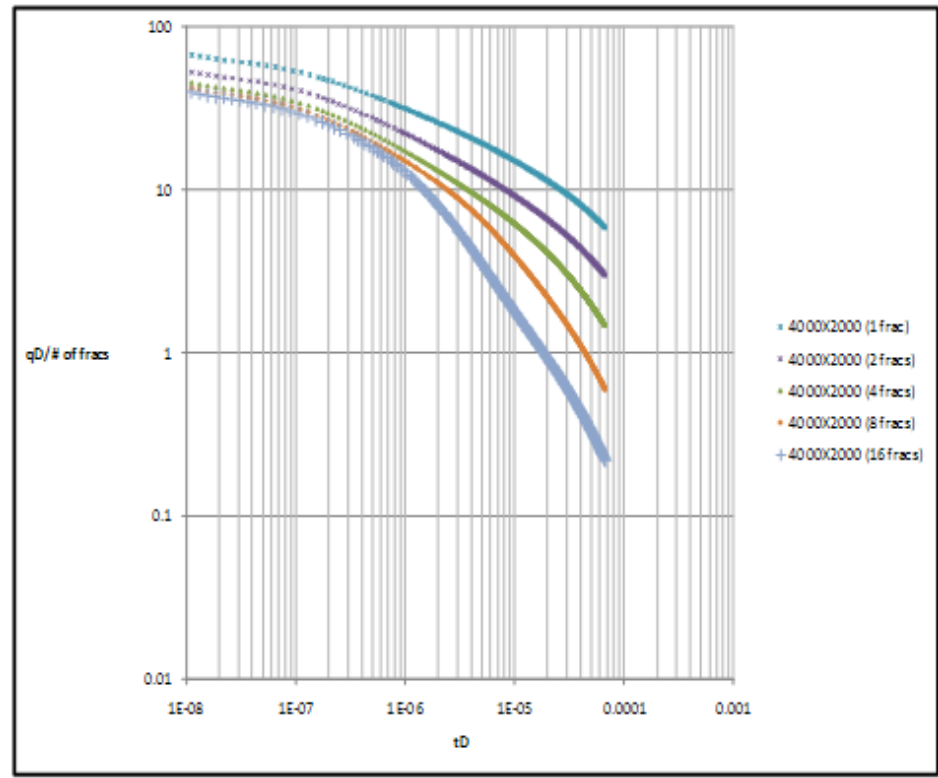

Figure 4-39: $q_{D} / \#$ of fractures vs. $t_{D}\left(4000 \times 2000 \mathrm{ft}^{2}\right)$ 
Another method for production type curve (Equations $14 \& 15$ ) were also used for a case with 3000 feet of horizontal lateral with different fractures in a $4000 \times 1000 \mathrm{ft}^{2}$ drainage area shown in Figure 4-40.

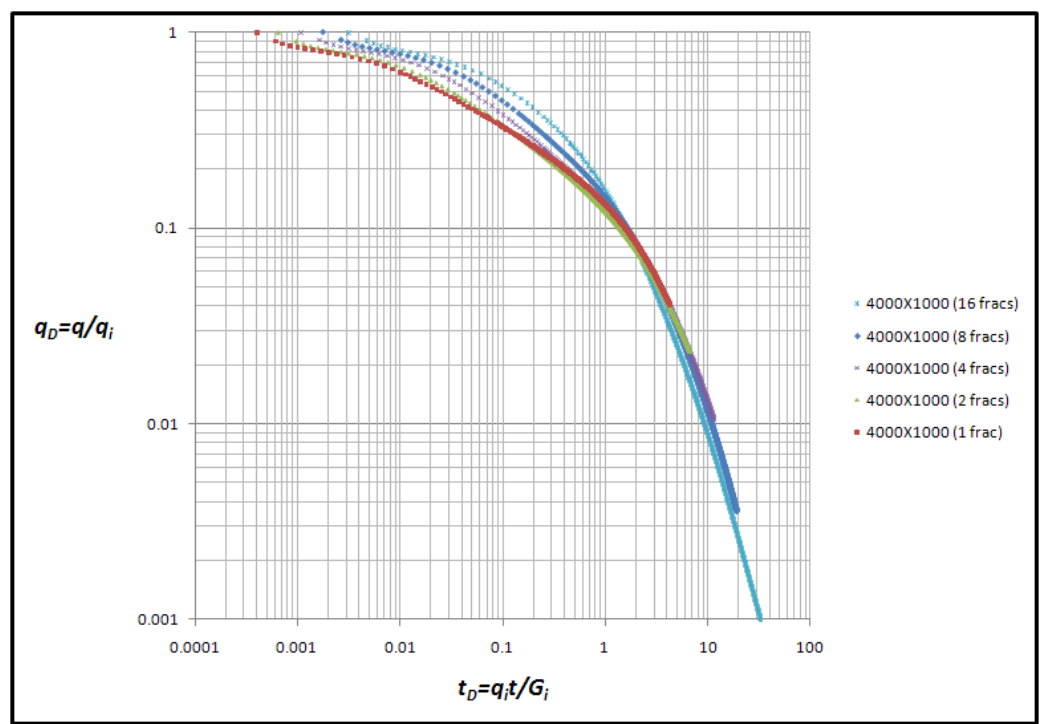

Figure 4-40: $q_{D}$ vs. $t_{D}\left(4000 \times 1000 \mathrm{ft}^{2}\right)$

Again, another method for production type curve (Equations $14 \& 15$ ) is used for a case with 3000 feet of horizontal lateral with different fractures in a $4000 \times 2000 \mathrm{ft}^{2}$ drainage area shown in Figure 4-41.

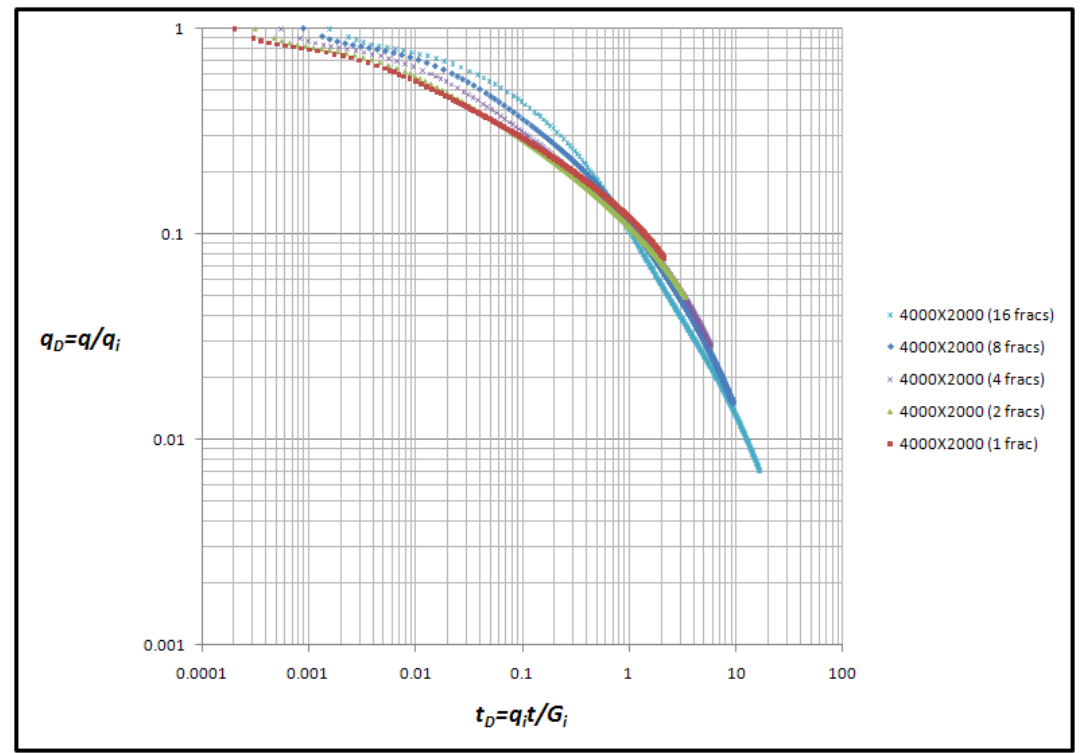

Figure 4-41: $q_{D}$ vs. $t_{D}\left(4000 \times 2000 \mathrm{ft}^{2}\right)$ 
As a result, PTC also indicates early linear flow regime for the same time period in a $4000 \times 1000$ and $4000 \times 2000 \mathrm{ft}^{2}$ drainage areas in $7 \& 13$ fractures respectively as shown in Figures 4-42 and 4-43.

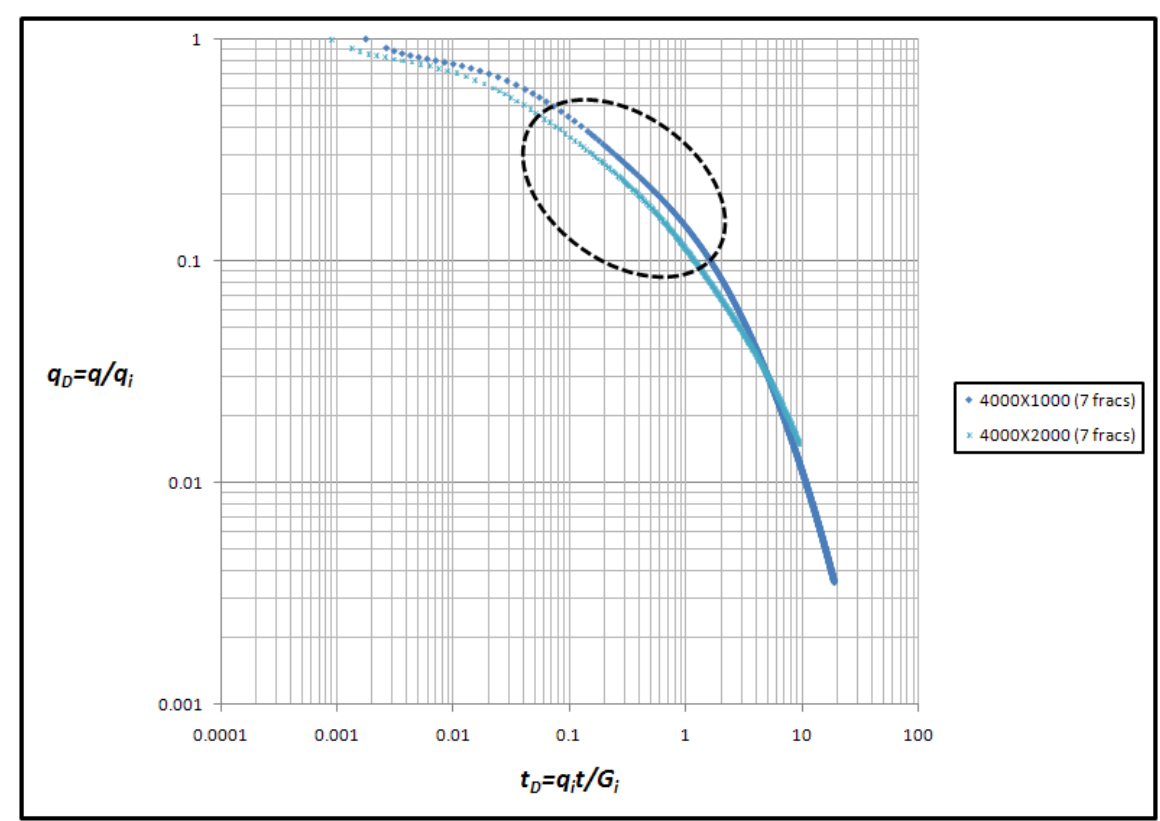

Figure 4-42: $q_{D} v s . t_{D}$ for $4000 \times 1000 \& 4000 \times 2000 \mathrm{ft}^{2}(7$ Fracs $)$

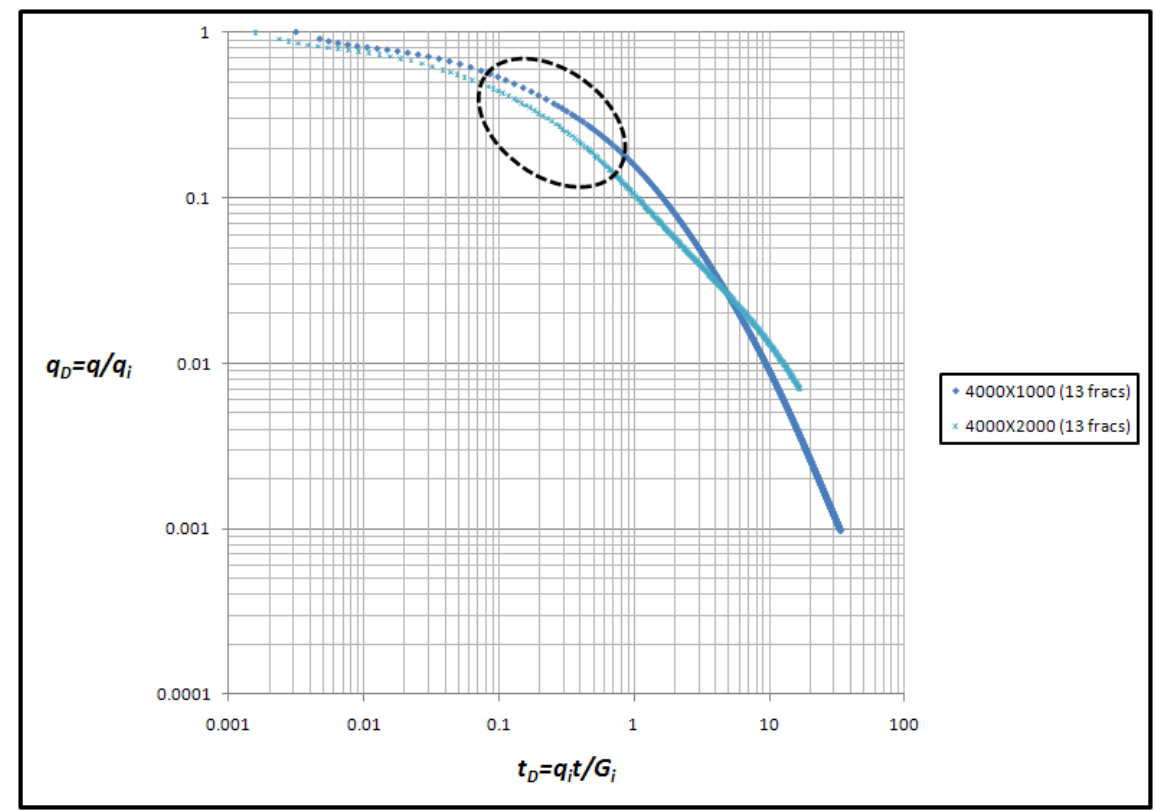

Figure 4-43: $q_{D} v s . t_{D}$ for $4000 \times 1000 \& 4000 \times 2000 \mathrm{ft}^{2}(13$ Fracs $)$ 
As a summary, inverse of flow rate $(1 / q)$ and its derivative along with the decline curve analysis and production type curve have indicated the same linear flow for the same time period in a $4000 \times 1000$ and $4000 \times 2000 \mathrm{ft}^{2}$ drainage areas. Table 12 shows the results for parameters studied in this section.

Table 12: Objective 4 results

\begin{tabular}{|c|l|}
\hline Parameter studied & \multicolumn{1}{|c|}{ Results } \\
\hline Study of the flow regimes & $\begin{array}{l}\text { Two separate flow regimes are observed: the linear flow and } \\
\text { the boundary effected flow. A late linear flow or tri-linear flow } \\
\text { was also observed for cases where the drainage area is } \\
\text { extended beyond the vicinity of the hydraulic fractures. }\end{array}$ \\
\hline \hline $\begin{array}{c}\text { Flow regimes verification } \\
\text { using decline curves } \\
\text { analysis (DCA) }\end{array}$ & Decline curve analysis confirmed the indicated flow regimes. \\
\hline \hline $\begin{array}{c}\text { Flow regime verification } \\
\text { using production type } \\
\text { curve (PTC) }\end{array}$ & $\begin{array}{l}\text { Attempts to develop production type curves showed promising } \\
\text { results however no unique one set of type curves can be found } \\
\text { for hydraulically fractured horizontal wells. }\end{array}$ \\
\hline
\end{tabular}




\section{CONCLUSIONS}

The purpose of this dissertation was to predict and analyze the production performance of horizontal wells with multiple hydraulic fractures in ultra-low permeability formations such as Marcellus shale. As a summary, the following conclusions were obtained:

1. Production is primarily controlled by hydraulic fractures.

2. The early production is significantly impacted by the number of hydraulic fractures.

3. The long term production indicates a diminishing improvement with number of hydraulic fractures.

4. The spacing and the location of the fractures have more significant impact on production than the number of hydraulic fractures.

5. The impact of desorption was found to be negligible during the early stage of production (first 5 years). However the effects on production are substantial at the latter stage.

6. Natural fracture permeability has a significant impact on production however matrix permeability effect is insignificant.

7. Fewer hydraulic fractures are necessary when natural fracture permeability is high.

8. Interporosity flow coefficient, $\lambda$, has a significant impact on production however Storativity coefficient, $\omega$, effect is insignificant.

9. Two separate flow regimes are observed: the linear flow and the boundary effected flow.

10. A late linear flow or tri-linear flow was also observed for cases where the drainage area is extended beyond the vicinity of the hydraulic fractures.

11. Decline curve analysis confirmed the presence of the early linear flow followed by a harmonic decline during depletion period.

12. Decline curve analysis confirmed that the linear flow period becomes significantly shorter as the number of hydraulic fractures increase.

13. Attempts to develop production type curves showed promising results however no unique one set of type curves can be found for hydraulically fractured horizontal wells. 


\section{REFERENCES}

Aminian, K., \& Ameri, S. (1989). Predicting horizontal well production performance using type curves. SPE 19342 .

Aminian, K., Ameri, S., \& Beg, N. (1987). Predicting gas well performance under altered conditions. SPE 17060 .

Aminian, K., Ameri, S., \& Hyman, M. (1986). Production decline type curves for gas wells producing under pseudo-steady conditions. SPE 15933.

Arps, J. J. (1945). Analysis of decline curves. Tran, AIME , 228-247.

Alenezi, F., Aminian, K., Ameri, S., \& Bilgesu, I. (2011). Development of type curves for gas production from hydraulically fractured horizontal wells in unconventional reservoirs. Morgantown, WV.

Belyadi, A., Aminian, K., \& Ameri, S. (2010). Performance of the hydraulically fractured horizontal wells in low permeability formation. SPE 139082 .

Barenblatt, Zheltov, \& Kochina. (1960). Basic concepts in the theory of seepage of homogeneous liquids in fissure rocks (Strata). PMM , 1286-1303.

Bello, R., \& Wattenbarger, R. (2010). Multi-stage hydraulically fractured shale gas rate transient analysis. SPE $126754,1-17$.

Bilgesu, \& Schweitzer. (2009). The role of economics on well and fracture design completions of marcellus shale wells. SPE 125975 , 1-6.

Brown, Ozkan, Raghavan, \& Kazemi. (2009). Practical solutions for pressure transient responses of fractured horizontal wells in unconventional reservoirs. SPE 125043 , 1-18.

Cheng. (2010). Impacts of the number of perforation clusters and cluster spacing on production performance of horizontal shale gas wells. SPE 138843 , 1-10.

Cipolla, Lolon, Erdle, \& Tathed. (2009). Modeling well performance in shale-gas reservoirs. SPE $125532,1-16$.

CMG (2010). Computer modeling group.

Ertekin, T., Abou-Kassem, J. H., \& King, G. R. (2001). Basic applied reservoir simulation. Richardson, Texas.

Fetkovich, M. (1980). Decline curve analysis using type curves. SPE 4629. 
Gringarten, A. (1978). Interpretation of tests in fissured and multilayered reservoirs with double-porosity behavior: Theory and practice. SPE , 549-564.

Hill, D. G., \& Nelson, C. R. (2000). Gas productive fractured shales: An Overview and update. Exploration \& Production, 1-10.

Lee, J., \& Wattenbarger, R. (1996). Gas Reservoir Engineering.

Lewis, A. M. (2008). Production data analysis of shale reservoirs. Louisiana State University.

Lu, J., Zhu, T., \& Tiab, D. (2009). Pressure behavoir of horizontal wells in dual-porosity, dual-permeability naturally fractured reservoirs. SPE 120103 , 1-23.

Ming, Fan, \& Lancaster. (1993). Measurement of shale matrix and fracture properties in naturally fractured cores using pulse testing. 8,2,31-45.

Moghadam, S., Mattar, L., \& Pooladi-Darvish, M. (2010). Dual porosity type curves for shale gas reservoirs. SPE 137535.

Nobakht, Mattar, Moghadam, \& Anderson. (2010). Simplified yet rigorous forecasting of tight/shale gas production in linear flow. SPE $133615,1-14$.

Osholake, T., Wang, J. Y., \& Ertekin, T. (2011). Factors affecting hydraulically fractured well performance in the Marcellus shale gas reservoirs. SPE 144076 , 1-12.

Ozkan, Brown, Raghavan, \& Kazemi. (2009). Comparison of fractured horizontal-well performance in conventional and unconventional reservoirs. SPE 121290 , 1-16.

Rosa, A., \& R.S., C. (1988). Transient pressure behavior of horizontal wells in naturally fractured reservoirs. SPE18302 .

Schlumberger. (2007). Eclipse BlackOil Reservoir Simulation.

Shahamat, M. S., \& Aguilera, R. (2008). Pressure-transient test design in dual porosity tight gas formation. SPE 115001.

Thompson, R. S., \& Wright, J. D. (1985). Oil Property Evaluation . Golden Colorado.

Warren, \& Root. (1965). Discussion of unsteady-state behavior of naturally fractured reservoirs. SPE , 64-65.

Warren, \& Root. (1962). The behavior of naturally fractured reservoirs. SPE 426. 


\section{APPENDICES}

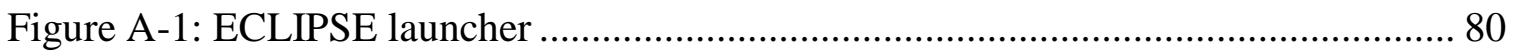

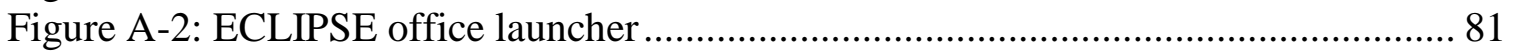

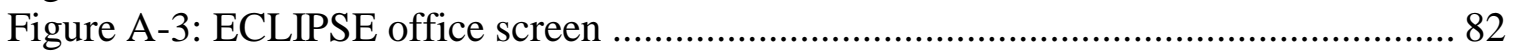

Figure A-4: Add ECLIPSE template screen .......................................................... 83

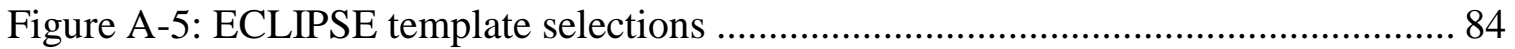

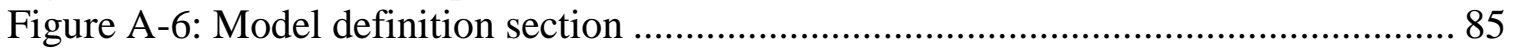

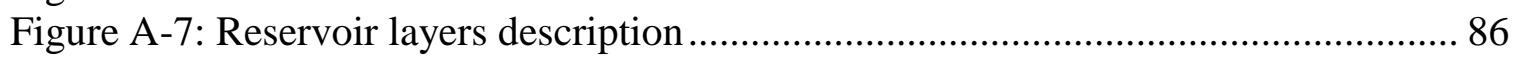

Figure A-8: Reservoir layers description layout .......................................................... 86

Figure A-9: Reservoir description for rock properties................................................. 87

Figure A-10: Reservoir description for non-equilibrium initial conditions ...................... 88

Figure A-11: Reservoir description for fracture …………........................................ 89

Figure A-12: Reservoir description for fracture ………............................................ 90

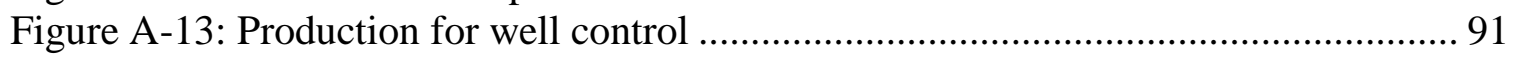

Figure A-14: Production for perforation control ......................................................... 91

Figure A-15: Fluid properties for PVT composition ................................................... 92

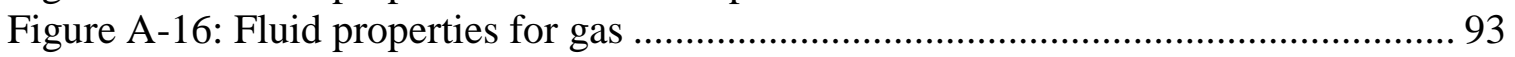

Figure A-17: Fluid properties for water.................................................................... 93

Figure A-18: Fluid properties for coal bed methane section ............................................ 94

Figure A-19: Fluid properties for advanced control ………......................................... 95

Figure A-20: Simulation control for gridding control ................................................... 96

Figure A-21: Simulation control for tubing control.................................................... 97

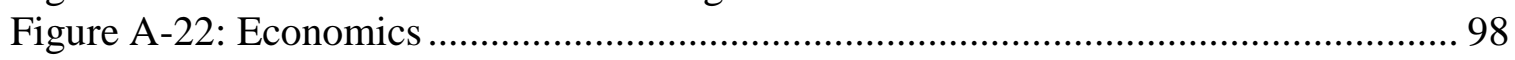

Figure A-23: Data manager module (DMM) ………….......................................... 99

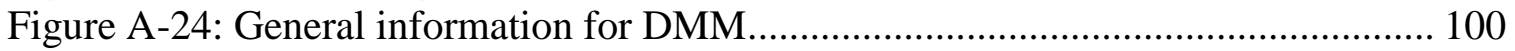

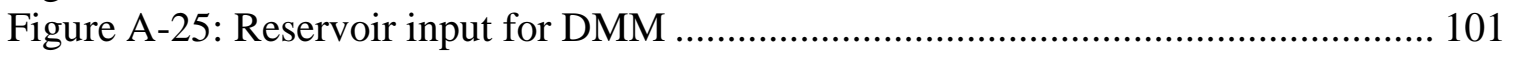

Figure A-26: PVT information for DMM............................................................. 102

Figure A-27: Misc/Sched information for DMM …………........................................ 103

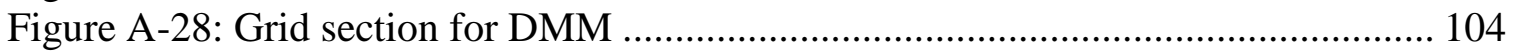

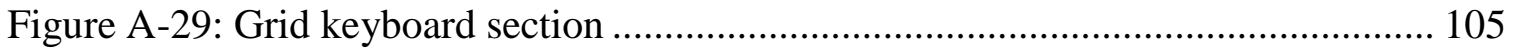

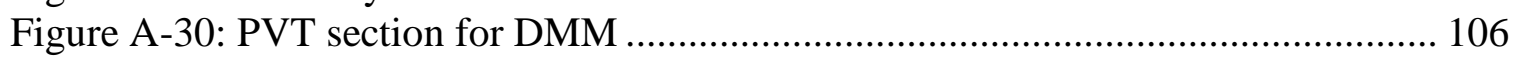

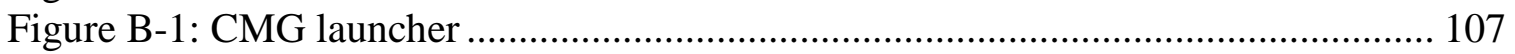

Figure B-2: Reservoir simulation settings ............................................................ 108

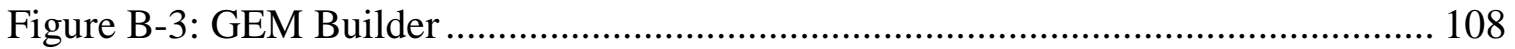

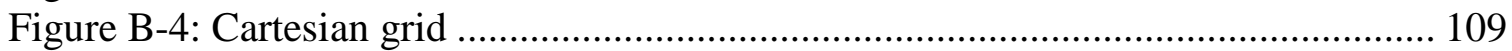

Figure B-5: General property specification ........................................................... 109

Figure B-6: Rock compressibility ................................................................... 110

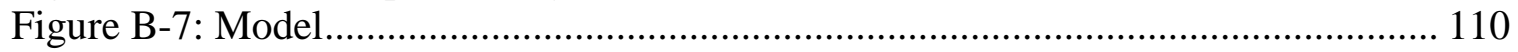

Figure B-8: Component properties ……………………................................... 111

Figure B-9: Relative permeability correlations......................................................... 112

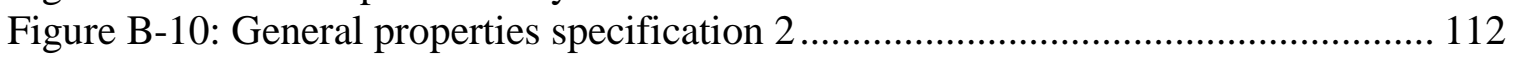

Figure B-11: Initial condition (calculation method) ……........................................... 113

Figure B-12: Initial condition (Init. Region parameters) .............................................. 114

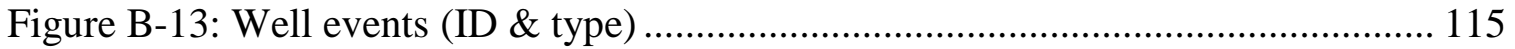

Figure B-14: Well events (constraints) ....................................................................... 116 


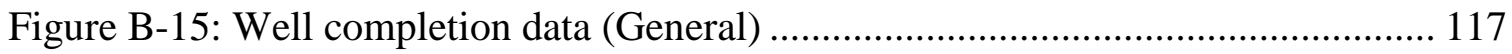

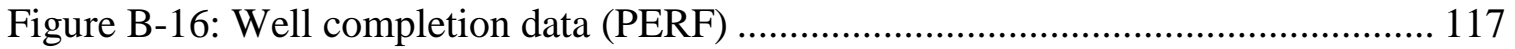

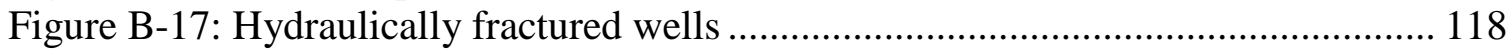

Figure B-18: Hydraulically fracture wells (Non-Darcy option) .................................. 119

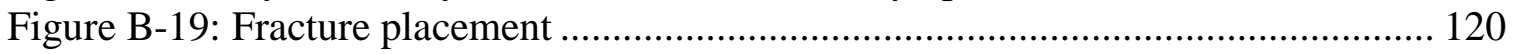

Figure B-20: Numerical ....................................................................................... 121

Figure C-1: 1 Horizontal (4 Fracs) \& 4 Vertical (1 Frac)- $4000 \times 1000 \mathrm{ft}^{2}$................... 122

Figure C-2: $4000 \times 1000 \mathrm{ft}^{2}$ (side view of the model) .............................................. 122

Figure C-3: $4000 \times 1000 \mathrm{ft}^{2}$ (different laterals)- No Fractures .................................... 123

Figure C-4: $4000 \times 1000 \mathrm{ft}^{2}$ (4000 ft lateral)- Different number of Fractures ................ 124

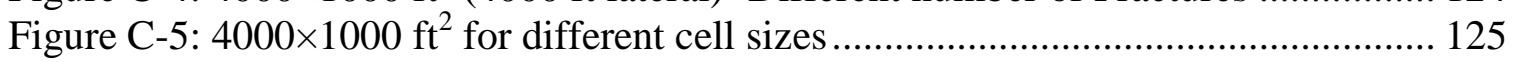




\section{APPENDIX A (ECLIPSE)}

Appendix A shows simple procedure using Schlumberger ECLIPSE software to model horizontal wells completed in shale. A coal bed methane template and Data Manager Module (DMM) were used to model shale in this research. The entire procedure to run the simulator is demonstrated in this section. Figure A-1 shows an Eclipse software launcher screen that was used in this research.

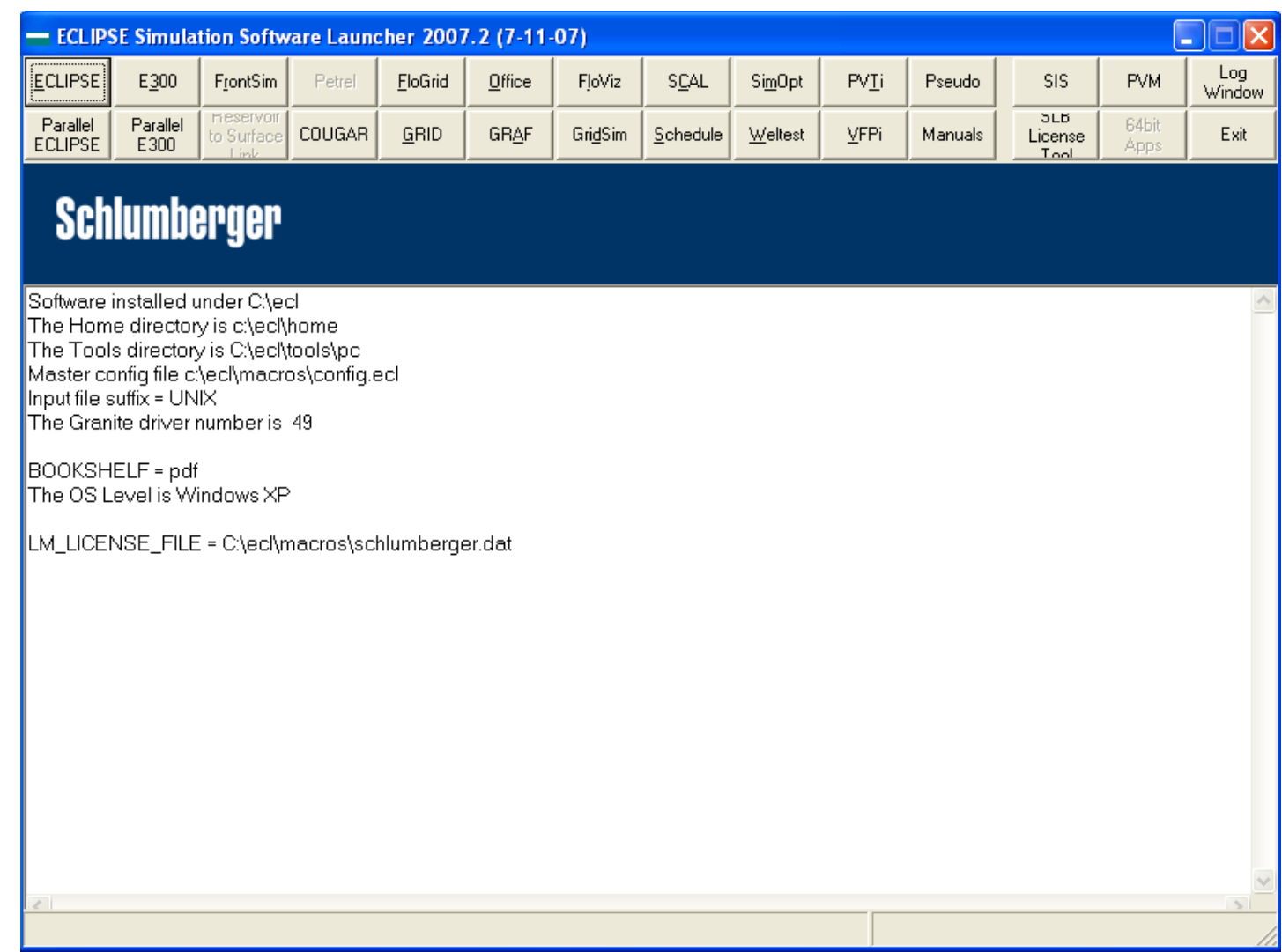

Figure A-1: ECLIPSE launcher 
The user selects ECLIPSE "Office" from the ECLIPSE launcher that is shown in figure A-1. The ECLIPSE office launcher then pops up after clicking on "Office" as shown in Figure A-2.

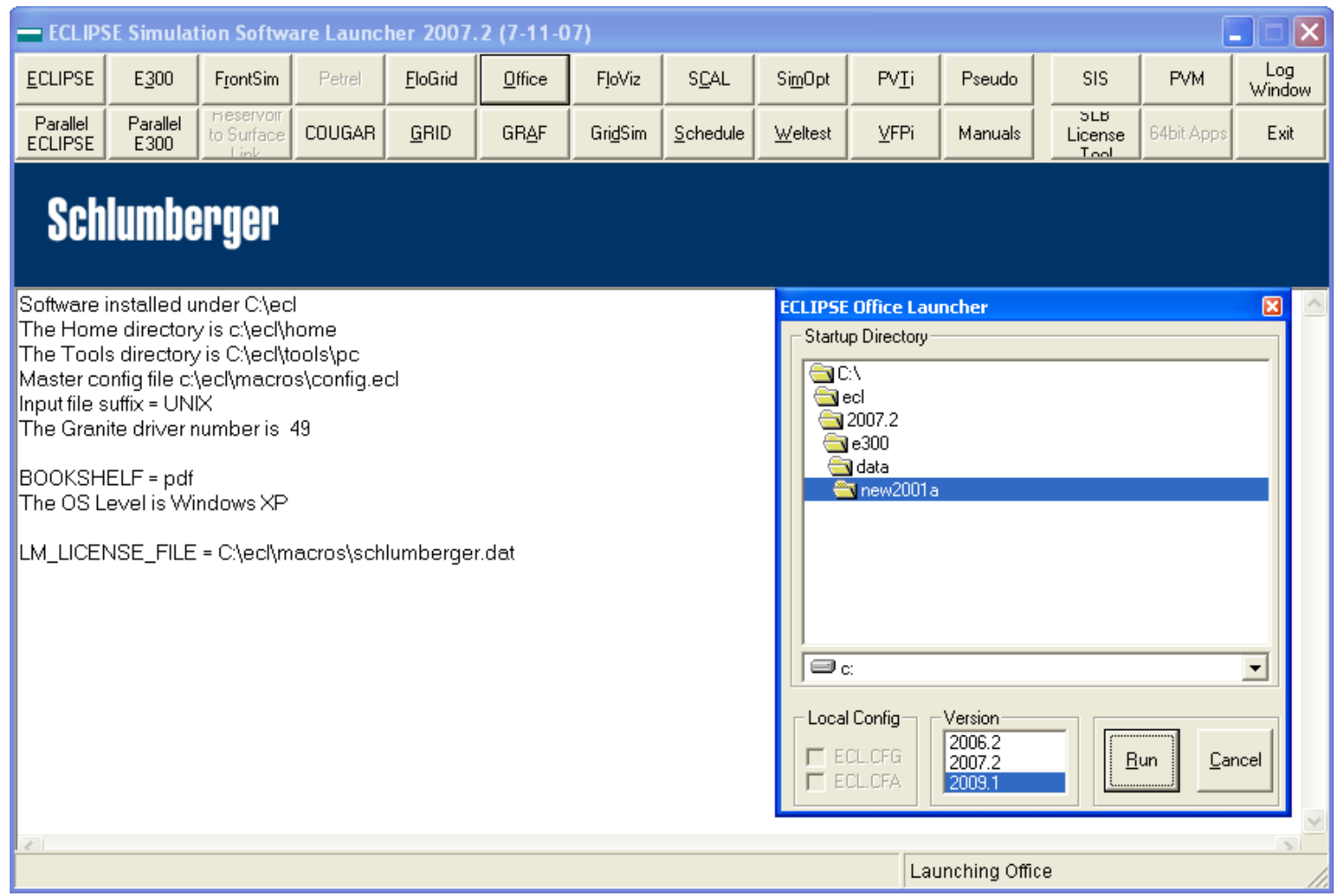

Figure A-2: ECLIPSE office launcher 
The user selects file-new project from the top menu bar as shown in Figure A-3. The user assigns this project the name "shale.off" for example.

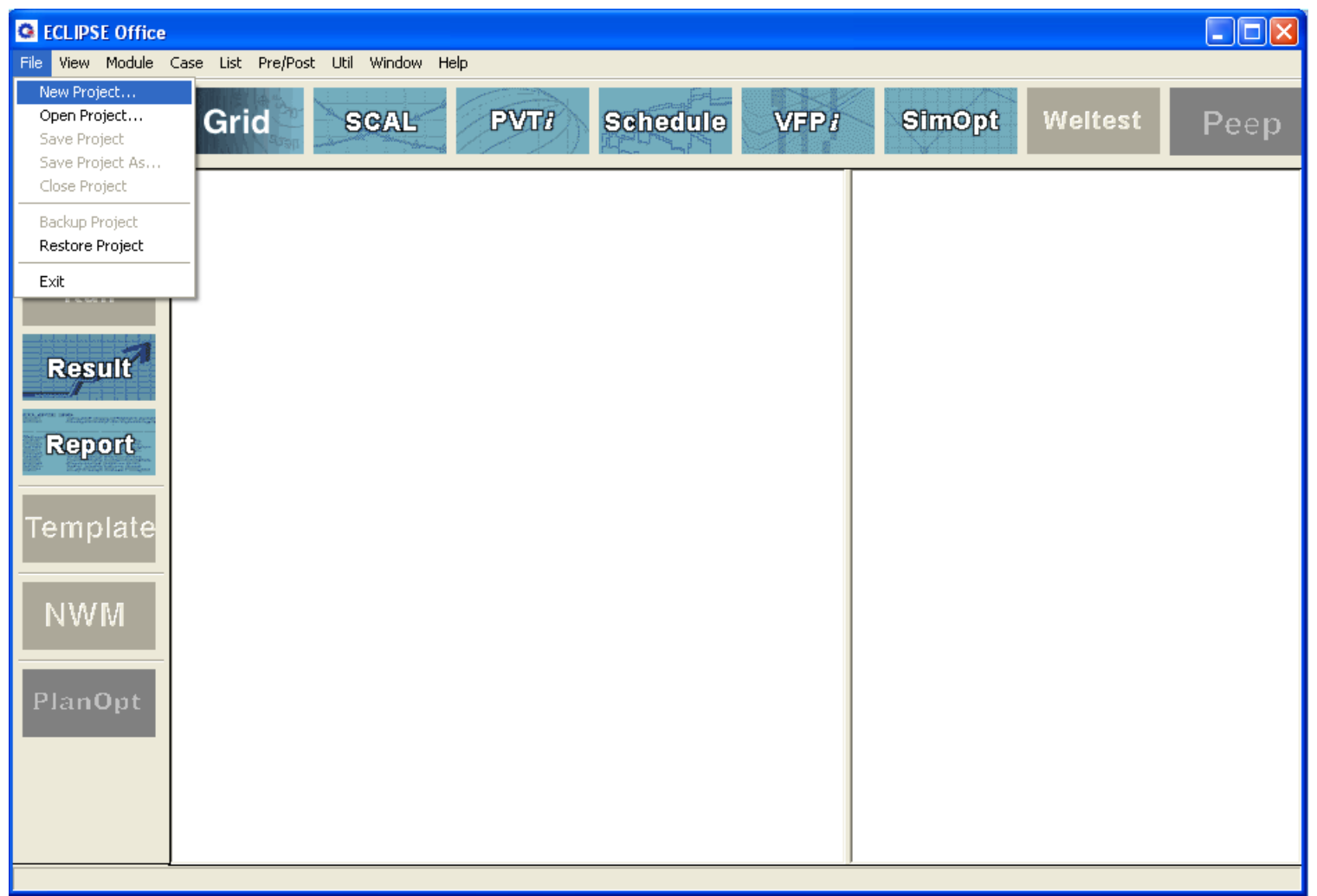

Figure A-3: ECLIPSE office screen 
Then the user selects "add template case" as shown below.

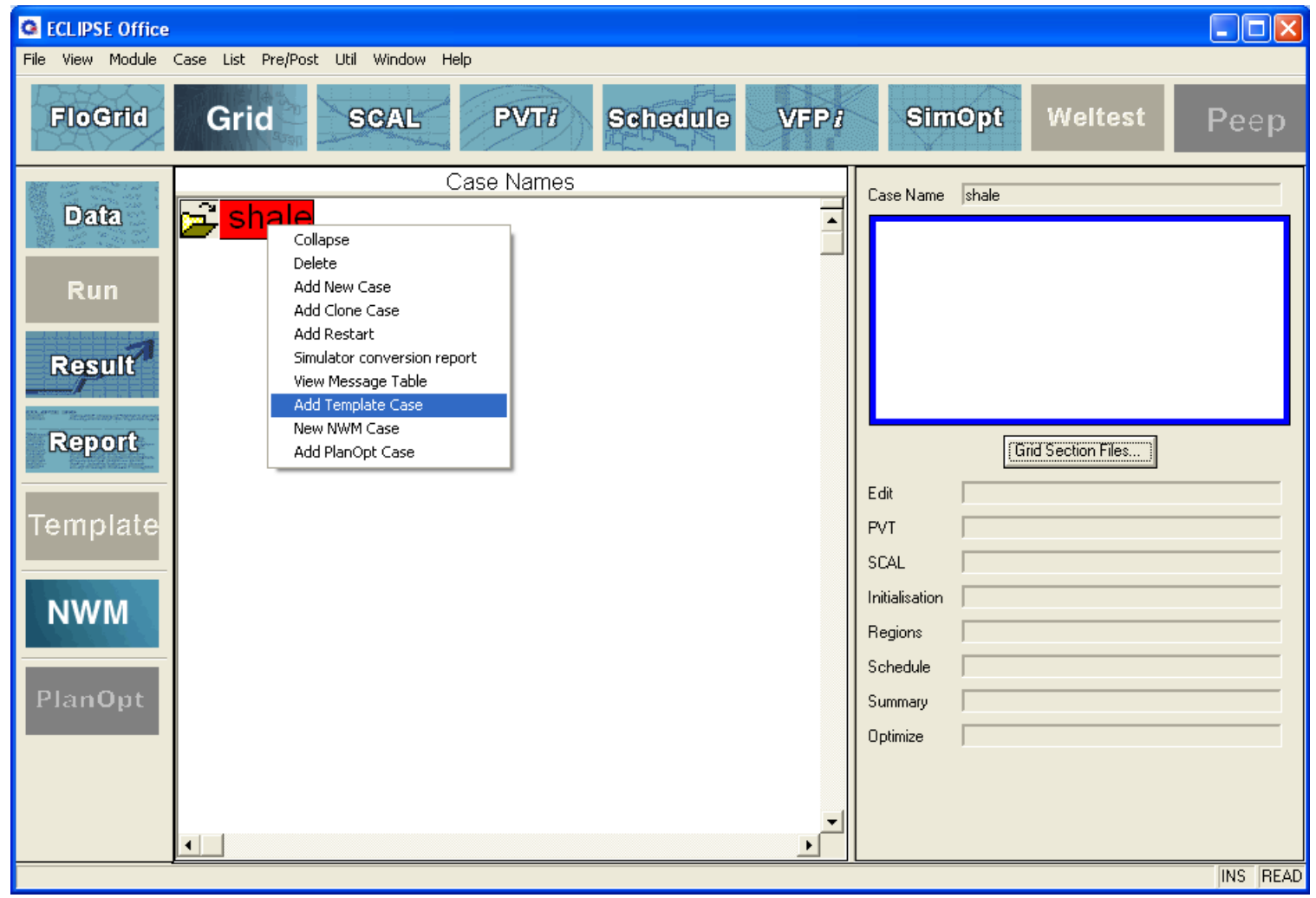

Figure A-4: Add ECLIPSE template screen 
Then the template selection panel will be displayed as shown in Figure A-5. There are four different template models in the ECLIPSE including single well radial, completion modeling tool, coal bed methane, and $\mathrm{CO}_{2}$ sequestration. However, coal bed methane model was used for shale properties in this research.

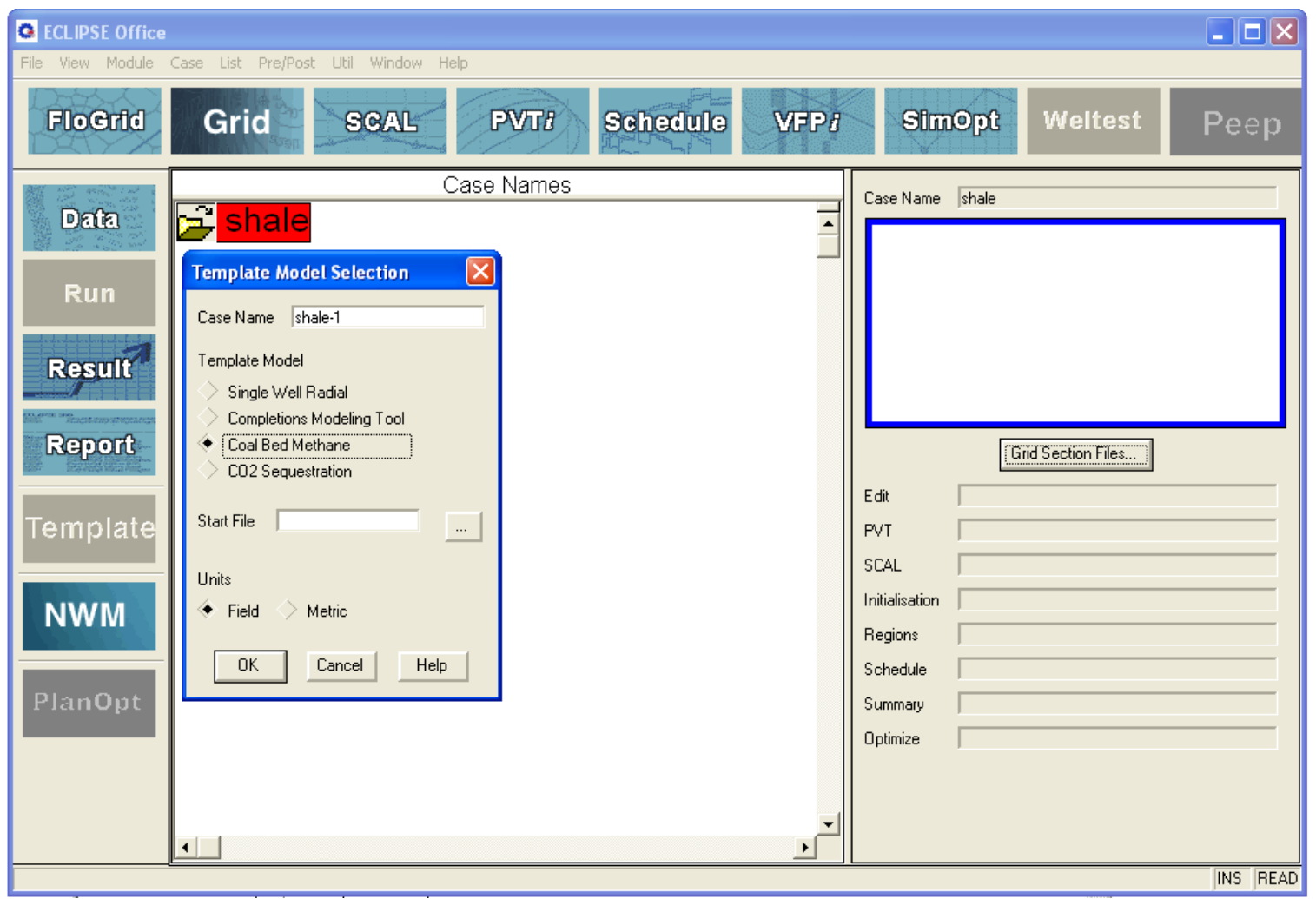

Figure A-5: ECLIPSE template selections 
The user clicks "OK" to open the coal bed methane template editor that is shown in Figure A-6. The user selects and enters the first workflow page that contains the model definition. Model definition properties including start day, end day, time intervals, model properties, etc were entered in this section. In addition, the user picks checkboxes that are needed for reservoir model.

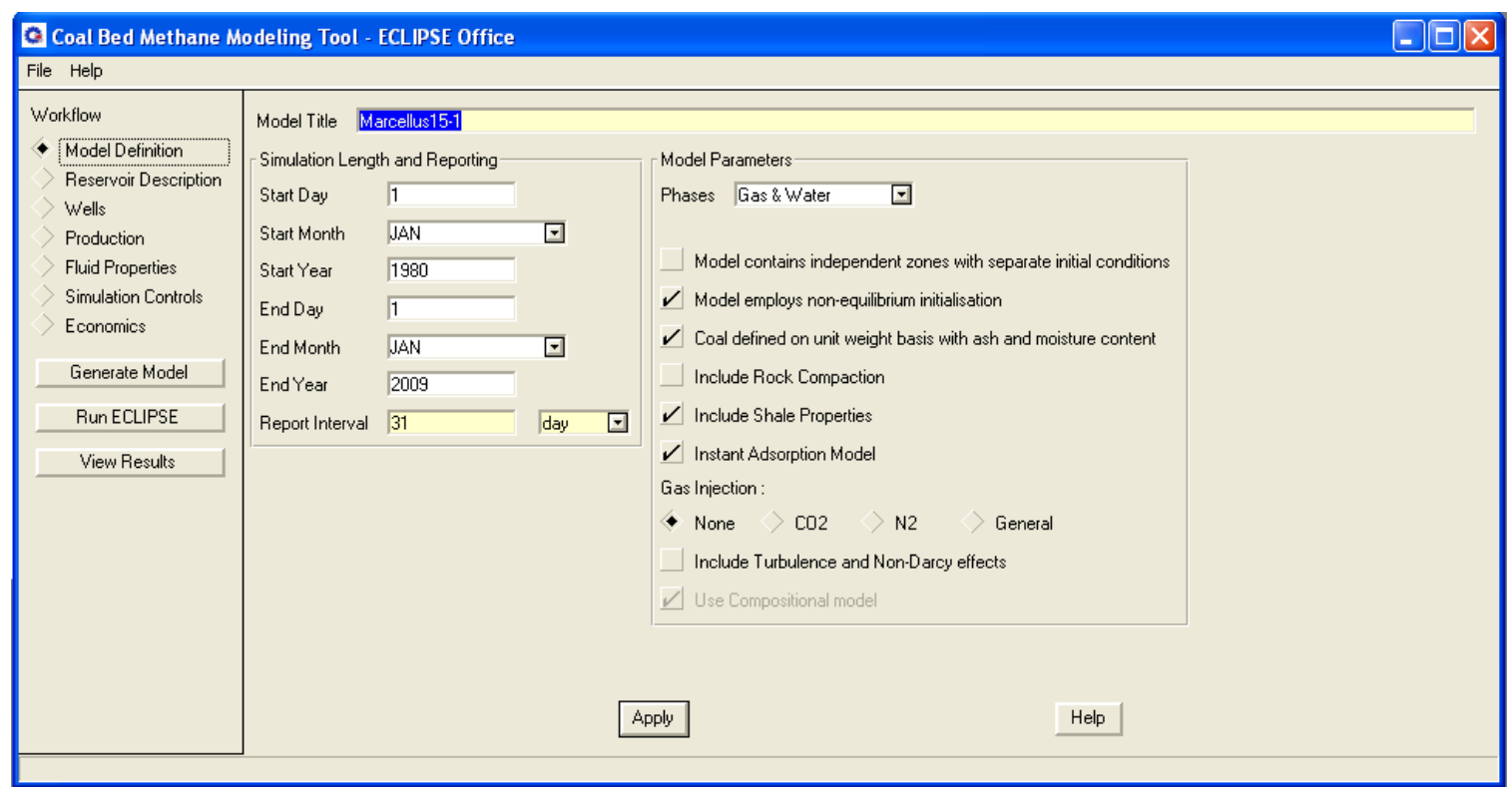

Figure A-6: Model definition section 
The second workflow data entry page provides access to the reservoir description. Reservoir description workflow consist of five data entry windows including layers, rock properties, non-equilibrium initial conditions, aquifer, and fractures. The layers data entry window is shown in Figure A-7. The user enters top depth left face, top depth right face, horizontal displacement, formation thickness, reservoir length, and reservoir width in this data entry window.

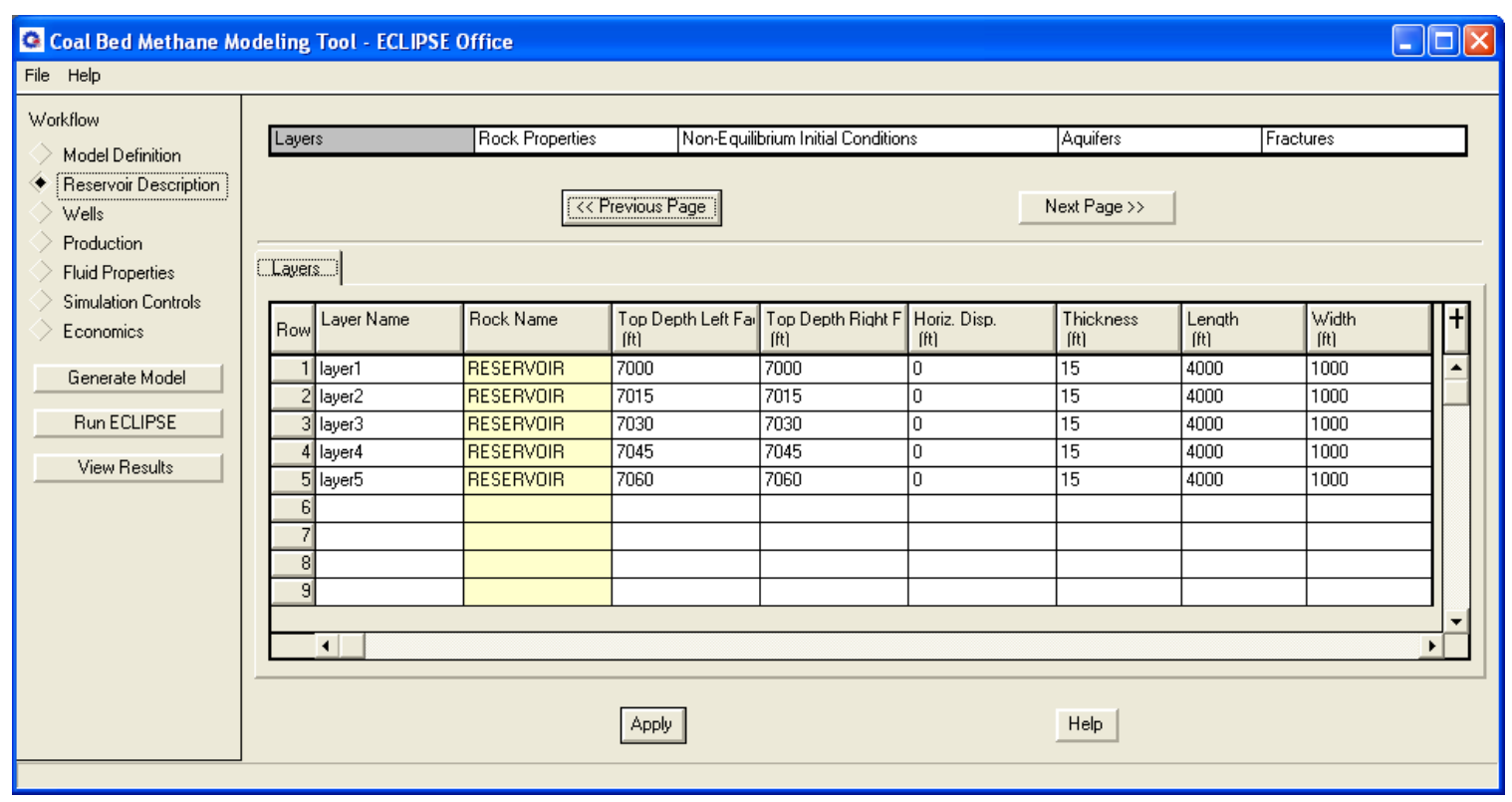

Figure A-7: Reservoir layers description

Selecting the "help" tab will allow the user to access the following definitions such as thickness, length, and width define the gross size of the layers as shown below.

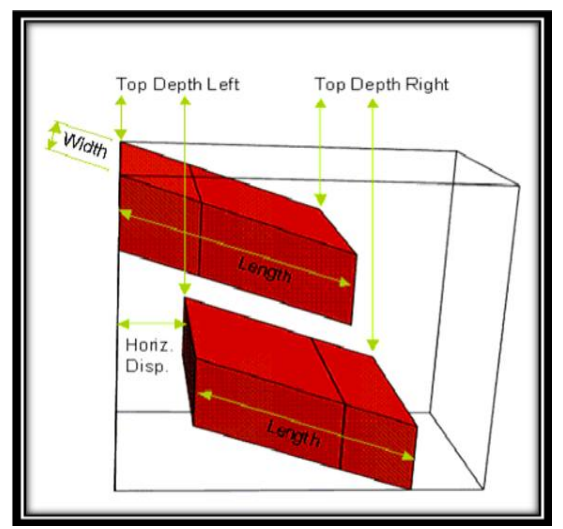

Figure A-8: Reservoir layers description layout 
The rock properties data entry window is shown in Figure A-9. The user enters fracture porosity, matrix porosity, bulk permeability, matrix permeability, matrix fracture sigma, coal compressibility, and rock density in this data entry window.

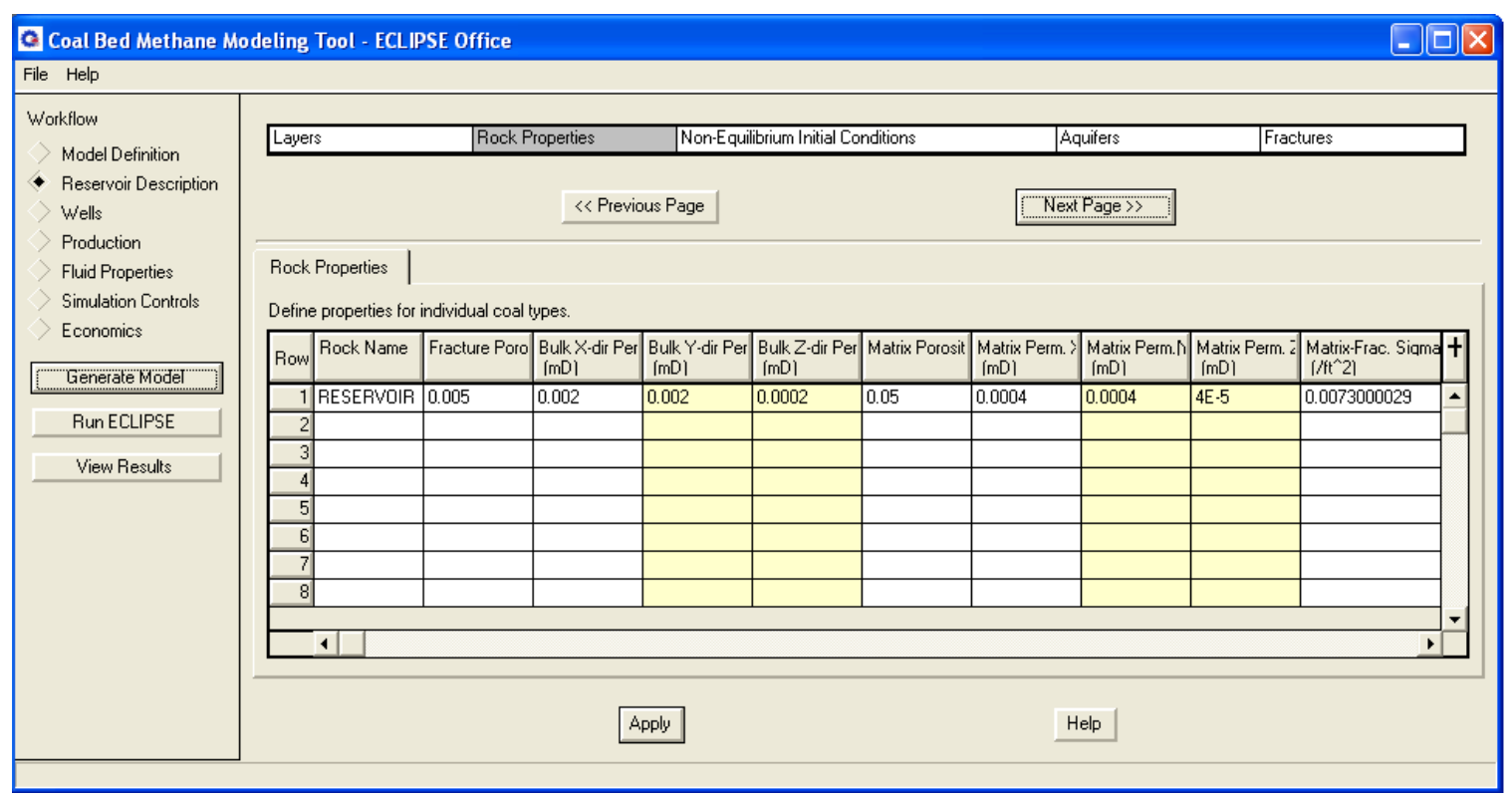

Figure A-9: Reservoir description for rock properties 
The non-equilibrium initial condition data entry window is shown in Figure A-10. The user enters reservoir pressure and water saturation in this data entry window.

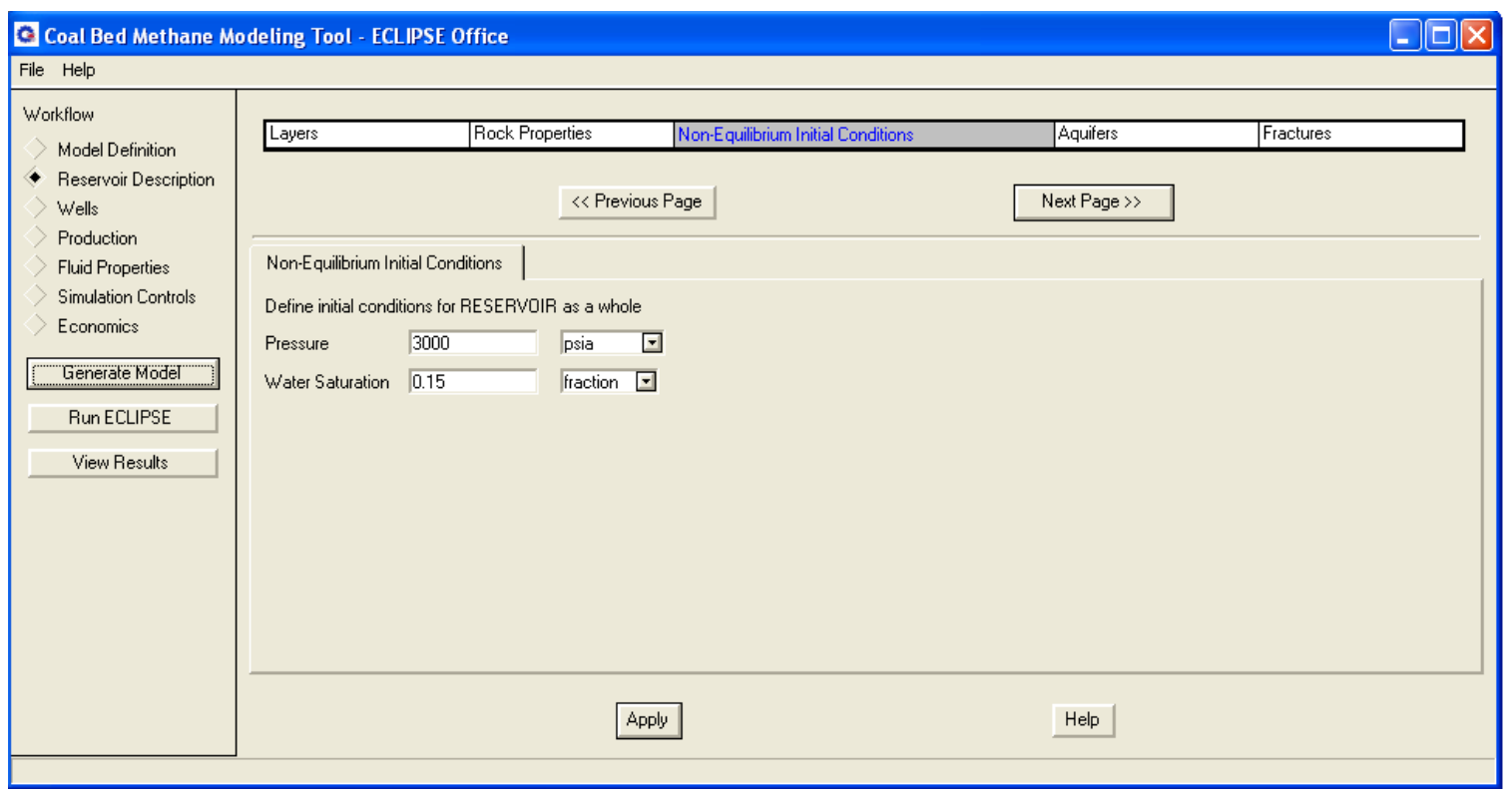

Figure A-10: Reservoir description for non-equilibrium initial conditions 
The aquifers data entry window was not used however the fracture data entry window is used. Fracture data entry window is shown in Figure A-11. The user enters parameters including fracture half length, width, top and bottom of fracture, fracture permeability and fracture porosity in this data entry window. For example, Figure A-11 shows a 4 stage fracture.

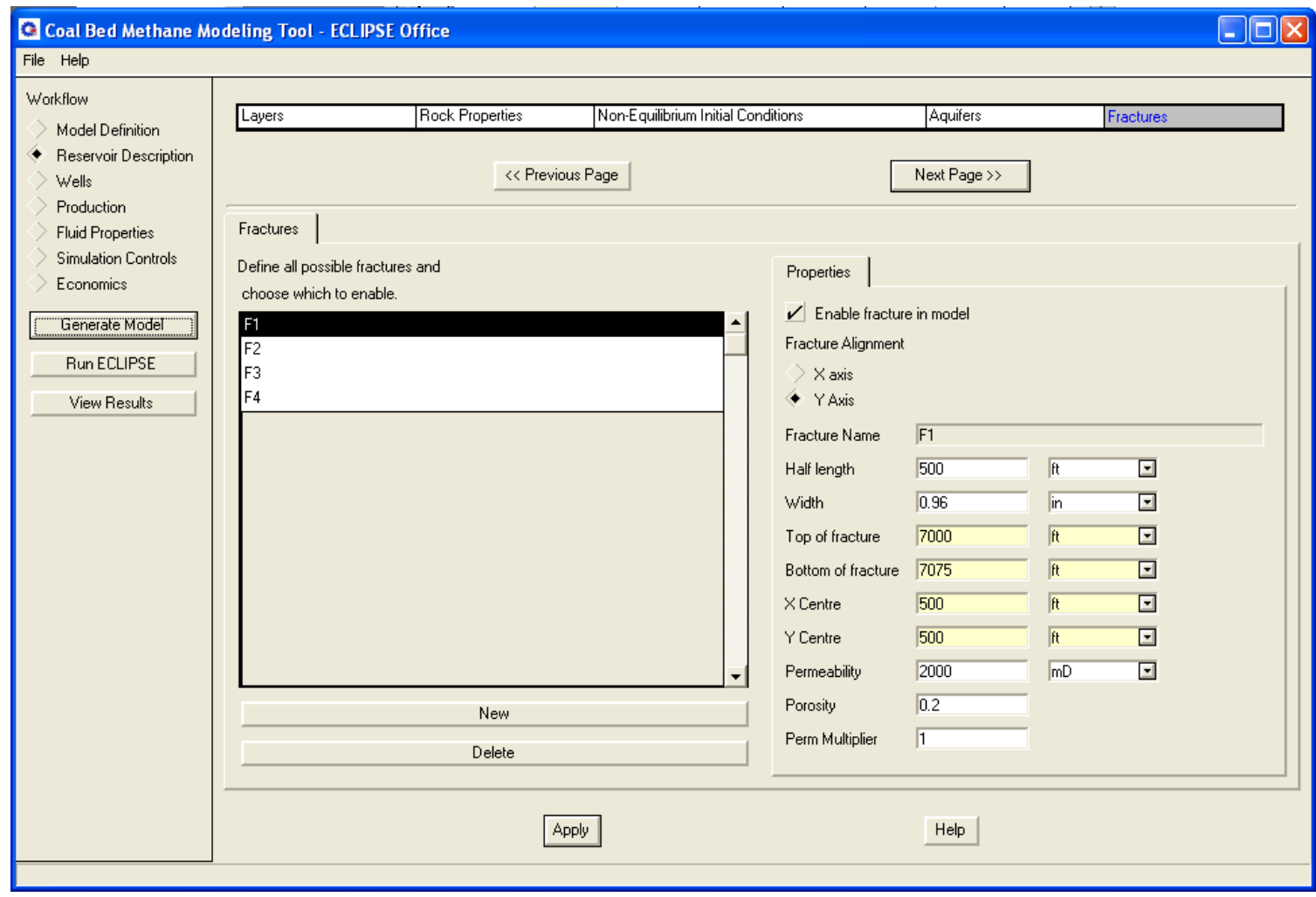

Figure A-11: Reservoir description for fracture 
The third workflow page provides access to well location in terms of its deviation survey coordinates. The user can add either vertical or horizontal wells in this model as shown in Figure A-12. In addition, the user can select the location of either vertical or horizontal well in this data entry window.

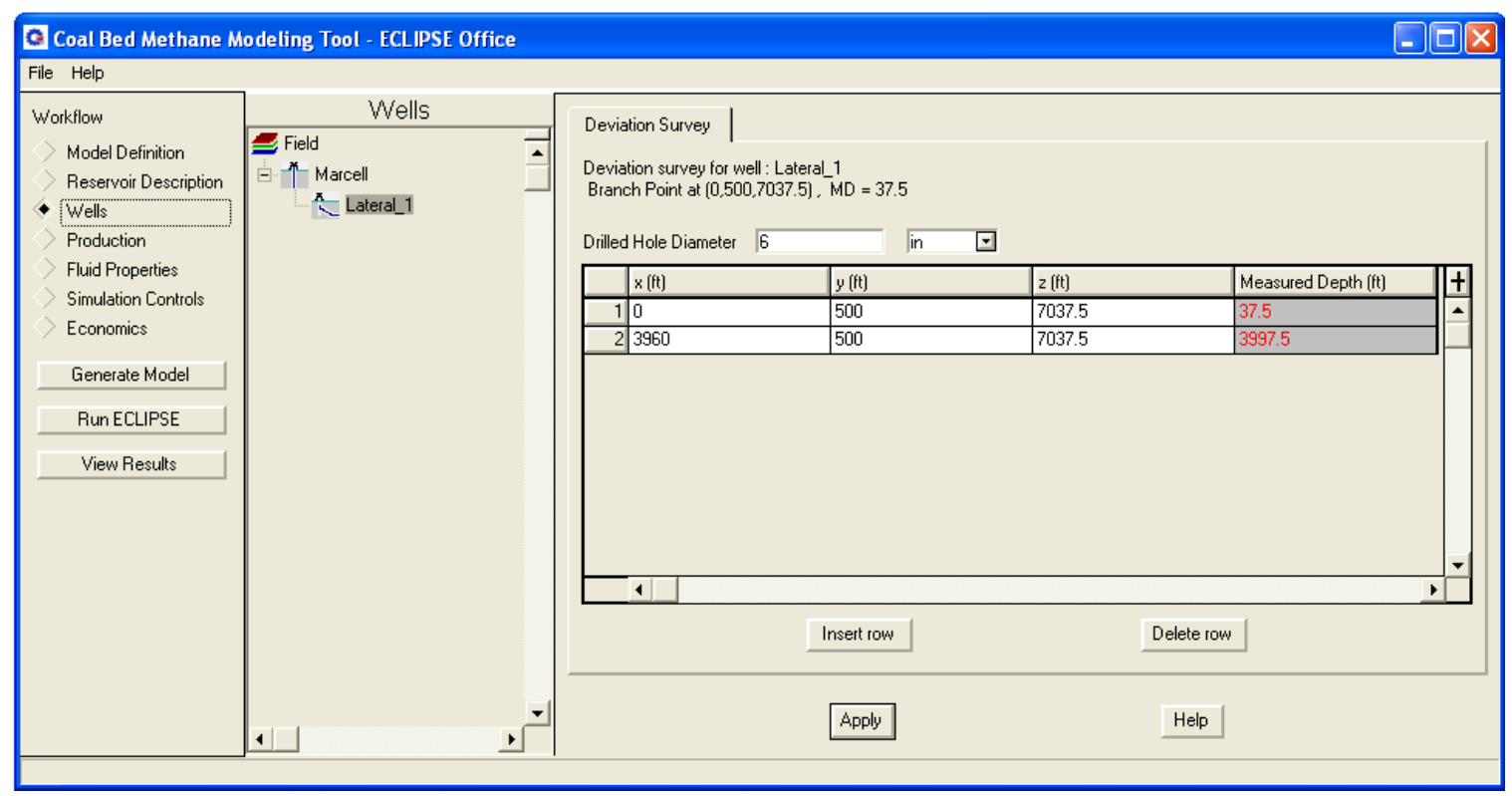

Figure A-12: Reservoir description for fracture 
The forth workflow data entry page provides access to well completion and production characteristics. The user selects the new event from the available event types. The user selects "Production from Marcell" for instance from the event drop-down box. Then the user clicks on new event. The "Production well schedule data" panel opens and the user selects the "Well controls" window. The user selects the bottomhole pressure (BHP) as control mode as shown in Figure A-13.

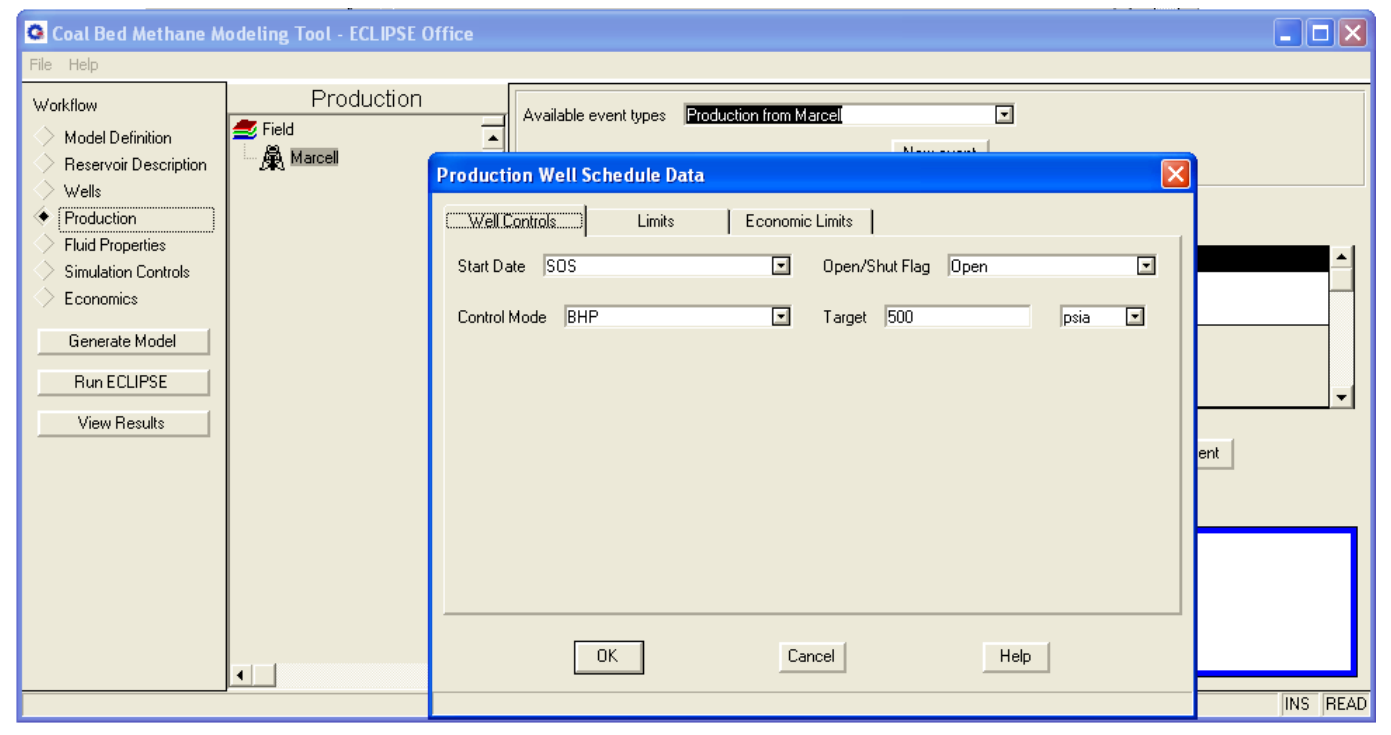

Figure A-13: Production for well control

In addition, the user selects "perforation_1" from the available event type's drop-down as shown in Figure A-14.

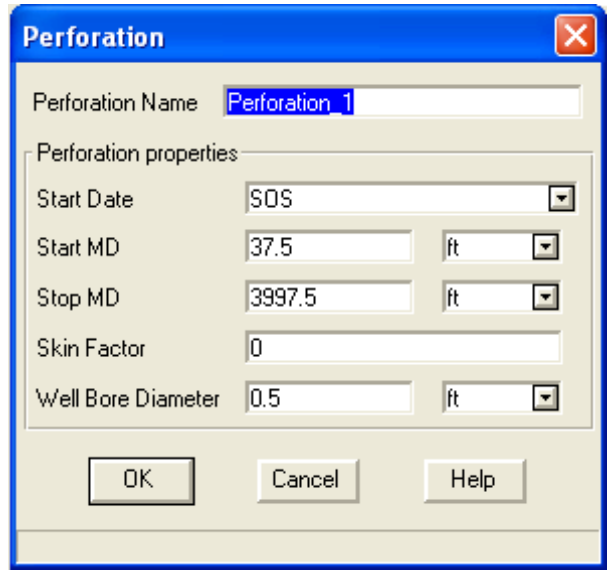

Figure A-14: Production for perforation control 
The fifth workflow data entry page provides access to PVT and fluid properties for the gas-water system, and the gas concentration properties for the coal bed methane.

Fluid properties workflow consist of four data entry windows including PVT composition, relative permeability, coal bed methane, and advanced. The fluid properties data entry window is shown in Figure A-14. The user enters standard pressure, standard temperature, and reference temperature including gas component $\left(\mathrm{C} 1-\mathrm{C} 7^{+}\right)$fraction in this data entry window as shown in Figure A-15.

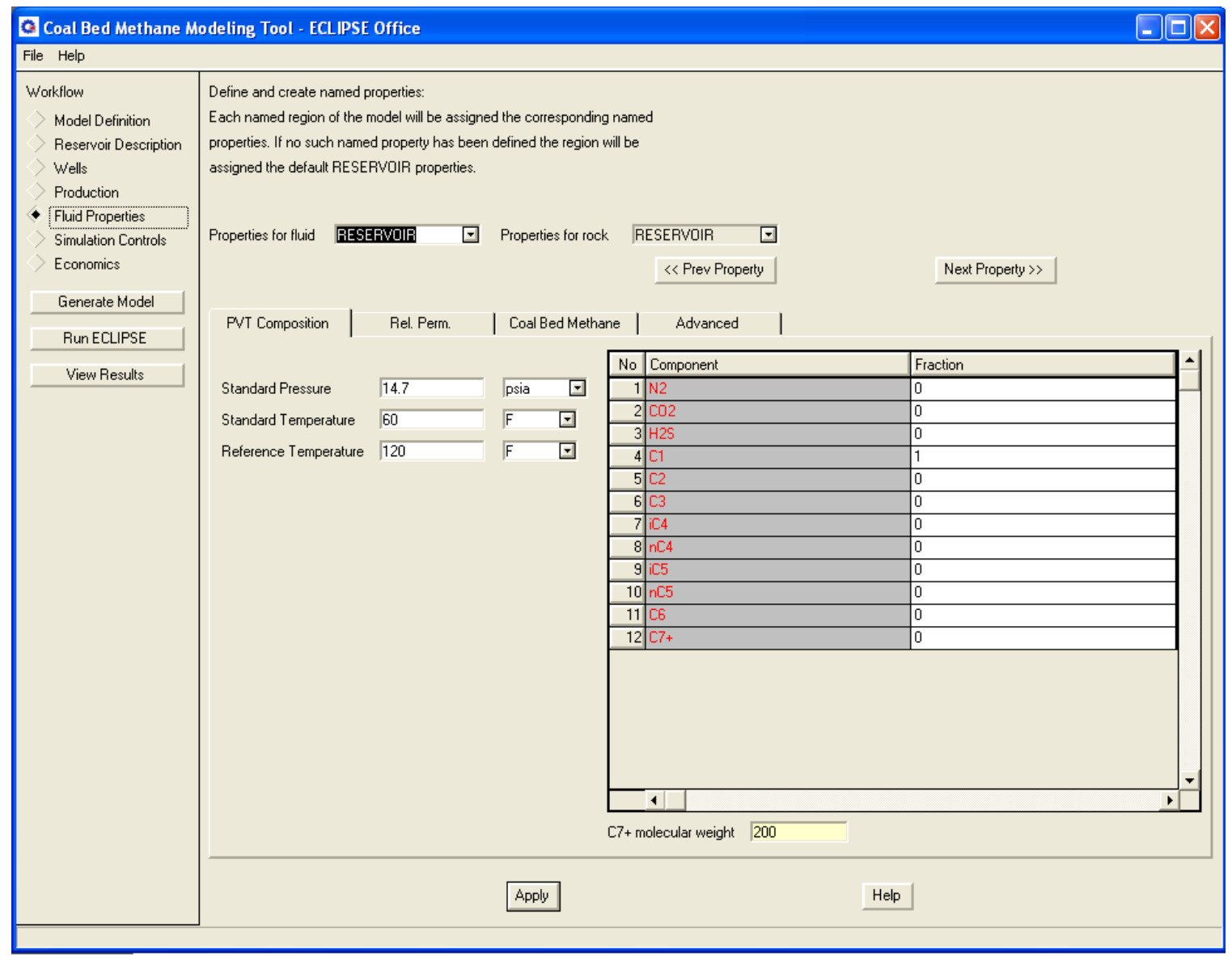

Figure A-15: Fluid properties for PVT composition 
The user specifies the standard Corey correlation for each phase present in the model including gas and water in this data entry window as shown in Figures A-16 and A-17.

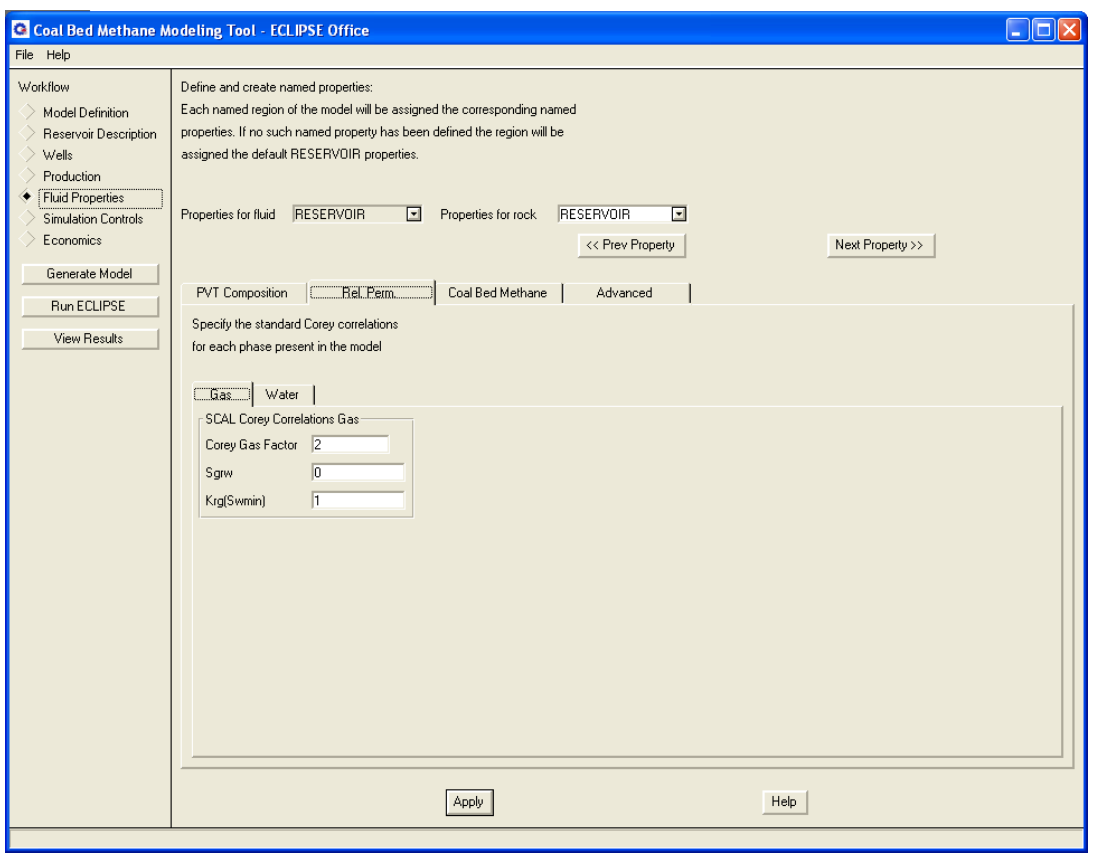

Figure A-16: Fluid properties for gas

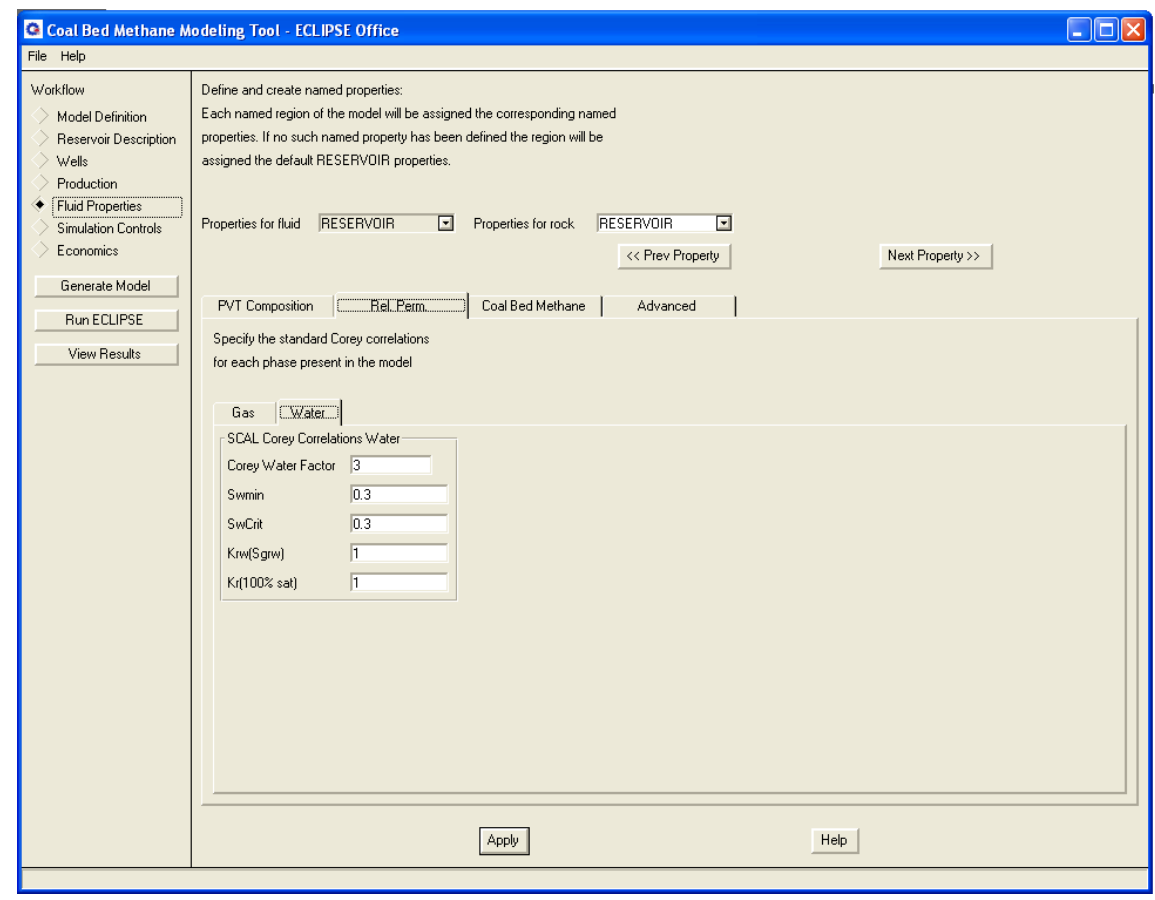

Figure A-17: Fluid properties for water 
The user assigns fluid properties including Langmuir pressure, Langmuir concentration, sorption time, and re-adsorption coefficient in the coal bed methane data entry window of fluid properties. Coal bed methane data entry window of the fluid properties is shown in Figure A-18.

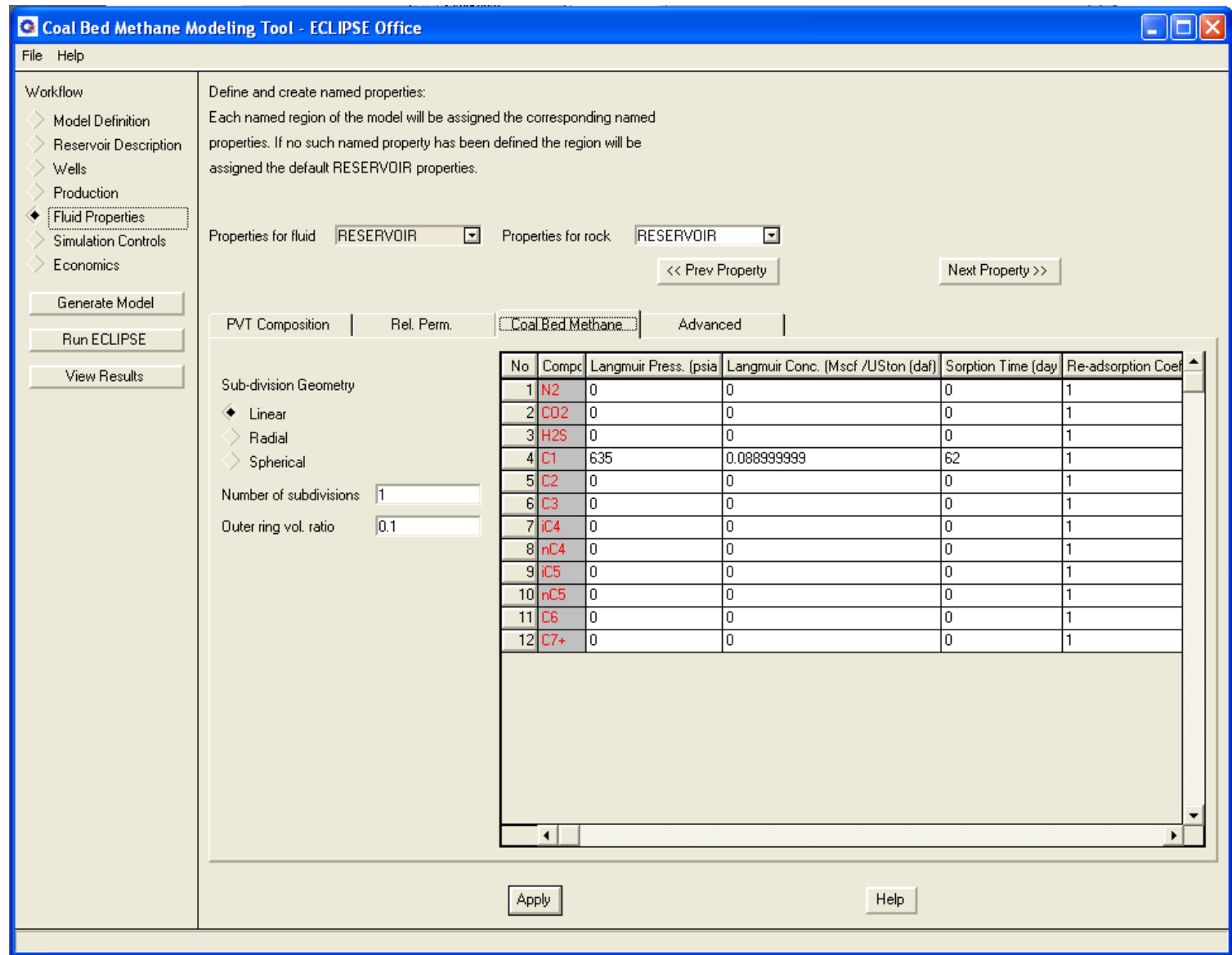

Figure A-18: Fluid properties for coal bed methane section 
The user loads data from correlation and plot the data in advanced data entry window as shown in Figure A-19.

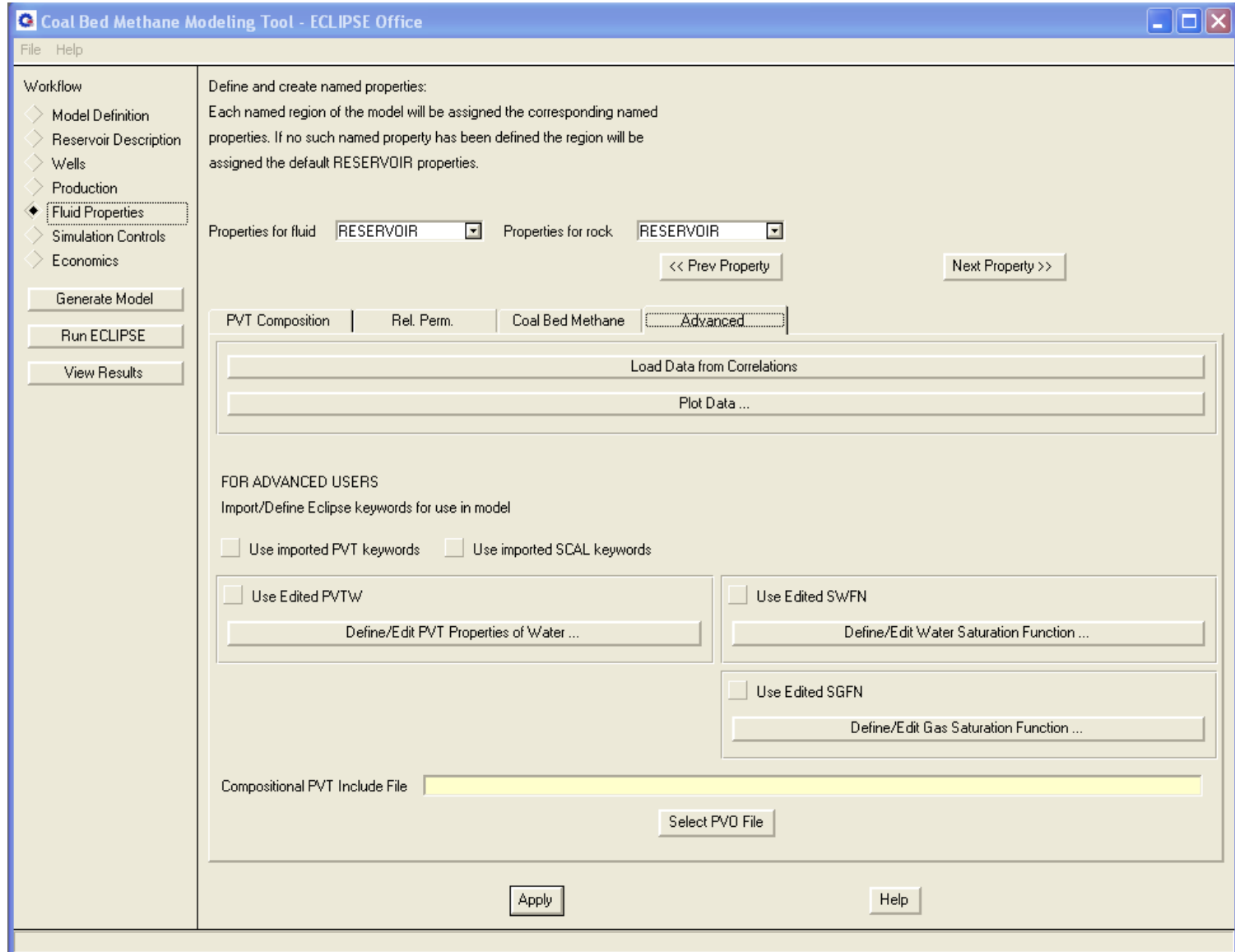

Figure A-19: Fluid properties for advanced control 
The sixth workflow data entry page provides access to simulation gridding controls.

The user enters values including the minimum, maximum cell sizes, and cell per layers in the gridding control data entry window as shown in Figure A-20.

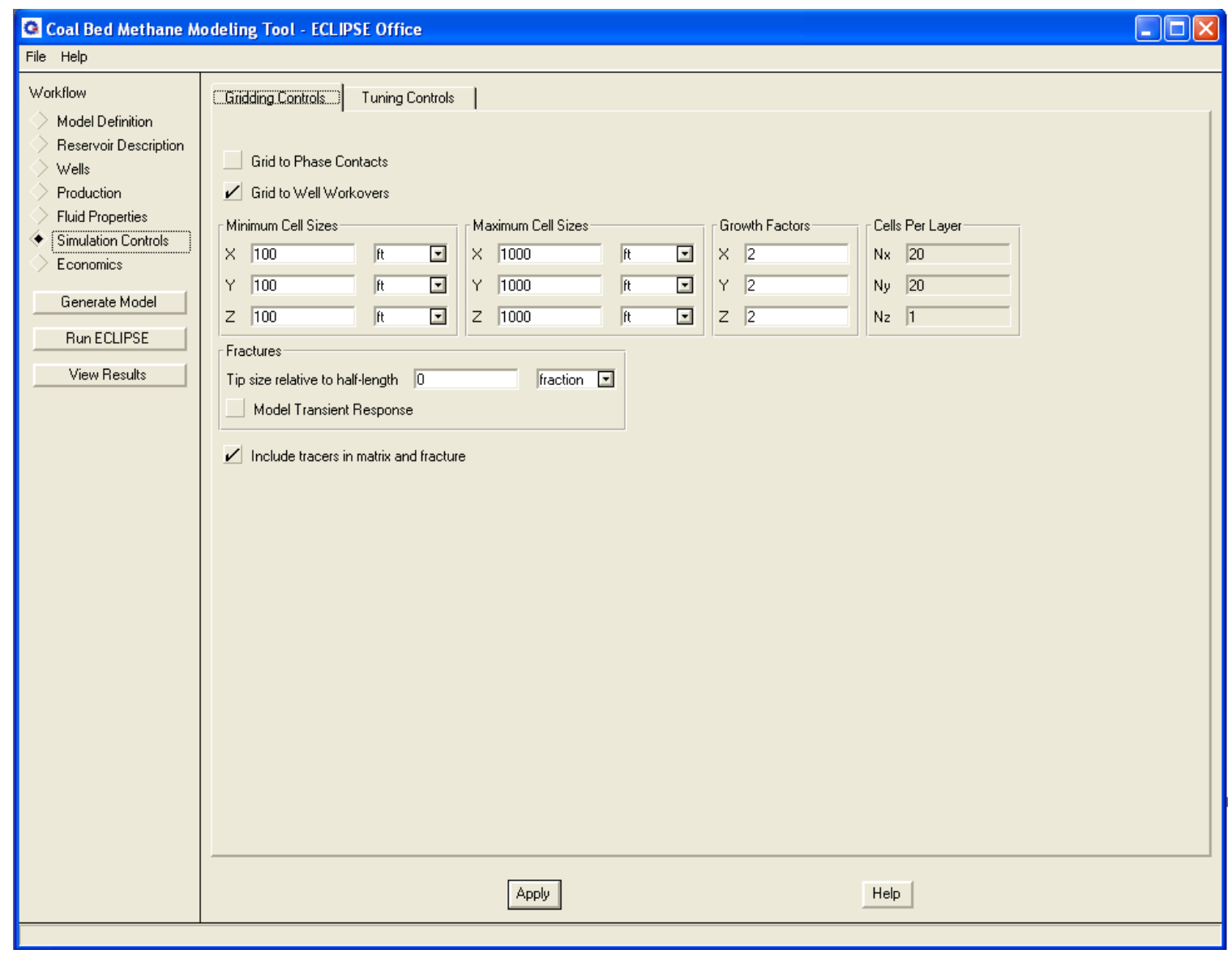

Figure A-20: Simulation control for gridding control 
In addition, the user enters parameters including first time-step, minimum time-step, maximum time-step, maximum pressure change per time-step, maximum non linear iteration, and maximum linear iteration in the tubing control data entry window. Tubing control data entry window is shown in Figure A-21.

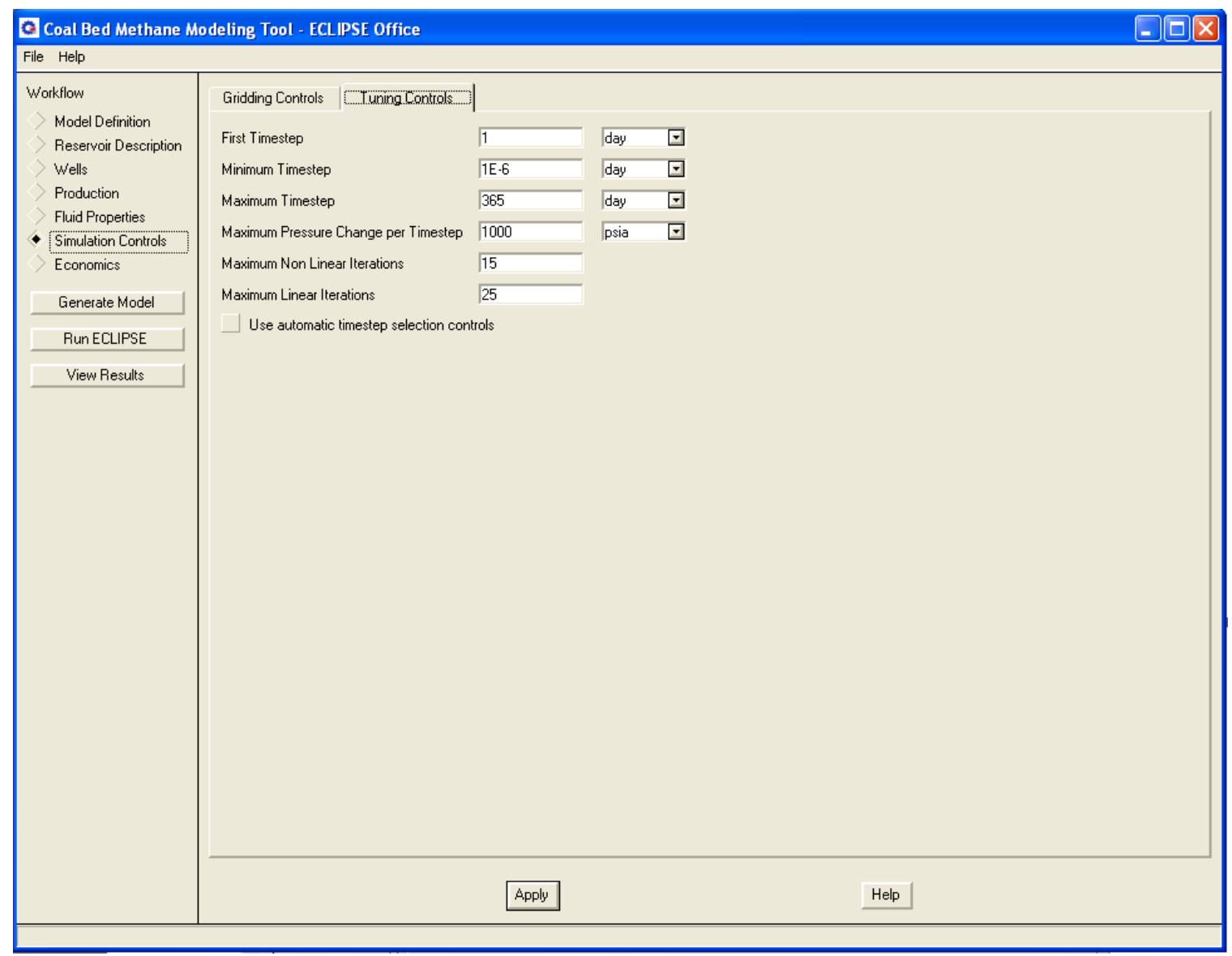

Figure A-21: Simulation control for tubing control 
The user can calculate Net Present Value (NPV) after entering all the cost values in the last workflow data entry page as shown in Figure A-22.

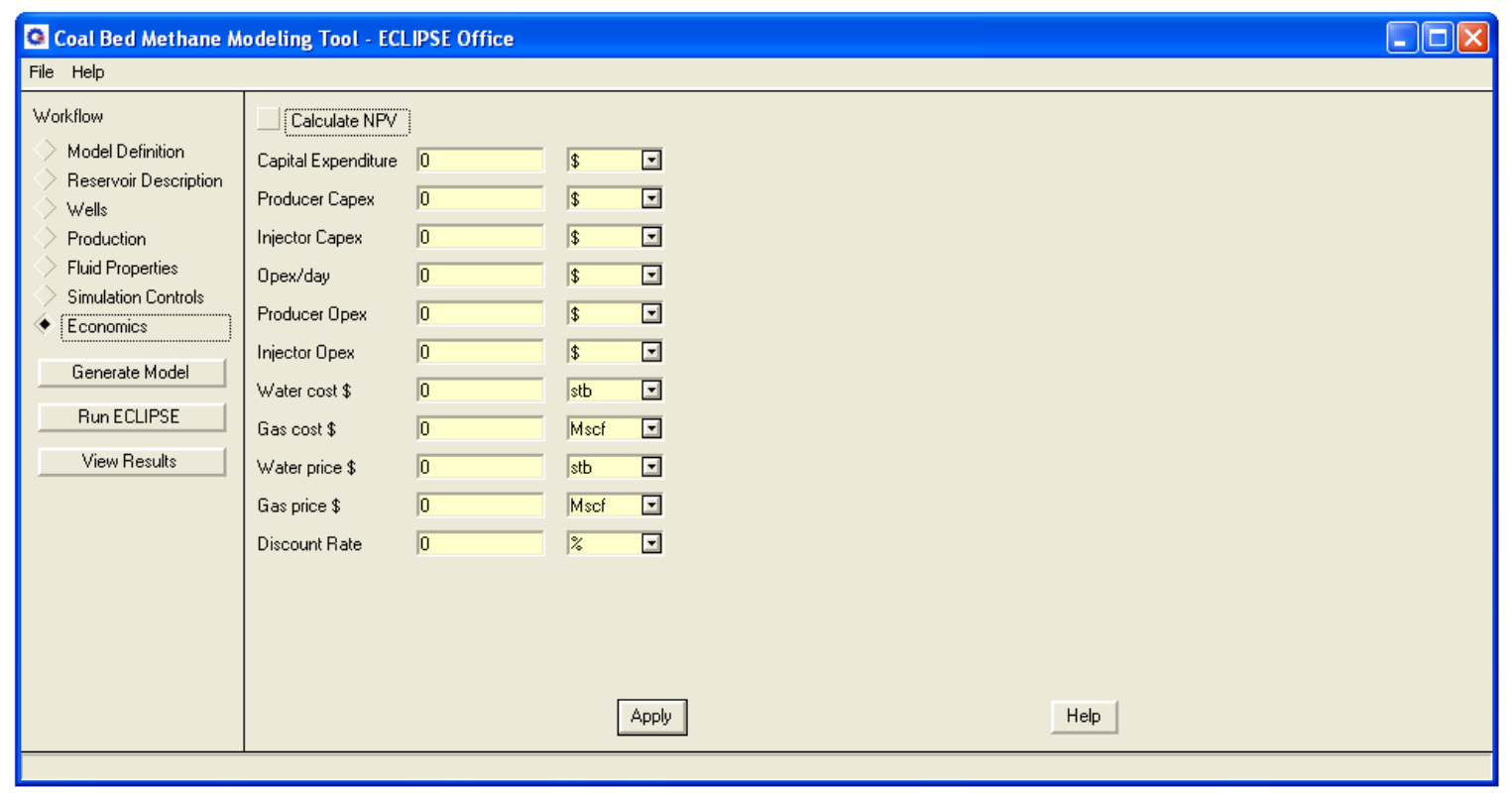

Figure A-22: Economics

Finally, there are three buttons that are available throughout the workflow. There are consisting of generate model, run ECLIPSE, and view results. The user is able at this time to click on "Generate model" and "Run ECLIPSE" tabs to run a simulator. The user can view the results including field production total, field production rate, field pressure, field gas recovery, field gas in place, well bottomhole pressure, etc. 
Data Manager Module (DMM) was also implemented in this research. The user can use DMM after building the CBM template. The user selects "DATA" from the menu bar in the main ECLIPSE office panel (Figure A-4) to activate the "Data Manager Module" as shown in Figure A-23.

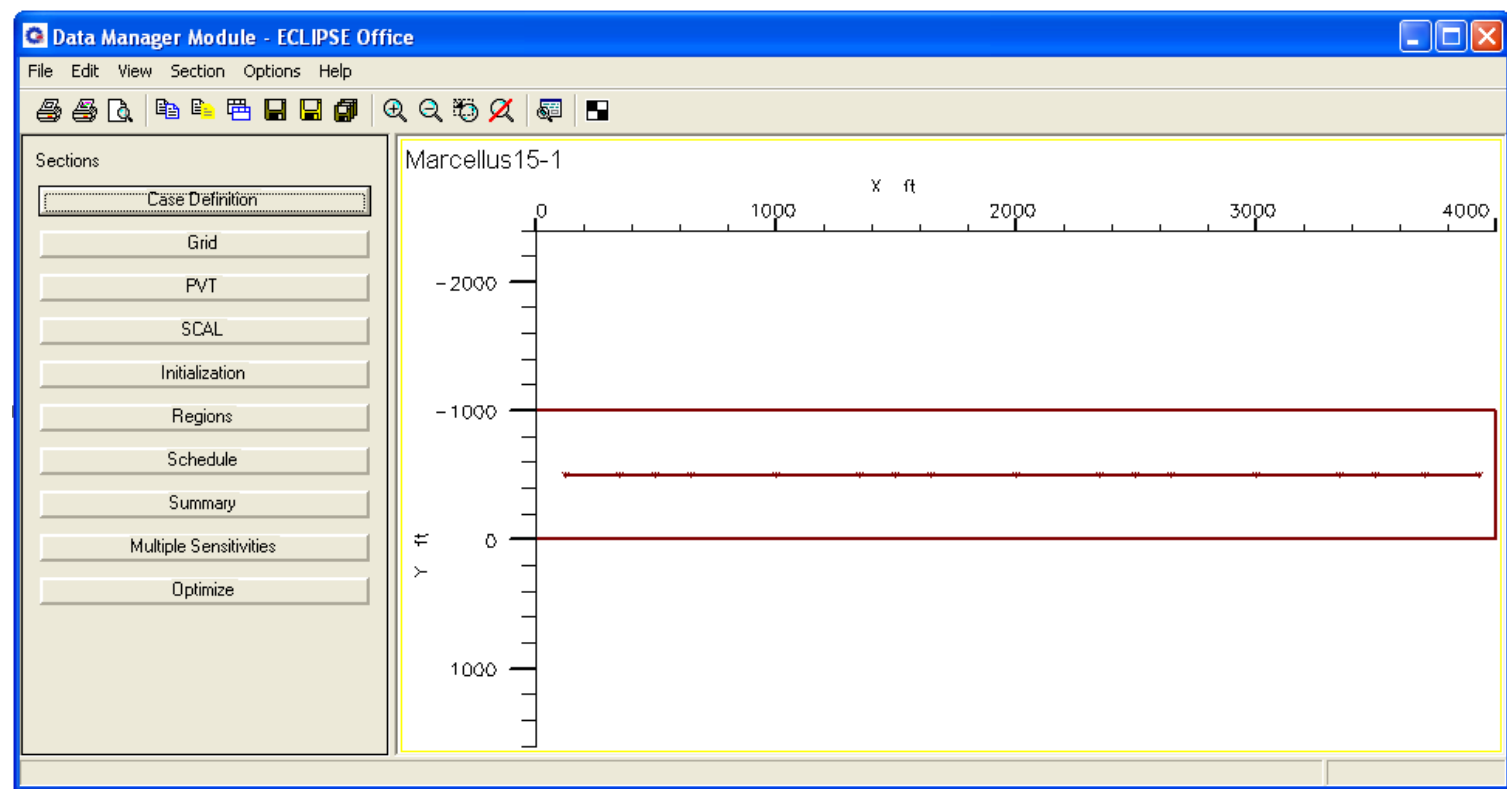

Figure A-23: Data manager module (DMM) 
The user selects "Case Definition" tab from data manager module editor as shown in Figure A-24. The user selects information including simulator type, model dimensions $(\mathrm{x}, \mathrm{y}, \mathrm{z})$ and simulation start day in "General" section.

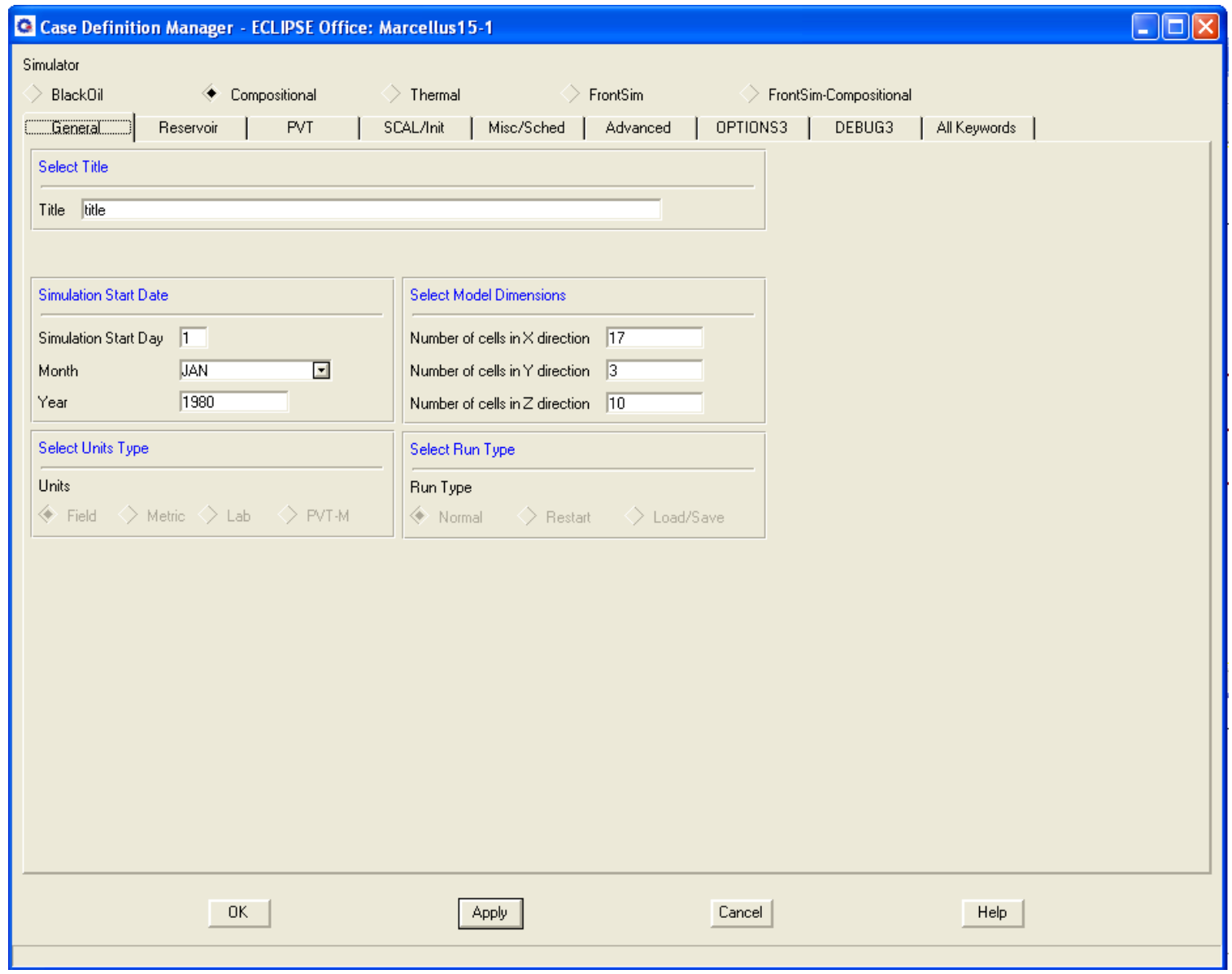

Figure A-24: General information for DMM 
The user selects "Reservoir" tab using data manager module editor as shown in figure in A-25. The user selects dual porosity and dual permeability model after checking the fractured reservoir section.

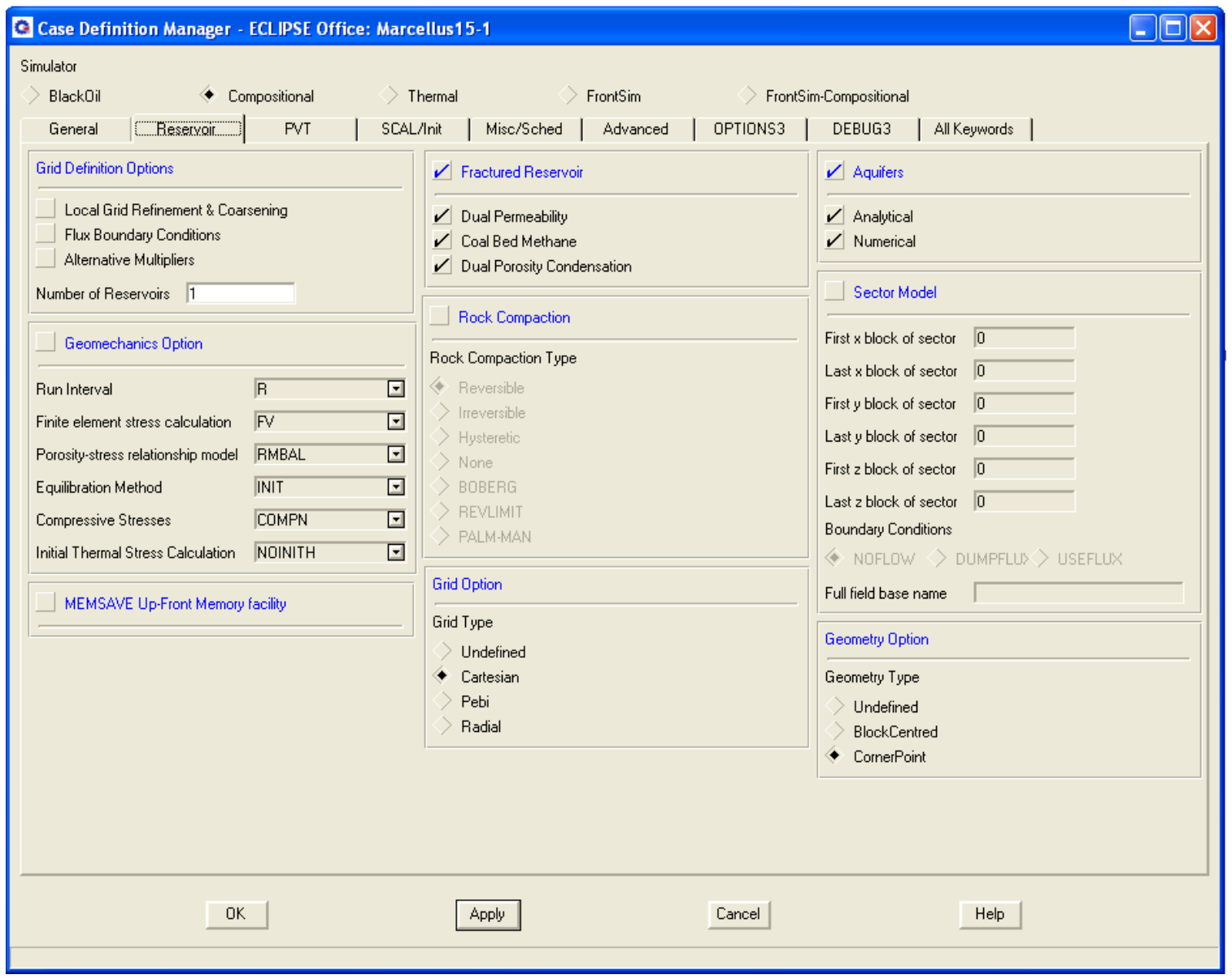

Figure A-25: Reservoir input for DMM 
The user selects the "PVT" tab to activate water, oil, gas, and dissolved gas as shown in Figure A-26.

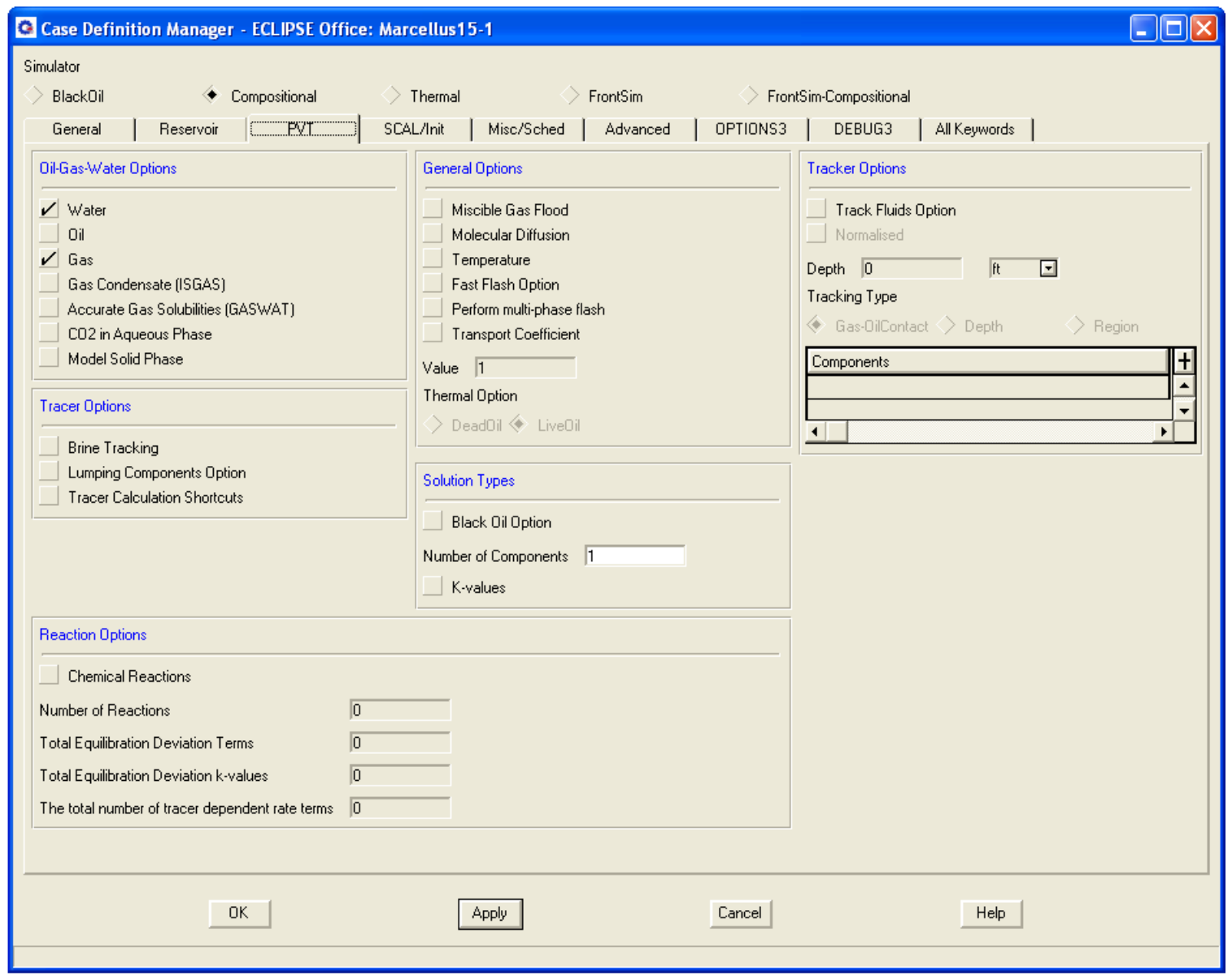

Figure A-26: PVT information for DMM 
The user selects "Misc/Sched" tab for the well options, transmissibility options, and pressure saturation options as shown in Figure A-27.

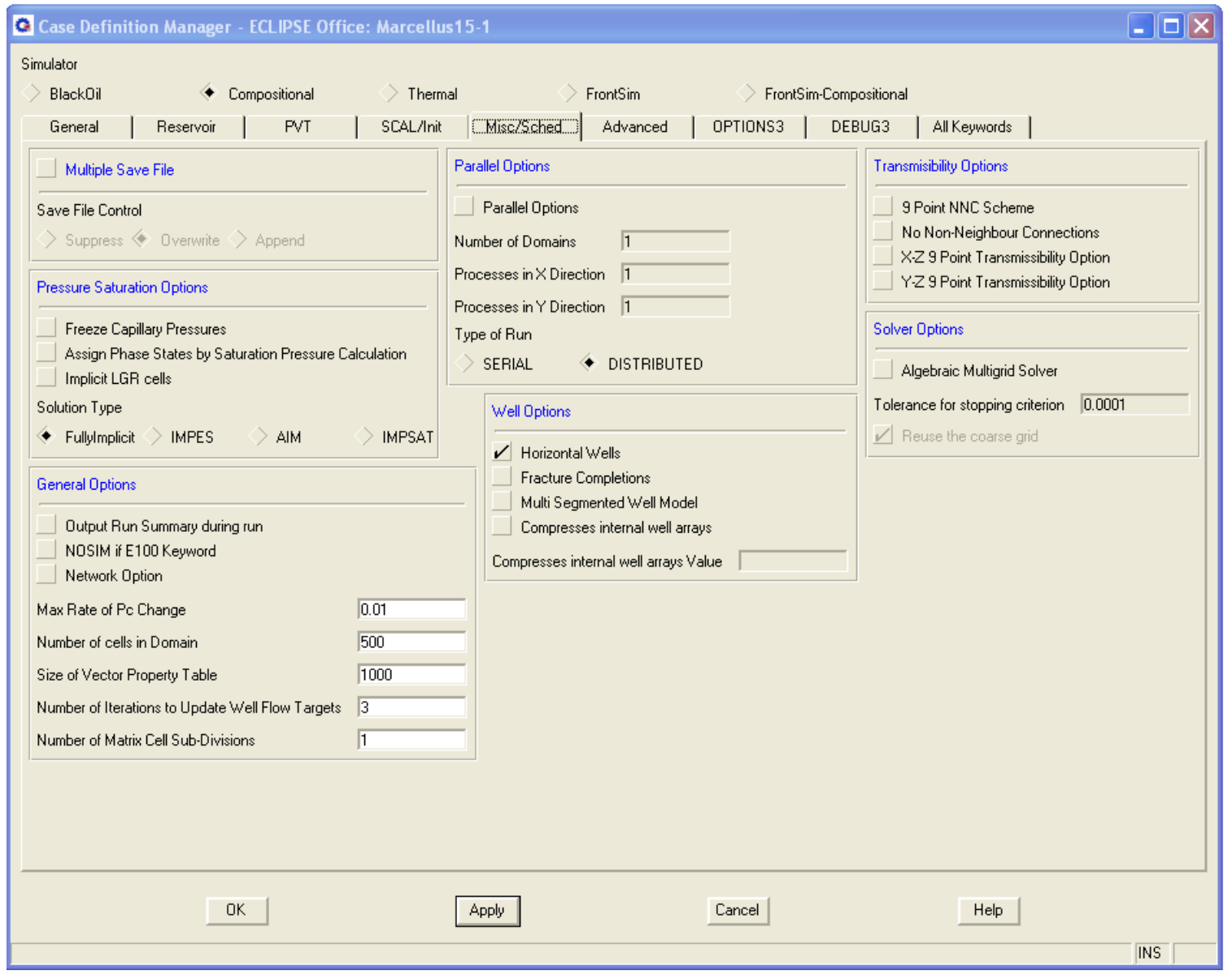

Figure A-27: Misc/Sched information for DMM 
Then the user selects "Grid" to open the grid definition section, where the geological properties are defined. The gird section is shown in Figure A-28.

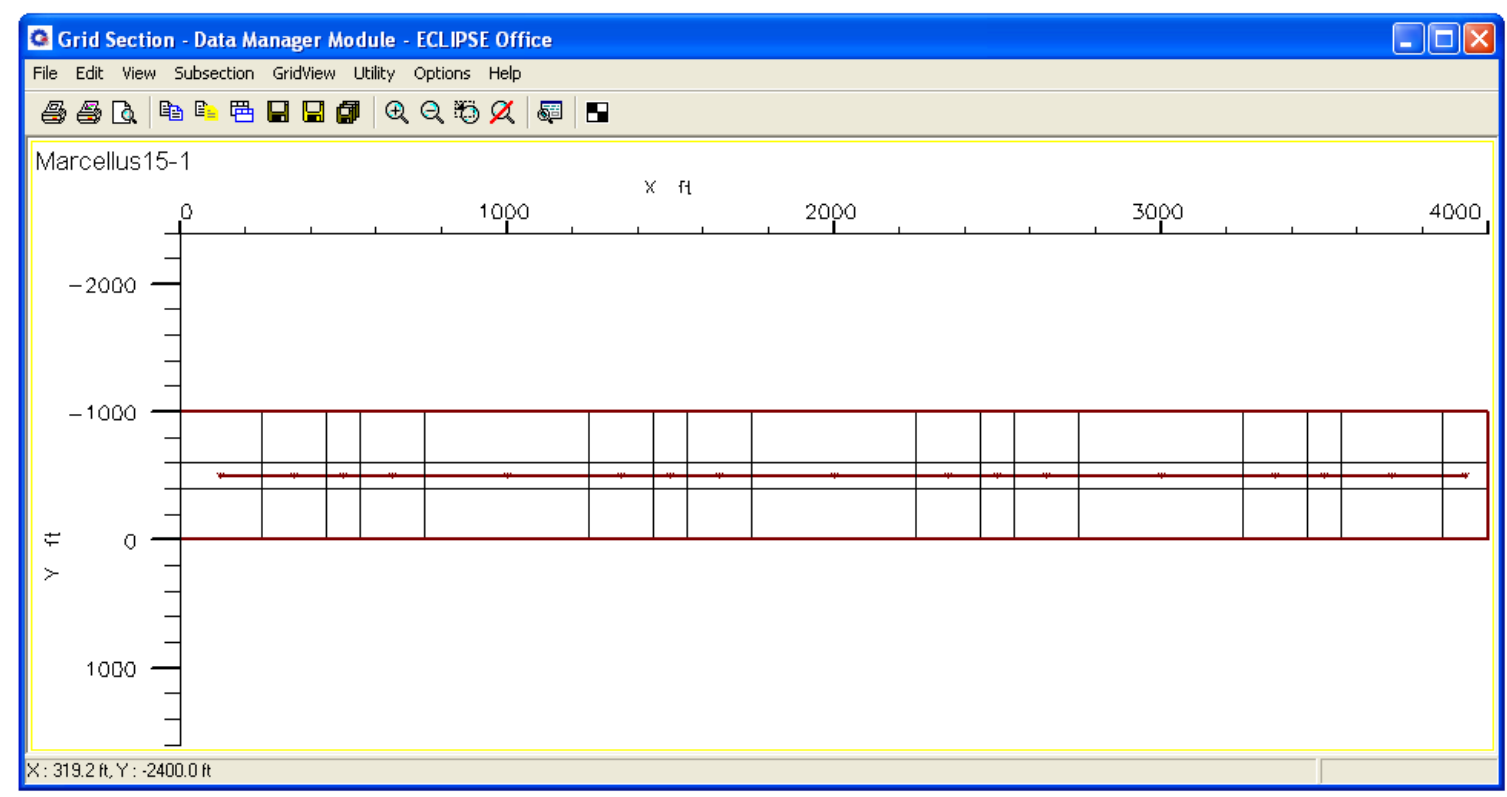

Figure A-28: Grid section for DMM 
In the grid selection, the user selects subsection to open grid keyboard section as shown in Figure A-29. The user can change the reservoir properties including porosity and permeability of each desired cell.

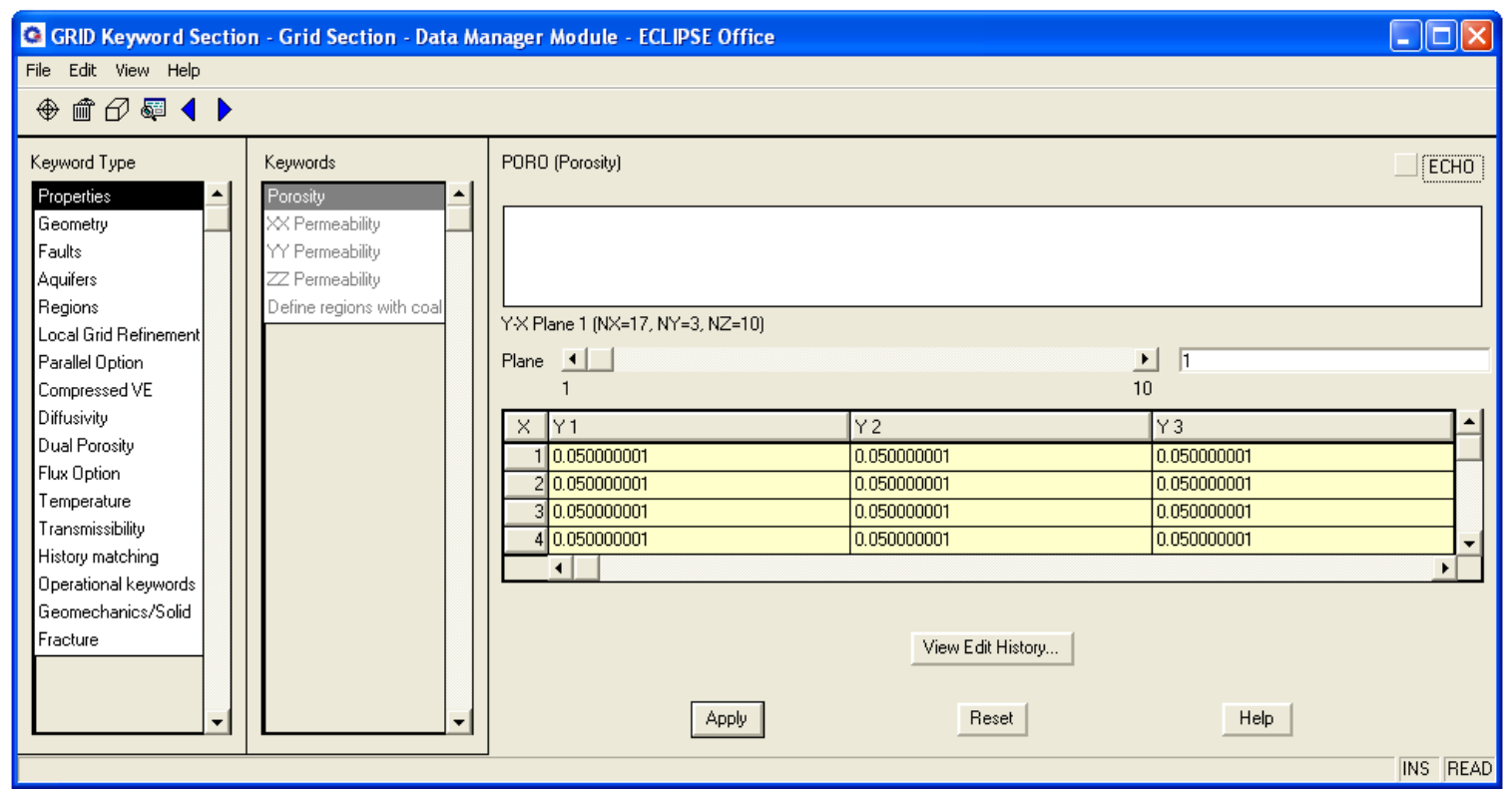

Figure A-29: Grid keyboard section 
Then the user selects data manager module and selects the "PVT" section as shown in Figure A-30.

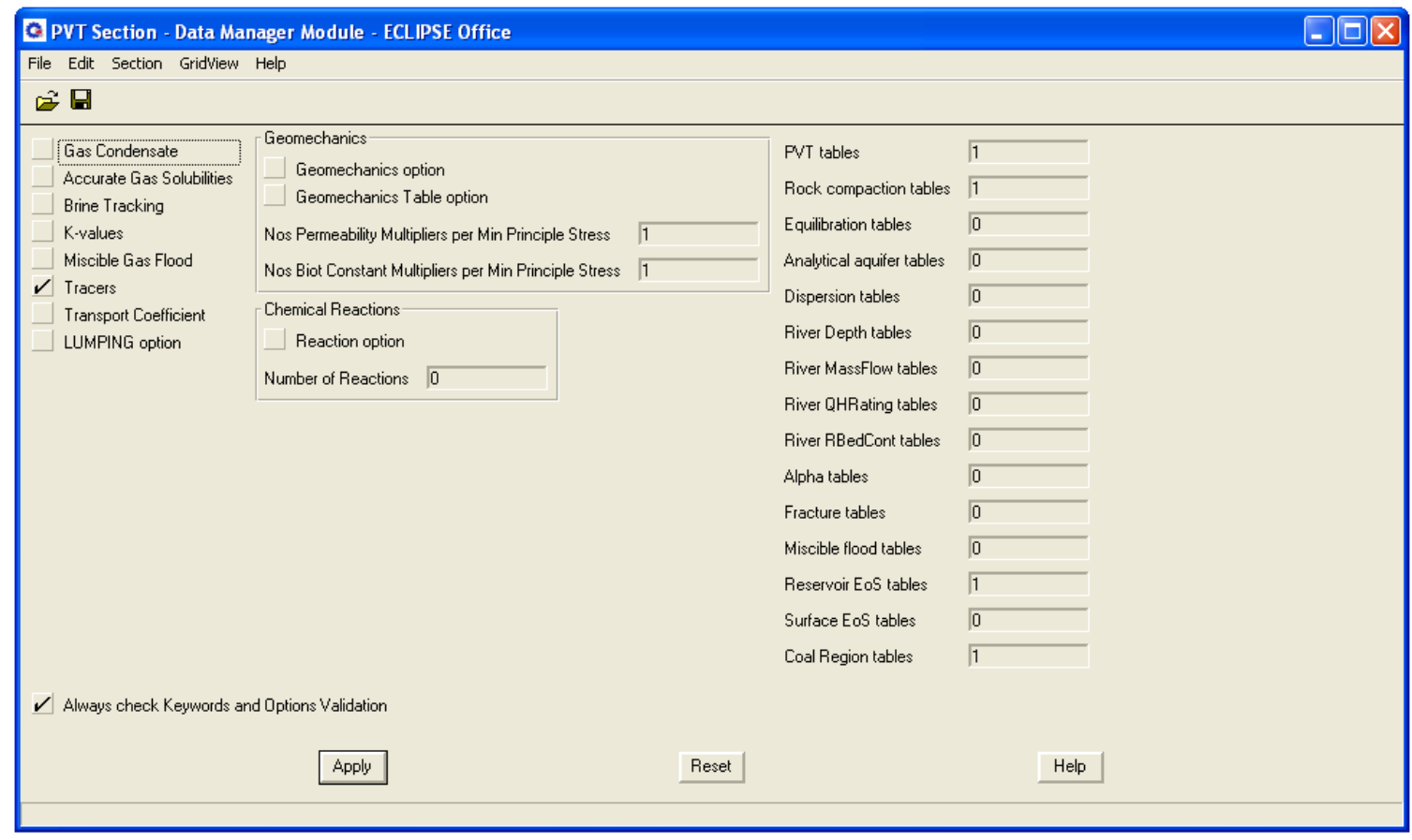

Figure A-30: PVT section for DMM

Finally the user selects the remaining tabs including "SCAL", "Initialization", "Regions", "Schedule", "Summary", "Multiple Sensitivities", and "Optimize" to complete and run data manager module section. Finally the user can view the results including field production total, field production rate, field pressure, field gas recovery, field gas in place, well bottomhole pressure, etc. 


\section{APPENDIX B (CMG)}

CMG (Computer Modeling Group) is one of the largest providers of reservoir simulation software in the world which was originated in 1978. Today, lots of oil and gas companies use $\mathrm{CMG}$ for simulation purposes. In this research, $\mathrm{CMG}$ was also used to compare the results from ECLIPSE for modeling horizontal wells completed in shale. Appendix B shows a simple procedure for creating "SHALE GAS" model using the BUILDER and GEM. The 2009 version of CMG was used in this research. The user can start BUILDER

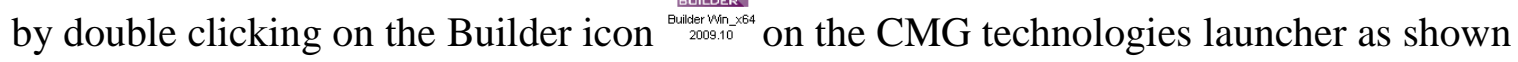
in Figure B-1.

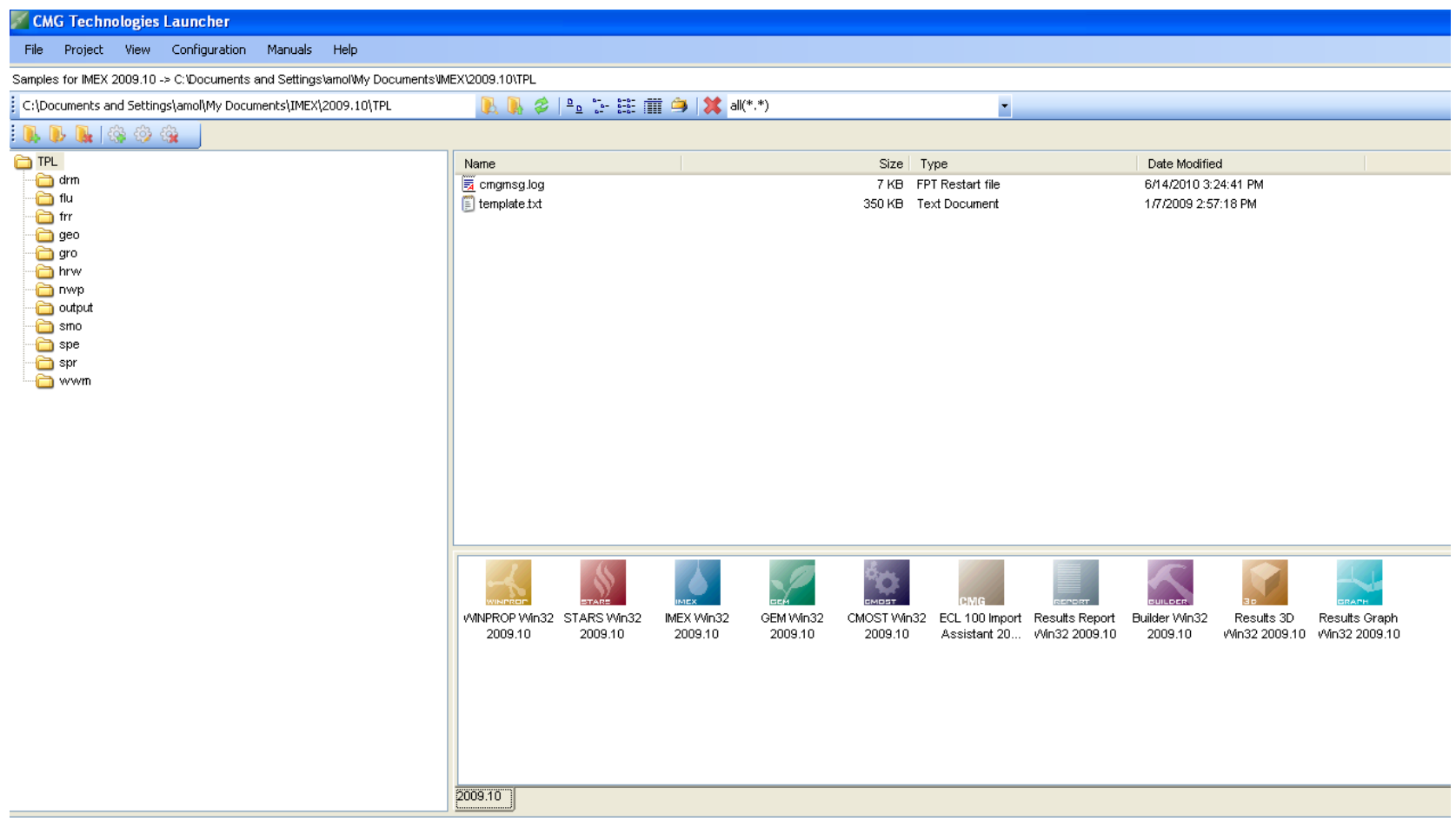

Figure B-1: CMG launcher 
The user selects GEM simulator, Field units, DUALPERM, Gilman and Kazemi for shape factor, and simulation start date as shown in Figure B-2.

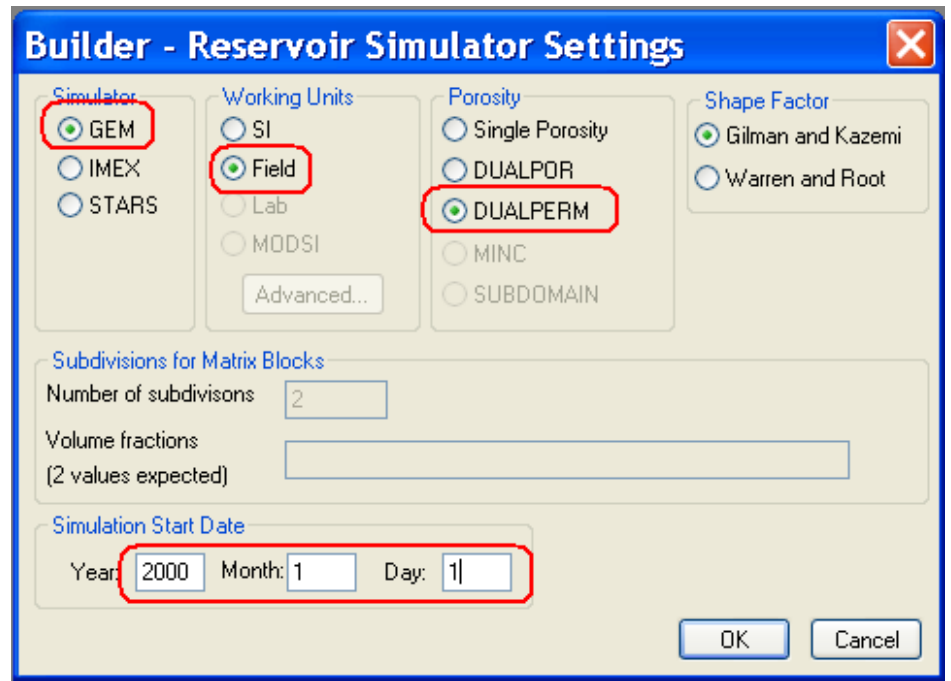

Figure B-2: Reservoir simulation settings

The user is able to view the CMG BUILDER by clicking "OK" as shown in Figure B-3.

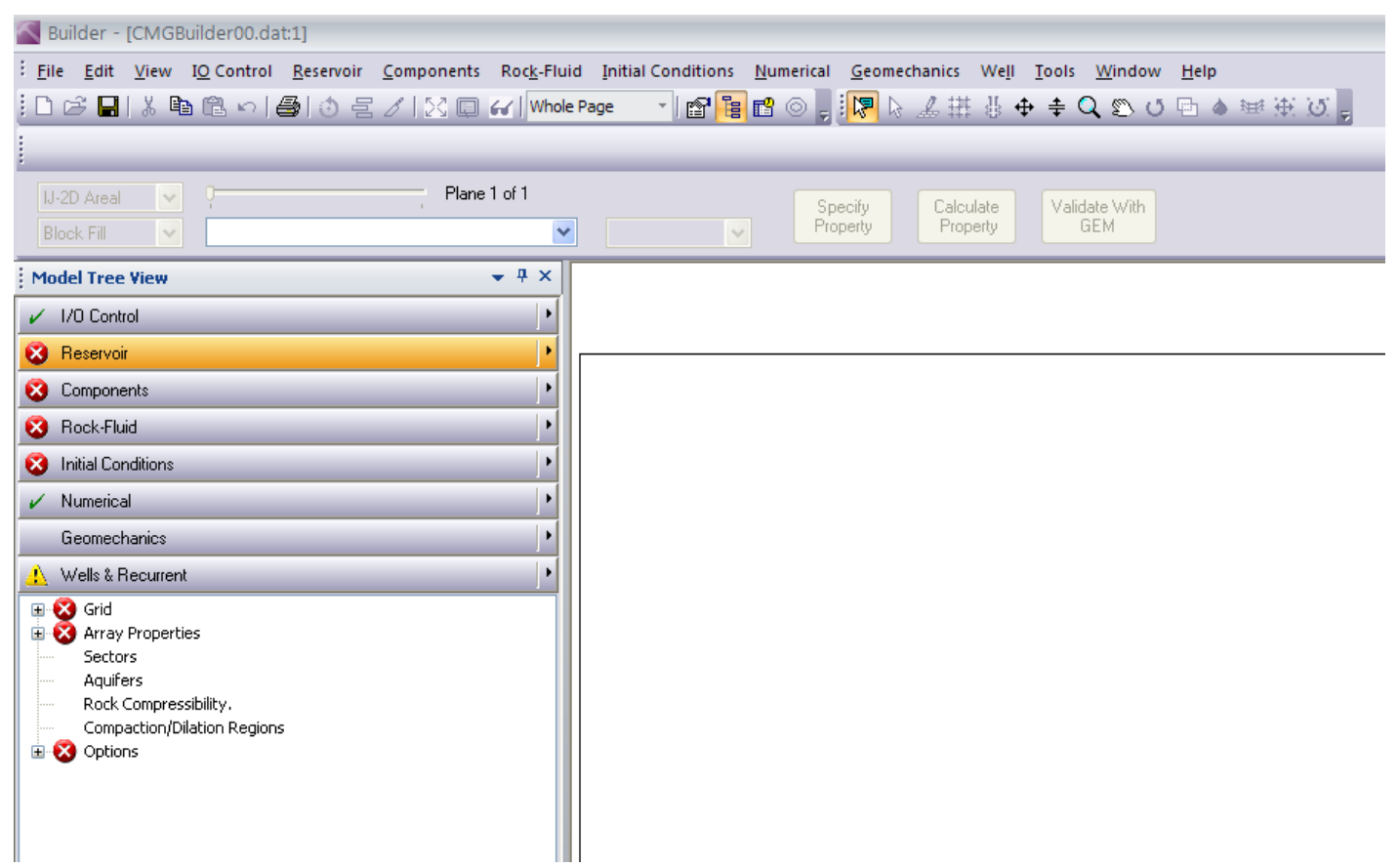

Figure B-3: GEM Builder 
The user clicks on the "Reservoir" tab in the model tree view and selects "Create grid" and then "Cartesian". The user inputs the number of grid blocks in the I-direction, Jdirection, and K-direction as shown in Figure B-4.

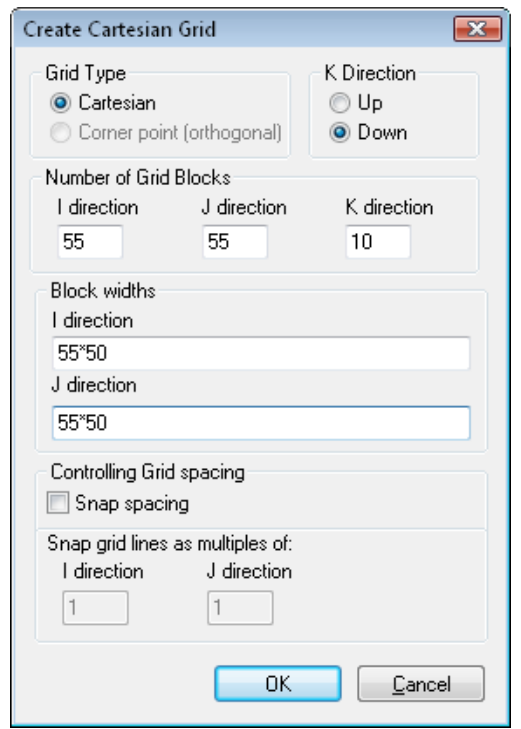

Figure B-4: Cartesian grid

The user selects the "Specify Property" tab and input the values including grid top, grid thickness, matrix porosity, fracture porosity, matrix permeability (I, J, and K-directions), fracture permeability (I, J, and K-directions), fracture spacing (I, J, and K-directions) and etc. "General Property Specification" screen is shown in Figure B-5.

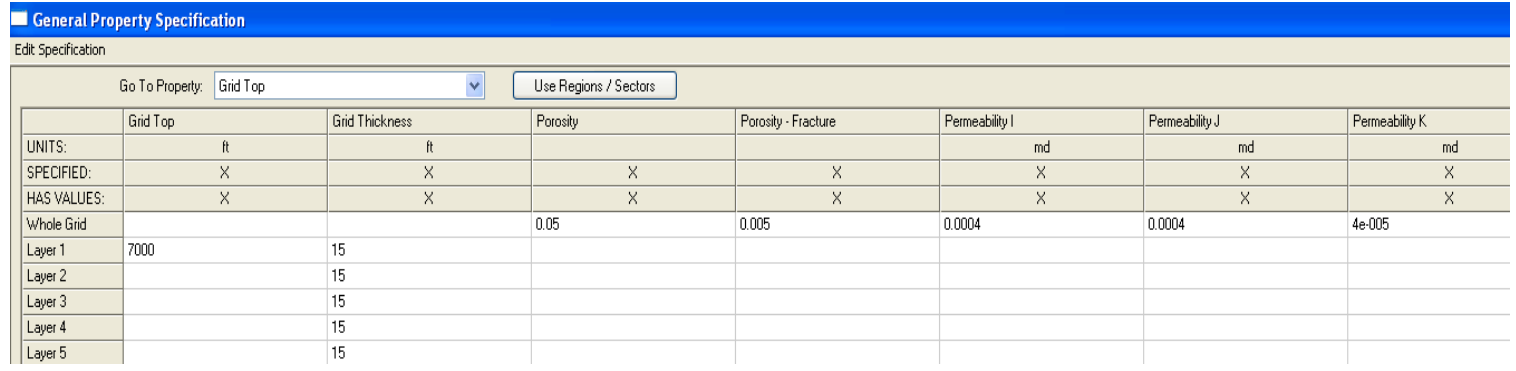

Figure B-5: General property specification 
The user double clicks on "Rock compressibility" from the reservoir section and inputs the reference pressure for both matrix and fracture, and reference temperature as shown in Figure B-6.

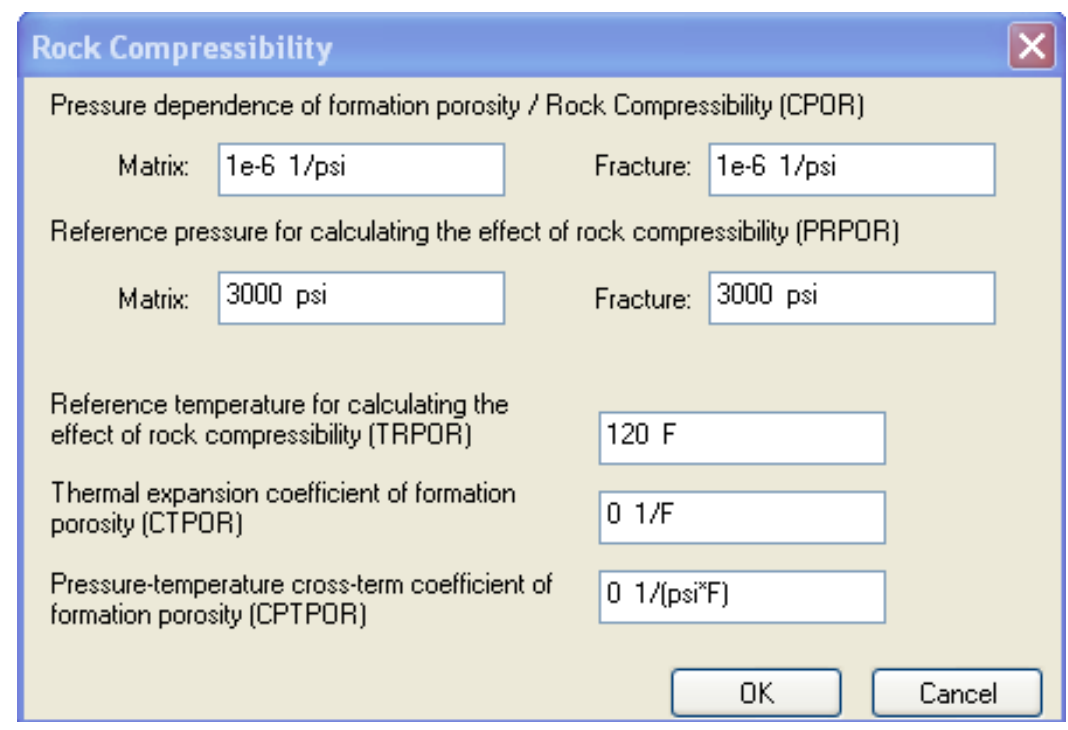

Figure B-6: Rock compressibility

The user clicks on the "Components" tab in the model tree view and select model equation of state (Peng-Robinsor) as shown in Figure B-7. In addition, the user sets the reservoir temperature to any specific value.

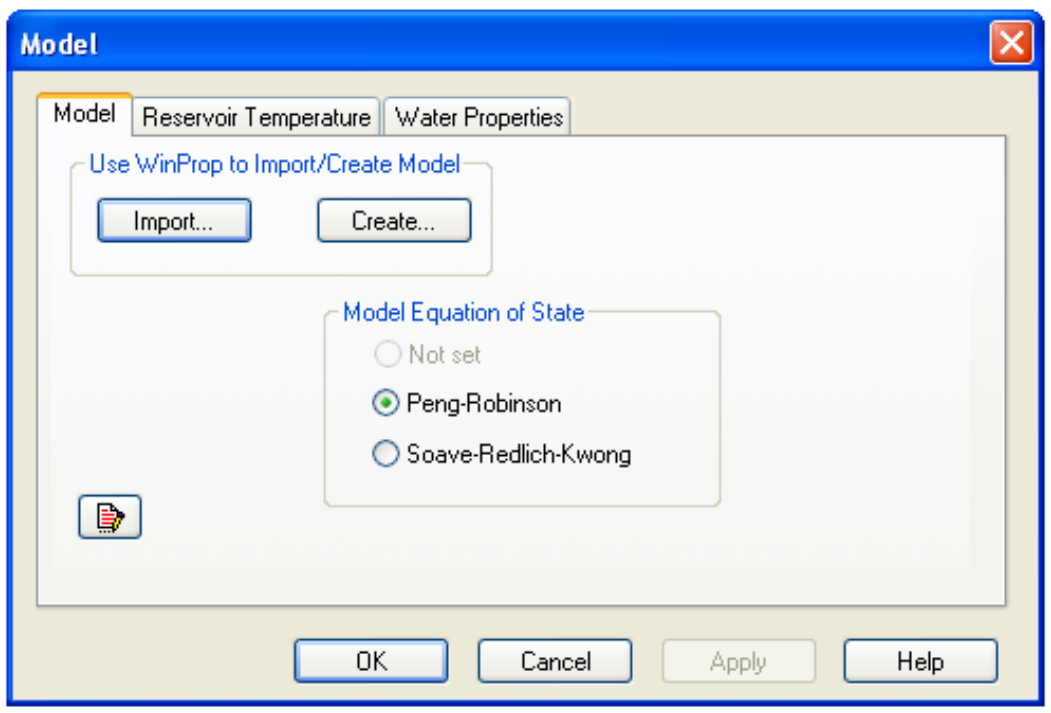

Figure B-7: Model 
The user clicks on the "Components" tab and goes to Add/Edit components and then add an EoSSet and goes to Add/Edit Components and selects $\mathrm{CH} 4$ from the list as shown in Figure B-8.

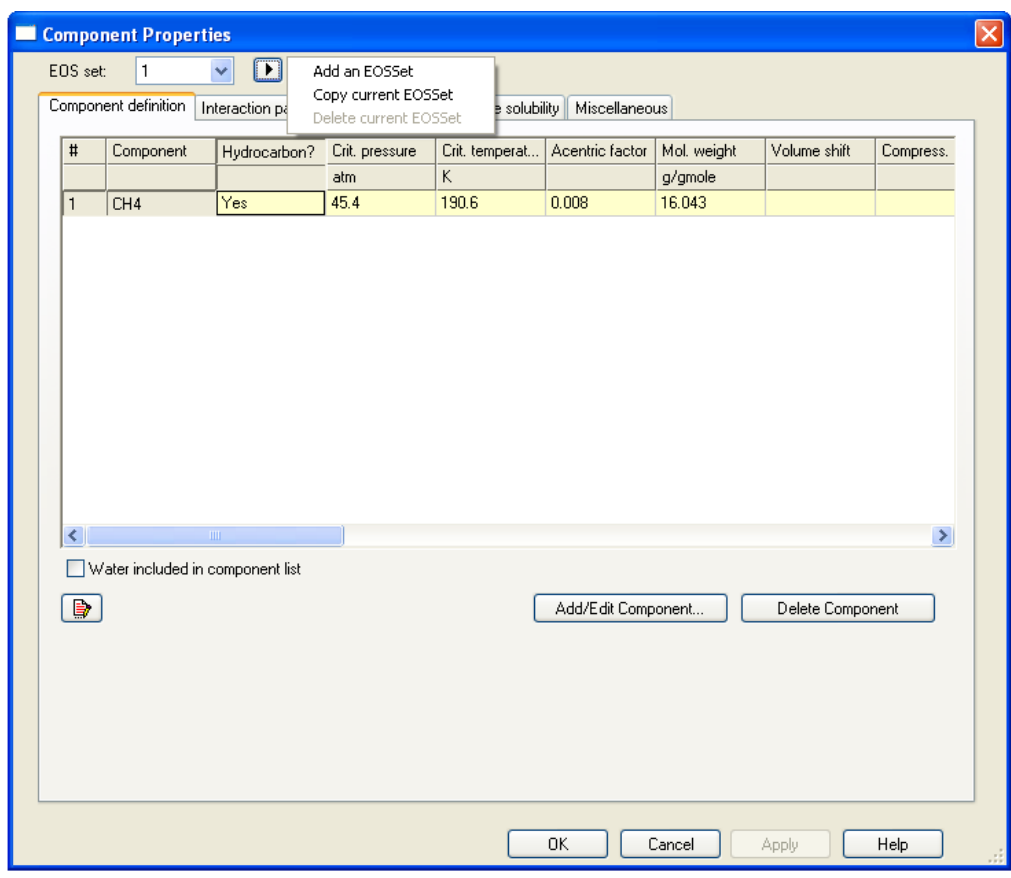

Figure B-8: Component properties 
The user clicks on the "Rock-Fluid" tab in the model tree view and select Create/Edit rock types. Then the user selects New Rock Type and chooses Tools and selects Generate table using correlation. A relative permeability correlation is shown in Figure B-9.

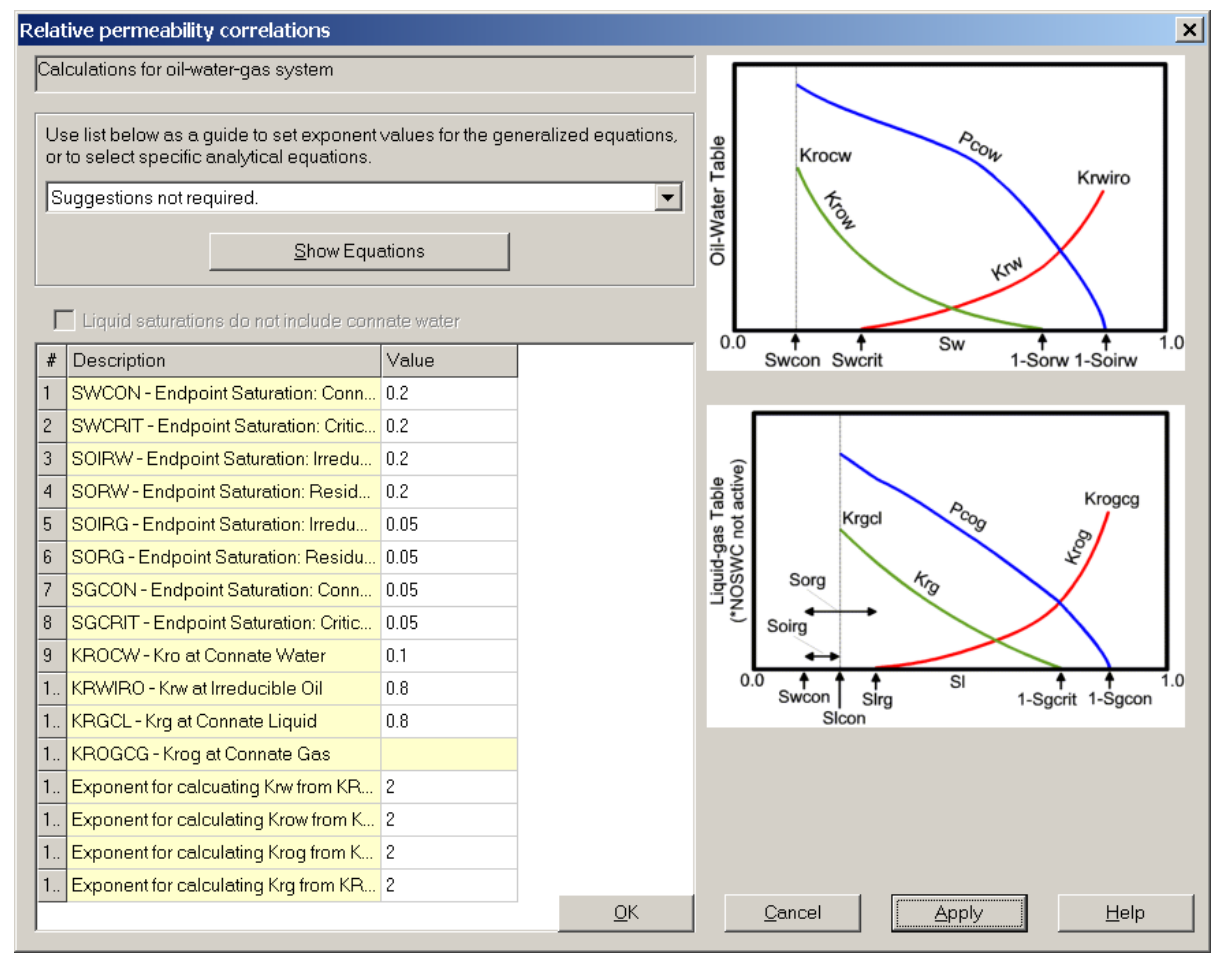

Figure B-9: Relative permeability correlations

The user again selects the "Specify Property" and input the values including maximal adsorbed mass (CH4)-matrix, maximal adsorbed mass (CH4)-fracture, Langmuir adsorption constant (CH4)-matrix, Langmuir adsorption constant (CH4)-fracture, and rock density as shown in Figure B-10.

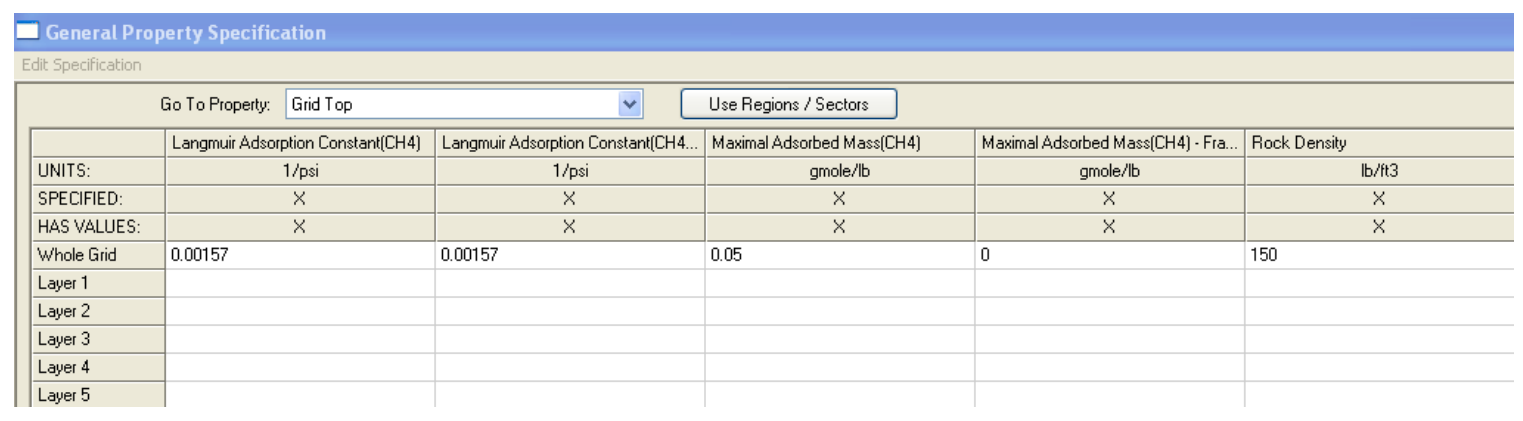

Figure B-10: General properties specification 2 
The user clicks on the "Initial Condition" tab in the model tree view and picks Initialization Setting then the user selects "water_gas" from the "Calculation Method" tab as shown in Figure B-11.

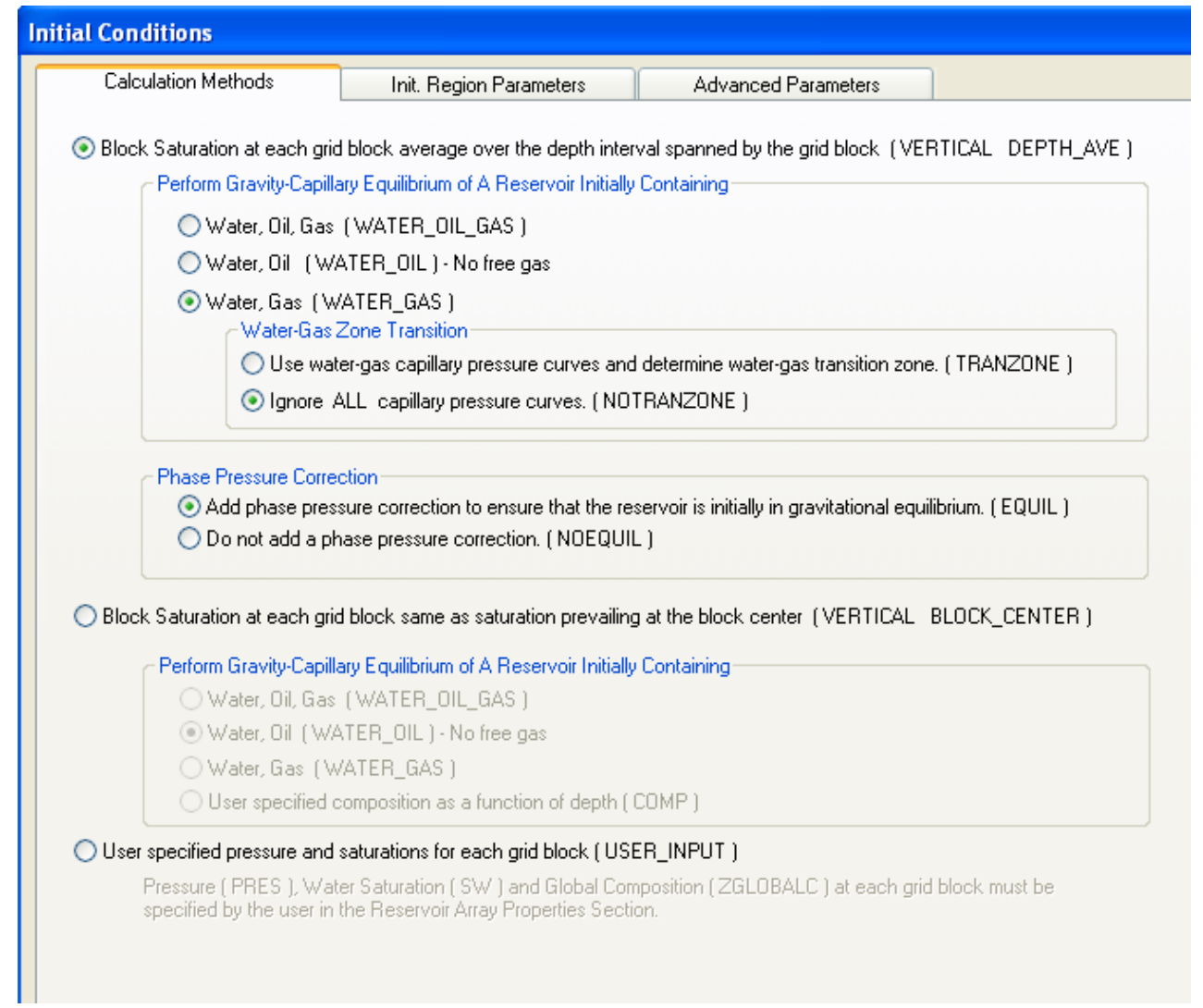

Figure B-11: Initial condition (calculation method) 
Then the user goes to "Init. Region Parameters" tab and enters the reference pressure, reference depth, water gas contact, gas cap mole fraction (ZGAS) as shown in Figure B12.

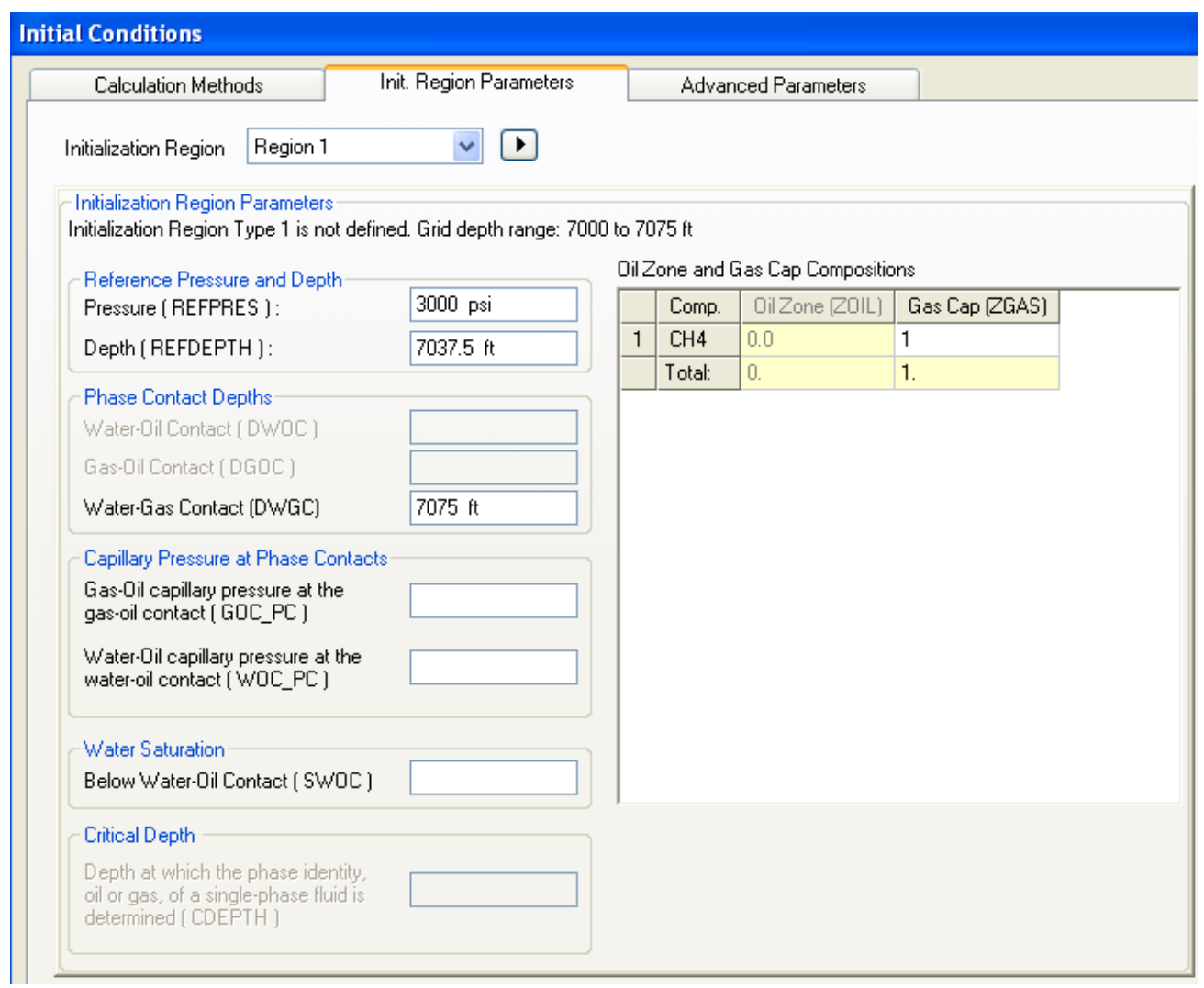

Figure B-12: Initial condition (Init. Region parameters) 
The user clicks on the "Wells \& Recurrent" tab in the model tree view and creates new well by right clicking on Wells and select New. This will allow the user to create a new well and the user gives a name "Horizontal" and selects type as "Producer" in Figure B13.

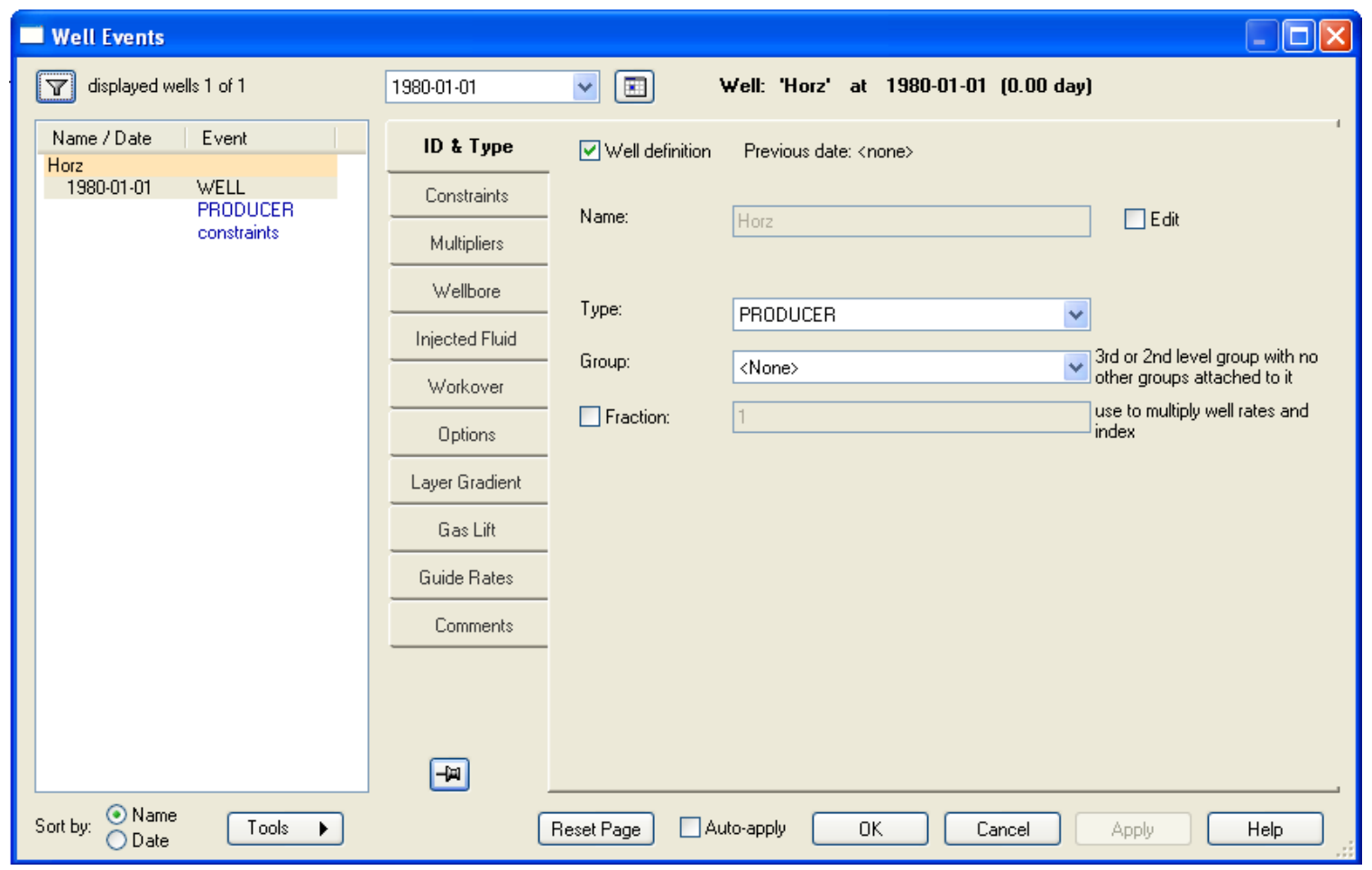

Figure B-13: Well events (ID \& type) 
The user clicks on "Constraints" tab and checks the box for Constraint definition. In addition the user selects new (in the Constraint column of the table), selects OPERATE. Then the user selects BHP bottomhole pressure, MIN, to any pressure as shown in Figure B-14.

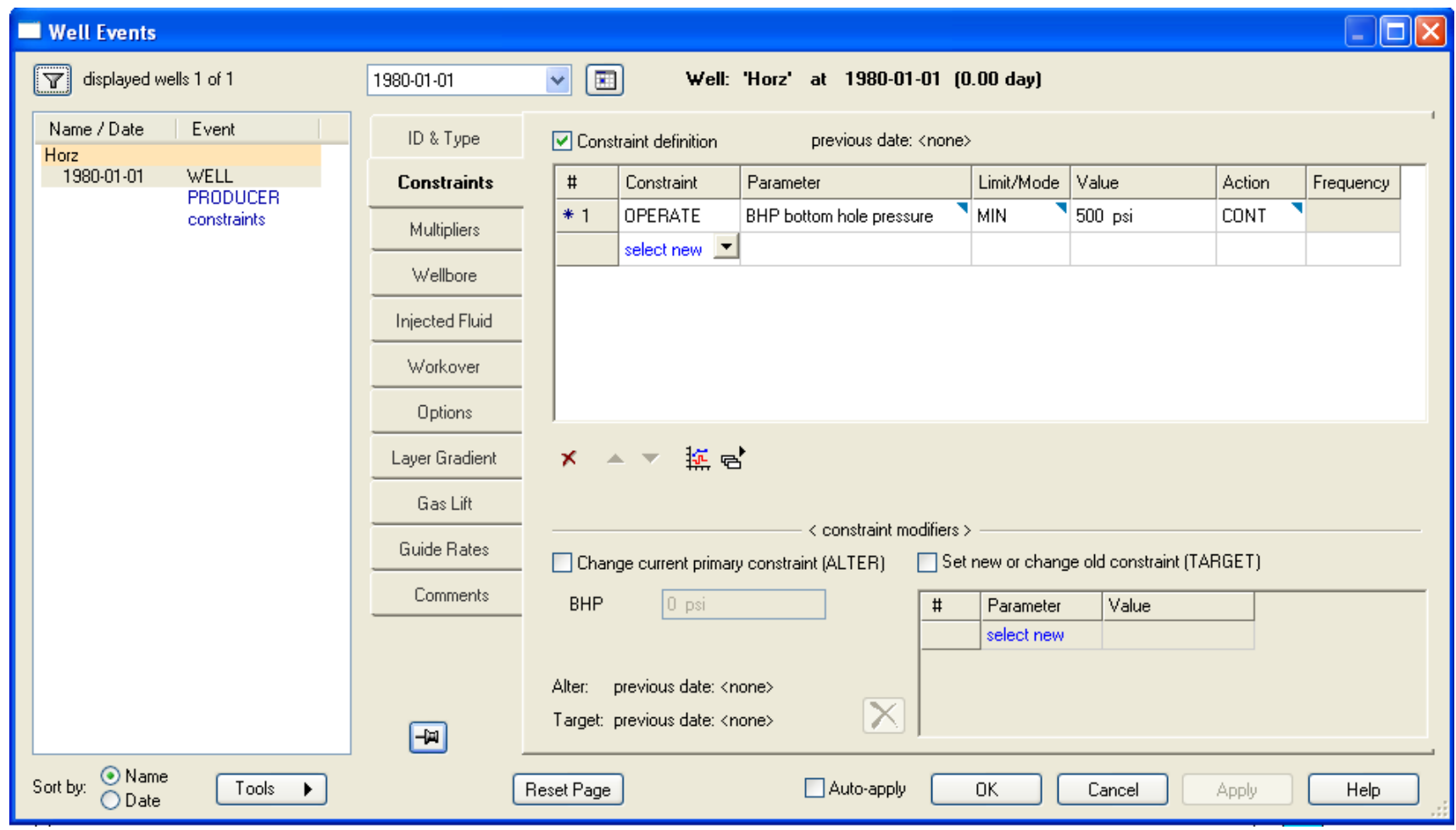

Figure B-14: Well events (constraints) 
The user double clicks on "PERF" and selects the general tab and fills out the information including direction, and radius of the wellbore as shown in Figure B-15.

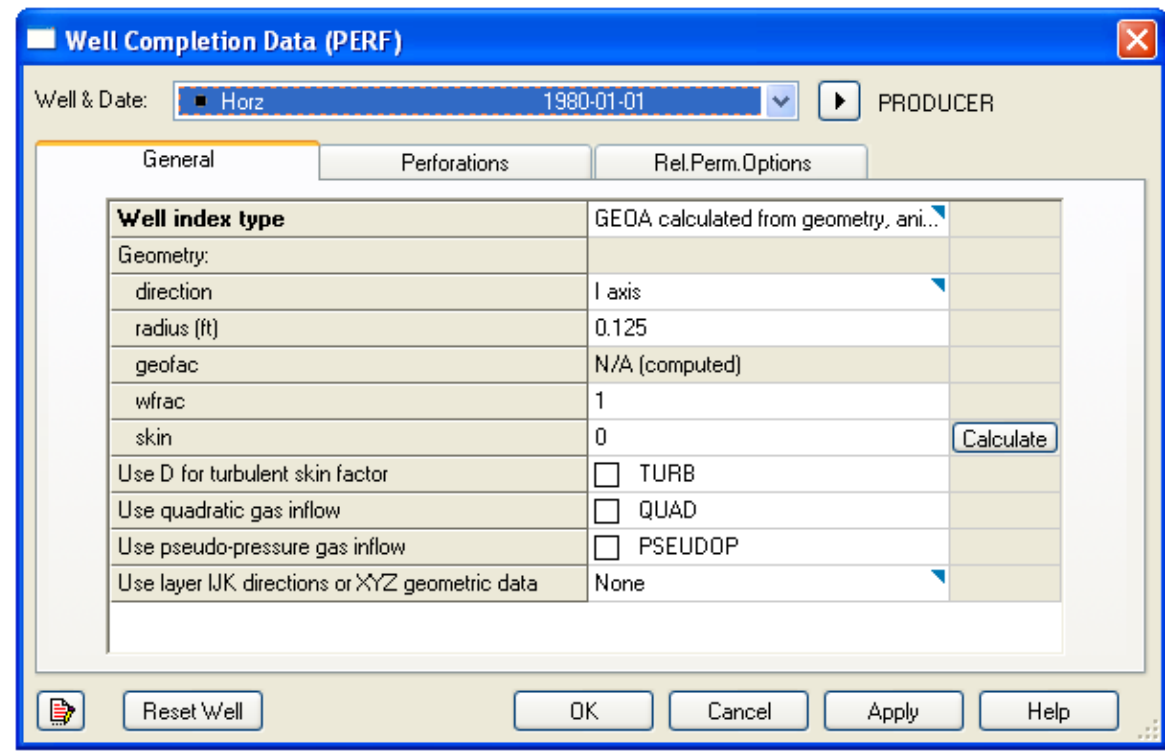

Figure B-15: Well completion data (General)

The user selects the perforation tab and to add perforation with the mouse, the user presses 8 Begin button and picks the blocks for perforations as shown in Figure B-16.

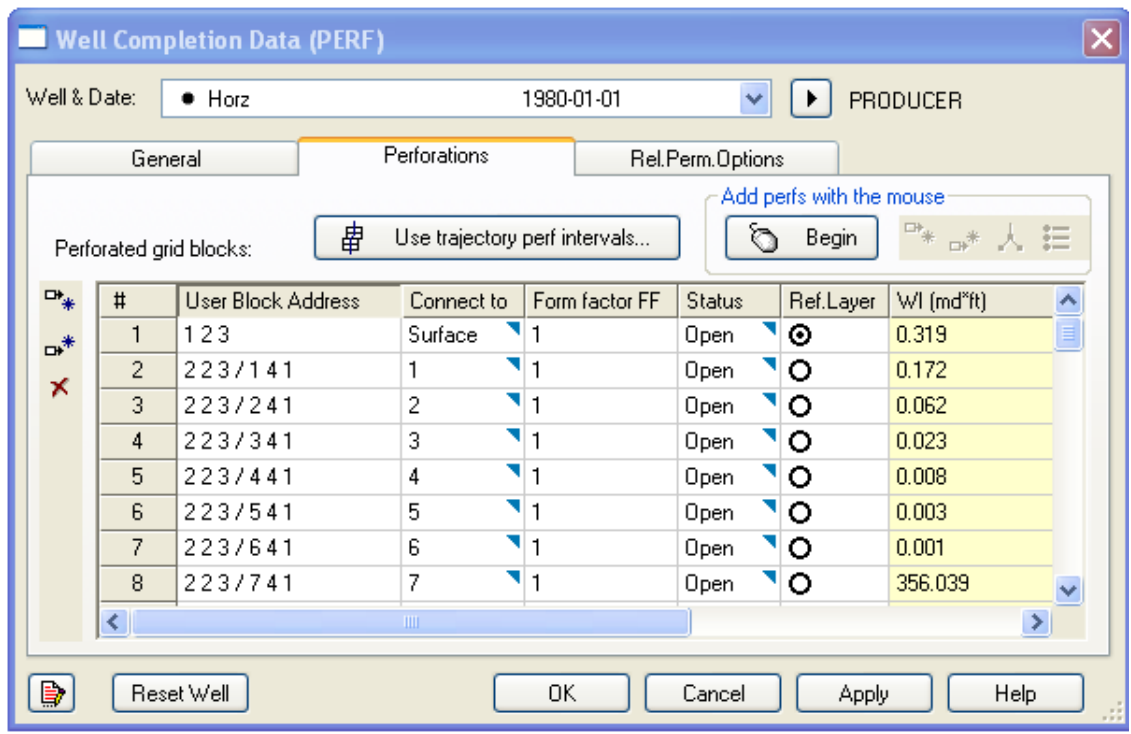

Figure B-16: Well completion data (PERF) 
The user is also able to add hydraulically fractured wells to the existing model. The user selects "Hydraulically Fractured Wells" from the Well menu to start the wizard. Then the user clicks "Tools" button and selects "Add new fracture" from the pop-up menu as shown in Figure B-17. The user assigns the fracture properties including fracture width, fracture permeability, fracture half length, and fracture orientation as shown in Figure B17.

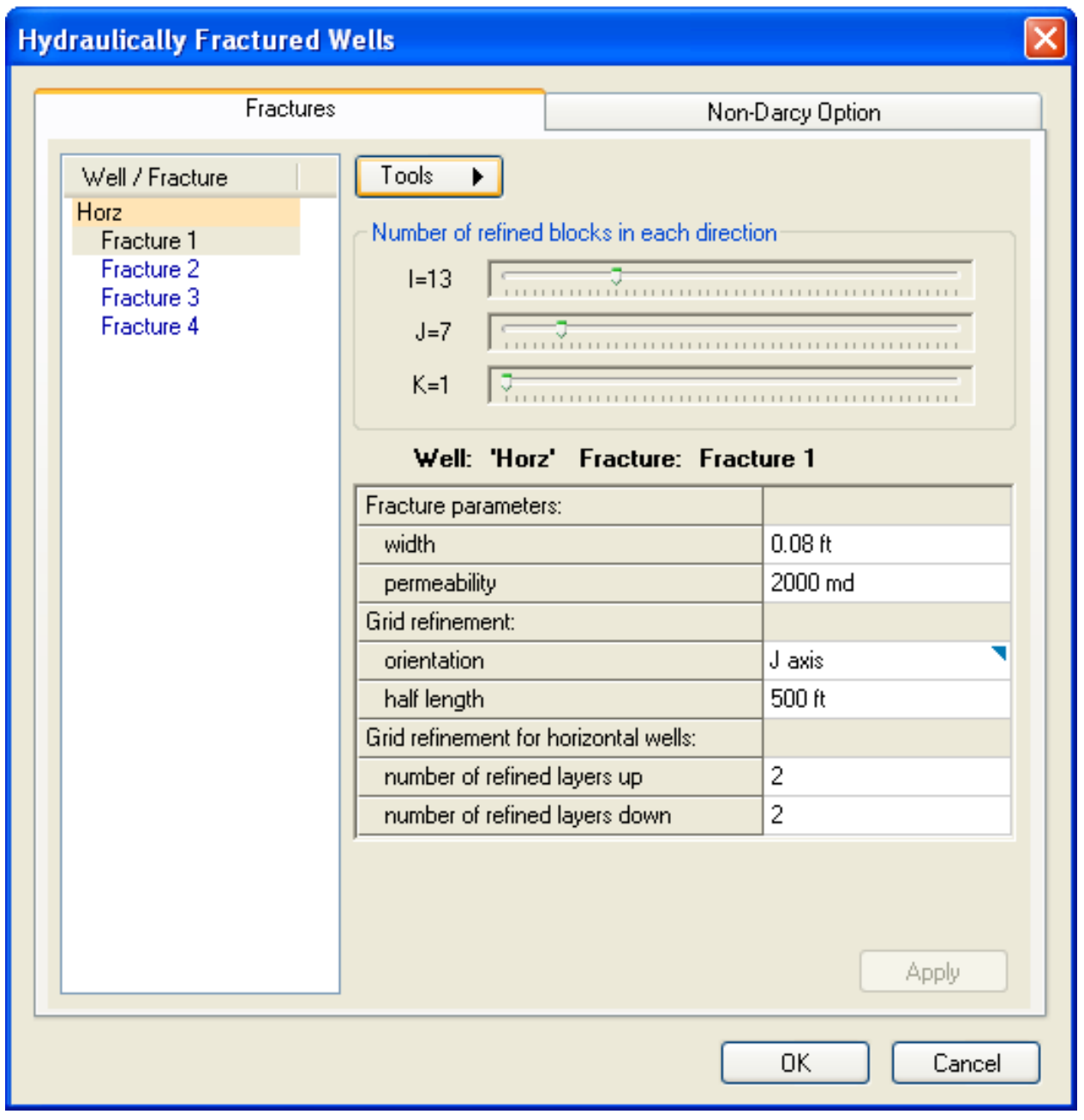

Figure B-17: Hydraulically fractured wells 
The user selects "Non-Darcy Option" tab from The Hydraulically Fractured Wells Wizard for selecting the correlation for non-Darcy gas flow calculations as shown in Figure B-18.

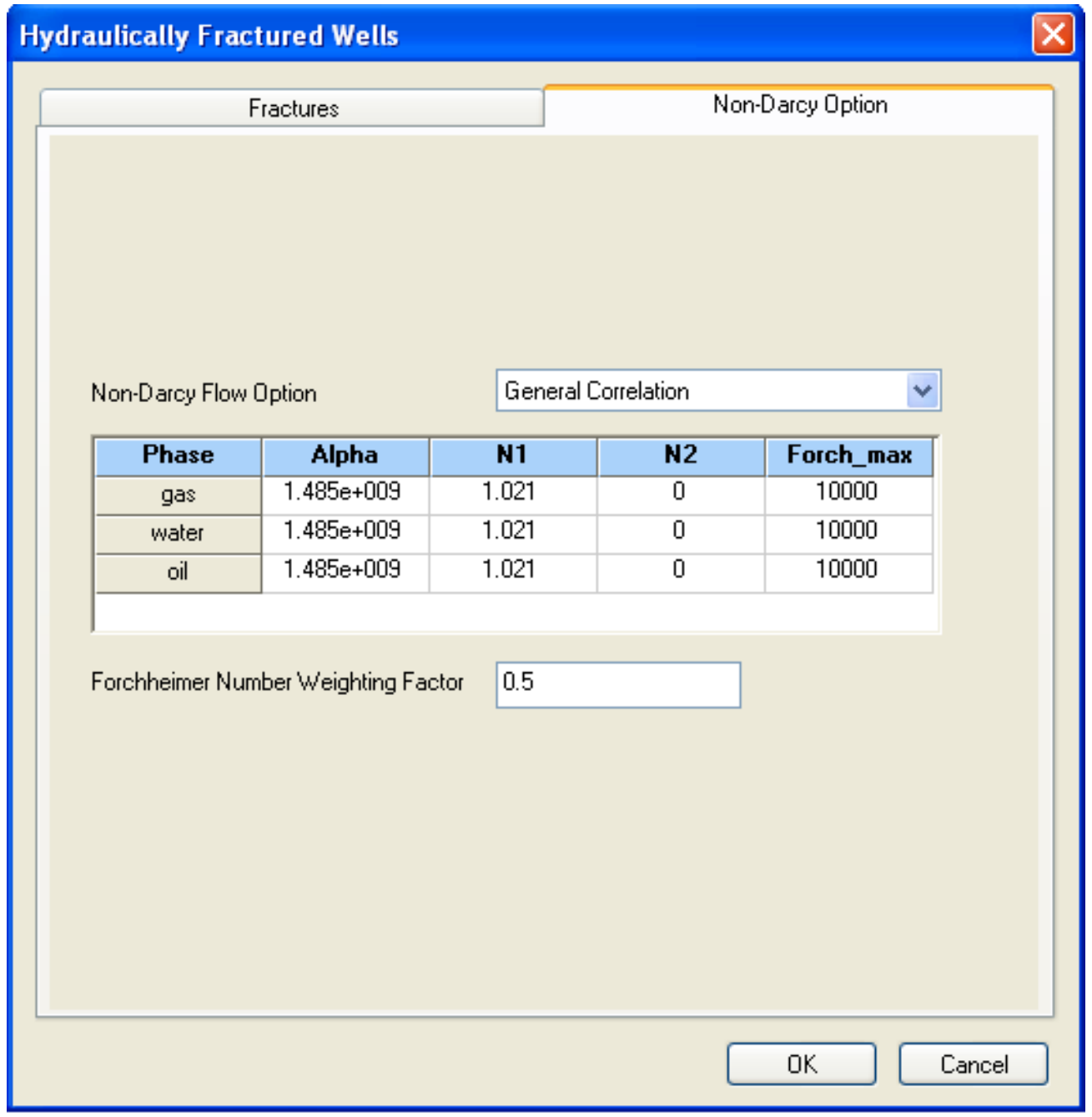

Figure B-18: Hydraulically fracture wells (Non-Darcy option) 
Once the user clicks on "Apply" button, a new dialog Fracture Placement pops up where the user is able to select perforations for the selected wells as shown in Figure B-19.

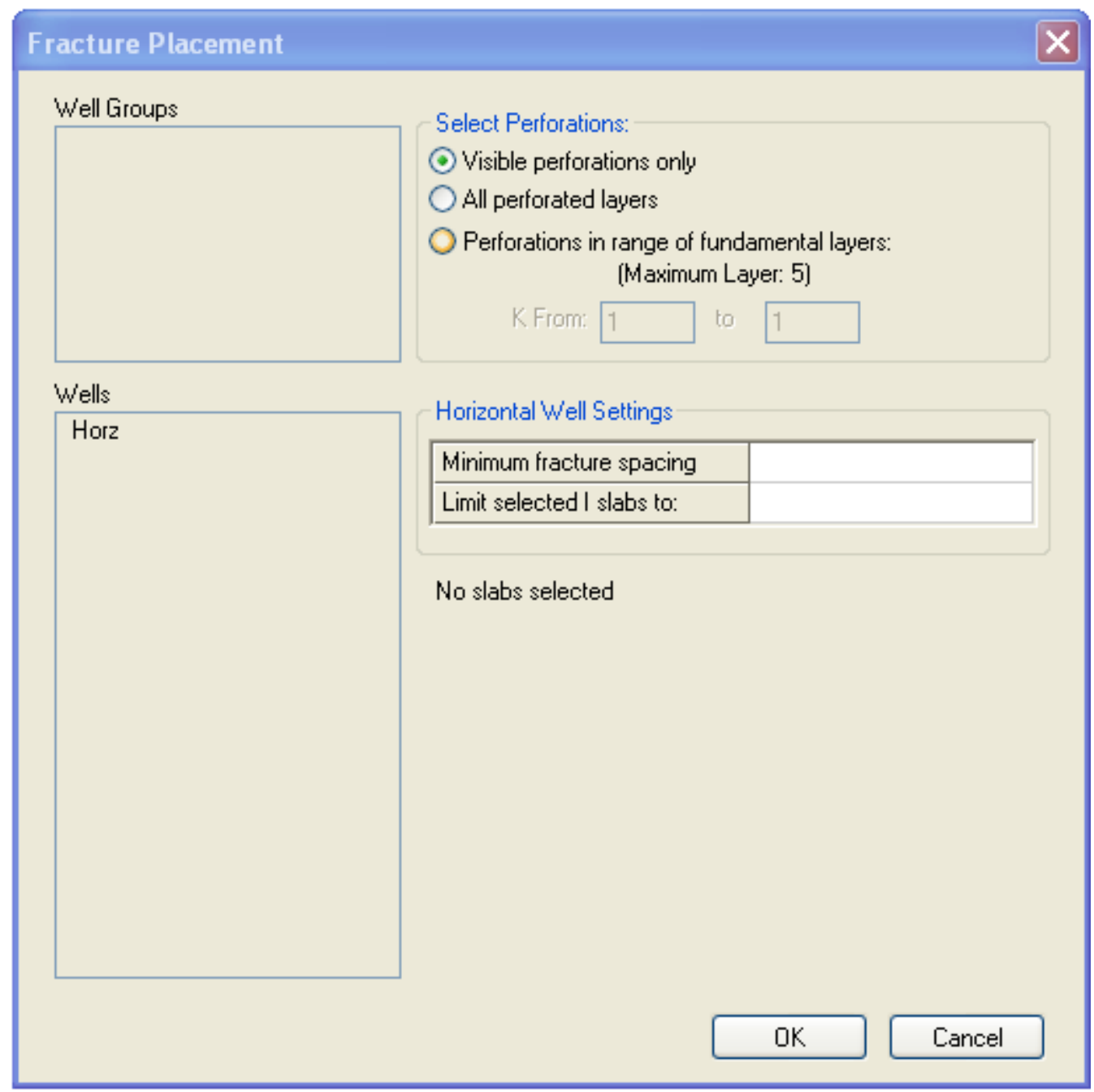

Figure B-19: Fracture placement 
The user also needs to modify some numerical parameters in order for the model to run smoothly as shown in Figure B-20.

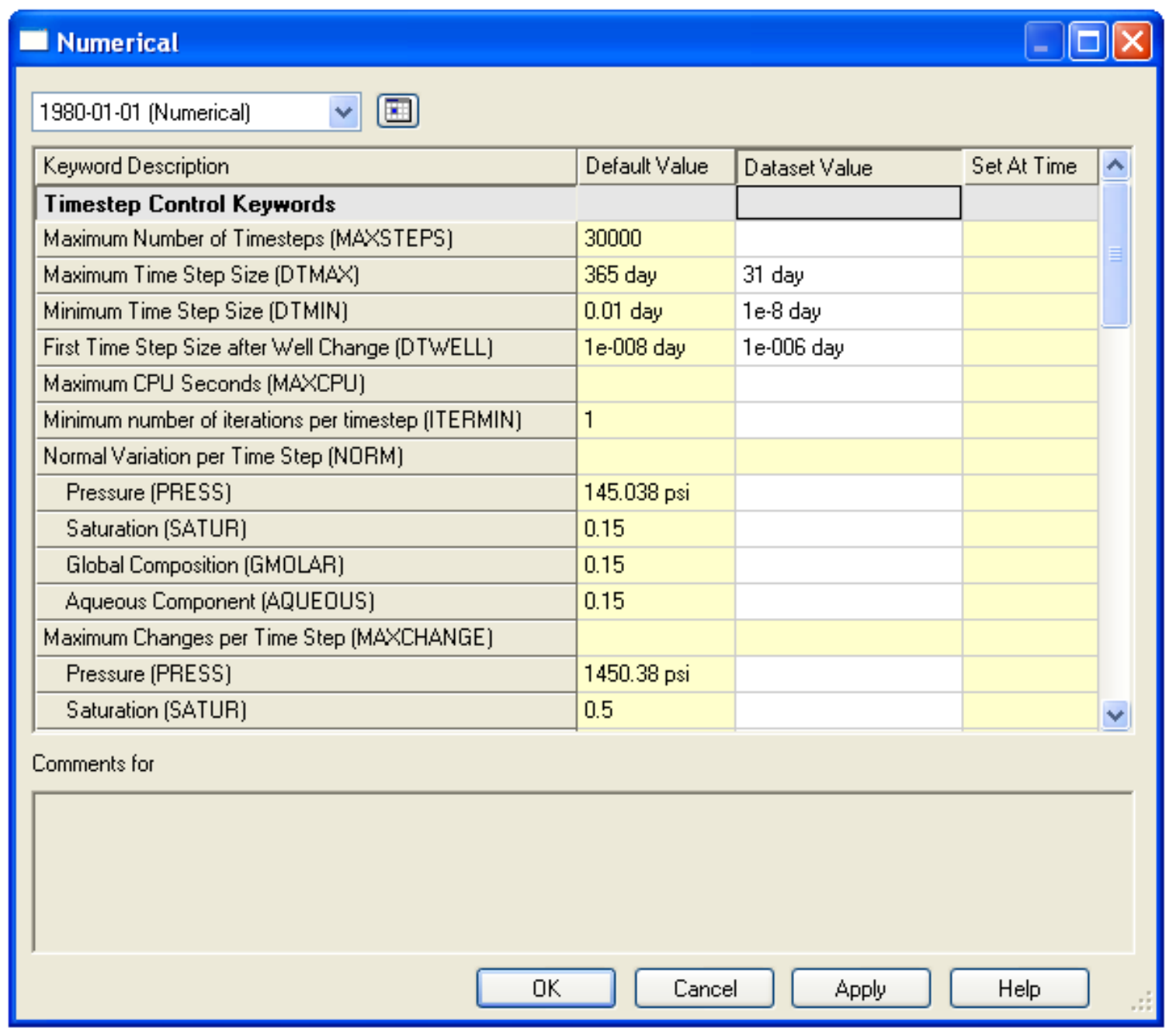

Figure B-20: Numerical

The user is able to run GEM model by clicking on "Validate with GEM" button and view the results by dragging and dropping onto the GEM icon from the CMG Launcher window. The user can view the results including field production total, field production rate, field pressure, field gas recovery, field gas in place, well bottomhole pressure, etc. 


\section{APPENDIX C (ECLIPSE MODELS LAYOUTS)}
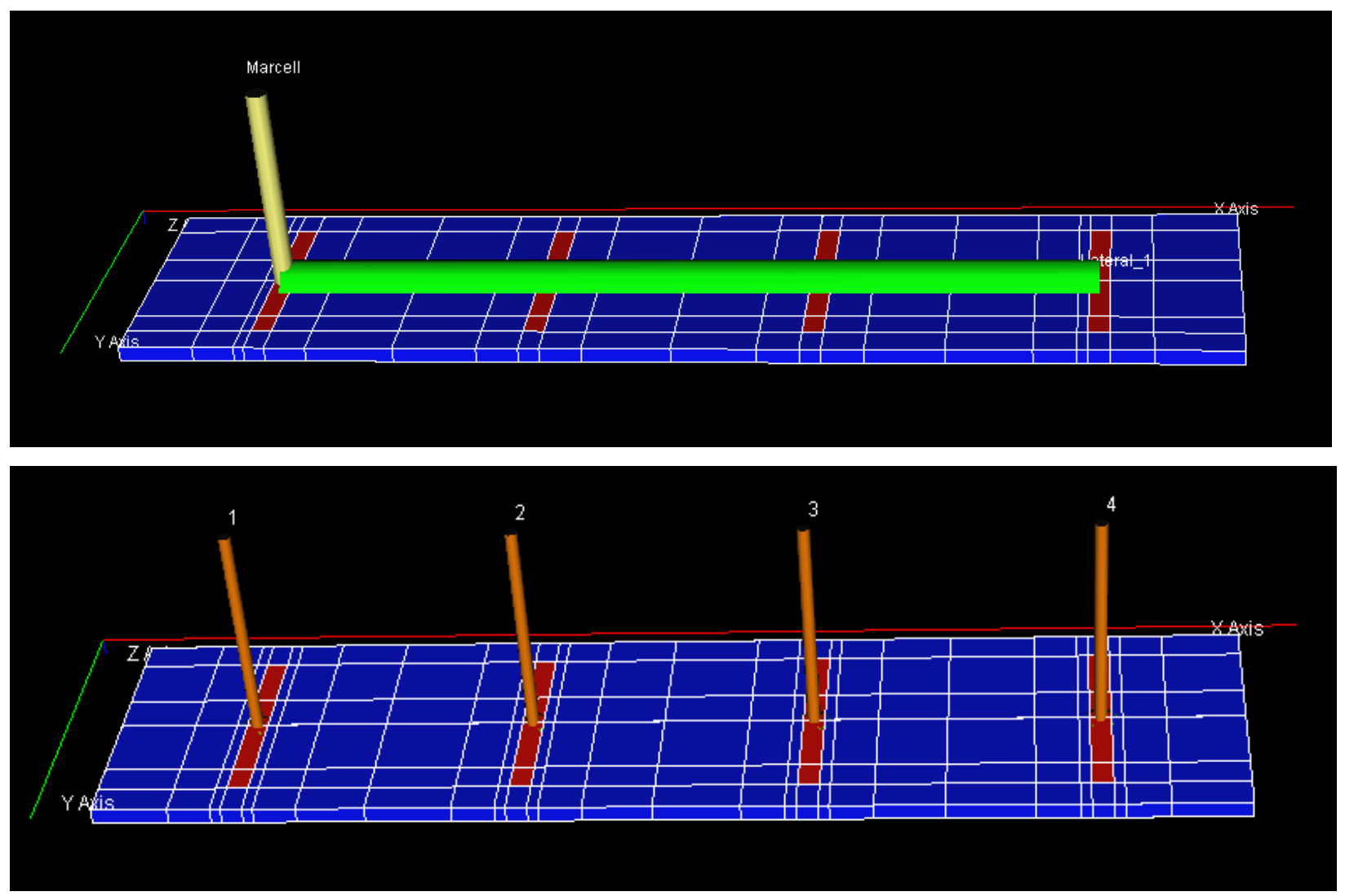

Figure C-1: 1 Horizontal (4 Fracs) \& 4 Vertical (1 Frac)- 4000×1000 $\mathrm{ft}^{2}$

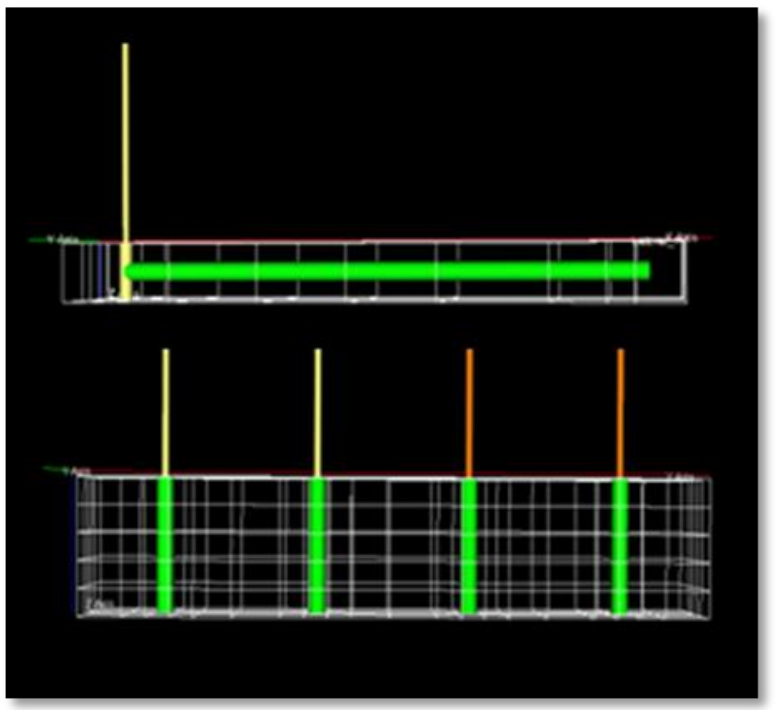

Figure C-2: $4000 \times 1000 \mathrm{ft}^{2}$ (side view of the model) 


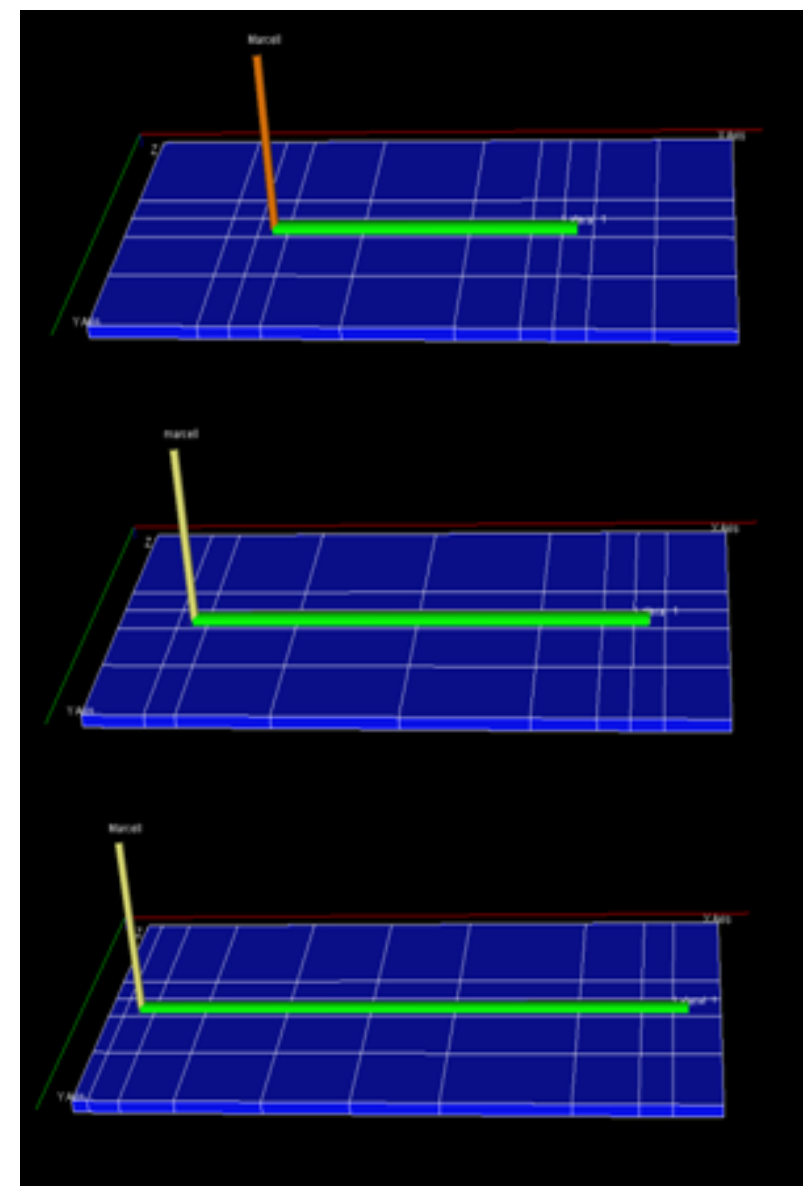

Figure C-3: $4000 \times 1000 \mathrm{ft}^{2}$ (different laterals)- No Fractures 


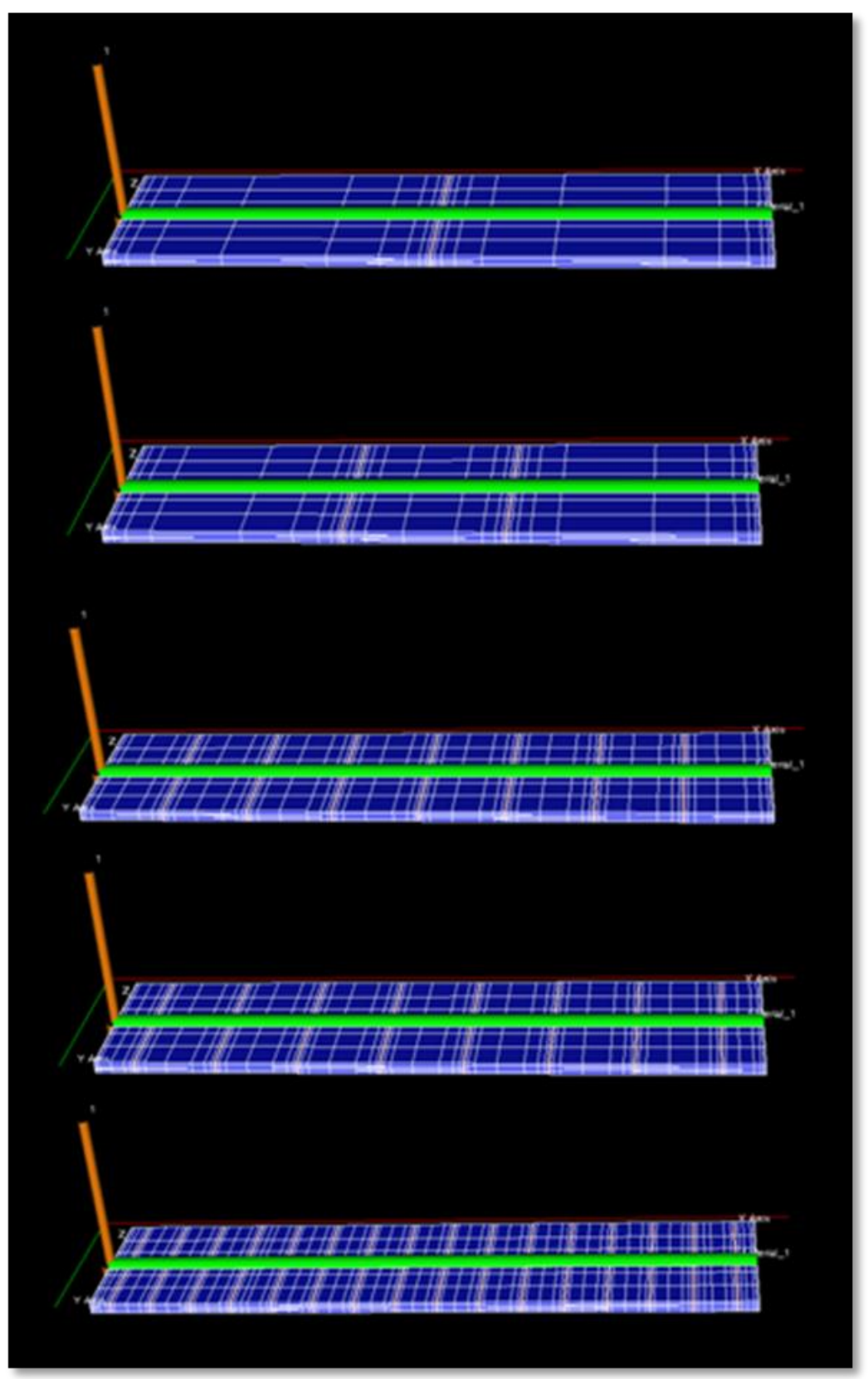

Figure C-4: $4000 \times 1000 \mathrm{ft}^{2}(4000 \mathrm{ft}$ lateral)- Different number of Fractures 


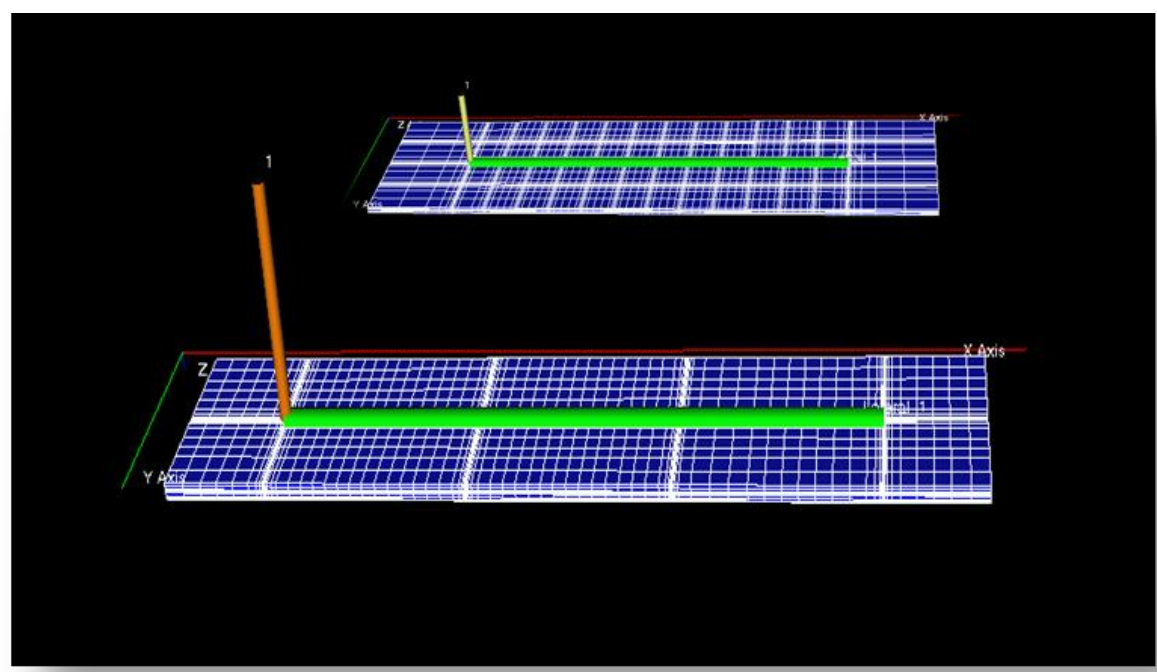

Figure C-5: $4000 \times 1000 \mathrm{ft}^{2}$ for different cell sizes

John H. 